
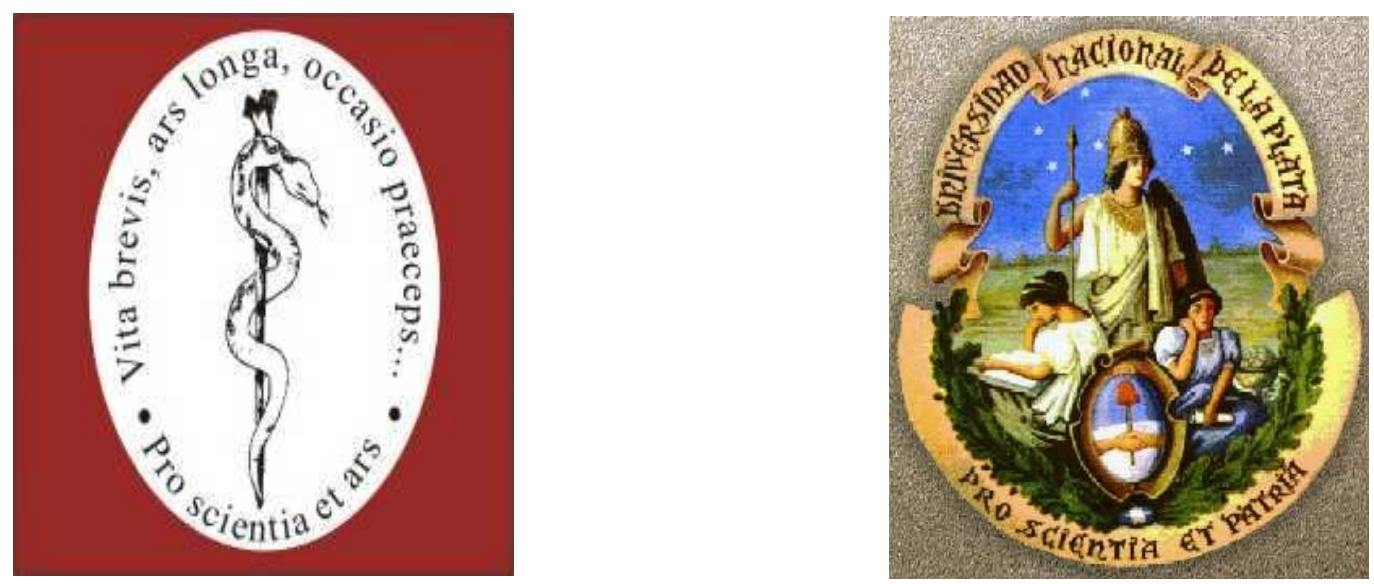

\title{
EVALUACIÓN DE LA CALIDAD DE VIDA RELACIONADA CON LA SALUD EN PERSONAS QUE VIVEN CON VIH/SIDA
}

Tesista: Méd. Judith Celina Bernstein

Director: Prof. Dr. Juan Ángel Basualdo Farjat

Lugar de trabajo: Cátedra de Microbiología y Parasitología Facultad de Ciencias Médicas, UNLP 
A la memoria de mis amados padres, Betty y Manuel. 


\section{AGRADECIMIENTOS}

Este gran desafío que constituyó la realización de mi tesis doctoral, no hubiese sido posible de concretar sin la invalorable colaboración del Prof. Dr. Juan A. Basualdo, que me impulsó en forma permanente a realizar mi doctorado y me enseñó que desde la adversidad se puede construir un nuevo camino.

Mi más vehemente gratitud hacia la Prof. Silvia Grenóvero, quien con su generosidad y su infinita paciencia colaboró conmigo en el procesamiento estadístico de los datos y en la redacción de este trabajo.

A mis pequeños hijos Axel y Alan y a mi esposo Raúl, soportes fundamentales de mi vida, que me han apoyado desde siempre en esta gran iniciativa.

Y por supuesto, mi más afectuoso reconocimiento a mis pacientes de la Unidad de Infectología del Hospital Mi Pueblo, que en forma desinteresada y solidaria han colaborado para poder llevar adelante este proyecto.

Judith Celina Bernstein, mayo de 2010 
Según vamos adquiriendo conocimiento, las cosas no se hacen más comprensibles, sino más misteriosas.

Albert Schweitzer 


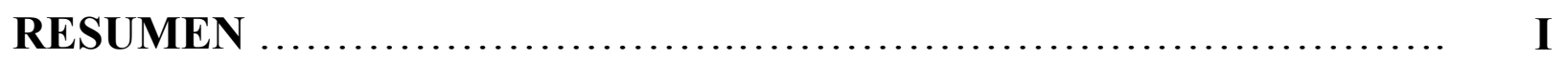

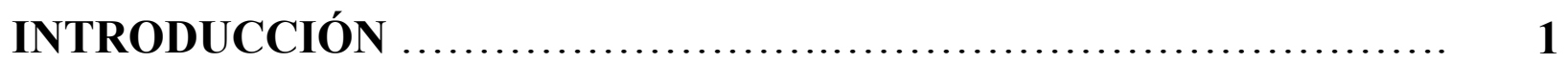

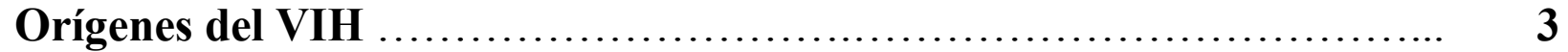

La infección por el virus de la inmunodeficiencia humana ............... 11

Historia natural de la infección ........................................ 19

El inicio de la epidemia de SIDA $\ldots \ldots \ldots \ldots \ldots \ldots \ldots \ldots \ldots \ldots \ldots \ldots \ldots, 24$

Situación actual de la epidemia de SIDA ............................ 25

Calidad de vida relacionada con la salud en personas que viven

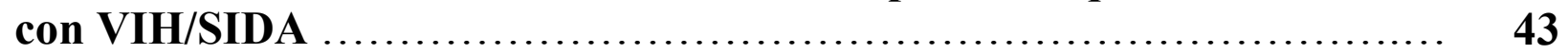

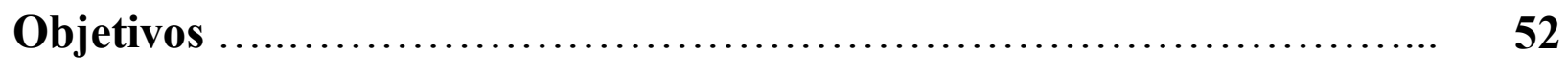

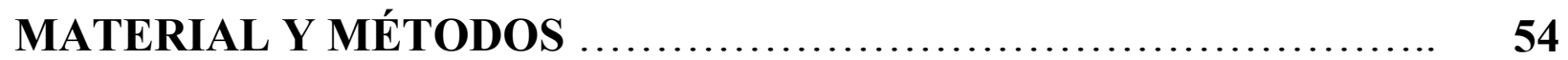

Participantes ......................................................... 54

Variables en estudio .................................................. 54

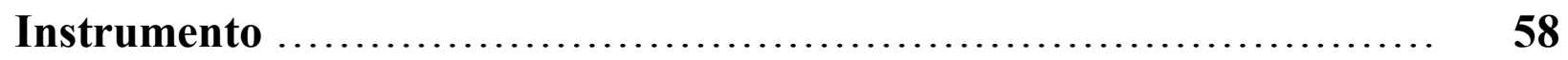

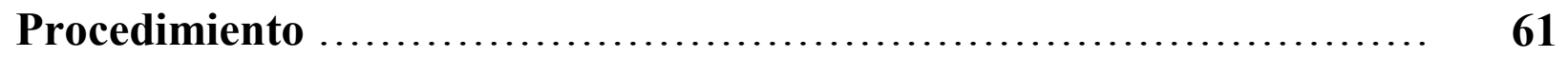

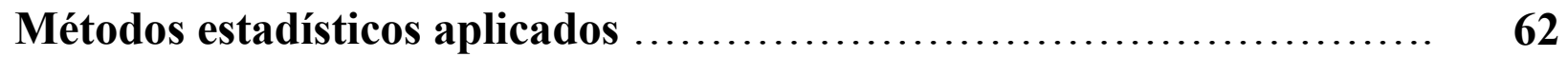

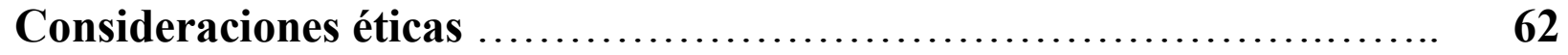

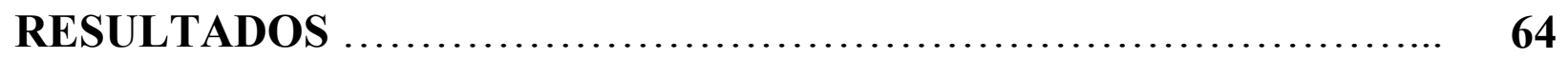

Análisis exploratorio: caracterización de los individuos evaluados ....... 64

Análisis de las dimensiones del Cuestionario de Salud SF-36 ............ 81

Correlación entre calidad de vida y variables clínicas, inmunológicas y sociológicas

Correlación entre variables sociológicas y puntuación obtenida en el

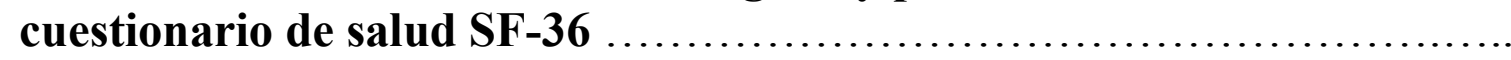

Correlación entre variables clínicas y puntuación obtenida en el cuestionario de salud SF-36

Correlación entre variables inmunológicas y puntuación obtenida en el cuestionario de salud SF-36

DISCUSIÓN

CONCLUSIONES 


\title{
ÍNDICE DE TABLAS, CUADROS Y FIGURAS
}

\author{
Tablas
}

Página

Tabla 1: Enfermedades indicadoras de caso de SIDA. CDC, 1997.

Tabla 2: Estadificación de caso de SIDA para adolescentes y adultos según categoría clínica y linfocitos T CD4+. CDC, 1993.

Tabla 3: Distribución de pacientes de la Unidad de Infectología, según edad y género. Hospital Zonal General de Agudos "Mi Pueblo". Florencio Varela, provincia de Buenos Aires, Argentina. Agosto 2005 - junio 2007.

Tabla 4: Distribución de pacientes de la Unidad de Infectología, según años de diagnóstico de la infección por VIH. Hospital Zonal General de Agudos "M Pueblo". Florencio Varela, provincia de Buenos Aires, Argentina. Agosto 2005 - junio 2007.

Tabla 5: Distribución de pacientes de la Unidad de Infectología según edad, género y años de diagnóstico. Hospital Zonal General de Agudos "Mi Pueblo". Florencio Varela, provincia de Buenos Aires, Argentina. Agosto 2005 - junio 2007.

Tabla 6: Distribución de pacientes de la Unidad de Infectología según la vía de transmisión de la infección por VIH, la edad y el género. Hospital Zonal General de Agudos "Mi Pueblo". Florencio Varela, provincia de Buenos Aires, Argentina. Agosto 2005 - junio 2007.

Tabla 7: Distribución de pacientes de la Unidad de Infectología según causa del diagnóstico de la infección por VIH, edad y género. Hospital Zonal General de Agudos "Mi Pueblo". Florencio Varela, provincia de Buenos Aires, Argentina. Agosto 2005 - junio 2007.

Tabla 8: Conductas de riesgo en parejas de pacientes de la Unidad de Infectología. Hospital Zonal General de Agudos "Mi Pueblo". Florencio Varela, provincia de Buenos Aires, Argentina. Agosto 2005 - junio 2007.

Tabla 9: Conductas de riesgo en parejas de pacientes y su distribución según el conocimiento de su condición serológica. Unidad de Infectología. Hospital Zonal General de Agudos "Mi Pueblo". Florencio Varela, provincia de Buenos Aires, Argentina. Agosto 2005 - junio 2007

Tabla 10: Conductas de riesgo en parejas de pacientes y su distribución según su conocimiento de la condición serológica y género. Unidad de Infectología. Hospital Zonal General de Agudos "Mi Pueblo". Florencio Varela, provincia de Buenos Aires, Argentina. Agosto 2005 - junio 2007.

Tabla 11: Tipo y cantidad de adicciones según edad en pacientes de la Unidad de Infectología. Hospital Zonal General de Agudos "Mi Pueblo". Florencio Varela, provincia de Buenos Aires, Argentina. Agosto 2005 - junio 2007.

Tabla 12: Enfermedades marcadoras de SIDA en pacientes de la Unidad de Infectología. Hospital Zonal General de Agudos "Mi Pueblo". Florencio Varela, provincia de Buenos Aires, Argentina. Agosto 2005 - junio 2007. 
Tabla 13: Presentación de la primera enfermedad marcadora de SIDA en pacientes de la Unidad de Infectología. Hospital Zonal General de Agudos "Mi Pueblo". Florencio Varela, provincia de Buenos Aires, Argentina. Agosto 2005 - junio 2007.

Tabla 14: Distribución de la presentación de la primera enfermedad marcadora de SIDA en pacientes de la Unidad de Infectología. Hospital Zonal General de Agudos "Mi Pueblo". Florencio Varela, provincia de Buenos Aires. Argentina. Agosto 2005 - junio 2007

Tabla 15: Distribución de la presentación y clase de la primera enfermedad marcadora de SIDA según la edad, en pacientes de la Unidad de Infectología. Hospital Zonal General de Agudos "Mi Pueblo". Florencio Varela, provincia de Buenos Aires, Argentina. Agosto 2005 - junio 2007.

Tabla 16: Presentación de enfermedad marcadora de SIDA según el género, en pacientes de la Unidad de Infectología. Hospital Zonal General de Agudos "Mi Pueblo". Florencio Varela, provincia de Buenos Aires, Argentina. Agosto 2005 - junio 2007.

Tabla 17: Distribución de la presentación de enfermedad marcadora de SIDA según el género, en pacientes de la Unidad de Infectología. Hospital Zonal General de Agudos "Mi Pueblo". Florencio Varela, provincia de Buenos Aires, Argentina. Agosto 2005 - junio 2007.

Tabla 18: Distribución de las puntuaciones de las dimensiones que integran la versión española del Cuestionario de Salud SF-36 según el género, en pacientes de la Unidad de Infectología. Hospital Zonal General de Agudos "Mi Pueblo". Florencio Varela, provincia de Buenos Aires, Argentina. Agosto 2005 - junio 2007.

Tabla 19: Análisis de las Dimensiones del Cuestionario de Salud SF-36 en pacientes de la Unidad de Infectología. Hospital Zonal General de Agudos "Mi Pueblo". Florencio Varela, provincia de Buenos Aires, Argentina. Agosto 2005 - junio 2007.

Tabla 20: Distribución de las puntuaciones de las dimensiones obtenidas del Cuestionario de Salud SF-36 según grupos de edades, en pacientes de la Unidad de Infectología. Hospital Zonal General de Agudos "Mi Pueblo". Florencio Varela, provincia de Buenos Aires, Argentina. Agosto 2005 junio 2007.

Tabla 21: Distribución de las puntuaciones de las dimensiones que integran la versión española del Cuestionario de Salud SF-36, según género y grupos de edad, en pacientes de la Unidad de Infectología. Hospital Zonal General de Agudos "Mi Pueblo". Florencio Varela, provincia de Buenos Aires, Argentina. Agosto 2005 - junio 2007

Tabla 22: Correlación entre calidad de vida relacionada con la salud y variables sociológicas en pacientes de la Unidad de Infectología. Hospital Zonal General de Agudos "Mi Pueblo". Florencio Varela, provincia de Buenos Aires, Argentina. Agosto 2005 - junio 2007.

Tabla 23. Variables sociológicas y puntuación obtenida en el Cuestionario de Salud SF-36 en pacientes de la Unidad de Infectología. Hospital Zonal General de Agudos "Mi Pueblo". Florencio Varela, provincia de Buenos Aires, Argentina. Agosto 2005 - junio 2007.

Tabla 24: Correlación entre calidad de vida relacionada con la salud y variables clínicas en pacientes de la Unidad de Infectología. Hospital Zonal General de Agudos "Mi Pueblo". Florencio Varela, provincia de Buenos Aires, Argentina. Agosto 2005 - junio 2007.

Tabla 25: Ocurrencia de enfermedad marcadora y puntuación obtenida en el cuestionario de salud SF-36 en pacientes de la Unidad de Infectología. Hospital Zonal General de Agudos "Mi Pueblo". 
Tabla 26: Número de enfermedades marcadoras y puntuación obtenida en el cuestionario de salud SF- 36 en pacientes de la Unidad de Infectología. Hospital Zonal General de Agudos "Mi Pueblo". Florencio Varela, provincia de Buenos Aires, Argentina. Agosto 2005 - junio 2007.

Tabla 27: Años de diagnóstico de la infección por VIH y puntuación obtenida en el cuestionario de salud SF-36 en pacientes de la Unidad de Infectología. Hospital Zonal General de Agudos "Mi Pueblo". Florencio Varela, provincia de Buenos Aires, Argentina. Agosto 2005 - junio 2007.

Tabla 28: Hospitalizaciones y puntuación obtenida en el cuestionario de salud SF-36 en pacientes de la Unidad de Infectología. Hospital Zonal General de Agudos "Mi Pueblo". Florencio Varela, provincia de Buenos Aires, Argentina. Agosto 2005 - junio 2007.

Tabla 29: Número de adicciones y puntuación obtenida en el cuestionario de salud SF-36 en pacientes de la Unidad de Infectología. Hospital Zonal General de Agudos "Mi Pueblo". Florencio Varela, provincia de Buenos Aires, Argentina. Agosto 2005 - junio 2007.

Tabla 30: Número de comorbilidades y puntuación obtenida en el cuestionario de salud SF-36 en pacientes de la Unidad de Infectología. Hospital Zonal General de Agudos "Mi Pueblo". Florencio Varela, provincia de Buenos Aires, Argentina. Agosto 2005 - junio 2007.

Tabla 31: Inicio de tratamiento antiretroviral de gran actividad y puntuación obtenida en el cuestionario de salud SF-36 en pacientes de la Unidad de Infectología. Hospital Zonal General de Agudos "Mi Pueblo". Florencio Varela, provincia de Buenos Aires, Argentina. Agosto 2005 - junio 2007.

Tabla 32: Asociación de drogas antiretrovirales recibidas y puntuación obtenida en el cuestionario de salud SF-36 en pacientes de la Unidad de Infectología. Hospital Zonal General de Agudos "Mi Pueblo". Florencio Varela, provincia de Buenos Aires, Argentina. Agosto 2005 - junio 2007

Tabla 33: Número de tratamientos antiretrovirales recibidos (switch) y puntuación obtenida en el cuestionario de salud SF-36 en pacientes de la Unidad de Infectología. Hospital Zonal General de Agudos "Mi Pueblo". Florencio Varela, provincia de Buenos Aires, Argentina. Agosto 2005 - junio 2007.

Tabla 34: Correlación entre calidad de vida relacionada con la salud y variables inmunológicas en pacientes de la Unidad de Infectología. Hospital Zonal General de Agudos "Mi Pueblo". Florencio Varela, provincia de Buenos Aires, Argentina. Agosto 2005 - junio 2007.

Tabla 35: Recuento de linfocitos T CD4 y puntuación obtenida en el cuestionario de salud SF-36 en pacientes de la Unidad de Infectología. Hospital Zonal General de Agudos "Mi Pueblo". Florencio Varela, provincia de Buenos Aires, Argentina. Agosto 2005 - junio 2007.

Tabla 36: Número de copias de carga viral y puntuación obtenida en el cuestionario de salud SF-36 en pacientes de la Unidad de Infectología. Hospital Zonal General de Agudos "Mi Pueblo". Florencio Varela, provincia de Buenos Aires, Argentina. Agosto 2005 - junio 2007.

\section{Cuadros}

Cuadro 1: Clasificación de las drogas utilizadas en el tratamiento antiretroviral de gran actividad administrado a los pacientes con infección por VIH/SIDA de la Unidad de Infectología. Hospital 
Zonal General de Agudos "Mi Pueblo". Florencio Varela, provincia de Buenos Aires. Argentina. Año 2006.

Cuadro 2: Combinaciones del tratamiento antiretroviral de gran actividad administrado a los pacientes con infección por VIH/SIDA de la Unidad de Infectología. Hospital Zonal General de Agudos "Mi Pueblo". Florencio Varela, provincia de Buenos Aires. Argentina. Año 2006

Cuadro 3: Contenido de las escalas del cuestionario de salud SF-36.

\section{Figuras}

Figura 1: Chimpancé Pan troglodytes troglodytes

Figura 2: Mono mangabey africano (Cercocebus atys).

Figura 3: Distribución geográfica de especies de chimpancé Pan troglodytes troglodytes....

Figura 4: Diversidad genética del VIH 1.

Figura 5: Relaciones filogenéticas entre el VIH 1, VIH 2 y SIV.

Figura 6: Niña camino al mercado en un poblado de la República Democrática del Congo; lleva una canasta con un brazo de mono y una rata gambiana. (Fotografía tomada por Lynn Johnson. National Geographic Stock, 2005).

Figura 7: Desposte de carne de monos en el Congo, África. (Fotografía tomada por Randy Olson. National Geographic Stock, 2005)....

Figura 8: Relación entre casos reportados de SIDA y centros de vacunación antipolio. Congo Belga, período 1957 a 1960

Figura 9: Virus de la inmunodeficiencia humana....

Figura 10: Estructura del virus de la inmunodeficiencia humana.

Figura 11: Receptores y correceptores de quimocinas en la interacción entre células blanco y el VIH.

Figura 12: Penetración del VIH al linfocito TCD4 mediante el uso de receptores y correceptores.....

Figura 13: Historia natural de la infección por VIH y su progresión a SIDA.

Figura 14: Prevalencia estimada del VIH en adultos en todo el mundo y en África subsahariana, $1990-2007$

Figura 15: Estimación mundial del número personas que viven con VIH. Período 1990 2007.

Figura 16: Estimación mundial del número de personas con infección por VIH por región. Período $1990-2007$.

Figura 17: Tasa de notificación de personas con infección por VIH/SIDA por 100.000 habitantes 
Figura 18: Regiones sanitarias de la provincia de Buenos Aires, Argentina. Año 2007

Figura 19: Tasa de infección por VIH cada 100.000 habitantes en regiones sanitarias seleccionadas de la provincia de Buenos Aires, Argentina. Período 2001- 2007.

Figura 20: Vías de transmisión de personas con infección por VIH en Argentina. Período 20012007.

Figura 21: Principales enfermedades marcadoras en casos de SIDA acumulados, provincia de Buenos Aires, Argentina, período 1985 - 2006.

Figura 22: Municipios que conforman el conurbano de la provincia de Buenos Aires, Argentina, año 2007.

Figura 23: Notificación de casos de infección por VIH y casos de SIDA, Región Sanitaria VI, provincia de Buenos Aires, Argentina, año 2007.

Figura 24: Casos de infección por VIH/SIDA según vía de transmisión, Región Sanitaria VI, provincia de Buenos Aires, Argentina, año 2007.

Figura 25: Notificación de casos de VIH/SIDA. Región Sanitaria VI, provincia de Buenos Aires, Argentina. Nivel de Instrucción. Año 2007.

Figura 26: Distribución según edad de casos de infección por VIH/SIDA, año 2007. Región Sanitaria VI, provincia de Buenos Aires, Argentina

Figura 27: Principales enfermedades marcadoras de SIDA notificadas. Región sanitaria VI, provincia de Buenos Aires, Argentina, año 2007.

Figura 28: Nivel de instrucción de pacientes de la Unidad de Infectología. Hospital Zonal General de Agudos "Mi Pueblo", Florencio Varela, provincia de Buenos Aires, Argentina. Agosto 2005 junio 2007.

Figura 29: Distribución de pacientes de la Unidad de Infectología, según años de diagnóstico de la infección por VIH. Hospital Zonal General de Agudos "Mi Pueblo". Florencio Varela, provincia de Buenos Aires, Argentina. Agosto 2005 - junio 2007.

Figura 30: Distribución de pacientes de la Unidad de Infectología según vía de transmisión de la infección por VIH. Hospital Zonal General de Agudos "Mi Pueblo". Florencio Varela, provincia de Buenos Aires, Argentina. Agosto 2005 - junio 2007.

Figura 31: Distribución de pacientes de la Unidad de Infectología según causa del diagnóstico de la infección por VIH. Hospital Zonal General de Agudos "Mi Pueblo". Florencio Varela, provincia de Buenos Aires, Argentina. Agosto 2005 - junio 2007

Figura 32: Recuento de linfocitos T CD4 en pacientes de la Unidad de Infectología. Hospital Zonal General de Agudos "Mi Pueblo". Florencio Varela, provincia de Buenos Aires, Argentina. Agosto 2005 - junio 2007.

Figura 33: Valores de carga viral plasmática en pacientes de la Unidad de Infectología. Hospital Zonal General de Agudos "Mi Pueblo". Florencio Varela, provincia de Buenos Aires, Argentina. 
Figura 34: Distribución de las puntuaciones de las dimensiones que integran la versión española del Cuestionario de Salud SF-36 en pacientes de la Unidad de Infectología. Hospital Zonal General de Agudos "Mi Pueblo". Florencio Varela, provincia de Buenos Aires, Argentina. Agosto 2005 - junio 2007.

Figura 35: Distribución de las puntuaciones de las dimensiones que integran la versión española del Cuestionario de Salud SF-36, según el género en pacientes de la Unidad de Infectología. Hospital Zonal General de Agudos "Mi Pueblo". Florencio Varela, provincia de Buenos Aires, Argentina. Agosto 2005 - junio 2007.

Figura 36: Síndrome de redistribución de la grasa corporal por lipodistrofia en un paciente bajo tratamiento antiretroviral de gran actividad.

Figura 37: Lipodistrofia facial en un paciente con infección por VIH/SIDA que recibe tratamiento antiretroviral de gran actividad. 


\section{LISTADO DE ABREVIATURAS}

Ac

ADN Ácido desoxirribonucleico

ARN Ácido ribonucleico

b-DNA Prueba de detección de DNA ramificado

CIE Clasificación internacional de enfermedades

CSF Componente sumario física

CDC Centros para el Control y la Prevención de Enfermedades

CSD Complejo SIDA-demencia

CVRS Calidad de vida relacionada con la salud

DE Desviación estandar

DIV Drogas de administración intravenosa

ELISA Prueba de enzima inmuno análisis

EPI Enfermedad pélvica inflamatoria

FTA-ABS Prueba treponémica de absorción-inmunofluorescencia

HBV Virus de la hepatitis B

HCV Virus de la hepatitis C

HPV Virus del papiloma humano

HSV Virus Herpes simple

HSV 8 Virus Herpes simple tipo 8

HPV Virus del papiloma humano

HTLV I Virus linfotrópico humano tipo I

HTLV II Virus linfotrópico humano tipo II

LCR Líquido cefalorraquídeo 


$\begin{array}{ll}\text { LT CD4+ } & \text { Linfocitos T helper CD4+ } \\ \text { LT CD8+ } & \text { Linfocitos T citotóxicos CD8+ } \\ \text { INTR } & \text { Inhibidores nucleósidos de la transcriptasa reversa } \\ \text { INNTR } & \text { Inhibidores no nucleósidos de la transcriptasa reversa } \\ \text { IP } & \text { Inhibidores de la proteasa } \\ \text { ITS } & \text { Infecciones de transmisión sexual } \\ \text { mL } & \text { Mililitro } \\ \text { mm } & \text { Milímetro cúbico } \\ \text { OMS } & \text { Organización Mundial de la Salud } \\ \text { OPV } & \text { Vacuna antipoliomielítica oral } \\ \text { PCR } & \text { Reacción en cadena de la polimerasa } \\ \text { RMN } & \text { Resonancia magnética nuclear } \\ \text { SAD } & \text { Síndrome ansioso-depresivo }\end{array}$

SF-36 Cuestionario de los Resultados Médicos Abreviado de Salud de 36 ítems

SIDA Síndrome de inmunodeficiencia adquirida

$\mathbf{S I V}_{\mathbf{c p z}} \quad$ Virus de la inmunodeficiencia de simios que afecta a los chimpancés

$\mathbf{S I V}_{\text {sm }} \quad$ Virus de la inmunodeficiencia de simios que afecta al mono mangabey africano

SLD Síndrome de lipodistrofia

SNC Sistema nervioso central

SRA Síndrome retroviral agudo

STLV 1 Virus linfotrópico para células T simiano de tipo 1 del chimpancé

TAC Tomografía axial computada

TARGA Tratamiento antiretroviral de gran actividad

TB Tuberculosis

UDI $_{\mathbf{s}} \quad$ Usuarios de drogas inyectables 
VDRL Venereal Diseases Research Laboratories

VIH 1 Virus de la inmunodeficiencia humana tipo 1

VIH 2 Virus de la inmunodeficiencia humana tipo 2 


\section{RESUMEN}

Fundamento: La medida de la calidad de vida relacionada con la salud (CVRS) tiene un particular interés en el escenario de las enfermedades en las que se ha conseguido una supervivencia prolongada mediante intervenciones terapéuticas específicas. La información obtenida de los pacientes por medio de la CVRS ha permitido valorar distintos componentes de la vida cotidiana potencialmente influidos por la enfermedad y su tratamiento. Los instrumentos que miden la CVRS son en su mayoría cuestionarios que recaban la información subjetiva proveniente del paciente, valorando diferentes áreas de la vida y la expresan en forma cuantitativa a través de perfiles y puntajes agregados. Los cuestionarios genéricos son independientes del diagnóstico clínico del paciente, permiten su aplicación en diferentes tipos de población, con distintas patologías y permiten comparar el impacto de diferentes enfermedades sobre la CVRS. El Cuestionario de los Resultados Médicos Abreviado SF-36, es uno de los instrumentos que posee propiedades psicométricas de validez, fiabilidad y sensibilidad al cambio. La infección por el virus de la inmunodeficiencia humana (VIH) y su progresión al síndrome de inmunodeficiencia adquirida (SIDA) origina un deterioro de las funciones físicas, psíquicas y sociales de los pacientes que determina un descenso en la sensación de bienestar. Todavía hay un conocimiento limitado del efecto del tratamiento antiretroviral de gran actividad (TARGA) y de la progresión de la enfermedad sobre la CVRS en personas que viven con VIH/SIDA. En la actualidad no se dispone de publicaciones sobre la CVRS en personas con VIH/SIDA que vivan en la Argentina.

Objetivos generales y específicos: Los objetivos del presente estudio fueron: evaluar la CVRS en personas que viven con VIH/SIDA, relacionar la calidad de vida con variables sociológicas, clínicas e inmunológicas, caracterizar el perfil socioepidemiológico de la población que vive con VIH/SIDA, identificar las adicciones y comorbilidades que se presentan en dicha población, conocer el grado de inmunosupresión determinado por el 
recuento de LT CD4+ y de la carga viral plasmática, conocer el tipo, ocurrencia y distribución de enfermedades marcadoras de SIDA que presentan los pacientes durante la evolución de su enfermedad, estimar la prevalencia de hospitalización en la población de pacientes, conocer los aspectos más relevantes del tratamiento antiretroviral que realizan los pacientes y establecer la relación entre variables sociológicas, clínicas e inmunológicas y la puntuación obtenida en las dimensiones que integran el cuestionario de salud SF-36.

Materiales y métodos: El estudio se realizó en la Unidad de Infectología del Hospital Zonal General de Agudos "Mi Pueblo" de Florencio Varela, provincia de Buenos Aires, Argentina, durante el período comprendido entre el $1^{\circ}$ de agosto de 2005 al 20 de junio de 2007. Se aplicó un diseño no experimental, observacional-correlacional, de corte transversal y retrospectivo. Se administró el cuestionario de Salud SF-36 al universo de 114 individuos, mayores de 15 años, de ambos géneros, con infección por VIH documentada y residentes en el partido de Florencio Varela. Para describir el perfil clínico y socio-epidemiológico de la población estudiada se recolectó información adicional relacionada con la enfermedad mediante las historias clínicas de los pacientes. Se confeccionó una base de datos utilizando el programa SPSS $11.5{ }^{\circledR}$ para Windows $2003^{\circledR}$ para la recolección, carga y edición de los datos obtenidos. Las técnicas descriptivas se emplearon para analizar los datos, utilizando escalas nominales y medidas de resumen; la verificación de relación entre las variables especificadas se realizó mediante los coeficientes R de Pearson y de Spearman. Se obtuvo el consentimiento verbal y se resguardó la confidencialidad de cada persona que participó en el estudio.

Resultados: La población evaluada tenía una edad promedio de 36 años, 56 \% fueron mujeres y 44 \% hombres; la mayoría poseía un nivel de instrucción consistente en escolaridad primaria completa o mayor. Más de la mitad de la población no tenía empleo, ni percibía planes sociales y el $81,6 \%$ no poseía obra social. Las relaciones heterosexuales fueron la principal vía de contagio, seguida de la drogadicción; ésta última prevaleció en los hombres. 
En ambos géneros la infección se transmitió principalmente en el grupo entre los 25 a 41 años de edad. Los principales motivos que determinaron la realización del diagnóstico de la infección por VIH fueron: la presentación de enfermedad marcadora de SIDA (35,1\%); el diagnóstico de la infección en la pareja sexual (23,7 \%); el embarazo (14,9\%); las conductas de riesgo en el paciente (12,3\%); el diagnóstico de la infección realizado al hijo (7,9\%); otros $(6,2 \%)$. La adicción referida con mayor frecuencia fue el tabaquismo, seguida del alcoholismo y la drogadicción no intravenosa; las mujeres presentaron menor frecuencia de adicciones que los hombres. Las comorbilidades de mayor prevalencia fueron: hepatopatía alcohólica, síndrome de lipodistrofia, hepatitis B, síndrome ansioso-depresivo, cáncer y hepatitis C. El 36,2 \% de los pacientes tenía inmunosupresión severa, con recuentos de LT CD $4+<200 / \mathrm{mm}^{3}$ y el $70 \%$ presentaba la carga viral plasmática detectable. Las enfermedades marcadoras de SIDA prevalentes, en orden de mayor a menor frecuencia, fueron: síndrome consuntivo asociado al VIH, candidiosis esofágica, tuberculosis pulmonar y extrapulmonar, toxoplasmosis cerebral, cáncer invasivo de cuello uterino, neumonía por Pneumocystis jiroveci, demencia asociada al SIDA, criptosporidiosis intestinal, criptococosis meníngea, histoplasmosis diseminada, sarcoma de Kaposi, Herpes simple mucocutáneo y leucoencefalopatía multifocal progresiva. La tuberculosis, en sus dos formas clínicas se presentó en los individuos jóvenes, entre 25 y 32 años. La mayoría de los casos de cáncer invasivo de cuello uterino ocurrieron en mujeres jóvenes entre los 25 y 41 años. El 47,4 \% de los pacientes requirió hospitalización en algún momento en la evolución de su enfermedad.

El $72,8 \%$ de los pacientes se hallaba en tratamiento antiretroviral, con diferentes asociaciones; el $46 \%$ recibían 2 inhibidores nucleósidos de la transcriptasa reversa (INTR) + 1 inhibidor no nucleósido de la transcriptasa reversa (INNTR), el 13,8 \% 2 INTR +1 inhibidor de la proteasa (IP), el $6 \% 2$ INTR + 2 IP y el 4,3\% 3 INTR. El 42,2 \% de los 
pacientes había cambiado una vez de tratamiento (switch), 12,9\% 2 veces, el 7,8 \% 3 veces y el 7,7 \% más de 4 veces.

Al analizar las puntuaciones obtenidas en el cuestionario de salud SF-36, se observó que las puntuaciones medias variaron de 79 en la función física a 58 en el rol emocional.

En el total de la población estudiada, la puntuación más baja obtenida fue en el rol emocional, con un elevado porcentaje de individuos con puntuación mínima. Las mujeres presentaron mejores puntuaciones en 5 dimensiones: función física, rol físico, salud general, vitalidad y función social. Los varones presentaron puntuaciones más elevadas solamente en: dolor corporal, rol emocional y salud mental. La verificación de contraste de puntuaciones medias de las distintas dimensiones del cuestionario, entre género, analizada mediante pruebas paramétricas, manifestó diferencias estadísticas sólo en el rol emocional $(\mathrm{p}<0,05)$.

Con respecto a la edad, al realizarse el análisis de varianza, se observaron diferencias técnica y estadísticamente significativas y presentando asociación sólo en el rol físico $(\mathrm{p}<0,05)$; las menores puntuaciones se obtuvieron en la franja etaria de 59 a 67 años, en todas las dimensiones del cuestionario. Comparando las puntuaciones con el género y grupos etarios, se observó que sólo en el rol emocional las mujeres presentaron puntuaciones más bajas que en los hombres, en todos los grupos etarios.

Al analizar la relación entre calidad de vida y las variables sociológicas, se advirtió que la relación entre todas las dimensiones del cuestionario y la edad, la vía de contagio de la infección por VIH y la causa del diagnóstico de la infección por VIH fue escasa y no significativa, con excepción del nivel de instrucción, donde se evidenció cierto grado de relación significativa. Los pacientes que no poseían obra social, plan social y empleo, y aquellos con estudios universitarios, presentaron las puntuaciones más bajas en el rol emocional. 
Se encontró cierto grado de correlación significativa entre la función física, el número de enfermedades marcadoras de SIDA y las hospitalizaciones. Los pacientes que tuvieron enfermedad marcadora de SIDA presentaron más bajas puntuaciones en la función física, rol físico, salud general, vitalidad y función social. Las puntuaciones del cuestionario disminuyeron al aumentar el número de enfermedades marcadoras padecidas. Aquellos individuos que requirieron hospitalización en algún momento de la evolución de su enfermedad, los que tuvieron mayor número de adicciones y comorbilidades, presentaron las menores puntuaciones en casi todas las dimensiones del cuestionario. Los pacientes que recibían TARGA desde hace 8 o más años, poseían los puntajes más bajos en el rol emocional, salud general, vitalidad, dolor corporal, salud mental, función social y función física; la menor puntuación en la función física y el rol físico se observó en aquellos medicados con regímenes que incluían drogas IP, asociadas a INTR.

La relación entre rol físico, dolor corporal, vitalidad, función social, rol emocional, salud mental y las variables inmunológicas fue escasa y técnicamente no significativa. La relación entre función física y variables inmunológicas tuvo un comportamiento diferencial; la carga viral y el número de copias expresó escasa relación, mientras que se manifestó cierto grado de correlación significativo con el recuento de LT CD4+. Los individuos que poseían un recuento de LT CD4+ menor de $200 / \mathrm{mm}^{3}$ y carga viral plasmática mayor de 100.000 copias/mL, presentaron puntuaciones menores en todas las dimensiones, salvo en dolor corporal.

Conclusiones: La realización de este trabajo ha demostrado que:

1. El perfil - clínico epidemiológico de la población de pacientes que viven con VIH/SIDA en Florencio Varela, justifica que es imperativo el trabajo prioritario sobre dos ejes fundamentales: la educación para la salud y la creación de redes de accesibilidad a los servicios de salud, tanto en el primero como en el segundo nivel de atención. 
2. Los pacientes se infectaron a una temprana edad; la mayoría de ellos contrajeron la infección durante la adolescencia o siendo adultos jóvenes y la transmisión se asocia preponderantemente a la vía heterosexual.

3. El principal motivo que lleva a la realización del diagnóstico de la infección por VIH en la población es la presentación de enfermedad marcadora de SIDA; el diagnóstico tardío es la resultante de grandes deficiencias en los programas de salud y de políticas que interfieren en la accesibilidad y eficacia de las medidas de prevención y atención relacionadas con el VIH.

4. La CVRS es un aspecto imprescindible a considerar cuando se planifica el tratamiento que recibirán estos pacientes; su medición permite detectar aspectos del estado de salud que los resultados clínicos tradicionales no reflejan, incorporando la percepción del paciente.

5. El Cuestionario MOS SF-36 fue comprendido por los pacientes, permitiendo su administración, por lo que el procedimiento de adaptación transcultural realizado para esta población del conurbano de la provincia de Buenos Aires permitirá utilizarlo en otras poblaciones de la Argentina.

6. Considerando el total de la población estudiada a la cual se le administró el cuestionario de salud SF-36, la puntuación más baja fue obtenida en el rol emocional, con un elevado porcentaje de individuos con puntuación mínima. Si bien existen diferencias entre género, edad y otros factores socio-epidemiológicos y clínicos, se ha demostrado que el estado emocional, la ansiedad y la depresión tienen un fundamental e importante efecto en la CVRS de la población y puede alterar la percepción de mejorías del estado de salud general.

7. La mejoría en la condición física de los pacientes no se acompañó paralelamente de la mejoría de su estado emocional, ni de la percepción de una mejor calidad de vida. 
8. Los valores poblacionales de referencia de CVRS en personas que viven con VIH/SIDA, obtenidos mediante la aplicación del cuestionario de salud SF-36 en esta población, permitirán la contextualización e interpretabilidad de los resultados obtenidos en futuros trabajos.

9. El desarrollo de estudios de CVRS en la población general y en diferentes tipos de patologías crónicas, son objetivos prioritarios para lograr la implementación generalizada de la medición de la CVRS como método útil, confiable y necesario para evaluar el impacto general de la enfermedad por VIH.

10. Los programas de tratamiento del SIDA — ya sean provenientes de instituciones de salud estatales o privadas - , no deben limitarse sólo a la provisión de medicamentos y pruebas de laboratorio, sino que deben contemplar ya mismo la incorporación de nuevos abordajes terapéuticos con el objetivo de mejorar no sólo las dimensiones físicas del individuo sino también las psíquicas y sociales. 


\section{INTRODUCCIÓN}

La enfermedad actualmente conocida como síndrome de inmunodeficiencia adquirida (SIDA), fue reportada por primera vez hace 26 años atrás en la publicación Morbidity and Mortality Weekly Report bajo el título "Pneumocystis pneumonia - Los Angeles". Ni siquiera el lector más pesimista hubiera podido anticipar la escala y magnitud que la epidemia asumió dos décadas después; millones de personas han muerto por la enfermedad, a lo que se suman las nuevas infecciones que ocurren diariamente en todas las regiones del planeta. ${ }^{1}$

La infección por el virus de la inmunodeficiencia humana del tipo 1 (VIH 1) es considerada como una de las más significativas enfermedades infecciosas emergentes y su estadío final, el SIDA, con un total estimado de 33,2 millones [30,6 - 36,1 millones] de personas infectadas a finales del año 2006, constituye el mayor desafío de Salud Pública. La infección por el VIH es contraída por más de 6800 personas y más de 5700 fallecen a causa del SIDA cada día, en la mayoría de los casos debido a un acceso inadecuado a los servicios de prevención y tratamiento. ${ }^{2}$

El SIDA es un fenómeno social reciente. Todo lo que hoy sabemos sobre el SIDA lo sabemos desde hace poco más de 20 años, precisamente cuando se asumía en Occidente que la ciencia y la medicina eran capaces de curar a la mayoría de las enfermedades infecciosas y hasta erradicar algunas de ellas. ${ }^{1}$

El descubrimiento de los retrovirus humanos ha sido, para los científicos, médicos y profesionales de la salud, extraordinario e imprevisto, pero también una gran frustración. ${ }^{3}$

Charles Rosenberg postula que una epidemia permite seccionar transversalmente una sociedad, reflejando la particular configuración de sus instituciones y su cultura. ${ }^{3}$ Cada sociedad en particular construye una respuesta característica a una epidemia. Una epidemia cumple una estructura dramática como fenómeno social, es decir, comienza en un momento en el tiempo, procede en un período espacio-temporal en el que la tensión lleva a una crisis individual y colectiva, y finalmente, sucumbe. En muchos aspectos, el SIDA no sigue el patrón tradicional de epidemia porque, lejos de sucumbir, todavía persiste. Es una epidemia postmoderna en el sentido de reflexiva, autoconsciente y burocráticamente estructurada, que existe en diferentes niveles simultáneamente. ${ }^{3}$ 
El conocimiento actual sitúa a las infecciones retrovirales humanas como zoonosis que se originaron a partir de fenómenos de salto de especies de primates a los humanos. El virus de la inmunodeficiencia de simios que afecta a los chimpancés $\left(\operatorname{SIV}_{\mathrm{cpz}}\right)$ es el precursor inmediato del VIH 1 y es probable que se hayan producido fenómenos de salto de especie similares entre determinados tipos de monos y chimpancés. Algunos tipos de SIV se encuentran estrechamente relacionados con el VIH 2, que infecta varias especies de monos, incluyendo el mono verde africano -su huésped natural- y se sabe que el SIV se ha transmitido a trabajadores de laboratorio. Otras especies albergan retrovirus análogos a los de los humanos y algunos primates africanos, como el virus de la leucemia felina, virus de la inmunodeficiencia felina, virus de la inmunodeficiencia bovina, virus de la anemia infecciosa equina, virus de la artritis-encefalitis caprina y el Virus maedi-visna de las ovejas. Todos estos retrovirus demuestran similitudes biológicas, morfológicas, bioquímicas y moleculares; los patrones comunes incluyen un período de meses a años de enfermedad subclínica, seguida por un inevitable desarrollo de inmunodeficiencia y enfermedad del sistema nervioso central $(\mathrm{SNC})$.

Los retrovirus patógenos humanos incluyen los lentivirus, dentro de los cuales se hallan el VIH 1 y 2 y los oncovirus entre los que se describen el virus linfotrópico humano I y II (HTLV I y II). La principal característica de los lentivirus es el establecimiento de infecciones persistentes denominadas lentas, debido a los prolongados períodos de incubación antes que se manifiesten los signos clínicos de la enfermedad. Pueden replicarse continuamente en sus células huésped, a pesar de una respuesta inmune competente. Además en algunos casos, causan una infección citocídica aguda, seguida por una infección persistente o una enfermedad lenta multisistémica.

Los retrovirus tienen un diámetro de $100 \mathrm{~nm}$ y contienen dos cadenas simples de ARN que permiten su recombinación entre sí; se hallan bajo dos formas principales: un provirus ADN y un virión infeccioso que contiene ARN. Las principales características de los retrovirus son: su gran diversidad genética, su capacidad de permanecer en estado de latencia debido a que el provirus se integra en el ADN cromosómico de la célula infectada y la capacidad de reducir la eficacia de la respuesta inmune del huésped debido a su tropismo hacia células T CD4+ y macrófagos. Los retrovirus emplean como estrategia de replicación la transcripción del ARN viral a un ADN lineal de doble cadena con la consiguiente integración en el genoma del huésped. La enzima característica utilizada en este proceso es una ADN polimerasa dependiente del ARN que invierte el flujo de la información genética, conocida 
como transcriptasa inversa. Esta enzima es tendente a los errores; con la renovación masiva de viriones en la célula huésped infectada, estos errores se acumulan en el ADN viral, siendo responsables de la relativamente elevada mutabilidad del VIH $1 .{ }^{4}$

En el año 1979 Robert Gallo y cols., del Instituto Nacional del Cáncer de Estados Unidos, descubrieron el primer retrovirus patógeno para el hombre, el virus linfotrópico de células T humano de tipo I (HTLV I), relacionado con la leucemia linfoma de células T y la paraparesia espástica tropical / mielopatía asociada a HTLV I; en 1981 descubrieron el virus linfotrópico de células T humano de tipo II (HTLV II), asociado a la leucemia de células vellosas. Estos descubrimientos proporcionaron la piedra fundamental para el posterior reconocimiento del tercer retrovirus humano, el VIH, aislado en 1983 simultáneamente por Luc Montagnier en el Instituto Pasteur de Francia y por Robert Gallo. ${ }^{5}$

\section{Orígenes del VIH}

El origen del VIH está relacionado con los virus aislados de los chimpancés. Frente a la ausencia de evidencia epidemiológica directa, los estudios moleculares realizados en lentivirus de primates proveen información certera acerca de los orígenes del VIH 1 y $2 .{ }^{6} \mathrm{La}$ información acumulada de años recientes ha demostrado que la transmisión de retrovirus de un primate a otro, incluyendo humanos, no es un hecho infrecuente; existen numerosos reportes de infecciones cruzadas entre distintos primates y el hombre, como el caso del virus linfotrópico para células T simiano de tipo 1 del chimpancé (STLV 1) que se ha transmitido al hombre, en donde evolucionó al HTLV I. ${ }^{7,8}$

Datos obtenidos por secuenciación molecular determinaron que el VIH 1 evolucionó en una subespecie de chimpancés denominada Pan troglodytes troglodytes (figura 1); éstos constituyen el reservorio natural del virus, cuyo hábitat es el oeste de la zona ecuatorial de África. ${ }^{9}$

Este virus no produce ningún tipo de enfermedad en los animales infectados y probablemente se haya propagado entre los chimpancés durante siglos. Es entonces de particular interés la evidencia de que, como en el caso de muchos virus, el VIH se transfirió en determinado momento al hombre, lo que significa que se originó como una infección zoonótica. $^{10}$

Existen distintas subespecies de chimpancés que habitan en las regiones donde se han encontrado los virus pertenecientes a los distintos grupos de VIH 1. La presencia de estos chimpancés coincide con el patrón de la epidemia de SIDA en esa zona de África. Hasta el 
presente, tres virus distintos de la inmunodeficiencia simiana (SIV) han sido aislados de estos chimpancés y se los ha denominado $\operatorname{SIV}_{\mathrm{cpz}}$.

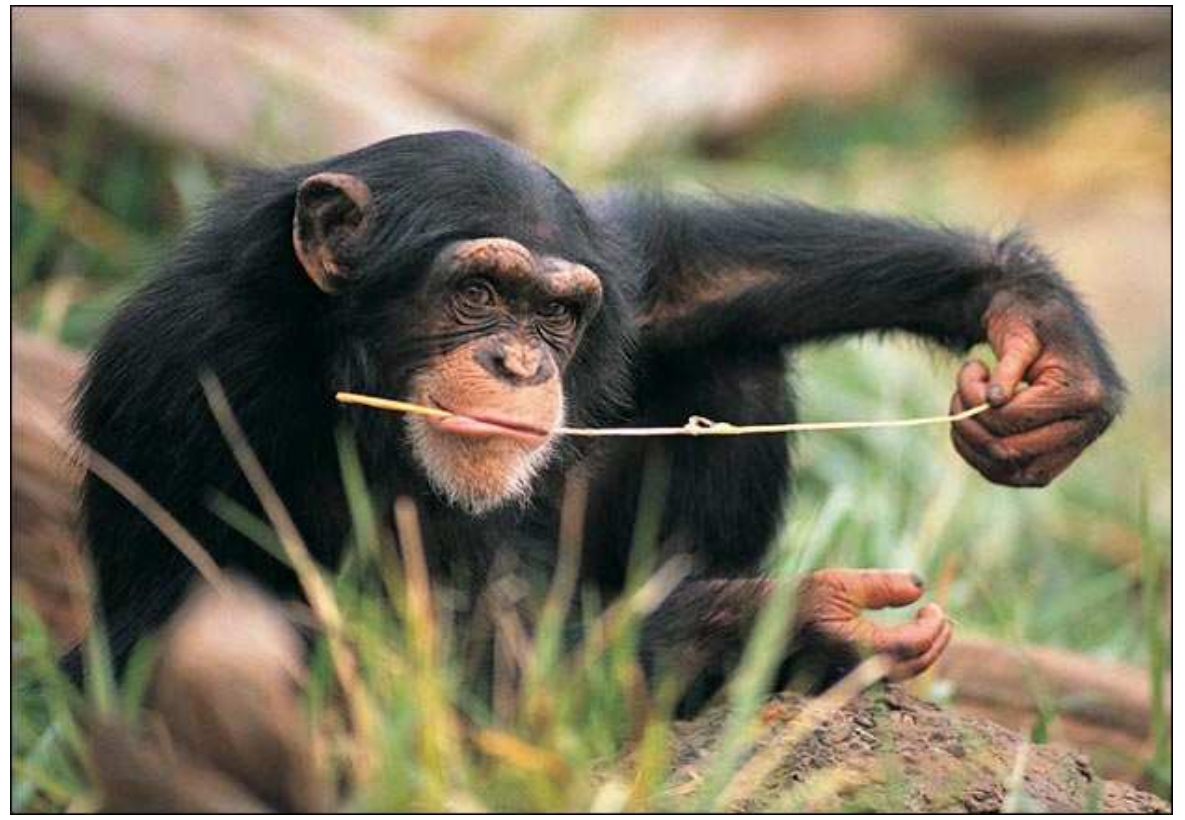

Figura 1: Chimpancé Pan troglodytes troglodytes.

Cada uno de ellos tiene una homología con los VIH del grupo $\mathrm{M}, \mathrm{N}$ u O. El análisis filogenético indica que el VIH 1 y el VIH 2 provienen de 2 linajes diferentes de SIV y por lo tanto tienen orígenes diferentes. Las cepas de SIV estrechamente relacionadas al VIH 2 han sido aisladas del mono mangabey africano (Cercocebus atys) y de 3 especies de macacos de África occidental (Figura 2).

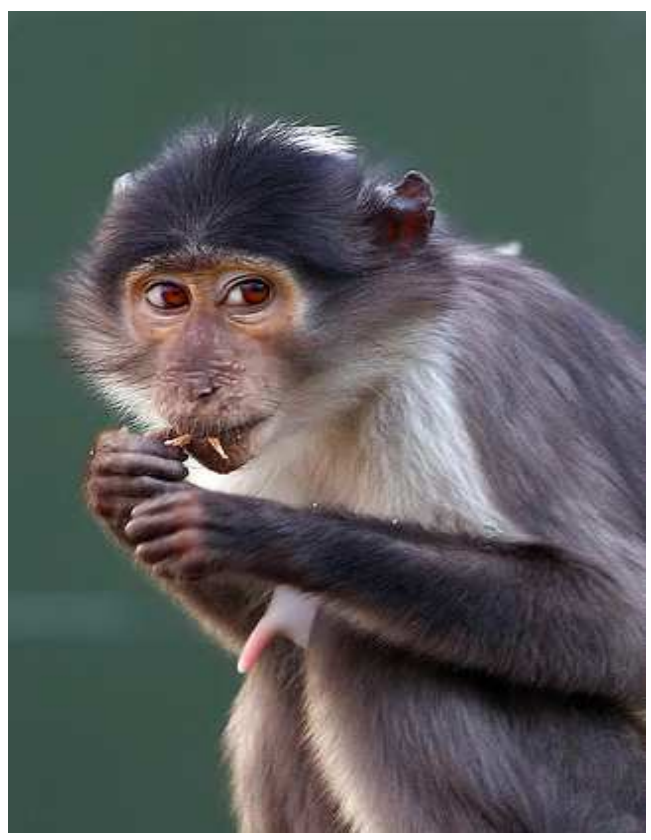

Figura 2: Mono mangabey africano (Cercocebus atys). 
El VIH 2 es sólo endémico en África occidental y es evidente que el SIV aislado del mono mangabey africano $\left(\mathrm{SIV}_{\mathrm{sm}}\right)$, que es su reservorio natural, ha sido transmitido al hombre en esa región. El estudio filogenético detallado de la relación entre $\operatorname{SIV}_{\mathrm{sm}}$ y las cepas del VIH 2 indican que el cruzamiento entre especies y su transmisión han ocurrido en múltiples ocasiones. El $\mathrm{SIV}_{\mathrm{sm}}$ también se ha transmitido a los seres humanos y aunque en su reservorio natural no es patógeno, cuando infecta a otras especies de primates o al hombre produce una enfermedad parecida al SIDA. ${ }^{11}$ Las únicas cepas de SIV estrechamente relacionadas al VIH 1 han sido aisladas del chimpancé Pan troglodytes troglodytes, que se distribuye a lo largo del África occidental y ecuatorial. Evidencia genética reciente obtenida del análisis de secuencias de DNA mitocondrial indica que los chimpancés pueden ser divididos en al menos 2 o quizás 4 distintas subespecies. Así, los chimpancés del oeste africano denominados Pan troglodytes verus son bastantes distintos de aquellos del África ecuatorial denominados Pan troglodytes troglodytes (Camerún, Guinea ecuatorial, Gabon y Congo-Brazzaville) y Pan troglodytes schweinfurthii que provienen del África central (norte y oeste del Congo, Ruanda, Burundi y oeste de Uganda y Tanzania). Sharp y colaboradores testearon anticuerpos y ácido nucleico viral en muestras de orina y materia fecal de chimpancés salvajes, demostrando la infección en 1 de cada 30 animales. No se ha documentado infección por $\operatorname{SIV}_{\mathrm{cpz}}$ en Pan troglodytes verus, lo que explica la ausencia aparente de infección por $\mathrm{SIV}_{\mathrm{cpz}}$ entre los chimpancés cautivos fuera de África, ya que estos animales provienen de la exportación desde África occidental (Figura 3) ${ }^{12}$

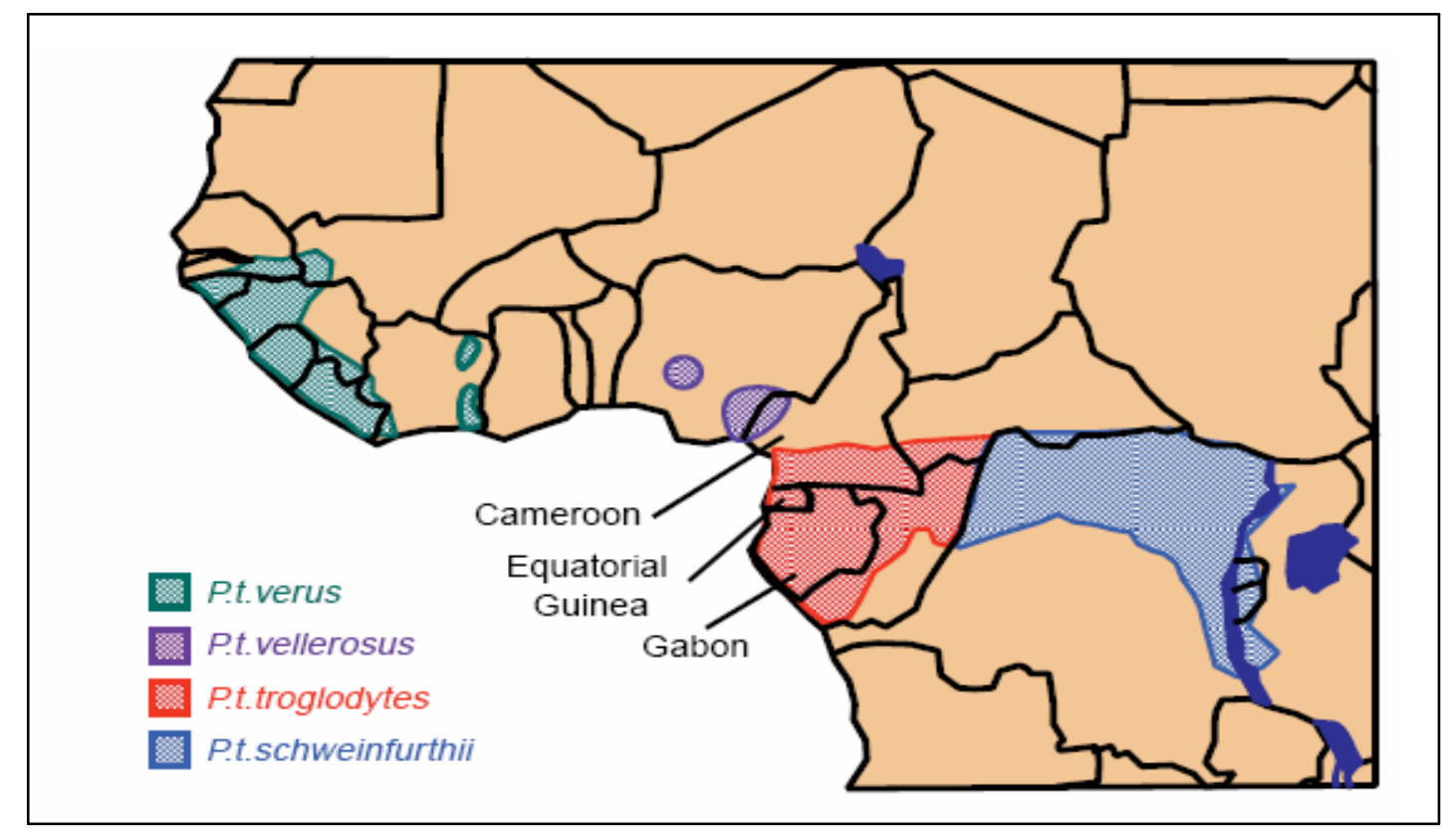

Figura 3: Distribución geográfica de especies de chimpancé Pan troglodytes troglodytes. Tomado de Gao y colaboradores ${ }^{9}$. 
Pero ¿cómo, cuándo y dónde ocurrió el cruzamiento y transmisión entre especies que dio origen a los VIH 1 y 2? Para comprender estas cuestiones es necesario estudiar la diversidad del VIH 1. El VIH 1 ha acumulado una considerable diversidad genética desde su arribo a los humanos, debido a su tasa de replicación elevada y a la natural propensión al error de su transcriptasa inversa, originando las cuasiespecies. El análisis filogenético indica que la diferentes cepas de VIH 1 pertenecen a 3 grupos: el grupo M o principal (main), el grupo O o divergente (outlier) y el grupo $\mathrm{N}$ (non-M, non-O). El grupo $\mathrm{M}$ es el responsable de la vasta mayoría de casos de SIDA en el mundo, se ha subdividido en 10 subtipos denominados de la A a la $\mathrm{K}$ y presenta además 2 formas recombinantes: CRF 01 AE/E y CRF 02 A/G (Figura 4). Las cepas divergentes forman el grupo O, descripto en 1990 por De Leys y colaboradores, cuyas cepas se han hallado en el oeste del África ecuatorial. ${ }^{6}$ En 1998, Simon y colaboradores describieron el tercer grupo proveniente de Camerún al que denominaron $\mathrm{N}$, que presenta secuencias distintas de los 2 grupos anteriores. ${ }^{13}$ Cada uno de los grupos proviene de distintos linajes de $\mathrm{SIV}_{\mathrm{cpz}}$.

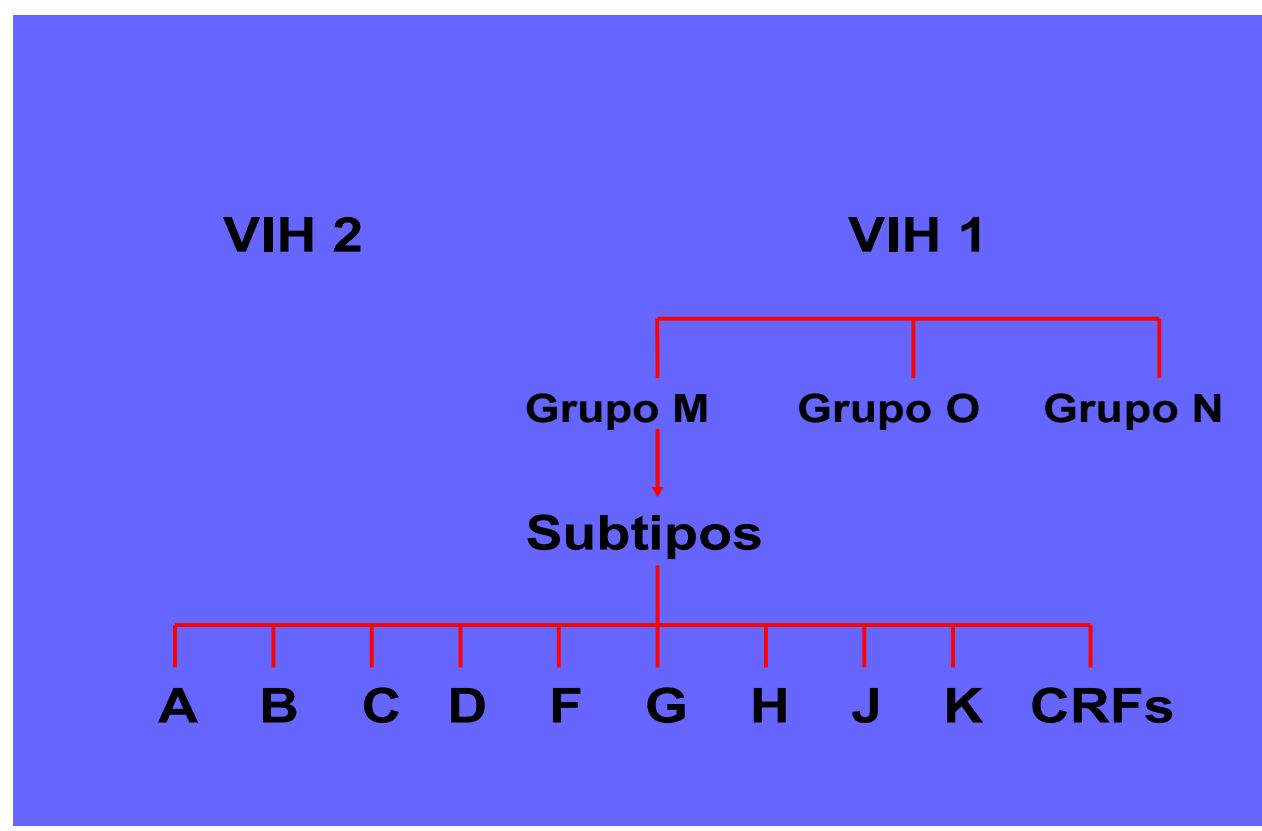

Figura 4: Diversidad genética del VIH 1.

Una segunda fuente importante de la diversidad genética de los lentivirus de primates es la recombinación; este efecto es más pronunciado cuando un solo individuo es infectado por diversas cepas provenientes de más de una fuente. La infección inicial transmite un rango limitado de variantes, generalmente de un único grupo y la exposición subsiguiente tras la infección escasamente da lugar a la infección por una segunda variante. Por lo tanto la 
mayoría de las personas afectadas parecen estar infectadas por una cepa única que evoluciona hacia múltiples cuasiespecies virales relacionadas a lo largo del curso de la infección ${ }^{14}$ En regiones donde circulan diferentes subtipos, $10 \%$ o más de las cepas de VIH grupo $\mathrm{M}$ son intersubtipos recombinantes y recientemente han sido identificadas cepas recombinantes del grupo M y O. ${ }^{6}$ El grupo $\mathrm{N}$ desciende de una cepa recombinante; en este caso el evento de recombinación debe haber ocurrido en chimpancés algún tiempo antes de la transmisión de este linaje a los humanos. Hahn y colaboradores han demostrado que las cepas de $\operatorname{SIV}_{\mathrm{cpz}}$ de origen geográfico conocido cercano al VIH 1 han sido aisladas hasta ahora sólo del chimpancé de la región occidental del África central. Particularmente, el VIH 1 grupo N tiene una gran similitud al $\mathrm{SIV}_{\mathrm{cpz}}$ aislado en esta región, lo que sugiere que la presencia de los 3 grupos de VIH 1 en humanos ha tenido su origen en 3 transferencias independientes (Figura 5). ${ }^{10,15,16}$

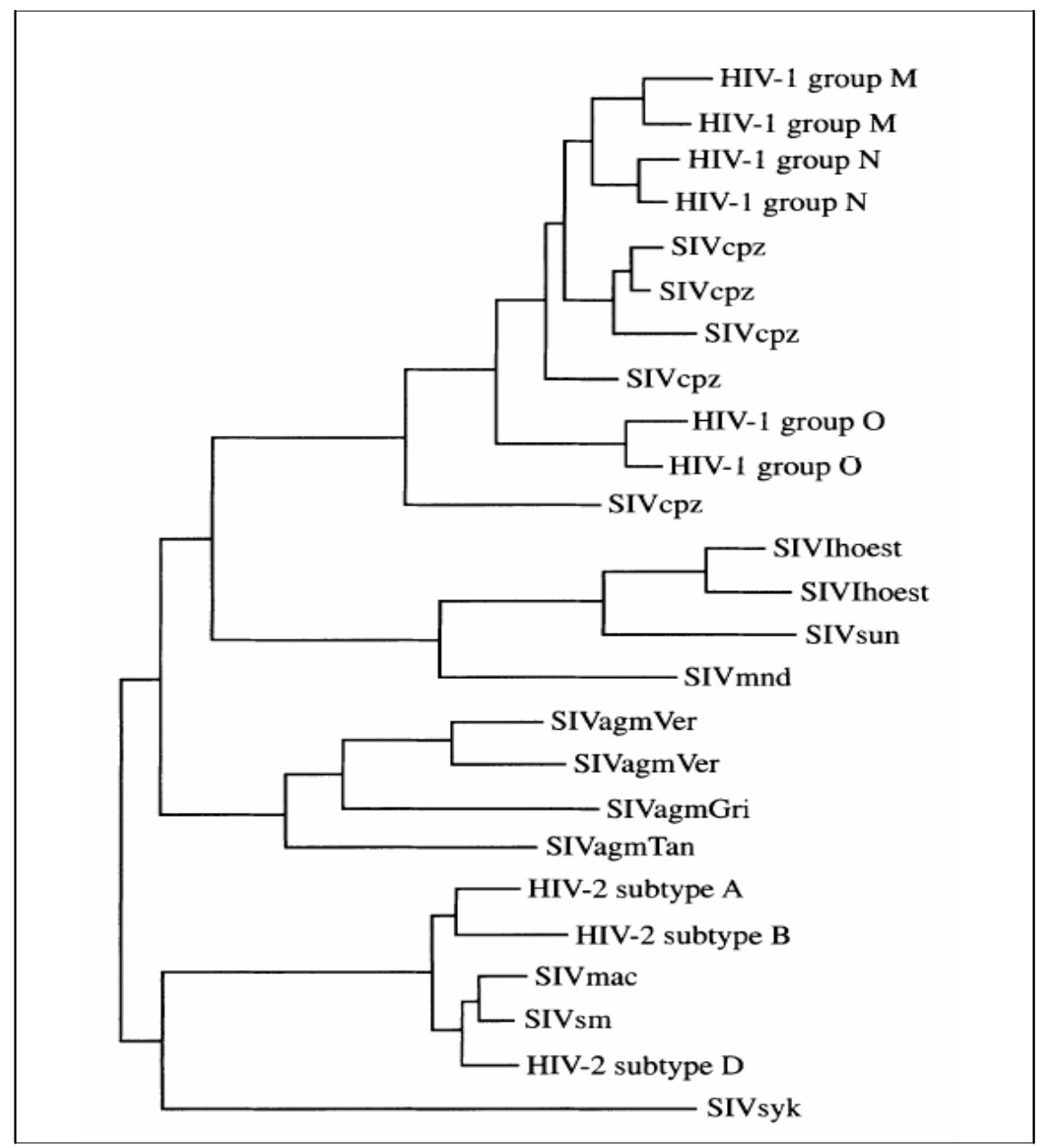

Figura 5: Relaciones filogenéticas entre el VIH 1, VIH 2 y SIV. Tomado de Sharp y colaboradores ${ }^{12}$. 
La distribución de las variantes del VIH es complicada debido a la potencial coinfección y recombinación genética entre distintas cepas virales. La mayor densidad de cepas de VIH ha sido hallada en el África sub sahariana. En contraste, la mayoría de los aislamientos reportados en Europa y las Américas pertenecen al subtipo B. Sin embargo, las múltiples introducciones de cepas de VIH en distintas regiones del mundo han incrementado la complejidad del cuadro epidemiológico.

Los diferentes subtipos tienen distinta distribución geográfica y algunos de ellos distinto grado de patogenicidad. El subtipo A/E predomina en Tailandia y la República Centro Africana. Los subtipos A y D predominan en África Central. El subtipo B prevalece en Europa, Oceanía, Japón, América del Norte y del Sur. El subtipo C es preponderante en Brasil, Asia y África. El F en Brasil, Rumania, Zaire y el subtipo H en Camerún, Zaire y Gabon. En la Argentina se caracterizaron los subtipos B, F y el recombinante B/F. ${ }^{16}$

Se han realizado numerosos estudios para tratar de estimar el año aproximado del origen del VIH 1 o el momento en que se desató su expansión desde una infección primitiva. El primer suero positivo para anticuerpos contra VIH 1 fue obtenido de una persona adulta en 1959 por Arno Motulsky en Léopoldville (ex Congo Belga) durante las campañas masivas de vacunación antipolio llevadas a cabo en el Congo durante 1957 a 1960, donde la poliomielitis era una enfermedad endémica. ${ }^{17}$

El RNA de esta muestra, la más antigua de la que se dispone, fue secuenciado; se demostró que al ubicar a este virus ZR59 en el árbol evolutivo del VIH, pertenecía al grupo M subtipo D, implicando que el antecesor común del grupo $\mathrm{M}$ debe haber existido anteriormente. ${ }^{17}$

Korber y colaboradores realizaron un completo análisis filogenético de la secuencia de genes de envoltura de aislamientos de VIH 1 obtenidos de un banco de muestras de 150 individuos; su conclusión fue que el VIH comenzó su evolución en el hombre entre los años 1910 y 1930, estimando el antecesor común del grupo M en el año 1931, con un intervalo de confianza entre 1915 y $1941 .{ }^{18}$ Otros investigadores han llegado a conclusiones similares. ${ }^{17}$, 19 - 21

El más probable mecanismo de transmisión del VIH del chimpancé al hombre ha sido por el contacto de sangre de chimpancés infectados con tejidos humanos expuestos por heridas abiertas o cortaduras en la piel durante la caza o al despostar su carne para ser consumida, ya que el chimpancé ha sido tradicionalmente una fuente de alimento para el 
hombre en ciertas áreas del África subsahariana (figuras 6 y 7). La exposición directa a la sangre o secreciones mucosas de animales parecería proveer la más simple explicación para el cruzamiento y transmisión entre especies del SIV y su posterior evolución al VIH. ${ }^{22}$
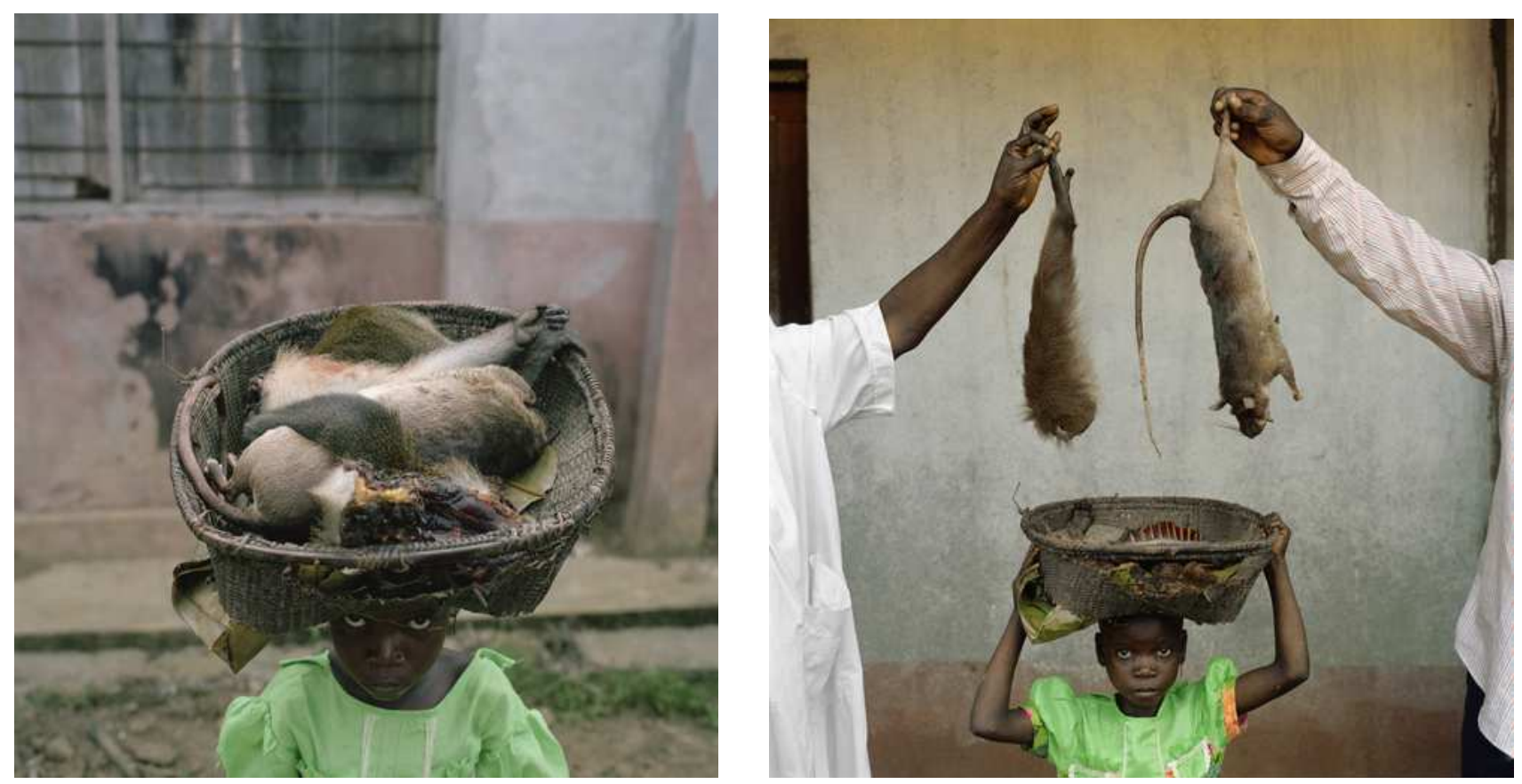

Figura 6: Niña camino al mercado en un poblado de la República Democrática del Congo; lleva una canasta con un brazo de mono y una rata gambiana. (Fotografía tomada por Lynn Johnson. National Geographic Stock, 2005).

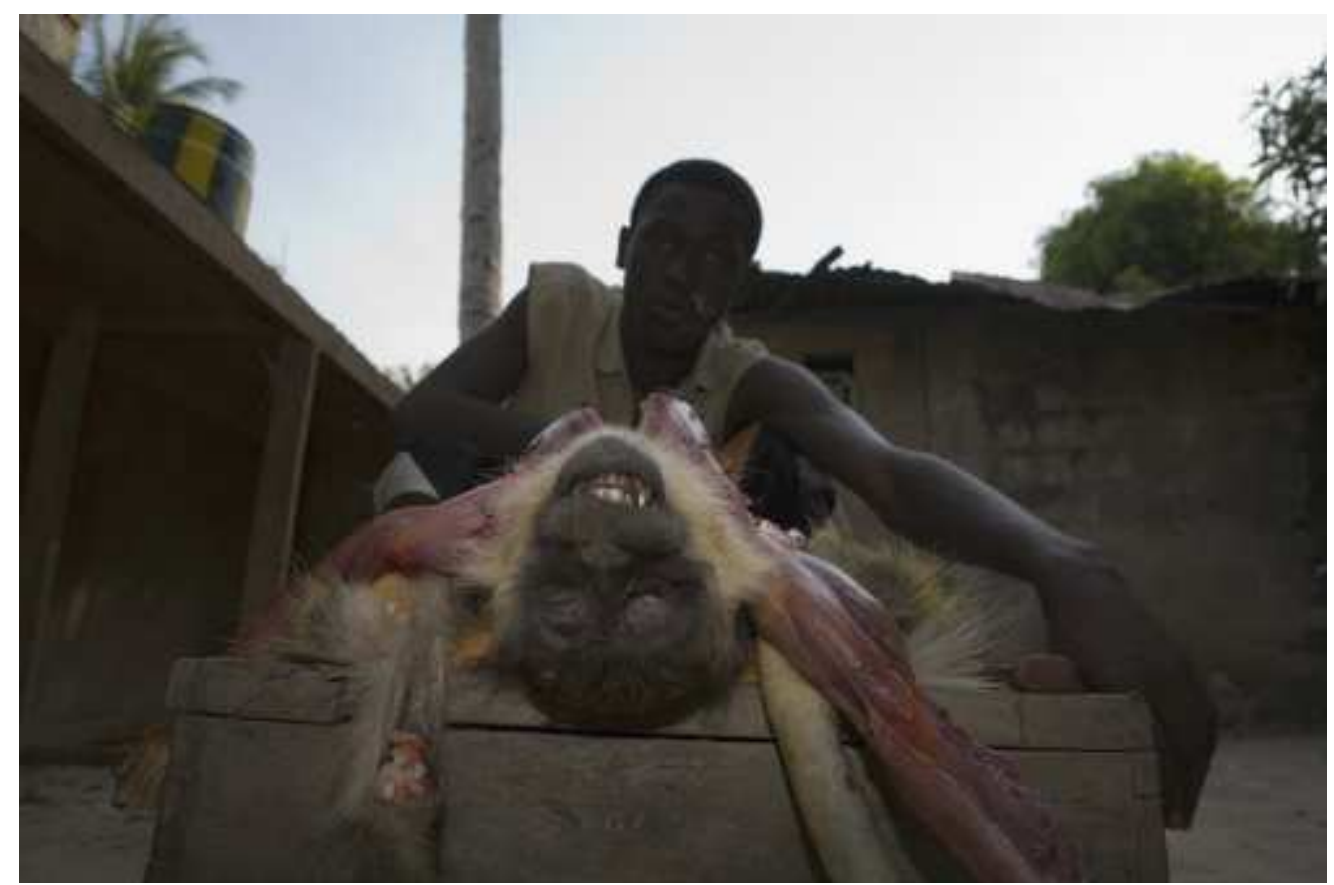

Figura 7: Desposte de carne de monos en el Congo, África. (Fotografía tomada por Randy Olson. National Geographic Stock, 2005). 
Sin embargo, se han propuesto formas de transmisión iatrogénica, siendo la que mayor evidencia ha planteado la hipótesis postulada por Louis Pascal en 1987 e investigada posteriormente por el periodista Edward Hooper, que explica la transferencia de los virus del SIDA desde sus huéspedes naturales al hombre a través de preparaciones para la vacuna antipoliomielítica oral (OPV) contaminada con SIV. ${ }^{23}$ Pascal postuló que el VIH 1 y 2 tienen su origen en las preparaciones de OPV provenientes de diferentes laboratorios, en particular, la OPV desarrollada por el grupo dirigido por Hilary Koprowski, que fue administrada indiscriminadamente a un millón de personas en el Congo Belga, Ruanda y Burundi a fines de la década de 1950, para la cual se usaron riñones recolectados de simios provenientes de la región cercana a Stanleyville (hoy Kisangani). ${ }^{23,}{ }^{24}$ Según esta hipótesis, los riñones derivados de chimpancés infectados con $\mathrm{SIV}_{\mathrm{cpz}}$ contaminaron esas preparaciones de OPV. Hooper ha demostrado que existe una poderosa coincidencia de tiempo y lugar entre la administración de OPV y los primeros casos de infección por VIH/SIDA. ${ }^{22-27}$ Richard Middleton también demostró que existe una incuestionable coincidencia entre las áreas en las que se llevaron a cabo las campañas de vacunación con OPV de fines de la década de 1950 y un aumento de 6 veces en la incidencia de sarcoma de Kaposi en África central durante la década de 1960 (Figura 8). ${ }^{26,27}$

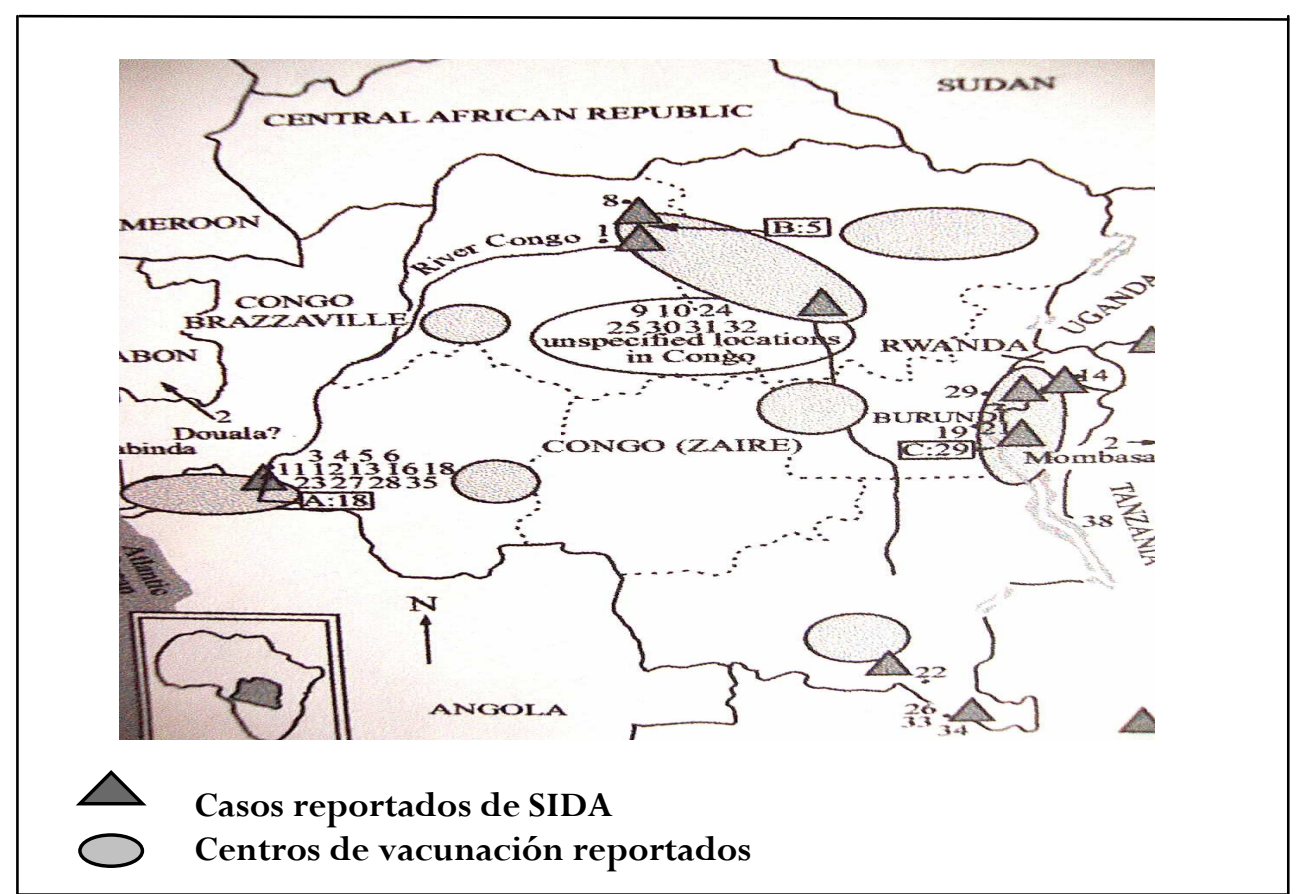

Figura 8: Relación entre casos reportados de SIDA y centros de vacunación antipolio. Congo Belga, período 1957 a 1960 . Tomado de Low-Beer ${ }^{27}$. 
Cualquiera de las numerosas mutaciones del genoma viral que permitió la transmisión exitosa del virus del chimpancé a los humanos probablemente tuvo lugar intermitentemente a través de los siglos. Ciertamente, es probable que la transmisión esporádica al hombre haya estado ocurriendo inadvertidamente a través de décadas y quizás de siglos. ${ }^{28}$

Si la transferencia natural puede ocurrir con el contacto de sangre o secreciones de primates infectados y el hombre durante la cacería u otras actividades, la pregunta que subyace es ¿por qué la epidemia de SIDA apareció en las últimas décadas del siglo XX? En este contexto es importante distinguir entre 2 etapas en el advenimiento de la epidemia. El primer estadío consiste en la transmisión del SIV al hombre. Dada la evidencia para numerosas transferencias entre $\operatorname{SIV}_{\mathrm{cpz}}$ (que origina los 3 grupos de VIH 1) y $\operatorname{SIV}_{\mathrm{sm}}$ (que origina los 5 subtipos de VIH 2), impresiona que el cruzamiento y transmisión entre especies ha ocurrido en múltiples ocasiones en el pasado. El segundo y último estadío es el establecimiento de la epidemia por el nuevo virus, que refleja los cambios en la estructura poblacional y en su comportamiento en África durante el siglo XX y tal vez intervenciones médicas que proveyeron la oportunidad de una rápida diseminación interhumana del virus. ${ }^{29}$

\section{La infección por el virus de la inmunodeficiencia humana}

El VIH es un virus envuelto de 80-100 nm de diámetro y simetría icosaédrica. La partícula viral madura está recubierta por una bicapa lipídica externa tomada de la célula huésped y una nucleocápside con un núcleo denso en forma de cono; este núcleo o core central es elongado, denso y cilíndrico y contiene el antígeno de grupo específico y dos cadenas idénticas de ARN de polaridad positiva que sirven como molde para la retrotranscripción a ADN (Figura 9).

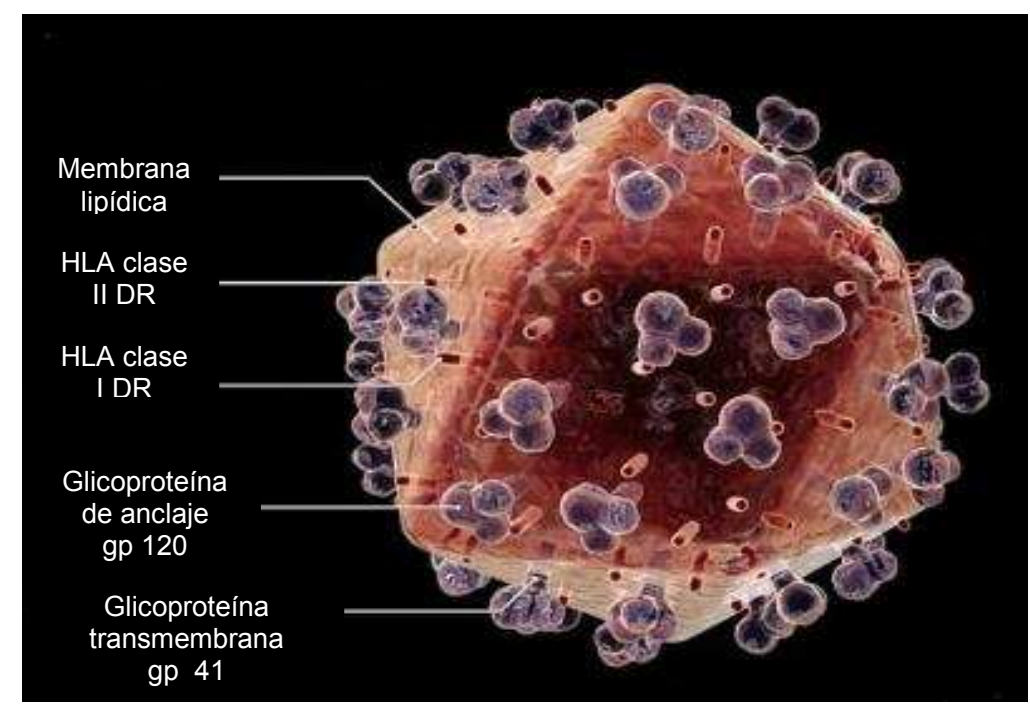

Figura 9: Virus de la inmunodeficiencia humana. 
Las proteínas regulatorias virales y las enzimas virales codificadas requeridas para una replicación efectiva (la transcriptasa inversa, la proteasa y la integrasa) están contenidas dentro de la partícula viral.

Como todos los retrovirus, VIH posee tres genes estructurales: gag, pol y env. El gen de antígeno de grupo (gag) codifica para la síntesis de proteínas p24, p17, p6, p7, p1 y p2, todas con funciones estructurales; p24 es una proteína del núcleo, al igual que p17 que interactúa con gp41. El gen env, referido a la envoltura, codifica la síntesis de las glicoproteínas de envoltura gp120 y gp41 a partir del precursor gp160. Estas moléculas sirven como estructuras de fijación a los receptores de superficie de las células blanco. El gen pol, que representa a la polimerasa, codifica la síntesis de 3 enzimas: la proteasa, la transcriptasa inversa (TI) y la integrasa.

La proteasa, que es esencial para el ensamblaje viral, posee la función de realizar el corte proteolítico de gag y pol; si esta enzima es inactivada se producen partículas no infectivas con proteínas gag no cortada y gag-pol.

La TI es una ADN polimerasa dependiente de ARN; esta enzima es capaz de sintetizar copias de ADN a partir de moldes de ARN y de ADN y de degradar el ARN viral a partir de híbridos de ARN-ADN; tiene actividad de polimerasa y ARNasa, necesarias para la replicación viral. La TI juega un importante papel en la generación de la diversidad genética en los retrovirus; la tasa de errores in vivo se estima en una incorporación errónea por ciclo de replicación; las variantes generadas por la TI generan diversidad en las secuencias que puede surgir bajo la presión selectiva de las respuestas inmunes o de los fármacos antivirales y puede permitir que los virus varíen su tropismo celular.

La integrasa actúa mediando en la unión del ADN viral de doble cadena con el genoma de la célula huésped y a esta integración del ADN viral se la denomina provirus. El provirus puede considerarse como un elemento genéticamente estable que permanece para el resto de la vida en el interior de la célula y, mediante la replicación celular, para toda la vida del individuo. ${ }^{14}$

La membrana viral externa, que incluye proteínas celulares y es rica en colesterol, contiene 72 proyecciones espiculadas que se hallan ensambladas como trímeros de la proteína externa de membrana gp120 unida a la porción transmembrana gp41 (Figura 10).

Cada virión maduro se compone de 2 cadenas de ARN rodeadas por 3 productos de corte del gen gag: la proteína matriz p17, la proteína principal de la cápside p24 que es la encargada de formar la cubierta de la cápside y la nucleoproteína p7 que se une estrechamente con el ARN viral. 


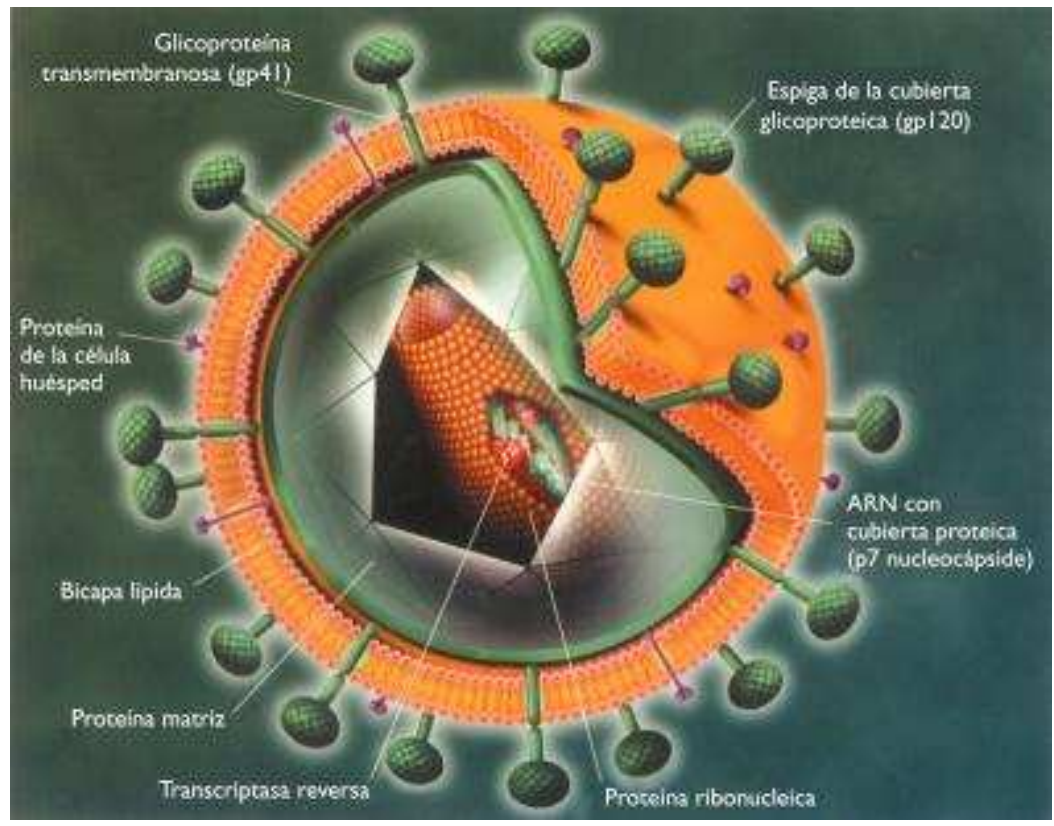

Figura 10: Estructura del virus de la inmunodeficiencia humana.

Al virión se incorporan una serie de otras proteínas virales precisas para las fases tempranas de la infección: la proteasa, la TI, la integrasa, el ARN de transferencia en el extremo 5' del ARN (que sirve como cebador para iniciar la síntesis de ADN de cadena con sentido negativo) y una pequeña proteína llamada proteína viral $\mathrm{r}$ (vpr), que contiene una señal de localización nuclear y se asocia en grandes cantidades a la nucleocápside, favoreciendo así la replicación viral en células primarias. ${ }^{30}$

El virus codifica al menos otros 6 genes reguladores y/o accesorios: vif, vpu, tat, rev y nef. La proteína de la infectividad del virión (vif) actúa como un factor promotor de la infectividad; la proteína viral u $(v p u)$ favorece la liberación de viriones desde las células; la proteína trans activadora de la transcripción (gen tat) activa la transcripción y produce supresión inmune; la proteína reguladora de la expresión de las proteínas del virión (gen rev) regula la expresión estructural de los genes; el factor regulador negativo (gen nef) disminuye la expresión de receptores CD4 en la superficie de las células infectadas y la proteína x del virión $(v p x)$, presente sólo en el VIH 2, cuya función se halla aún en estudio. ${ }^{31}$

El ciclo vital del VIH presenta dos fases distintas. Los eventos iniciales tempranos incluyen la adsorción y penetración viral al citoplasma, la transcripción inversa, la entrada en el núcleo y la integración del ADN como provirus. La segunda fase se produce a lo largo del resto de la vida de la célula infectada, según las proteínas celulares y virales regulan la producción de proteínas virales y de nuevos viriones infectivos. ${ }^{32}$ 
La fusión del VIH a la célula huésped depende de la unión secuencial de la glicoproteína viral gp120 al receptor CD4 (presente en aproximadamente el $60 \%$ de los linfocitos $\mathrm{T}$, en los precursores de células $\mathrm{T}$ de la médula ósea y el timo, en los monocitos, eosinófilos, las células dendríticas, los macrófagos y en las células de la microglía del sistema nervioso central) y a los receptores de quimocinas (CCR5 o CXCR4), pero la maquinaria de fusión se localiza en gp41. Aunque el evento inicial de la infección viral es la unión de la glicoproteína de envoltura viral gp120 a la molécula CD4+ presente en la membrana celular, el virus requiere de un co-receptor para ingresar al citoplasma. Las cepas macrófago-trópicas utilizan el receptor de quimocinas denominado CCR5 para este propósito (cepas R5). Aquellas variantes que exhiben tropismo hacia las células $\mathrm{T}$ y que utilizan el receptor CXCR4 para su ingreso a las células se denominan cepas X4 (Figura 11).

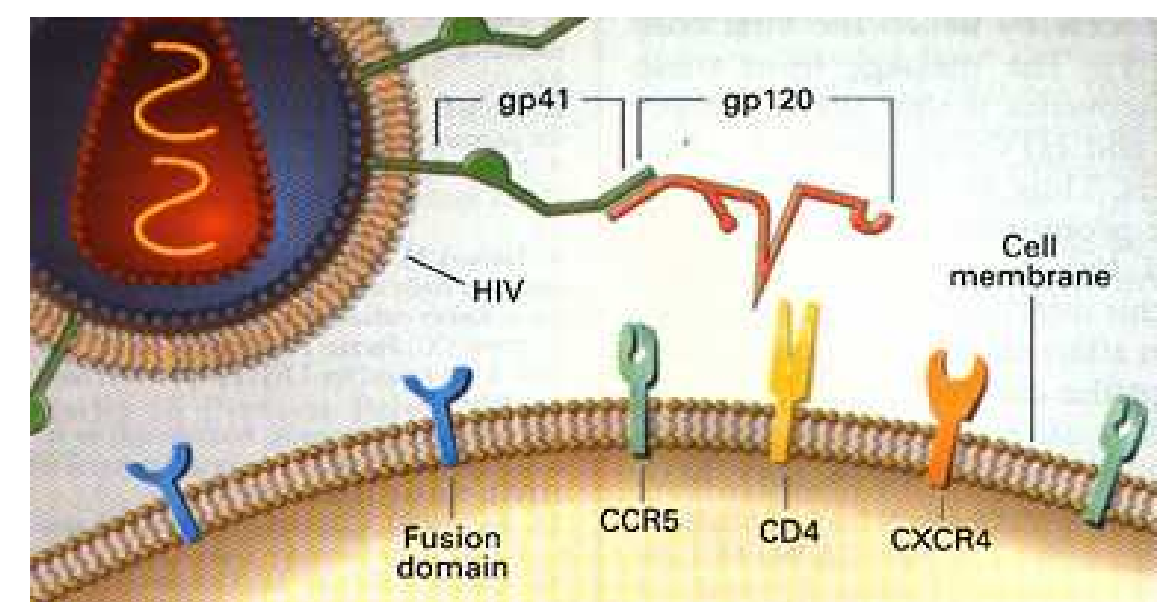

Figura 11: Receptores y correceptores de quimocinas en la interacción entre células blanco y el VIH.

Las células de Langerhans -blanco inicial de la infección- expresan el receptor CCR5 pero carecen de receptores CXCR4, lo que explica parcialmente por qué la infección por VIH es preferentemente transmitida por variantes R5. ${ }^{33,34}$

Tras la unión inicial de la gp120 a las moléculas CD4 de la superficie celular, se produce un cambio en la configuración que fomenta la unión al correceptor de quimocina CCR5 para conseguir entrar en la célula, seleccionando así las variantes llamadas anteriormente "no formadoras de sincitios" que tienen tropismo por los macrófagos. Las cepas sin tropismo hacia los macrófagos - antes denominadas "formadoras de sincitios"-, se encuentran en las fases tardías de la infección, utilizan el receptor CXCR4 para facilitar su entrada y no se transmiten fácilmente de persona a persona (Figura 12). ${ }^{33}$ 


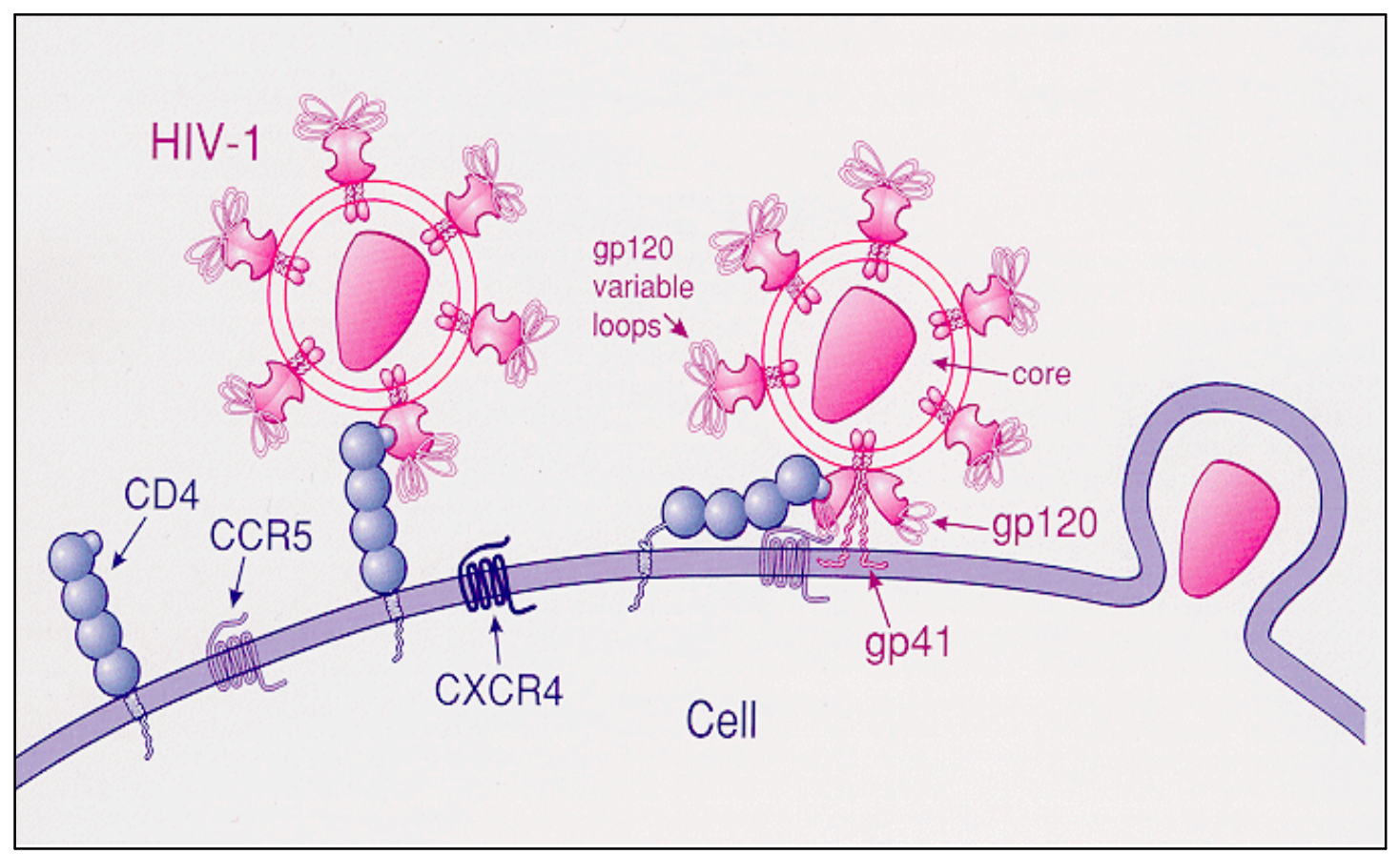

Figura 12: Penetración del VIH al linfocito TCD4 mediante el uso de receptores y correceptores.

El evento patogénico central en la infección por el VIH es la marcada y progresiva disminución en los linfocitos T helper CD4+ (LT CD4+). La pérdida de estas células produce un grave estado de inmunodeficiencia que deja a las personas susceptibles a una amplia variedad de infecciones oportunistas. Una vez que la infección por el VIH se ha establecido, induce una respuesta inmune humoral y celular. El rápido recambio de células infectadas y la emergencia de cepas con elevada patogenicidad, caracterizan la naturaleza progresiva de esta infección viral; su diversidad genética, el tropismo para determinadas células y la habilidad para replicarse de cara a una enérgica respuesta inmune, son algunos de los mecanismos virales adaptativos que llevan a una infección crónica. ${ }^{14}$

La extensión de la enfermedad causada por el VIH varía desde una leve inmunodeficiencia a una grave y progresiva inmunosupresión, con infecciones oportunistas, neoplasias y una variada asociación de disfunciones del sistema nervioso central (SNC). ${ }^{34}$

Los factores genéticos juegan un rol importante en la eficiencia de la transmisión; se ha encontrado en personas expuestas al virus no infectadas, un gen CCR5 mutante que codifica un receptor que es incapaz de unirse al virus, lo que sugiere fuertemente que es necesaria una proteína CCR5 funcional para que se produzca la infección. El ser homocigótico para esta mutación es un poderoso factor protector, pero cuando está presente en el estado heterocigótico, no previene la infección aunque puede retrasar la progresión de la enfermedad. ${ }^{14}$ 
El VIH es transmitido a través del contacto íntimo heterosexual u homosexual, a través de la inyección de sangre o sus productos (transfusión, drogadicción endovenosa, trasplante de órganos, iatrogénica) y por transmisión materno-fetal. ${ }^{2}$ Sin embargo, los estudios epidemiológicos indican que el VIH no se transmite eficientemente sino que el intercambio de fluidos biológicos usualmente requiere varias exposiciones. En contraste, otras infecciones de transmisión sexual (ITS) producen contagio luego de una sola exposición; se infectan el $25 \%$ de las personas luego de una sola exposición a Neisseria gonorrhoeae. Se estima la infectividad del VIH para un solo contacto sexual en el 0,3\%; algunas personas se han infectado luego de uno o varios contactos sexuales, mientras que otros permanecen sin infectarse luego de cientos de contactos. ${ }^{34}$

Las abundantes células inflamatorias en las úlceras genitales, como resultado de las infecciones venéreas, la ectopía cervical y la infección con otras ITS, proveen un reservorio para la infección por VIH e incrementan el riesgo del contagio. La transmisión es más efectiva de un hombre a una mujer que de una mujer a un hombre, debido al rol receptivo de ella. Hay muy escasas partículas virales detectables en la saliva, haciendo de la forma oral un medio de transmisión aún no demostrable. ${ }^{35}$

Las primeras células diana de la inoculación intravaginal del virus son las células de Langerhans y las células T. Múltiples variables, incluyendo la vía de la exposición, la dosis infectante, el contexto inmunológico y las infecciones concomitantes influyen en la probabilidad de transmisión. ${ }^{36}$

En las personas que se infectan por contacto sexual, el virus toma como blanco las células de Langerhans presentes en la lámina propia del epitelio; estas células migran hacia tejidos más profundos donde se fusionan rápidamente con linfocitos, lo que conduce a la infección de un gran número de LT CD4+. El virus aparece en los ganglios linfáticos regionales dentro de las 48 horas de producida la inoculación intravaginal experimental en macacos. La llegada del VIH a estos ganglios coincide con un notable incremento en el número de LT CD4+ infectados, lo que conduce a la aparición de un pico de viremia plasmático que en humanos ocurre entre 4 y 11 días después de la infección y alcanza concentraciones que exceden el millón de partículas virales por mililitro $(\mathrm{mL})$. La elevación de la viremia favorece la diseminación de la infección en los órganos linfoides y causa la aparición de grandes cantidades de virus en las secreciones genitales y la leche materna, haciendo que esta etapa sea el período de mayor contagiosidad. ${ }^{34}$

Este estadío agudo de la infección se manifiesta clínicamente como una enfermedad transitoria similar a la gripe, denominada "síndrome retroviral agudo" (SRA). La respuesta 
inmune probablemente es la responsable del síndrome agudo mononucleósico que se observa en la primoinfección. El número de LT CD4+ circulantes disminuye significativamente, entre un 20 y un $40 \%$ durante la fase aguda de la infección, mientras aumentan los linfocitos $\mathrm{T}$ citotóxicos CD8+ (LT CD8+), lo que provoca la inversión del cociente entre células CD4+ y CD8+. Esta fase se ve seguida de una marcada reducción de la viremia para llegar a un nivel de equilibrio, probablemente debido a la vigorosa respuesta celular antiviral. Las pruebas diagnósticas basadas en la detección de anticuerpos contra el VIH arrojan resultados negativos en este período y sólo comienzan a positivizarse a partir de los 21 días posteriores a la infección; este intervalo entre el inicio de la viremia y la aparición de anticuerpos detectables se conoce como "ventana inmunológica". 35

El VIH cruza la barrera hematoencefálica en etapas tempranas de la enfermedad; más del $50 \%$ de las personas infectadas desarrollan enfermedades neurológicas en el curso de la infección. La enfermedad puede ser causada de forma directa por la infección del SNC o de forma secundaria por infecciones o tumores relacionados con la inmunodeficiencia. La enfermedad neurológica primaria puede producirse en cualquier momento en el curso de la infección y en cualquier localización del sistema nervioso central (SNC); el complejo SIDAdemencia (CSD), la neuropatía y mielopatía vacuolar y la neuropatía periférica son las formas de presentación más frecuentes. La neuropatía periférica y la disfunción cognitiva asociada al VIH constituyen las principales alteraciones neurológicas de la infección por VIH/SIDA. El examen de los tejidos cerebrales y de la médula espinal muestra niveles elevados de ARN del VIH y expresión de proteínas virales en células de la microglía y macrófagos en el $90 \%$ de los pacientes sintomáticos; también se ha demostrado la presencia del virus en los ganglios de las raíces dorsales y en los nervios periféricos. El daño observado en el CSD no es específico de un tipo celular sino generalizado, afectando a todas las células de una determinada zona del cerebro, encontrándose las lesiones ampliamente distribuidas. Así, la patología no se limita sólo a las células infectadas. Agrupaciones de células microgliales infectadas por el VIH forman nódulos y sincitios multinucleares característicos, con pérdida de tejidos circundantes, lo que da lugar a lesiones espongiformes. ${ }^{36}$

A la fase aguda asociada con la seroconversión le sigue una larga fase asintomática que se prolonga durante años, denominada "fase de latencia clínica"; sin embargo, el virus continúa replicando activamente en los órganos linfoides, por lo que no existe ninguna latencia verdadera en términos microbiológicos. Durante este período asintomático se producen grandes cantidades de virus en el interior de los ganglios linfáticos foliculares; el 
mayor deterioro de la función inmunológica ocurre durante este período, con la disminución progresiva en el número de LT CD4+ circulantes, que se infectan en gran número al atravesar la red de células dendríticas foliculares. ${ }^{36}$

A lo largo de los años y a medida que la carga viral aumenta progresivamente se acumulan cantidades significativas de VIH en los centros germinales del ganglio linfático, en células CD4+ infectadas y en células dendríticas foliculares. La presencia de virus en el interior del ganglio induce la producción de citoquinas como el factor de necrosis tumoral $\alpha$ e interleuquina 6; ambas citoquinas son potentes estimuladoras de la replicación viral, lo que conduce a un círculo vicioso en el interior de los ganglios linfáticos cuya resultante final es un importante incremento en la replicación viral. ${ }^{36}$

La arquitectura ganglionar refleja una atrofia progresiva de los centros germinales, cuya severidad muestra una perfecta correlación con la profundidad de la inmunodeficiencia. Las células CD4+ infectadas por el VIH pueden sufrir el efecto citopático directo del virus cuando grandes cantidades de partículas virales abandonan la célula causando su lisis o cuando las proteínas y los ácidos nucleicos virales se acumulan en el citoplasma interfiriendo con la maquinaria celular. Los efectos indirectos de la infección causan defectos en la proliferación y diferenciación de las células $\mathrm{T}$, desregulación o hipo-secreción de interleuquina 2 y otras citoquinas, disminución de la expresión del receptor de interleuquina 2 y defectos en las células progenitoras de la serie leucocitaria. Los linfocitos infectados por el VIH podrían fusionarse con las células cercanas aunque éstas no estén infectadas, formando células gigantes multinucleadas o sincitios celulares. La formación de sincitio se ha asociado in vitro con la destrucción de células no infectadas. Algunas cepas del VIH poseen mayor capacidad que otras para inducir la formación de sincitio celulares y la capacidad para inducir sincitio de una cepa viral en particular se correlaciona con la velocidad con que cursa la progresión hacia SIDA. ${ }^{36,37}$

La infección aguda de las células $\mathrm{T}$ por el VIH induce apoptosis in vitro y se ha demostrado que las células $\mathrm{T}$ de individuos infectados por el VIH presentan apoptosis en mayor proporción que las células $\mathrm{T}$ de sujetos normales, particularmente después de la activación celular. La unión simultánea de una molécula gp120 a dos moléculas CD4+ es suficiente para desencadenar apoptosis si la célula recibe luego una señal de presentación del antígeno. Curiosamente, mientras estas células desaparecen progresivamente de la sangre, ellas no disminuyen en ganglios linfáticos. Por el contrario, el número total frecuentemente aumenta en estos ganglios y sólo tardíamente las células CD4+ comienzan a desaparecer de los ganglios linfáticos. De hecho, este aumento en la masa total de linfocitos CD4+ podría 
contribuir al desarrollo de la linfadenopatía habitualmente presente en las personas infectadas por el VIH.

La acumulación progresiva de virus en el ganglio linfático finalmente provoca el colapso de la red de células dendríticas foliculares. La destrucción completa de la arquitectura del ganglio linfático puede impedir el desarrollo de respuesta inmune no sólo contra el VIH sino contra muchos otros patógenos, incluyendo gérmenes oportunistas. La desorganización final de los folículos linfoides preanuncia la inminente aparición de enfermedades marcadoras de SIDA.

Durante una respuesta inmune normal, numerosos componentes inmunológicos se movilizan: los LT CD4+ proliferan rápidamente e incrementan su secreción de citoquinas, preparando a otras células para que desarrollen sus funciones específicas y proliferen a su vez; cuando el estímulo inmunológico desaparece, el sistema inmune regresa a un estado de relativa quiescencia. Durante la infección por VIH, el sistema inmune puede permanecer crónicamente activado, con numerosas consecuencias negativas: la replicación viral ocurre mucho más eficientemente en LT CD4+ activados. La activación inmunológica crónica también es un estímulo para la apoptosis y una producción exagerada de citoquinas puede incrementar la replicación viral. Las infecciones causadas por otros patógenos contribuyen a la progresión al SIDA por medio de los efectos acumulativos de numerosas rondas de activación inmune y aumento de la replicación viral. ${ }^{36,37}$

\section{Historia natural de la infección}

Como se ha mencionado, la consecuencia de la infección por el VIH es una enfermedad crónica e irreversible, cuyo curso se caracteriza por un deterioro progresivo de la inmunidad mediada por células. El SIDA constituye el estadío más avanzado de esta enfermedad, en el que el huésped infectado no puede controlar ni los organismos oportunistas ni los procesos cancerígenos que en las personas inmunocompetentes no suelen causar enfermedad alguna. La historia natural de la infección por el VIH, en ausencia del tratamiento antiretroviral y desde el momento de la primoinfección hasta la muerte, cursa en un período promedio de 10 años (Figura 13). ${ }^{37}$

Se ha explicado que el evento clínico inicial de la infección es el SRA, que se produce en las primeras semanas de la infección viral, dando un cuadro clínico similar a la mononucleosis, caracterizado por fiebre, malestar general, mialgias, adenopatías, faringitis no exudativa, trombocitopenia con leucopenia, diarrea, cefalea y un exantema máculo-papular roseoliforme o urticariforme que predomina en el tronco. En estos pacientes se puede 
observar una amplia variedad de enfermedades oportunistas, debido a la estrepitosa caída en el recuento de LT CD4+ que acompaña al SRA, junto con una elevada concentración plasmática del ARN VIH. La recuperación clínica se produce en 10 a 15 días y se acompaña de la reducción abrupta de la viremia plasmática y el desarrollo de anticuerpos (Ac) que dan lugar a la seroconversión -que se produce entre los 22 a 27 días de la infección- y el desarrollo de la respuesta inmune contra el VIH. El recuento de LT CD4+ declina gradualmente a través de los años, con un descenso acelerado alrededor de 1,5 a 2 años antes de que se realice el diagnóstico de SIDA. La pendiente de este descenso está directamente relacionada con el aumento de la carga viral plasmática. Con la persistencia de la infección, los niveles de ARN viral comienzan gradualmente a aumentar, acompañándose de una reducción rápida de las cifras de LT CD4+; a medida que el recuento de LT CD4+ disminuye, el riesgo de infecciones oportunistas, neoplasias, emaciación, complicaciones neurológicas y muerte aumenta en forma sustancial (Figura 13). ${ }^{38}$

La progresión de la enfermedad por VIH presenta una gran variabilidad, desde los pacientes que progresan de infección a SIDA en menos de 5 años hasta los que permanecen asintomáticos, sin tratamiento o sin evidencia del declinar inmunológico durante muchos años y que se denominan "no progresores a largo plazo". Sin tratamiento, la media de supervivencia tras el diagnóstico de SIDA definido clínicamente es de 18 meses; los enfermos diagnosticados con una infección oportunista son los que presentan una mayor mortalidad. ${ }^{39}$

El uso del tratamiento antiretroviral de gran actividad (TARGA) determinó un cambio radical en la historia natural de la infección por VIH. El tratamiento combinado con varias drogas produjo la mejoría del pronóstico en comparación con el uso de monoterapia, demostrando el efecto beneficioso del TARGA en la progresión clínica, virológica e inmunológica de la enfermedad. Al mejorar la supervivencia, las enfermedades crónicas son la causa más frecuente del fallecimiento en las personas con SIDA. ${ }^{40}$

La linfadenopatía generalizada persistente suele comenzar con el SRA y su patogénesis se relaciona con la rápida infección de LT CD4+ en los ganglios linfáticos por el VIH tras la infección inicial; se define como la presencia de linfadenopatía en 2 o más localizaciones extrainguinales durante un tiempo mínimo de 3 a 6 meses sin otra causa etiológica y se caracteriza por la hiperplasia folicular sin patógenos específicos. La progresión de la infección por el VIH hacia la enfermedad avanzada se acompaña de involución de las adenopatías junto con la degeneración de los centros germinales foliculares y la desaparición de la hiperplasia. ${ }^{14}$ 


\section{HISTORIA NATURAL DE LA INFECCIÓN POR VIH}

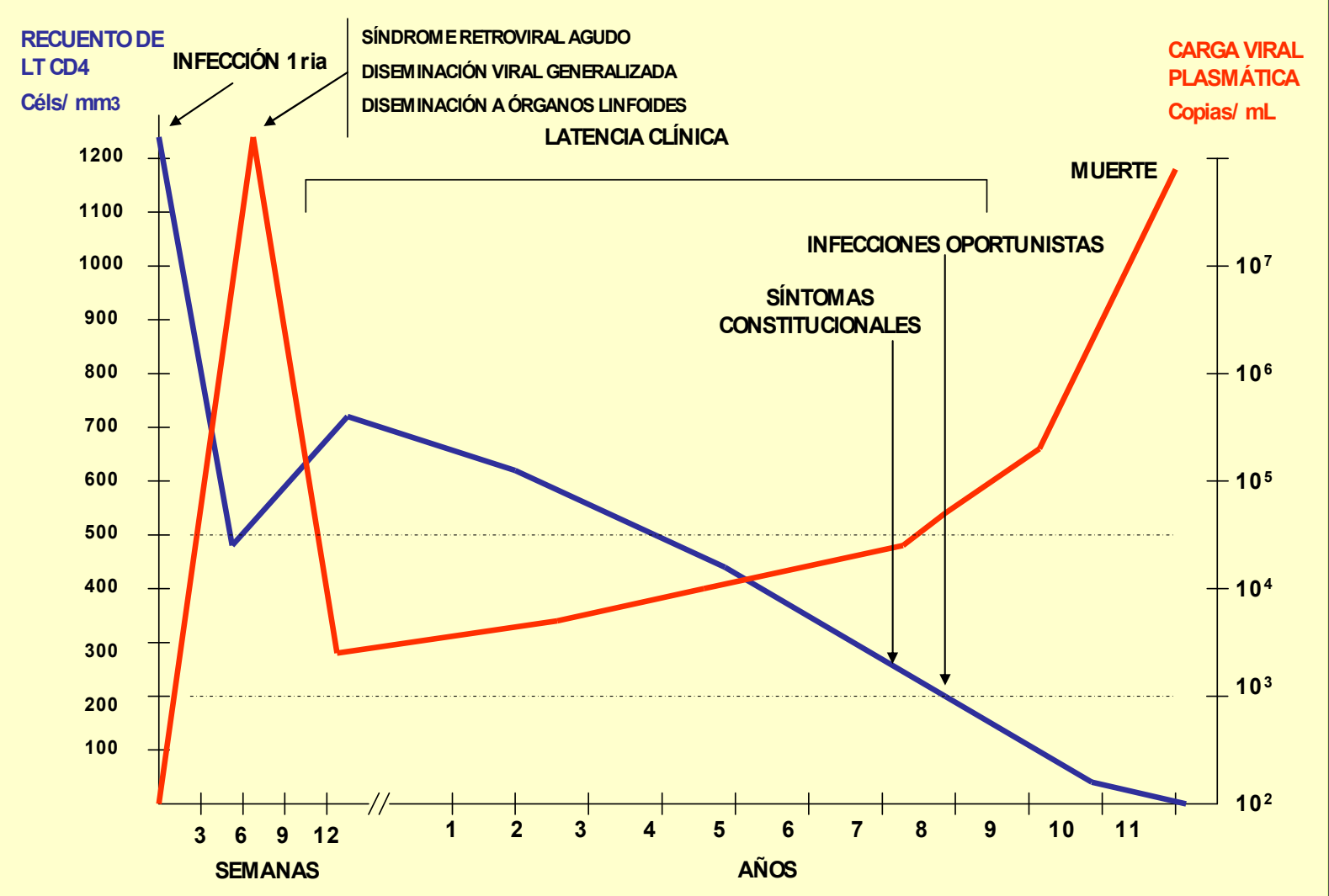

Figura 13: Historia natural de la infección por VIH y su progresión a SIDA.

A la fase aguda asociada con la seroconversión le sigue una larga fase asintomática que se prolonga durante años, denominada "latencia clínica" en la que, como se explicó precedentemente, grandes cantidades de virus son producidos en el interior de los ganglios linfáticos donde permanecen atrapados en las células dendríticas foliculares. Es en este período, de duración variable, donde ocurre el deterioro progresivo de la función inmunológica, debido a que en la medida que la carga viral aumenta progresivamente en el plasma, significativas cantidades del VIH se acumulan en los centros germinales del ganglio linfático, en los LT CD4+ y en las células dendríticas foliculares lo que llevará a la destrucción de la arquitectura ganglionar normal y al desarrollo de la atrofia ganglionar y la consecuente progresión en la inmunodeficiencia. Este período tiene gran importancia desde el punto de vista clínico y epidemiológico, porque al estar la persona infectada libre de síntomas no se suele realizar el diagnóstico y por lo tanto se incrementa el riesgo de contagio de las parejas sexuales y de los hijos de las mujeres infectadas. 
Si bien la infección por VIH suele ser completamente asintomática, algunos enfermos presentan síntomas sistémicos inespecíficos en los meses o años siguientes a la primoinfección, siendo los más frecuentemente relatados la fatiga, la fiebre de bajo grado, sudores nocturnos, diarrea intermitente y la pérdida de peso.

De las personas infectadas, un $10 \%$ permanecerá asintomático, con recuentos de LT CD4+ estables, función inmune intacta y muy baja tasa de replicación viral por un período mayor de 12 a 15 años, a los que se los denomina "progresores lentos". El $90 \%$ restante evolucionará según los patrones esperables de la enfermedad. ${ }^{36}$

En los pacientes con enfermedad avanzada por VIH o SIDA, con cargas virales elevadas y depleción grave de la LT CD4+, la enfermedad sistémica (fatiga, pérdida ponderal mayor al $10 \%$ del peso corporal, malestar general, leucoplasia vellosa, candidiasis oral y fiebre) suele anunciar el inicio de las infecciones oportunistas y neoplasias. ${ }^{36}$

La enfermedad avanzada y el SIDA se caracterizan por la presencia de un recuento de LT CD4 $+<200 / \mathrm{mm}^{3}$, que generalmente coincide con una intensa actividad replicativa viral, con la presencia de infecciones oportunistas y neoplasias, trastornos neurológicos y, en numerosos casos, por un importante deterioro del estado general de la persona. Múltiples infecciones por virus, bacterias, hongos, protozoos, helmintos y artrópodos, así como distintas clases de neoplasias han sido reportadas. ${ }^{4,36,39,41,42}$

Entre las infecciones y neoplasias que definen al SIDA podemos mencionar a la candidiasis esofágica, neumonía por Pneumocystis jiroveci, neumonía bacteriana recurrente, cáncer cervical invasivo, micosis profundas, síndrome de desgaste asociado al VIH, tuberculosis, sarcoma de Kaposi, demencia asociada al SIDA, toxoplasmosis cerebral, criptococosis meníngea, criptosporidiosis intestinal y otras. Las enfermedades indicadoras de SIDA según la clasificación de los Centros para el Control y la Prevención de Enfermedades (CDC) revisada en 1997 se enumeran en la tabla $1 .{ }^{41}$

La estadificación de la enfermedad según las categorías clínicas y el recuento de células CD4+ se muestran en la tabla $2 .^{42}$

A pesar de que las causas de las diferentes manifestaciones clínicas asociadas a la infección por el VIH no son aún completamente comprendidas, se relacionan con la prevalencia de patógenos oportunistas en el medio ambiente y con el comportamiento y las condiciones ambientales que exponen a las personas a esos patógenos. ${ }^{36}$ 
Tabla 1: Enfermedades indicadoras de caso de SIDA. CDC, 1997.

Cáncer cervical invasivo

Candidiasis esofágica, traqueal, bronquial o pulmonar

Coccidioidomicosis extrapulmonar

Criptococosis extrapulmonar

Criptosporidiosis diarrea de más de 1 mes de evolución

Demencia asociada al VIH

Estrongiloidiosis extraintestinal

Herpes simplex con úlceras mucocutáneas de más de 1 mes de evolución o bronquitis, neumonitis o esofagitis

Histoplasmosis extrapulmonar

Infección por Citomegalovirus de cualquier órgano excepto hígado, bazo, ganglio linfático u ojo

Infección por Mycobacterium avium-intracellulare o M. kansasii diseminada o extrapulmonar

Isosporosis con diarrea de más de 1 mes de evolución

Linfoma de Burkitt, inmunoblástico, primario de SNC

Leucoencefalopatía multifocal progresiva

Nocardiosis

Neumonía bacteriana recurrente ( $\geq 2$ episodios en 12 meses)

Neumonía por Pneumocystis jiroveci

Sarcoma de Kaposi en paciente $<60$ años (o $>60$ años con serología positiva para VIH)

Sepsis recurrente por especies de Salmonella no tífica

Síndrome consuntivo asociado al VIH

Tuberculosis pulmonar y extrapulmonar

Toxoplasmosis cerebral o de órganos internos

Tabla 2: Estadificación de caso de SIDA para adolescentes y adultos según categoría clínica y linfocitos T CD4+. CDC, 1993.

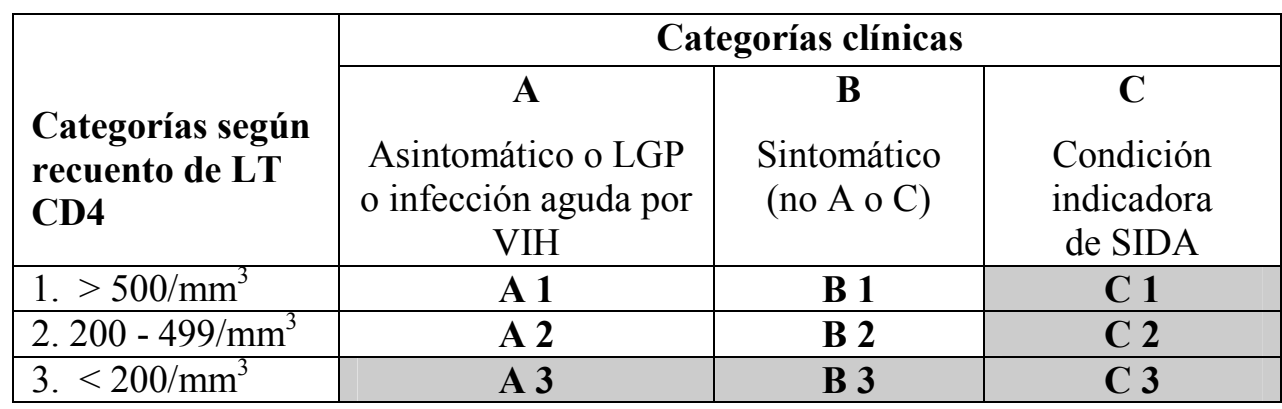

Todos los pacientes en las categorías A3, B3 y C1-3 presentan SIDA.

La tuberculosis (TB) es probablemente la más grave y frecuente infección oportunista en personas infectadas con VIH en África, América Latina y Asia. La neumonía por Pneumocystis jiroveci es la infección oportunista más común reportada en los Estados Unidos y Europa, mientras que es mucho menos frecuente en África. Similarmente, las infecciones por micobacterias no TB, principalmente Mycobacterium avium complex, que es común en personas con SIDA en los países desarrollados, no ha sido reconocida como un problema 
sustancial en África. Las infecciones fúngicas como la criptococosis meníngea y la candidiosis esofágica presentan una gran prevalencia en Latinoamérica y el Sudeste asiático. Debido a la falta de métodos de diagnóstico en la mayoría de los países subdesarrollados, ciertos síndromes son reportados con elevada frecuencia, como síndrome consuntivo, diarrea crónica, fiebre crónica, usualmente sin diagnóstico específico. En estos países el progreso de la infección a SIDA se debe a la realización de un diagnóstico tardío, a las infecciones oportunistas prevalentes como la TB y la falta de acceso al TARGA y a la atención médica. ${ }^{43}$

\section{El inicio de la epidemia de SIDA}

Así como ocurre en diferentes enfermedades infecciosas, la transmisión no se transforma en epidemia a menos que se presenten ciertas condiciones. Casos intermitentes de infección por VIH en una aldea de África pudieron haberse transmitido de una persona infectada a su pareja sexual y probablemente haya resultado en la muerte de ambos, finalizando así la diseminación de la infección. Sólo cuando las condiciones sociales y demográficas permitieron la rápida diseminación del virus entre las personas emergió la epidemia actual. Esas condiciones incluyeron la migración masiva de personas desde áreas rurales a urbanas, la separación de familias debido a la migración en búsqueda de oportunidades laborales con las consiguientes prácticas de promiscuidad entre trabajadores sexuales y la contaminación de los bancos de sangre. ${ }^{44}$

La combinación de la rareza de la infección, quizás confinada inicialmente a individuos de áreas rurales de África, sumada a la falta de atención médica en esas regiones, pudieron haber permitido que enfermedades y muertes esporádicas pasen desapercibidas. Más aún, el hecho es que el SIDA en el Congo fue inadvertido por aproximadamente 20 años (desde principios de la década de 1960 hasta 1983), aún cuando la prevalencia de casos aumentaba. También en los Estados Unidos y Europa, donde los casos de SIDA se remontan al menos a 1974, la enfermedad no fue reconocida hasta 1981. ${ }^{44,45}$

Los primeros casos de infección por VIH 1 grupo M fueron documentados en CongoKinshasa (Zaire), Ruanda y Burundi. La diseminación desde Congo-Kinshasa a los países vecinos -Congo-Brazzaville, República Centro Africana, Uganda y Zambia- comienza en 1958 a 1959, cuando miles de refugiados de Kinshasa llegaron a Brazzaville durante los enfrentamientos ocurridos antes de la independencia. El VIH llegó en el ferry y en las decenas de botes pesqueros que a diario cruzaban el río Congo a Brazzaville y a otras ciudades a lo largo de los $2700 \mathrm{~km}$ de este río, que actuó como la principal ruta de transporte. ${ }^{25}$ La llegada de la infección a Tanzania y Uganda se produjo luego de la guerra de liberación de 1971 a 
1981; choferes de camiones y trabajadores "golondrina" de las minas llevaron la infección desde Tanzania a Zambia y África del sur. Estas fueron las semillas de la epidemia en África. La diseminación del SIDA desde el Congo a Haití se ha explicado por los cientos de haitianos que participaron en los programas de educación de la UNESCO en el Congo entre 1960 y 1975; todos ellos eran solteros y regresaban regularmente en las vacaciones a Haití. De Haití el SIDA se diseminó a través de trabajadores que migraban al Caribe en busca de empleo. Los turistas homosexuales importaron el SIDA desde Puerto Príncipe a los Estados Unidos. ${ }^{46} \mathrm{La}$ introducción de la epidemia en los países desarrollados comenzó luego de la "revolución gay”, que se originó en la ciudad de Nueva York en el año 1969. ${ }^{47}$ El establecimiento demográfico de las prácticas homosexuales de riesgo se concentraron principalmente en las ciudades de Nueva York, San Francisco y Los Angeles entre los años 1970 y 1980, donde desafortunadamente, esta población de adultos predominantemente jóvenes, constituyó un blanco perfecto para una epidemia de una enfermedad de transmisión sexual. Patrones similares pronto se observaron en Canadá, Australia y Europa occidental. ${ }^{48-50}$

La epidemia de SIDA se inicia oficialmente en los Estados Unidos, el día 5 de junio de 1981, con el reporte en la publicación Morbidity and Mortality Weekly Report del CDC, de 5 casos de neumonía por Pneumocystis jiroveci en hombres jóvenes homosexuales asistidos en el Centro Médico de la Universidad de California. ${ }^{51}$ Sin embargo, en poco tiempo se hizo aparente que estos primeros casos no habían sido los primeros; ya en 1979 otros médicos de la costa este y oeste de ese país habían reportado enfermedades no diagnosticadas en ese entonces, que eran compatibles con casos de SIDA. Y estudios en receptores europeos de factor VIII importado de Estados Unidos demostraron que el VIH ya estaba presente en donantes de plasma en 1977. ${ }^{49}$

\section{Situación actual de la epidemia del SIDA}

La pandemia de infección por VIH/SIDA refleja la coexistencia de varias subepidemias en distintas regiones y poblaciones. Muchos factores epidemiológicos, sociodemográficos, de comportamiento y biológicos contribuyen a las diferentes vías de diseminación del VIH. La característica de cada subepidemia está determinada por el grado en que las personas están expuestas al VIH por uno o más de los 3 modelos primarios de transmisión sexual (vaginal, anal y oral), parenteral (por inyección, transfusión o trasplante) y de madre a hijo. La vasta mayoría de las infecciones por VIH en el mundo son por transmisión heterosexual, con un riesgo de transmisión del 0,1 al $3 \%$, según el tipo de exposición receptiva. Muchos factores influencian el riesgo de transmisión sexual, incluyendo 
prácticas sexuales específicas, la presencia de otras ITS y el estadío de la infección del compañero sexual. En algunos países del África subsahariana, Caribe y Latinoamérica, la infección se ha transmitido principalmente por vía heterosexual y las más elevadas tasas de infección se reportaron en trabajadoras sexuales, sus contactos masculinos y adultos jóvenes de áreas urbanas, predominando el subtipo B. ${ }^{2,52}$

La transmisión del VIH 1 de madre a hijo ocurre durante la gestación, el parto o el amamantamiento; el riesgo de transmisión vertical puede llegar a ser hasta del 29 \%. La transmisión del VIH 2 es mucho menos eficiente, cercana al $1 \%{ }^{2}$

En contraste a la gran dispersión del VIH 1 y de sus varios subtipos, la distribución de la infección por VIH 2 permanece geográficamente limitada al África occidental, con una tendencia al descenso en su incidencia. Los casos de personas infectadas con VIH 2 reportados en otras partes del mundo provienen de los países de África occidental o han tenido parejas sexuales procedentes de ese lugar. Los estudios serológicos retrospectivos indican que los primeros casos de infección por VIH 2 se han producido en la década de 1960. 52, 53

En un tiempo relativamente corto, la epidemia se desarrolló rápidamente y de forma diferente en las distintas regiones del mundo. El estadío emergente de la epidemia se caracterizó por una limitada detección de infecciones que aumentó rápida y silenciosamente en unos pocos años, en grupos con conductas de riesgo, particularmente en asentamientos urbanos, antes que el impacto clínico de la enfermedad avanzada haya sido reconocido. La prevalencia de la infección por VIH en esta etapa fue elevada en trabajadores sexuales, personas con ITS y usuarios de drogas inyectables $\left(\mathrm{UDI}_{\mathrm{s}}\right)$. Luego, comenzó a diseminarse gradualmente a personas en bajo riesgo y la población rural. Posteriormente la epidemia se estabilizó y desarrolló características endémicas, donde la enfermedad clínica fue reconocible y donde el número de nuevas infecciones se ha aproximado al número de personas infectadas que han muerto. Este eventual "equilibrio" en la prevalencia de la infección varía enormemente en distintas poblaciones, presumiblemente debido a la variabilidad demográfica, biológica, de comportamientos y a factores de intervención. ${ }^{47-49}$

En general, en los países industrializados de América del Norte, Europa y costa del Pacífico, la epidemia se encuentra en un aparente estado de estabilidad, a pesar de que algunas subepidemias están ocurriendo en pequeños sub grupos dentro de los países. La epidemia emergente en algunas regiones de Asia se halla en una fase dinámica, debido al elevado número de habitantes, aunque su tasa de prevalencia es menor que en otras áreas. ${ }^{49}$ 
África ha sido la región más severamente afectada por la epidemia de VIH/SIDA; esta elevada prevalencia, la amplia distribución de subtipos de VIH 1 y 2 y la variación genética de subtipos sugieren que el VIH ha permanecido en este continente desde hace un largo tiempo, en comparación con otras regiones. En África predomina la transmisión heterosexual y la prevalencia oscila entre el 5 y el $35 \%$ en algunas regiones del este y del sur. La seroprevalencia de la infección por VIH 2 en la población urbana de países del África occidental es del $1 \%$, manteniéndose estable a lo largo del tiempo. La seroprevalencia de infección dual por VIH 1 y 2 es mayor, siendo del $10 \%$ en Guinea Bissau, Gambia, Costa de Marfil, Mali, Burkina Faso y Angola (Figura 14). ${ }^{2}$

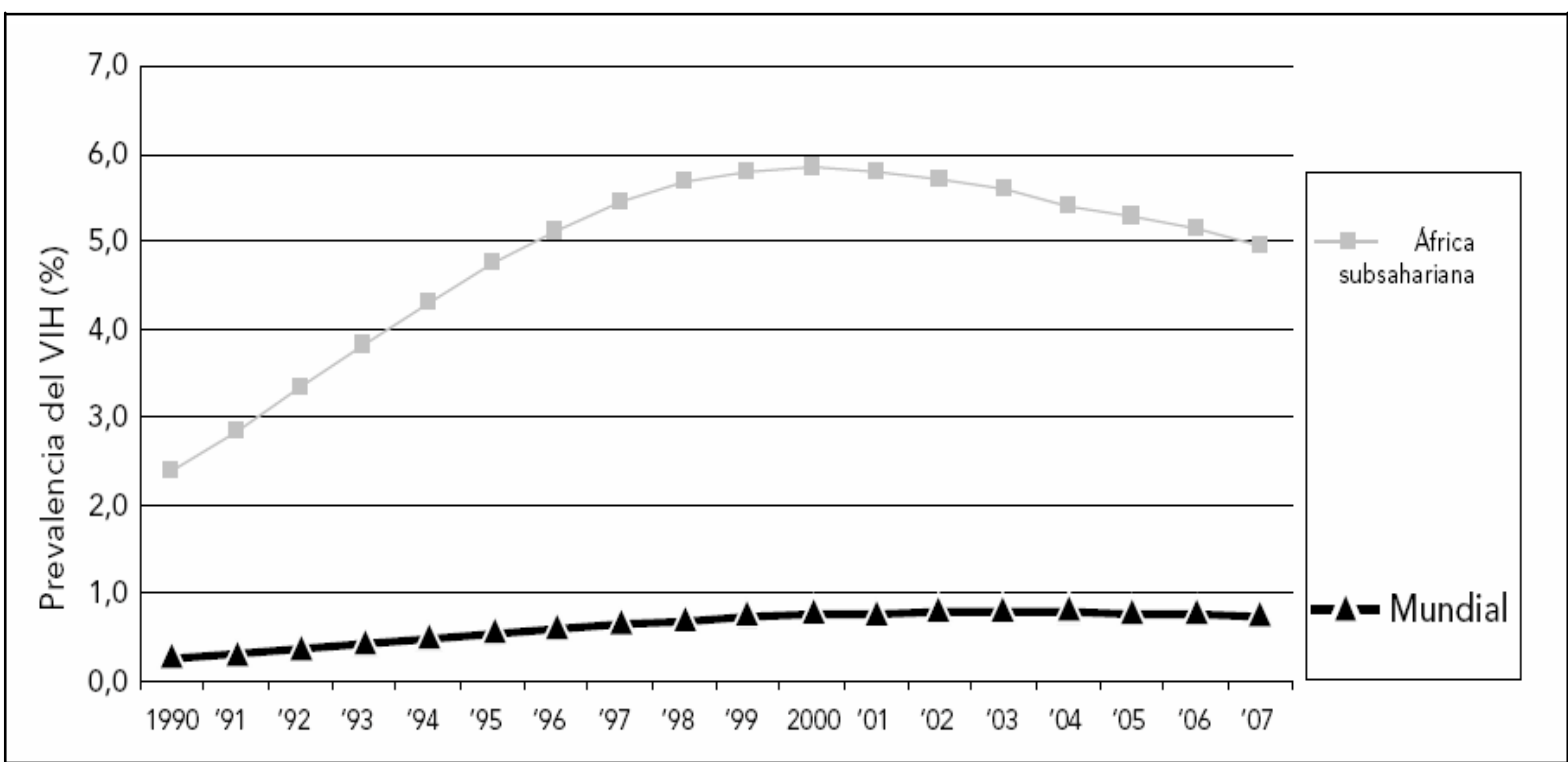

Figura 14: Prevalencia estimada del VIH en adultos en todo el mundo y en África subsahariana, 1990-2007.

En los últimos años se han producido prometedores avances en las iniciativas mundiales para abordar la epidemia de SIDA, incluido un mayor acceso a los programas de tratamiento y prevención. Sin embargo, el número de personas que viven con VIH sigue aumentando, así como el de defunciones causadas por SIDA. Si bien la prevalencia porcentual se ha estabilizado, la continuidad (aunque a un menor ritmo) de las nuevas infecciones contribuye a que el número estimado de personas que viven con VIH a diciembre de 2007, 33,2 millones [30,6 - 36,1 millones], sea más elevado que nunca (Figuras 15 y 16). Esa cifra incluye los 2,5 millones [2,2 - 2,6 millones] de niños menores de 15 años infectados. En muchas regiones del mundo, las nuevas infecciones por VIH se concentran entre los jóvenes de 15 a 24 años de edad. ${ }^{2}$ 
África subsahariana continúa siendo la región más afectada por la pandemia del SIDA, con 22,5 millones de personas viviendo con VIH y una tasa de incidencia del 5,0 \%. Más de dos tercios (68\%) de la población adulta y aproximadamente el $90 \%$ de los niños infectados por el VIH viven en esta región, donde se produjeron el 76\% de las defunciones mundiales por SIDA en el año 2007.

A diferencia de otras regiones, la mayoría de las personas que viven con VIH en África subsahariana (61\%) son mujeres; por cada 10 varones adultos infectados hay 14 mujeres adultas infectadas por el virus, aunque a nivel mundial y en cada una de las regiones hay actualmente un aumento en la proporción de mujeres mayores de 15 años VIH postivas.

Sudáfrica es el país que registra el mayor número de infecciones por el VIH de todo el mundo, con una prevalencia de la infección en embarazadas del 29\% en el año 2006. La mayor prevalencia alcanzada en la población adulta superó el 15\% en ocho países: Botswana, Lesotho, Mozambique, Namibia, Sudáfrica, Swazilandia, Zambia y Zimbabwe. ${ }^{2}$ Según estimaciones de las Naciones Unidas, para el año 2010 - 2015 la expectativa de vida en los 9 países africanos que presentan la mayor prevalencia de infección caerá a un promedio de 16 años. $^{28}$

\section{millones de personas}

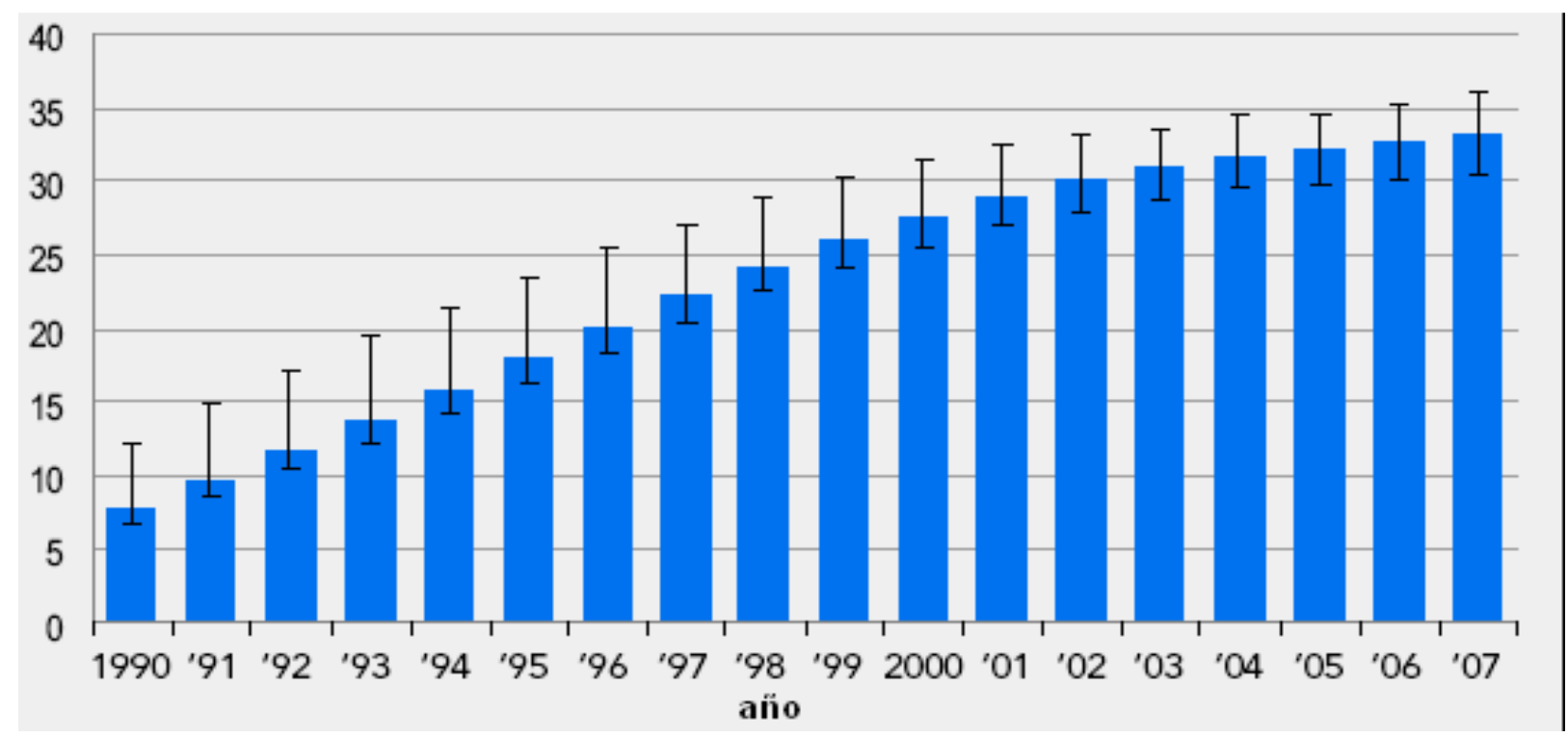

I Esta barra indica el intervalo de la estimación.

Figura 15: Estimación mundial del número personas que viven con VIH. Período 1990 - 2007.* *Fuente: AIDS epidemic update, december 2007 - UNAIDS /WHO. 


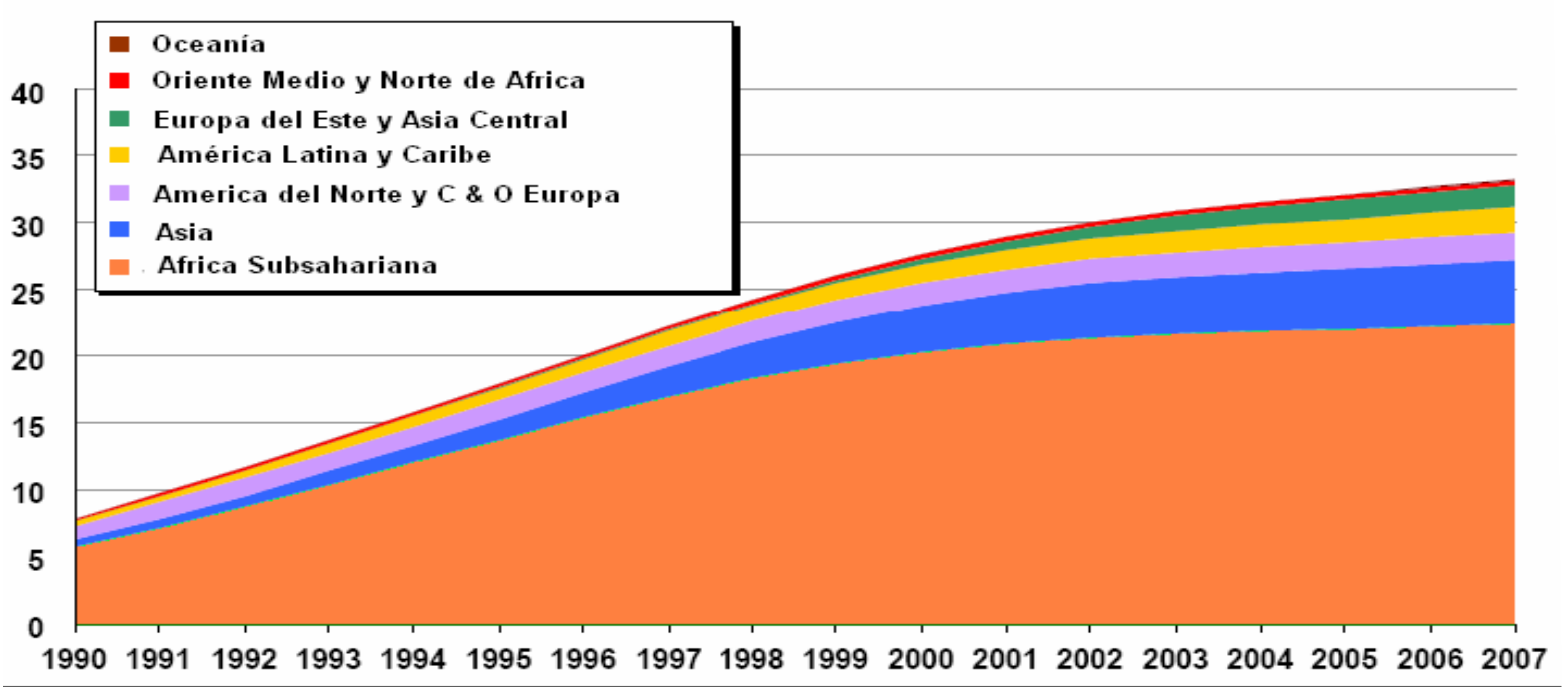

Figura 16: Estimación mundial del número de personas con infección por VIH por región. Período 1990 - 2007.*

*Fuente: AIDS epidemic update, december 2007 - UNAIDS /WHO

Pese a las recientes mejoras registradas en algunos países, la vigilancia epidemiológica en África del norte y Medio oriente sigue siendo limitada y los números notificados de casos de VIH en la región siguen siendo pequeños. La mayoría de las infecciones se producen en varones y en zonas urbanas, a excepción de Sudán, el país donde se registra la prevalencia más elevada de la región y donde las relaciones heterosexuales peligrosas son el factor de riesgo más importante para la infección. Si bien las relaciones sexuales remuneradas sin protección constituyen un factor clave en la epidemia del VIH en toda la región, la exposición a equipos de inyección de drogas contaminados es la principal vía de transmisión del VIH en Afganistán, la República Islámica de Irán, la Jamahiriya Árabe Libia, Túnez, y contribuye a las epidemias de Argelia, Marruecos y la República Árabe Siria. ${ }^{2}$

El incremento más preocupante de la epidemia se registró en Europa oriental y Asia central, principalmente en la Federación Rusa (el país con la epidemia más extendida de Europa) y Ucrania, aunque también en Azerbaiyán, Georgia y Kazajstán; Uzbekistán en este momento padece la mayor epidemia de Asia central. De los nuevos casos de infección por VIH notificados en 2006 en Europa oriental y Asia central para los cuales había información sobre la vía de transmisión, casi dos tercios (62\%) eran atribuibles al consumo de drogas inyectables y más de un tercio (37\%), a las relaciones heterosexuales sin protección. ${ }^{2}$

En Asia, la mayor prevalencia de VIH se manifiesta en Asia sudoriental, donde se observa una amplia variación en las tendencias epidémicas entre los diferentes países. 
Mientras que en Camboya, Myanmar, India y Tailandia la epidemia muestra un descenso en la prevalencia, con cifras menores al 1,5\%, en Indonesia, Vietnam y Pakistán la prevalencia ha aumentado. Los factores de riesgo principales asociados con la infección por el VIH son el uso de material contaminado para la inyección de drogas y las relaciones sexuales sin protección con parejas no habituales o profesionales del género. ${ }^{2}$

En Europa Central, Occidental, Central y América del Norte, el número total de personas que viven con el VIH está en aumento. Este incremento se debe principalmente a los efectos de la prolongación de la vida por la terapia antiretroviral y a un aumento en el número de nuevos diagnósticos de VIH en Europa Occidental a partir de 2002, combinado con un número relativamente estable de nuevas infecciones por el VIH cada año en América del Norte. En conjunto, aproximadamente 2,1 millones [1,1 millones - 3,0 millones] de personas en América del Norte, Europa Occidental y Central vivían con el VIH en 2007. En un contexto de acceso generalizado al tratamiento antiretroviral, se han producido comparativamente pocas defunciones a causa del SIDA, 32.000 [20.000 - 84.000] en 2007. ${ }^{2}$

En Oceanía la principal forma de transmisión de la infección son las prácticas sexuales sin protección entre varones, aunque el número de personas que se infectan a través de las relaciones heterosexuales está en aumento, principalmente en Papua Nueva Guinea, donde la epidemia aún se encuentra en expansión. ${ }^{2}$

En América Latina y el Caribe las epidemias continúan generalmente estables, aunque se siguen registrando brotes del virus entre los usuarios de drogas intravenosas $\left(\mathrm{UDI}_{\mathrm{s}}\right)$ y los varones que tienen relaciones sexuales con hombres en la mayor parte de los países de América del Sur y principalmente en el Caribe, donde las relaciones sexuales entre varones representan uno de cada 10 casos notificados. La prevalencia del VIH en adultos en el Caribe se estimó en un $1,0 \%$ [0,9\% - 1,2\%] en 2007. La prevalencia en esta región es más elevada en la República Dominicana y en Haití, que en conjunto dan cuenta de casi tres cuartos de las 230.000 [210.000 - 270.000] personas que viven con el VIH en el Caribe, aunque la prevalencia también es elevada en Jamaica, Bahamas y Trinidad-Tobago (2,0 \% a 4,0\%). Cuba tiene la menor prevalencia, por debajo del 0,1\%. El modo principal de transmisión del VIH en esta región es la vía sexual; las relaciones sexuales sin protección entre profesionales del género y clientes constituyen un factor significativo en la transmisión del VIH. ${ }^{2}$ Las epidemias esencialmente heterosexuales del Caribe ocurren en el contexto de flagrantes desigualdades de género y están impulsadas por una próspera industria del género, que sirve a clientes tanto locales como extranjeros. ${ }^{54}$ 
En América Latina la transmisión del VIH se está produciendo en el contexto de factores comunes a la mayoría de los países latinoamericanos: pobreza y migración generalizada, información insuficiente acerca de las tendencias de la epidemia fuera de las grandes zonas urbanas y homofobia. Concretamente, en muchas de las epidemias de América Latina, el papel de las relaciones sexuales sin protección entre varones tiende a negarse e ignorarse en las estrategias para afrontar el VIH, sobre todo en América Central y la región andina de Sudamérica. ${ }^{55} \mathrm{La}$ transmisión del VIH en esta región sigue produciéndose en poblaciones de mayor riesgo de exposición, principalmente mujeres y hombres trabajadores sexuales y hombres que tienen relaciones sexuales con hombres. El número estimado de nuevas infecciones por el VIH en América Latina en 2007 fue 100.000 [47.000 - 220.000], lo que eleva a 1,6 millones [1,4 millones - 1,9 millones] el número total de personas que viven con el VIH en esta región; las 2/3 partes de estas personas viven en los 4 países más grandes: Argentina, Brasil, Colombia y México. ${ }^{2}$ Sin embargo, la prevalencia estimada del VIH es máxima en los países más pequeños de América Central (1 \% a 2,5\%), principalmente en El Salvador, Guatemala, Panamá, Honduras y Belice. ${ }^{56}$ Según las estimaciones, aproximadamente 58.000 [49.000 - 91.000] personas fallecieron a causa del SIDA durante 2007. Las relaciones sexuales sin protección entre varones representaron hasta el $25 \%-35 \%$ de los casos de SIDA comunicados en Argentina, Bolivia, Brasil, Guatemala y Perú. ${ }^{56}$ En América del Sur, las relaciones sexuales sin protección entre varones constituyen un factor importante en las epidemias de Bolivia, Chile, Ecuador y Perú, así como en varios países de América Central, entre ellos, El Salvador, Guatemala, Honduras, México, Nicaragua y Panamá. ${ }^{2}$ Al mismo tiempo, los niveles de infección por VIH varían ampliamente entre las profesionales sexuales femeninas; la prevalencia de la infección es muy baja en Venezuela y Chile pero se han registrado tasas de prevalencia entre el $2,8 \%$ y el $6,3 \%$ en algunas ciudades de Argentina y Brasil. ${ }^{57-59}$

La epidemia de SIDA en Argentina ha evolucionado en forma disímil desde que se registró el primer caso en el año 1982; hasta el 31 de diciembre de 2007 se ha notificado un total de 67.245 personas con infección por VIH y de ellas, 35.572 han desarrollado en algún momento una enfermedad marcadora de SIDA. ${ }^{60}$ La tasa de incidencia para el año 2007 de infección por VIH es de 8,7 por 100.000 habitantes, mientras que la tasa de incidencia de casos de SIDA por 100.000 habitantes es de 2,8; si las comparamos con las tasas notificadas en años anteriores, observamos una caída en ambas tasas, atribuida probablemente a un retraso en la notificación. La tasa de incidencia de SIDA alcanzó un pico en el año 1997 (9,1 
por 100.000 habitantes), cuando se produjo un cambio en la definición de caso de SIDA y se incorporan 3 nuevas enfermedades marcadoras: TB pulmonar, neumonía bacteriana recurrente y cáncer de cuello uterino invasivo, causantes del $30 \%$ de los casos de SIDA diagnosticados en ese año. ${ }^{41,61}$ En los años siguientes se observa una disminución en forma constante de la notificación de casos de SIDA, que coincide con la aplicación del TARGA a partir de 1997, influyendo directamente para el descenso de la tasa de incidencia de diagnóstico de enfermo de SIDA, que disminuyó hasta estabilizarse alrededor de 5 casos de SIDA por 100.000 habitantes. ${ }^{61,62}$ La tasa de infección por VIH en el Gran Buenos Aires es 10,3 por 100.000 habitantes para el año 2007.

A lo largo del tiempo, se han producido cambios en el patrón de distribución geográfica de las personas infectadas; las tasas más elevadas de notificaciones de VIH/SIDA para el año 2007 correspondieron a: Ciudad de Buenos Aires (31,7 por 100.000), Tierra del Fuego (20,3 por 100.000), Buenos Aires (18,8 por 100.000), Chubut (18,2 por 100.000) y Neuquén (13,0 por 100.000) (Figura 17).

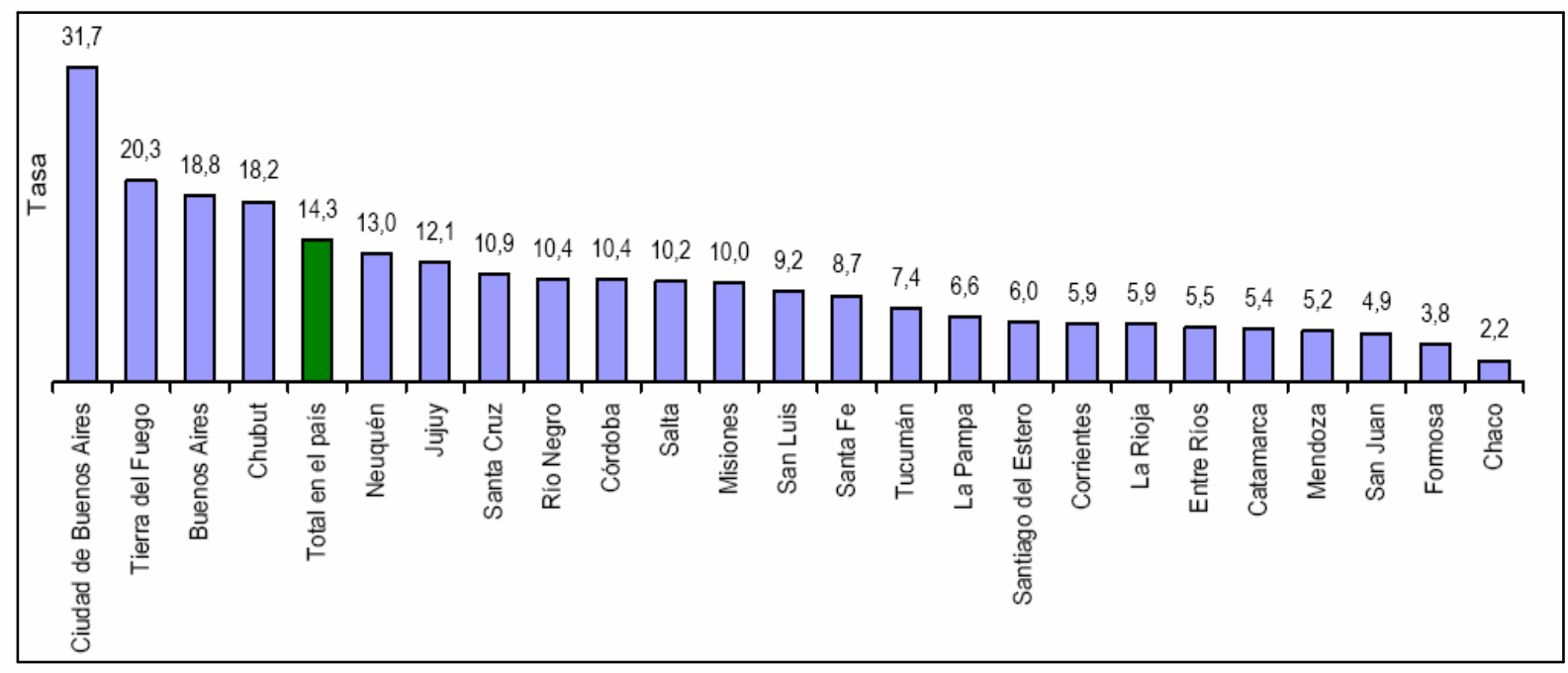

Figura 17: Tasa de notificación de personas con infección por VIH/SIDA por 100.000 habitantes por provincia. Año 2007. República Argentina.*

*Fuente: Boletín sobre el VIH - SIDA en la Argentina. Dirección de SIDA y Enfermedades de Transmisión Sexual. Ministerio de Salud de la Nación. Buenos Aires: Agosto 2008. Año XI, número 25.

Las estimaciones realizadas durante el año 2007 en forma conjunta entre ONUSIDA, OMS y la Dirección de SIDA y ETS del Ministerio de Salud de la Nación, muestran que aproximadamente 134.000 (128.000 a 140.000) personas viven con VIH/SIDA en Argentina, de las cuales un $50 \%$ desconocerían su situación serológica. La proporción de personas diagnosticadas que viven en la región central del país (Ciudad de Buenos Aires, Gran Buenos 
Aires, provincia de Buenos Aires, Córdoba, Santa Fe y Entre Ríos) ha disminuido pero aún hoy en esta región se concentra más de tres cuartas partes de la epidemia. ${ }^{60}$

La provincia de Buenos Aires está sub dividida en distritos o regiones sanitarias, denominadas de la I a la XI, integrados por distintos municipios o partidos, que conforman una división territorial de la provincia de Buenos Aires, de acuerdo a sus diferentes características sanitarias y demográficas (Figura 18).

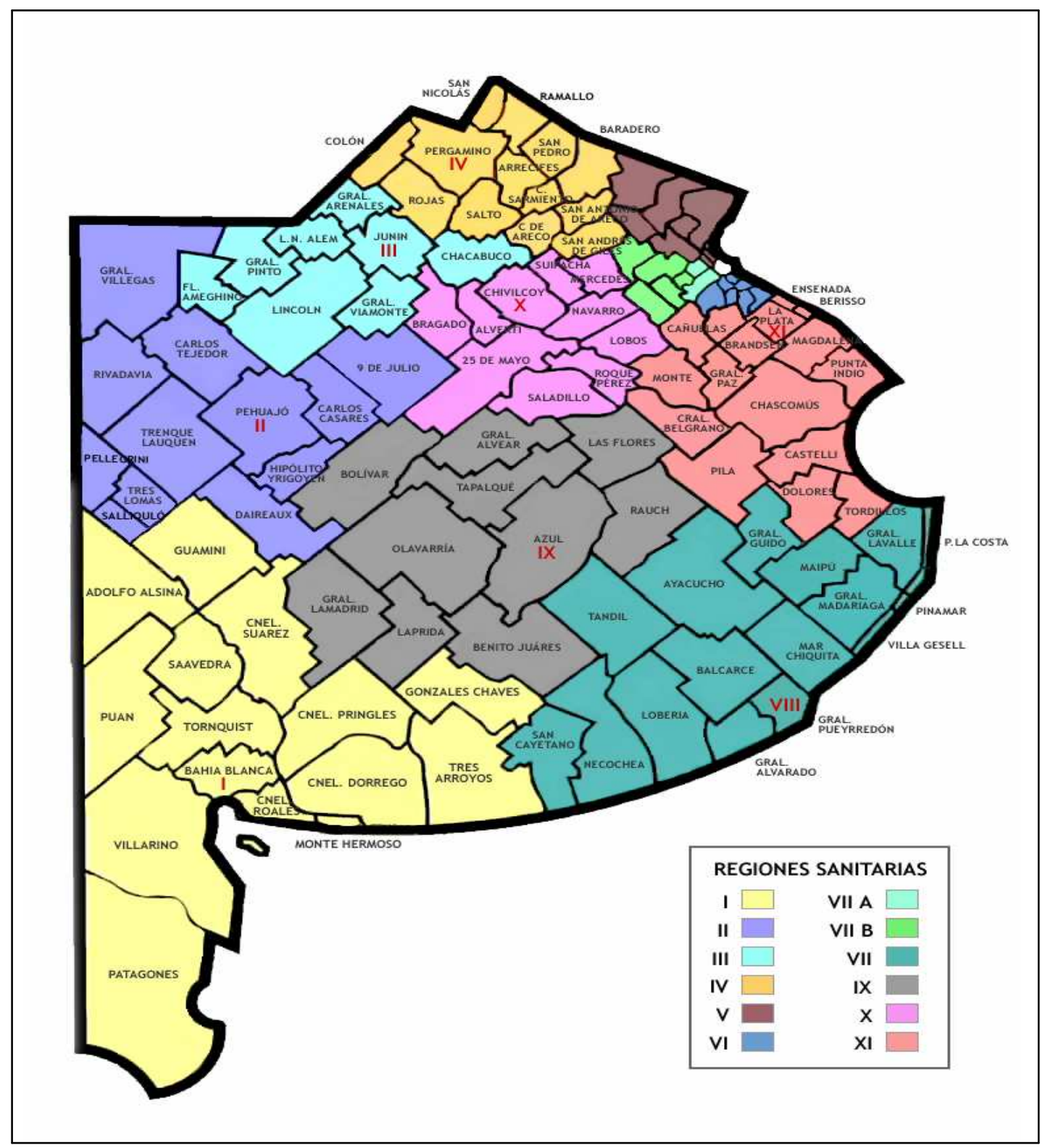

Figura 18: Regiones sanitarias de la provincia de Buenos Aires, Argentina, año 2007.

Considerando que la provincia de Buenos Aires concentra aproximadamente el $50 \%$ de las notificaciones de VIH/SIDA, es importante analizar el comportamiento de las tasa de 
notificación en las distintas regiones sanitarias en que se divide esta provincia, que mantuvo una tasa de incidencia de 20 por 100.000 habitantes a lo largo del período 2001 a 2005. Las regiones sanitarias V, VI, VIIa, VIIb, VIII y IX (este y nordeste de la provincia) presentan tasas de incidencia por arriba del 10 por 100.000 habitantes, que son las que aportan la mayor cantidad de diagnósticos y en consecuencia arrastran o definen la tasa provincial. Por otro lado, las regiones I, II, III, IV, IX y X, tienen tasas muy bajas (Figura 19). ${ }^{63}$

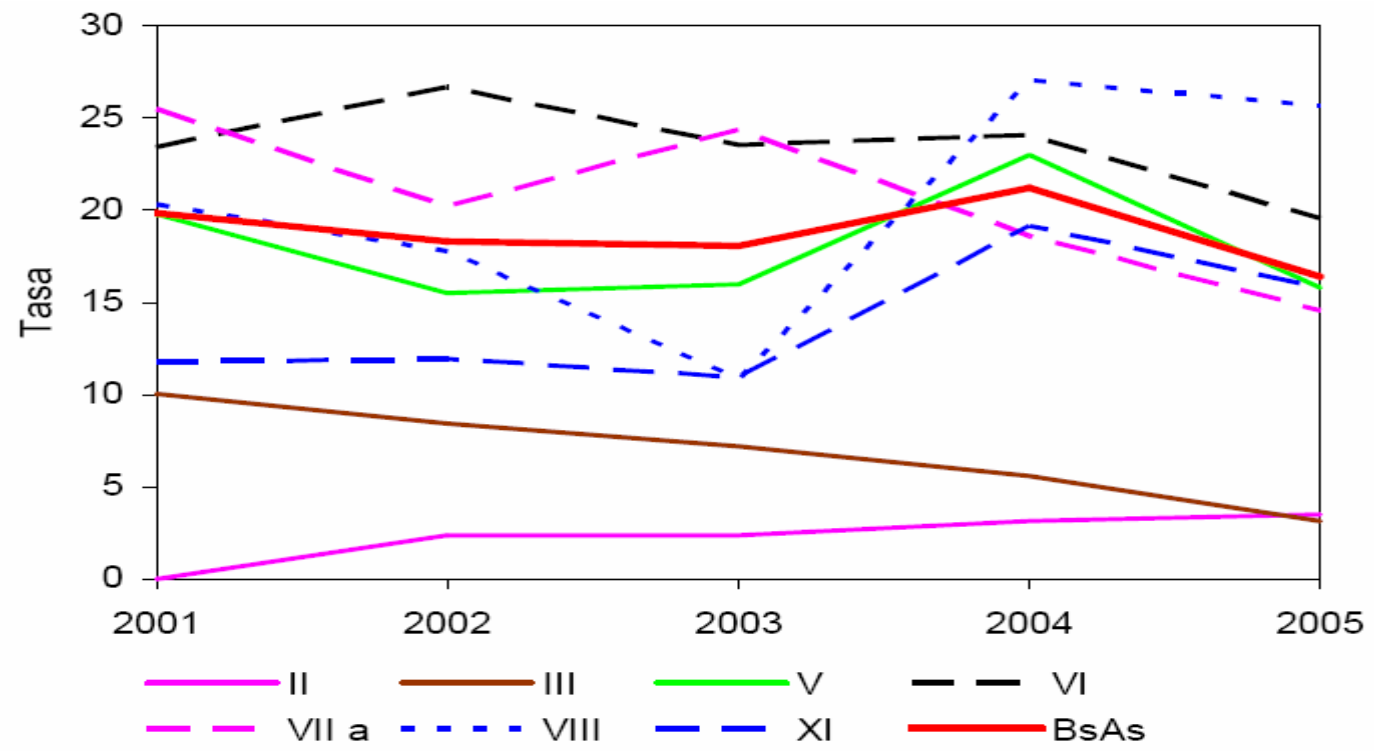

Figura 19: Tasa de infección por VIH cada 100.000 habitantes en regiones sanitarias seleccionadas de la provincia de Buenos Aires, Argentina. Período 2001- 2007.*

*Fuente: Boletín sobre el VIH - SIDA en la Argentina. Dirección de SIDA y Enfermedades de Transmisión Sexual. Ministerio de Salud de la Nación. Buenos Aires: Agosto 2008. Año XI, número 25.

Al analizar la evolución de la distribución de casos de SIDA por género, hasta el año 1987 era predominantemente en hombres. En ese mismo año se diagnosticó el primer caso de SIDA en mujeres y la razón hombre/mujer fue de 92/1. La razón hombre/mujer de notificaciones de infección por VIH a nivel nacional ha descendido levemente entre los años 2001 y 2007, de 1,9 a 1,7. Sin embargo, esta tendencia cambia cuando la información se desagrega por regiones; en el Gran Buenos Aires, esta razón ha descendido para el mismo período de 1,5 a 1,3. Actualmente, la razón hombre/mujer para los nuevos diagnósticos de SIDA se ha estrechado hasta 2,4 hombres por cada mujer infectada. ${ }^{64}$ La relación hombre/mujer en personas infectadas por VIH mayores de 15 años en la provincia de Buenos Aires, durante el período comprendido entre los años 2001 a 2007, es de 1,7/1. ${ }^{63}$ Argentina, como el resto de los países del mundo, expresa la feminización de la epidemia, ya que el 
número de casos de SIDA diagnosticados en mujeres no ha dejado de aumentar, con un total de $75,1 \%$ de casos acumulados de SIDA. Unido esto a que la mayor concentración de casos se ha presentado en edades sexualmente activas, radica la importancia de focalizar acciones de prevención y diagnóstico precoz de la infección por VIH/SIDA en la mujer, principalmente en la embarazada, para poder suministrar el tratamiento adecuado y evitar así la transmisión vertical.

La infección por VIH es una enfermedad totalmente prevenible modificando las conductas y el comportamiento de riesgo. Estas medidas incluyen la educación y modificación de conductas, promoción del uso de preservativo, provisión, tratamiento de las ITS, tratamiento de los $\mathrm{UDI}_{\mathrm{s}}$, acceso a jeringas y agujas estériles y el uso de la profilaxis con drogas antiretrovirales para prevenir la transmisión madre a hijo. ${ }^{58}$

Actualmente la infección afecta principalmente a la franja de edad de población económicamente activa y se concentra mayoritariamente en ambos géneros entre los 25 y 39 años. La edad de diagnóstico de la infección ha aumentado en el período 2001 a 2007 . La mediana de la edad de diagnóstico en los varones aumentó de 32 a 36 años en este período, mientras que en las mujeres se mantuvo relativamente estable pasando de 31 a 32 años; esto significa que se ha ampliado la diferencia de edad de diagnóstico entre ambos géneros. En el Gran Buenos Aires, la mediana de diagnóstico de infección por VIH para el período 2005 2007 fue de 36 años en hombres y de 32 años en las mujeres; el diagnóstico más temprano en las mujeres puede asociarse a una mayor accesibilidad al análisis de VIH durante el embarazo, que en más del $30 \%$ es el momento del diagnóstico de VIH. ${ }^{60}$

La transmisión sexual, principalmente heterosexual, se ha convertido en la principal vía de propagación de la infección por VIH en la Argentina. ${ }^{58}$ El consumo de drogas de administración intravenosa (DIV), así como la utilización de equipos de inyección no estériles, que antes representaban un importante factor de riesgo, han disminuido en la última década, sobre todo desde el año 2001, cuando muchos usuarios dejaron de inyectarse y pasaron a consumir drogas por vía inhalatoria, más baratas. En Buenos Aires, los UDIs sólo representaron el $5 \%$ de las nuevas infecciones en el período 2003-2005. ${ }^{61,63}$ En varios estudios se ha documentado que son VIH positivos hasta el $44 \%$ de los UDI , el 7 al $15 \%$ de los varones que tienen relaciones sexuales con varones y el $6 \%$ de las trabajadoras sexuales. ${ }^{55,57}$ En algunas prisiones de nuestro país han resultado seropositivos hasta un $28 \%$ de los reclusos. ${ }^{61}$ 
Desde principios de la década de 1990 en los casos diagnosticados de SIDA las relaciones sexuales sin protección se han convertido en el principal modo de transmisión del VIH, estimándose que las relaciones heterosexuales sin protección fueron las responsables de aproximadamente 4 a 5 de nuevos diagnósticos de VIH a partir del año 2005. ${ }^{64,65}$

El patrón que identifica las vías de transmisión de las personas infectadas entre los años 2001 y 2007 se asocia preponderantemente a la vía sexual: el $82 \%$ de las mujeres y el 73 $\%$ de los varones se infectaron por esa vía en dicho período (Figura 20). En el caso de los varones, el $31 \%$ se infectó por prácticas sexuales con otros hombres y el $42 \%$ en una relación heterosexual. A su vez, el $5 \%$ de las mujeres y el $15 \%$ de los hombres fueron notificados como UDIs. El 4,3 \% de los diagnósticos (1493 personas) corresponde a infecciones por transmisión vertical, con 700 varones que se infectaron en este período por esta vía, 789 mujeres y 4 niños con género desconocido.

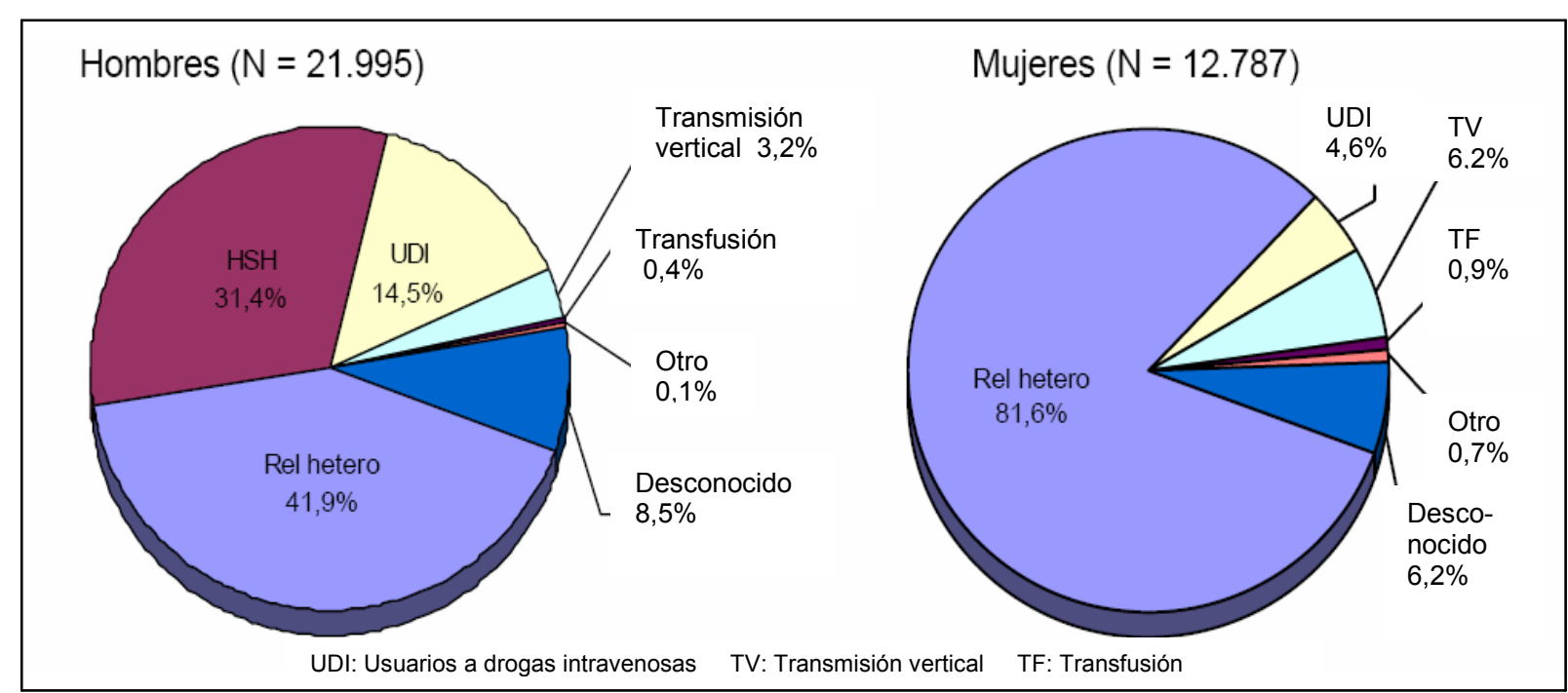

Figura 20: Vías de transmisión de personas con infección por VIH en Argentina. Período 2001- 2007.* *Fuente: Boletín sobre el VIH - SIDA en la Argentina. Dirección de SIDA y Enfermedades de Transmisión Sexual. Ministerio de Salud de la Nación. Buenos Aires: Agosto 2008. Año XI, número 25 .

Cuando se considera todo el país, las vías de transmisión presentan cambios importantes a lo largo del período 2001-2007. En ambos géneros, disminuye aproximadamente a la tercera parte la transmisión asociada al consumo de drogas y aumenta la transmisión durante relaciones heterosexuales. La proporción de hombres infectados por relaciones sexuales con otros hombres es la única que no cambia a lo largo del período. El aumento de las transmisiones en relaciones heterosexuales en detrimento de la de usuarios de 
drogas observado en el país se repite prácticamente en todas las regiones para ambos géneros. En relación con los hombres, esta tendencia es muy pronunciada en el Gran Buenos Aires, con un $20 \%$ de incremento de infecciones asociadas a la vía heterosexual y una disminución del mismo orden de UDIs. La proporción de transmisiones debidas a género entre hombres desciende levemente o se mantiene constante en la mayoría de las regiones, excepto en la Patagonia, en donde se registra un incremento del $9 \%$ en esta categoría de vía de transmisión, siendo Córdoba la provincia con el mayor porcentaje de transmisión homosexual para el período 2005-2007. En el Gran Buenos Aires, las vías de contagio para el período 2001-2007 presentan la siguiente distribución: la transmisión por relaciones heterosexuales con un $60 \%$, seguido por hombres que tienen sexo con hombres con el $13 \%$, UDIs con el $17 \%$ y un $6 \%$ de transmisión vertical. ${ }^{60}$

La tasa de mortalidad por SIDA en la Argentina alcanzó un pico de 58,4 defunciones por millón de habitantes en el año 1996, para luego descender hasta estabilizarse en el año 1999 en alrededor de 40 personas por millón; a partir del año 2004, comenzó a descender nuevamente para alcanzar en el año 2006 una tasa de 36 defunciones por millón.

Se ha notificado un descenso más marcado en la tasa de mortalidad masculina que en la femenina; en 1997 la tasa de varones casi cuadruplicaba la de mujeres, ubicándose en 77,4 y 24,1 respectivamente. Esta brecha se ha reducido por la caída en al mortalidad de hombres, que en el año 2006 era casi el triple que la de mujeres. La tasa de varones disminuyó entre 1997 y 2006 en un $30 \%$, en tanto que la de mujeres disminuyó en un $20 \%$. A nivel regional, en la Ciudad y en la provincia de Buenos Aires, la tasa de mortalidad para ambos géneros presenta un descenso sostenido. ${ }^{60,62}$

La mayor prevalencia de enfermedades marcadoras en los nuevos diagnósticos de SIDA de los últimos 6 años son: neumonía por Pneumocystis jiroveci, neumonía bacteriana recurrente, síndrome de desgaste por VIH, criptococosis meníngea, tuberculosis pulmonar y diseminada, encefalopatía por VIH, candidiasis esofágica y toxoplasmosis cerebral. ${ }^{60}$

En la provincia de Buenos Aires, las principales enfermedades marcadoras de SIDA notificadas en el período comprendido entre los años 1985 y 2006 han sido: neumonía por Pneumocystis jiroveci, tuberculosis pulmonar, síndrome de desgaste por VIH, tuberculosis diseminada o extrapulmonar, toxoplasmosis cerebral, candidiasis esofágica e infecciones bacterianas múltiples (Figura 21). ${ }^{60,66}$ 


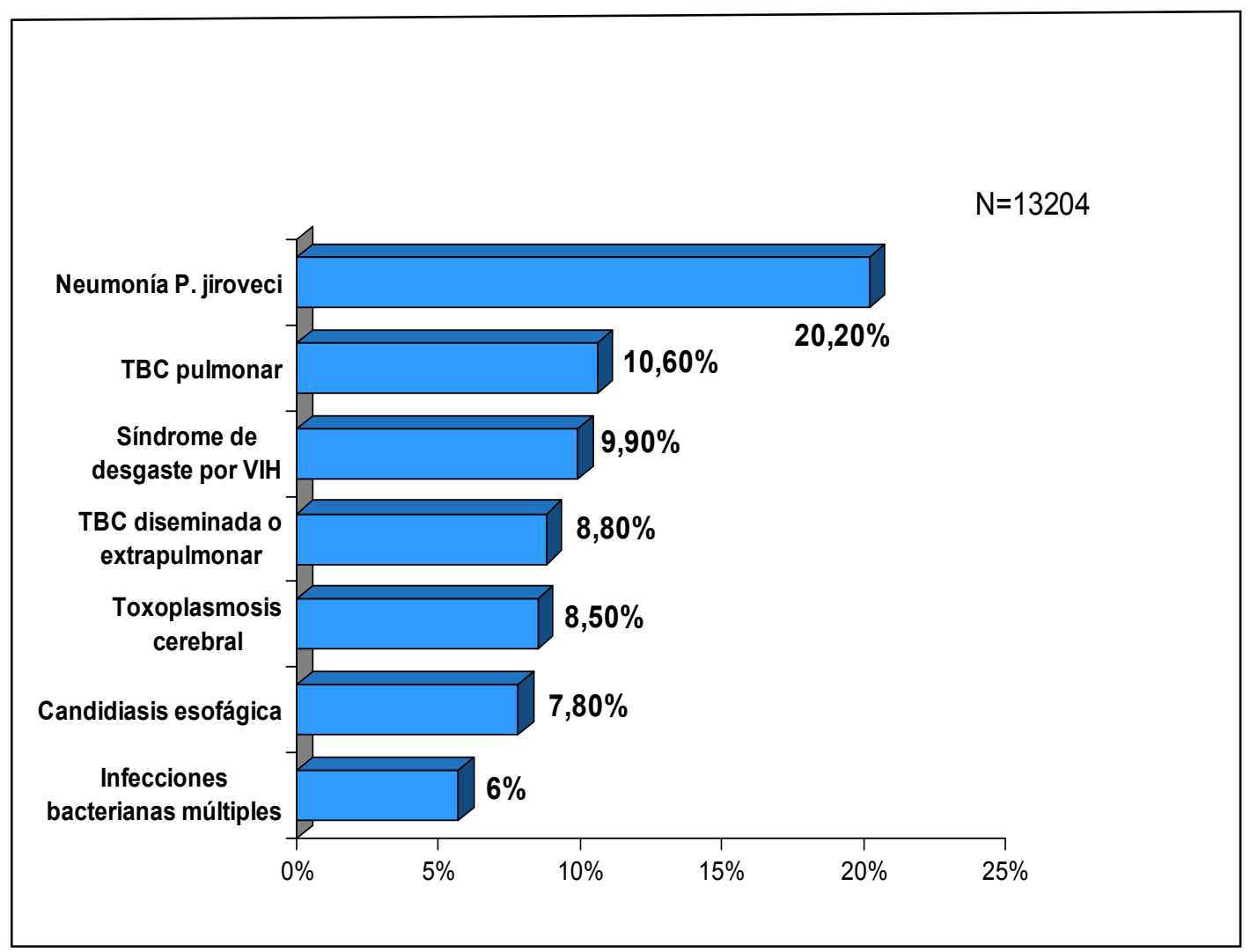

Figura 21: Principales enfermedades marcadoras en casos de SIDA acumulados, provincia de Buenos Aires, Argentina, período 1985 - 2006

Como se mencionó anteriormente, la provincia de Buenos Aires está subdividida en regiones sanitarias, denominadas de la I a la XI, integradas por distintos municipios o partidos, que conforman una división territorial de la provincia de Buenos Aires (Figura 22).

La región sanitaria VI, ubicada en el sur del conurbano bonaerense, está integrada por los partidos de Avellaneda, Lanús, Quilmes, Berazategui, Almirante Brown, Esteban Echeverría, Ezeiza, Lomas de Zamora y Florencio Varela. En la figura 20 se puede observar su ubicación geográfica en el conurbano de la provincia de Buenos Aires.

Esta región posee una superficie de $1187 \mathrm{~km}^{2}$, con una población de 3.407 .415 habitantes y una densidad de 2870,6 habitantes $/ \mathrm{km}^{2}$. 


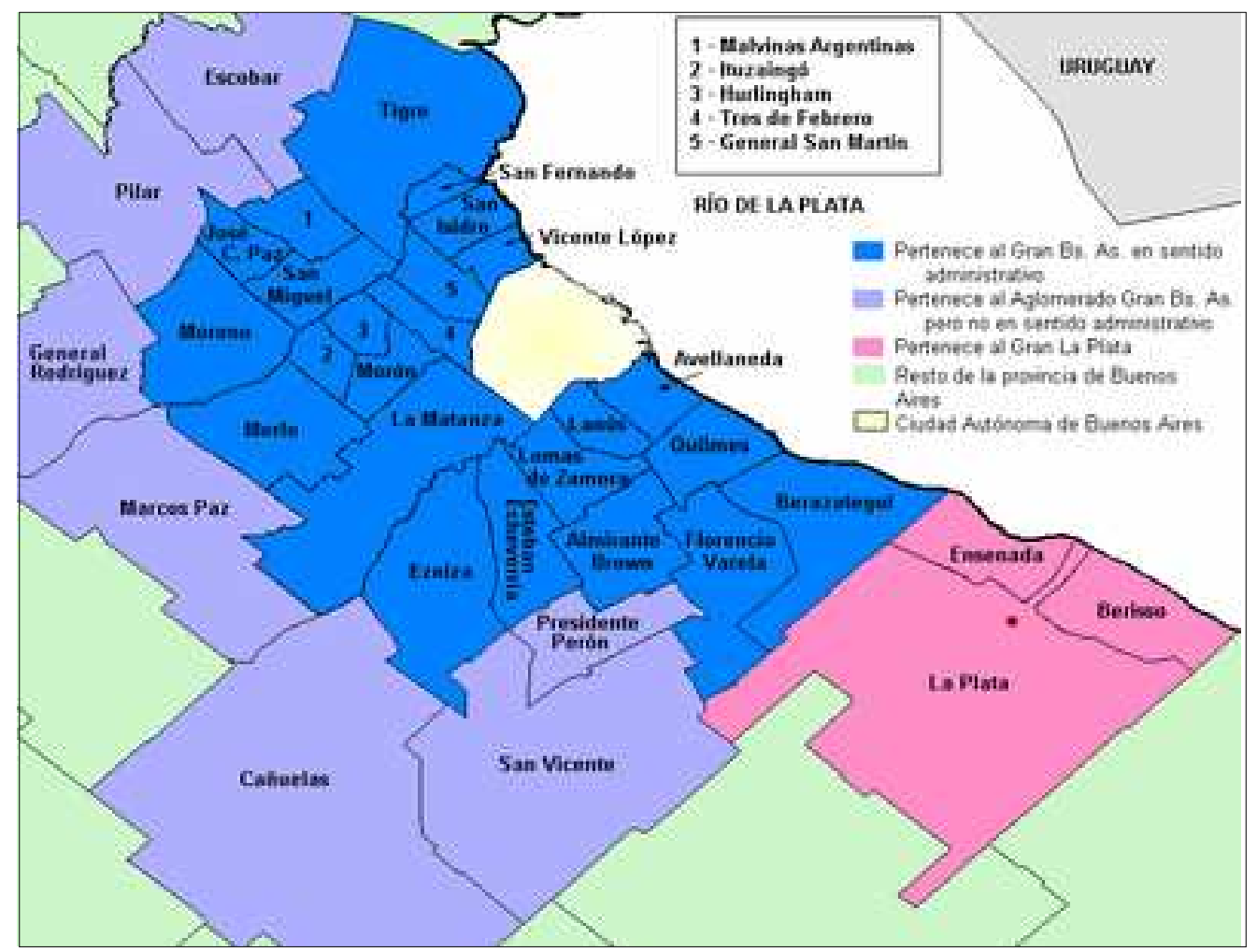

Figura 22: Municipios que conforman el conurbano de la provincia de Buenos Aires, Argentina, año 2007.

El partido de Florencio Varela forma parte del Área Metropolitana de Buenos Aires; está ubicado a $35^{\circ} 02^{\prime}$ de latitud sur y $60^{\circ} 15^{\prime}$ de longitud oeste. Se encuentra en el límite del área metropolitana que rodea a la Capital Federal, en el denominado $3^{\circ}$ cordón del conurbano sur. Su cabecera está a $23 \mathrm{~km}$ de la Ciudad Autónoma de Buenos Aires y a $35 \mathrm{~km}$ de la ciudad de La Plata. Limita al norte con los partidos de Almirante Brown y Quilmes, al este con el partido de Berazategui, al sur con el partido de La Plata y al oeste con los partidos de San Vicente, Presidente Perón y Almirante Brown (Figura 22).

Su superficie total es de $206 \mathrm{~km}^{2}$, siendo el $36 \%$ urbana el 1,5\% semiurbana, el $5 \%$ industrial, el $34 \%$ complementaria y el $23,5 \%$ rural.

La región sanitaria VI es el distrito que concentra el mayor número de casos acumulados de SIDA e infección por VIH de la provincia de Buenos Aires, presentando en el año 2007 la segunda tasa de incidencia más elevada de la provincia (luego de la región sanitaria VIII con cabecera en Mar del Plata), con un valor de 10,6 por 100.000 habitantes para el año 2007. ${ }^{63}$

Durante el año 2007 se notificaron en esta región 735 nuevos casos de infección por VIH/SIDA, de los cuales 236 (28 \%) correspondieron a casos de SIDA y 599 (72 \%) a 
infectados. De estos 735 casos, 24 (3,3 \%) residen en el partido de Florencio Varela. La distribución por género fue del $50 \%$ hombres y el $50 \%$ mujeres (Figura 23).

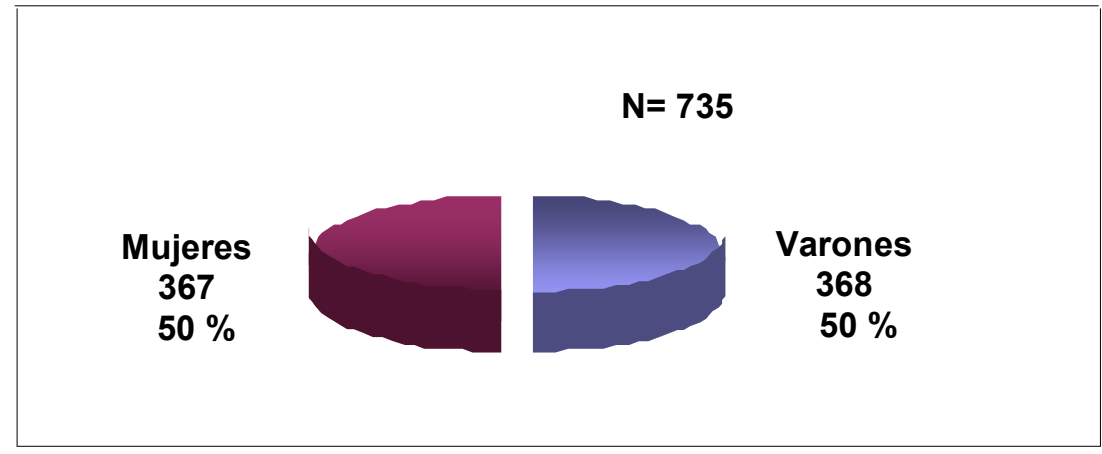

Figura 23: Notificación de casos de infección por VIH y casos de SIDA, Región Sanitaria VI, provincia de Buenos Aires, Argentina, año 2007.

Las principales vías de transmisión fueron la heterosexual $(59,7 \%)$, la adicción a drogas intravenosas $(25,5 \%)$, la homosexual $(5,3 \%)$, la transmisión de la madre al hijo $(1,5$ \%) y la transfusión de sangre y hemoderivados (0,8 \%) (Figura 24).

Del total de casos notificados, el $14 \%$ de los pacientes tenía cobertura social mientras que el $86 \%$ no poseía. El $24 \%$ de la población tenía trabajo, el $72 \%$ no trabajaba y se desconocía la información en el $4 \%$ de los casos notificados.

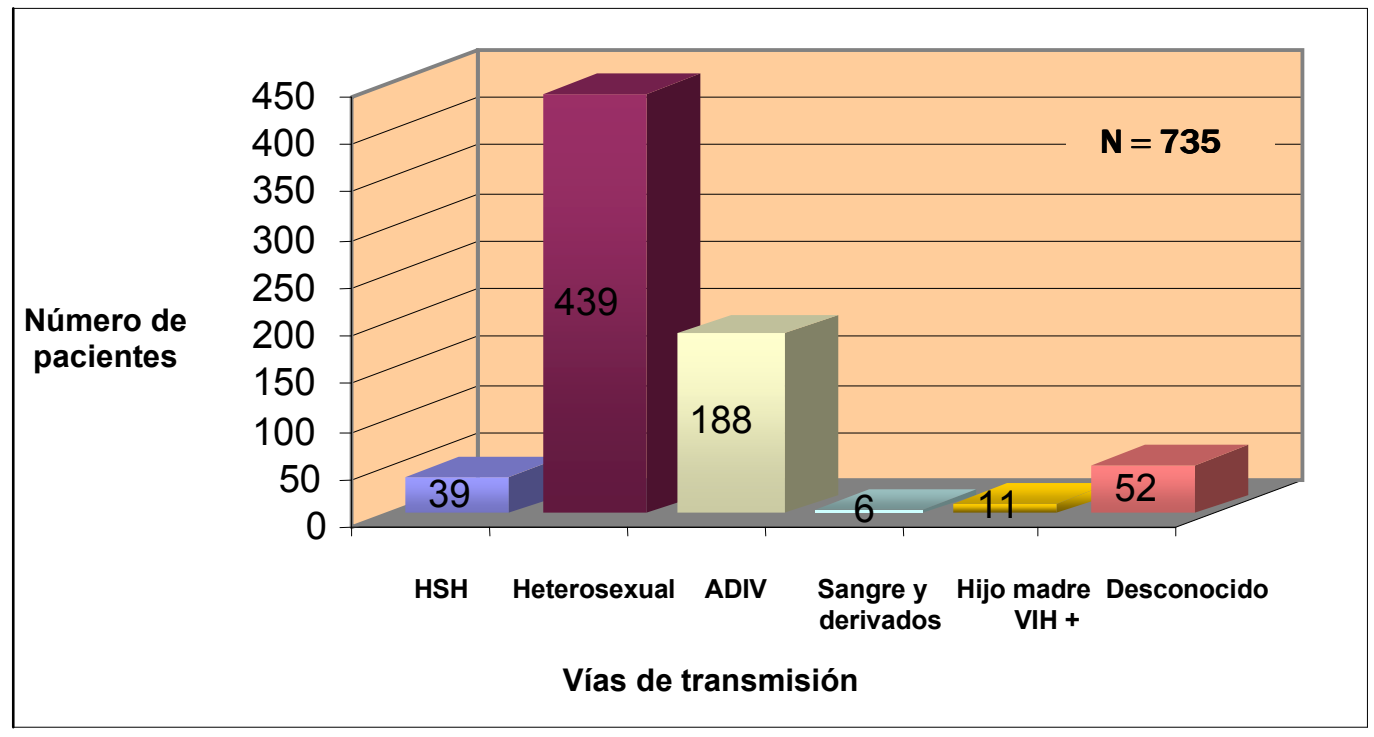

Figura 24: Casos de infección por VIH/SIDA según vía de transmisión, Región Sanitaria VI, provincia de Buenos Aires, Argentina, año 2007.

Con respecto al nivel de instrucción, la mayoría de la población poseía instrucción primaria completa, como puede observarse en la figura 25 . 


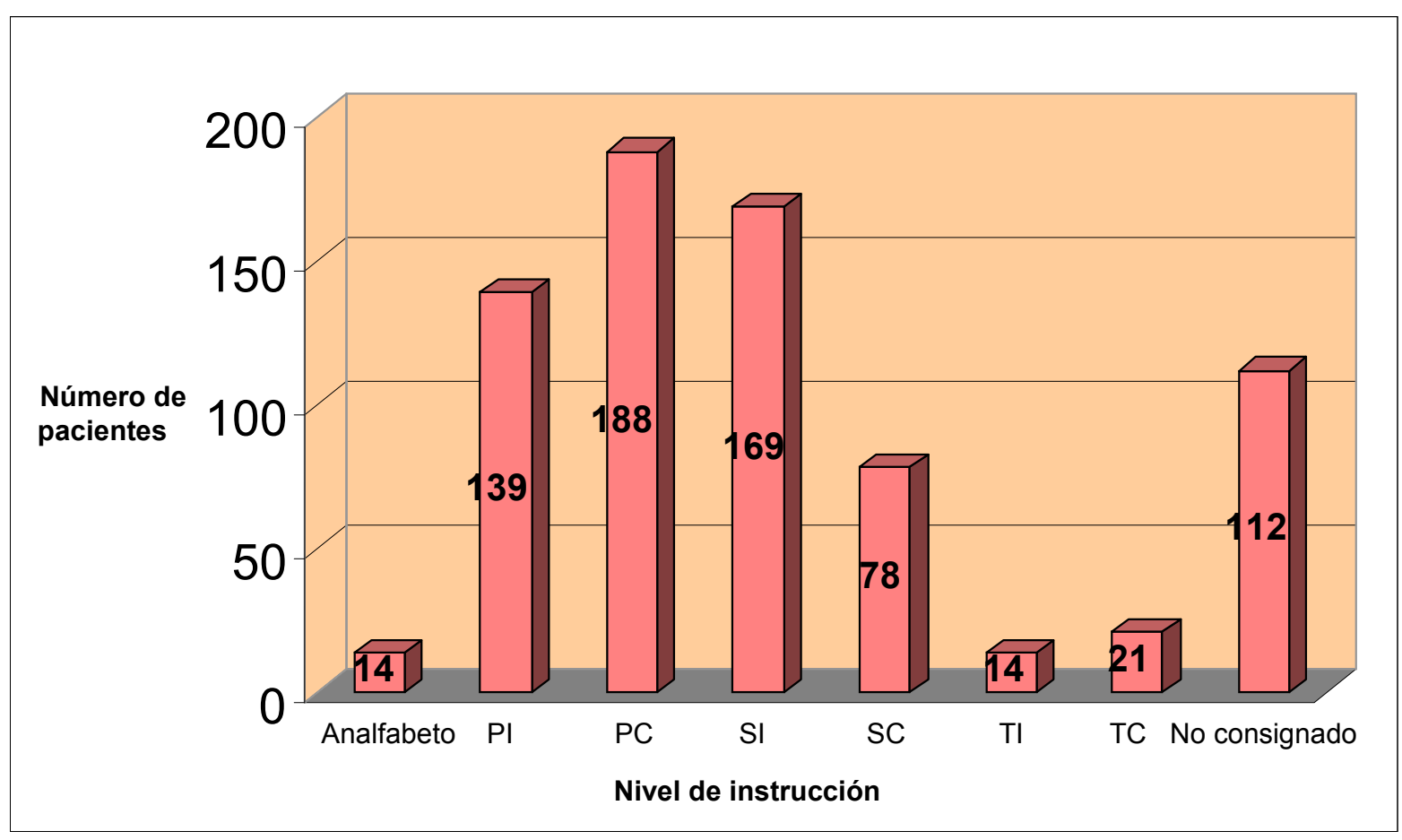

PI: Primaria incompleta; PC: Primaria completa; SI: Secundaria incompleta; SC: Secundaria completa; TI: Terciaria incompleta; TC: Terciaria competa

Figura 25: Notificación de casos de VIH/SIDA. Región Sanitaria VI, provincia de Buenos Aires, Argentina. Nivel de Instrucción. Año 2007.

La mediana de la edad de diagnóstico de infección por VIH en hombres en la región Sanitaria VI ha aumentado de 32 años (período 2001-2002) a 36 años (período 2005-2007) y en las mujeres de 30 a 32 años en iguales períodos. La distribución etaria de los casos de infección por VIH/SIDA en nuestra región, correspondiente al año 2007, se detalla en la figura 26.

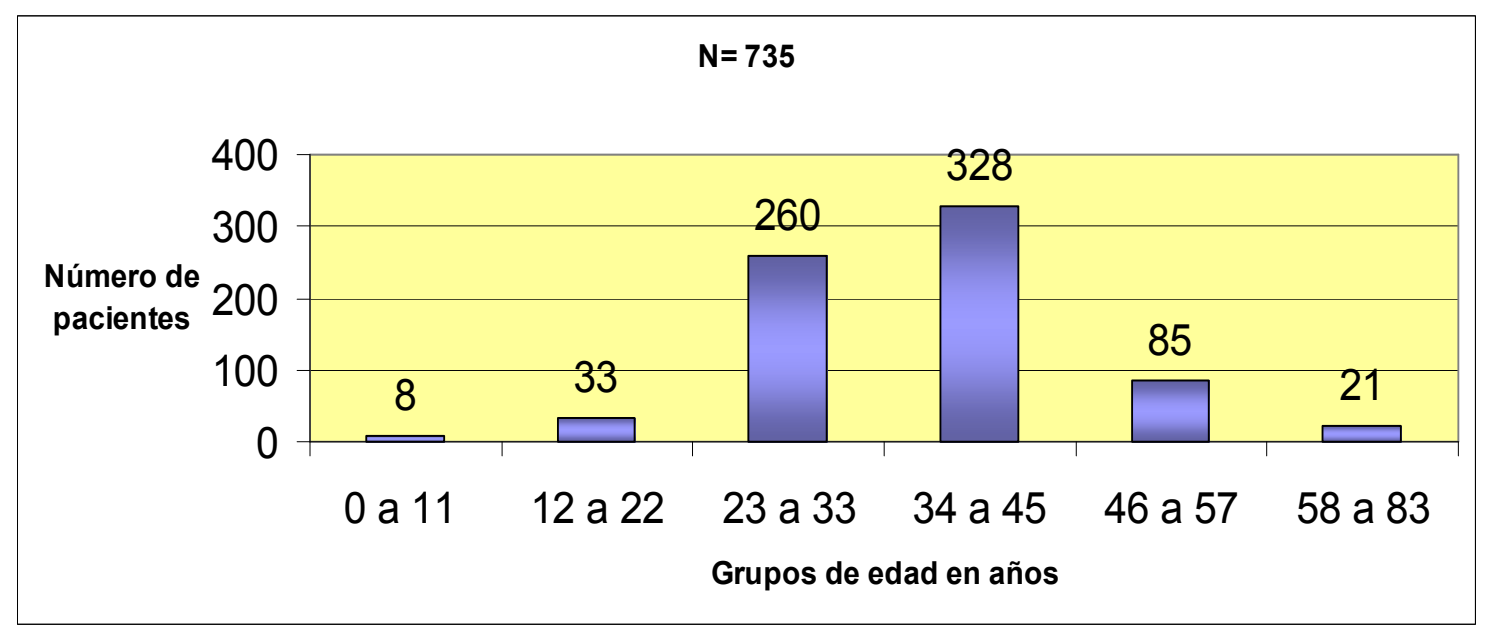

Figura 26: Distribución según edad de casos de infección por VIH/SIDA, año 2007. Región Sanitaria VI, provincia de Buenos Aires, Argentina. 
Las principales enfermedades marcadoras de SIDA notificadas en la región fueron: TB pulmonar, neumonía por $P$. jiroveci, candidiosis esofágica, infecciones bacterianas recurrentes, criptococosis meníngea, TB extrapulmonar, toxoplasmosis cerebral, neumonía bacteriana y síndrome de desgaste (Figura 27).

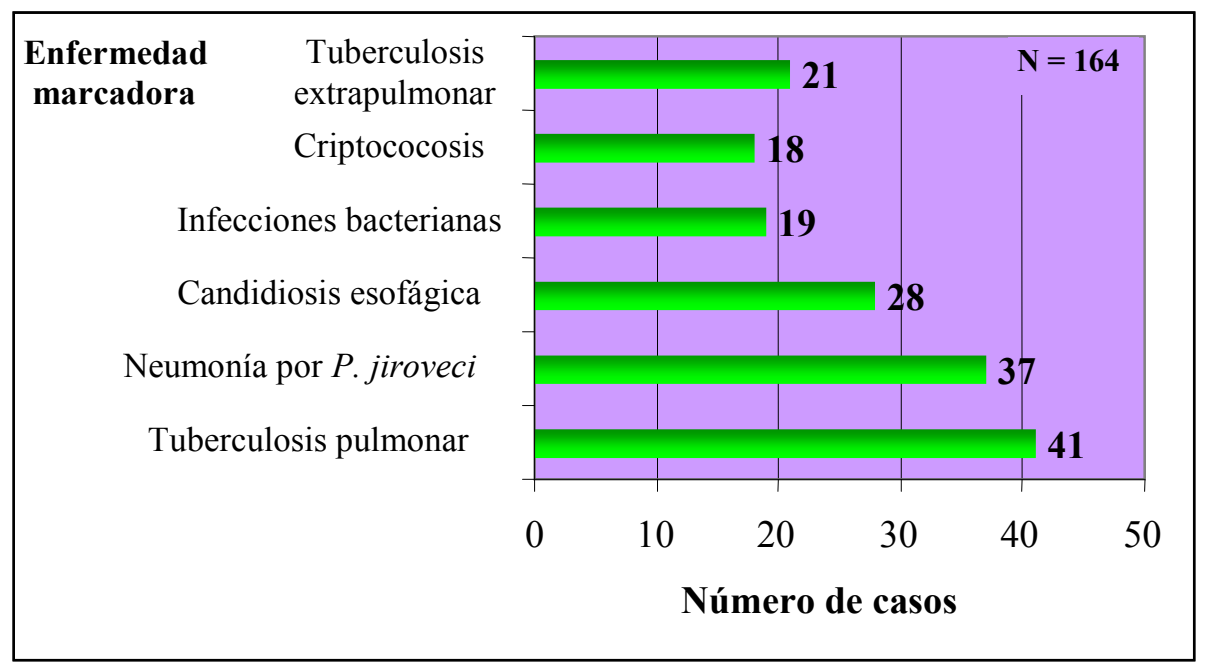

Figura 27: Principales enfermedades marcadoras de SIDA notificadas. Región sanitaria VI, provincia de Buenos Aires, Argentina, año 2007.

Otras comorbilidades notificadas conjuntamente con la infección por VIH/SIDA fueron en orden de frecuencia: hepatitis B y C, herpes zoster, candidiosis oral y sífilis. ${ }^{63}$

Las tasas de mortalidad por SIDA han disminuido en todos los distritos de nuestro país, así como en otras regiones de América, Europa y Australia. Este hecho se debe a varios factores, entre otros, la administración de quimioprofilaxis contra infecciones oportunistas, la mayor experiencia entre los profesionales médicos en el cuidado de los pacientes con VIH/SIDA y la mejoría en el acceso a la atención médica. Sin embargo, el factor más influyente ha sido el uso de potentes drogas antiretrovirales, administradas en combinación. Esta combinación de fármacos, conocida como "tratamiento antiretroviral de gran actividad" (TARGA), ha producido un dramático cambio en la historia natural de la enfermedad, revirtiendo el SIDA en pacientes con enfermedad avanzada y previniendo la progresión de la enfermedad en aquellos con un estado de relativa salud. Se han desarrollado guías de consenso para el uso del TARGA en adultos, niños y embarazadas; estas recomendaciones han mejorado el pronóstico de las personas infectadas con VIH y redujeron notablemente la transmisión de la infección de la madre al niño. ${ }^{65}$ 
Sin embargo, a pesar de los enormes beneficios del TARGA, muchos pacientes no han obtenido las respuestas adecuadas a estos regímenes, no han tolerado los efectos adversos o tóxicos o han tenido problemas en la adherencia al tratamiento debido al gran número de pastillas que deben ingerir, a las numerosas interacciones con otras drogas o a esquemas complicados que incluyen la ingesta con o sin alimentos o con o sin líquidos. Además se presenta la emergencia y diseminación de cepas resistentes a las drogas antiretrovirales disponibles, lo que constituye un problema creciente. Si bien hay evidencia del mejoramiento de la función inmunológica en la mayoría de los pacientes que reciben terapia combinada, la completa normalización del sistema inmune y la erradicación completa del virus del organismo no se ha podido lograr con los tratamientos actualmente disponibles. La persistencia latente del VIH a pesar del TARGA, que exitosamente suprime los niveles detectables de ARN VIH plasmáticos, sugiere la necesidad del tratamiento a largo plazo; en pacientes que han presentado supresión plasmática de la carga viral, los niveles han rebotado invariablemente dentro de las 3 semanas posteriores a la suspensión del tratamiento. ${ }^{67}$

Cuando en la práctica médica asistencial indicamos el tratamiento a nuestros pacientes, intentamos lograr uno o más de tres objetivos principales: prolongar su sobrevida, reducir las complicaciones y aliviar los síntomas, contribuyendo a que los pacientes se sientan mejor. Sin embargo, a la hora de investigar la eficacia de un tratamiento o la evolución de una enfermedad, lo más habitual es que las metas elegidas por los investigadores estén relacionadas preferentemente con los dos primeros objetivos. Es menos frecuente que se analicen aspectos relacionados con el tercer objetivo y esto no es porque se trate de una perspectiva poco importante para médicos o pacientes, sino porque su medición es comparativamente más compleja. ¿De qué manera medimos cómo se sienten los pacientes y cómo los afecta su enfermedad en el desarrollo de sus actividades cotidianas? La evaluación de la calidad de vida relacionada con la salud intenta responder a esta pregunta. ${ }^{68}$

\section{Calidad de vida relacionada con la salud en personas que viven con VIH/SIDA}

Han pasado 26 años desde que los primeros casos de SIDA fueron reconocidos; durante las primeras dos décadas se establecieron importantes avances metodológicos en el campo de la investigación clínica aplicada y potentes tratamientos farmacológicos antivirales fueron desarrollados para beneficiar a millones de personas infectadas. ${ }^{52}$ La infección por el VIH constituye un grave problema de salud pública con importantes implicaciones sanitarias y sociales. Al igual que en otras enfermedades crónicas, caracterizadas por pérdidas 
progresivas de la capacidad funcional y autonomía del individuo, el deterioro gradual de carácter físico, psicológico y social del paciente conduce a un deterioro tanto en su tipo de vida como en la autopercepción de su salud. ${ }^{68}$

Existe un creciente interés en la revaloración de los criterios tradicionales de evaluación de resultados, tanto en los ensayos clínicos como en la práctica clínica; un reconocimiento, cada día mayor, de la necesidad de humanizar los servicios sanitarios; una oportunidad para incorporar a las ciencias sociales y del comportamiento en las áreas centrales de la investigación médica. Así, escuchar al paciente, tomar en cuenta su punto de vista, personalizar las decisiones médicas de acuerdo con un beneficio individual óptimo y dar poder de decisión a los pacientes, son maneras de reforzar los compromisos con la misión de la medicina. ${ }^{69}$

Asistimos en la actualidad a un gran auge del enfoque de la enfermedad dentro de un contexto más "personal", en el que se consideran tanto los factores psicológicos como los sociales y la implicancia que la enfermedad tiene en la vida de las personas. Los aspectos sociales y familiares influyen decisivamente en la evolución de cualquier patología crónica, sea a través de las descompensaciones, la utilización de recursos sanitarios, la adherencia al tratamiento o la comorbilidad de trastornos afectivos; también en la misma medida determinan la calidad de vida autopercibida. ${ }^{68}$

La diversidad de los fenómenos vinculados al seguimiento y al desenlace de la infección por VIH, así como su mayor supervivencia, impulsó el desarrollo de abordajes metodológicos distintos a los parámetros clínicos convencionales (recuento de LT CD4+, determinación de la carga viral plasmática, pruebas de genotipificación y resistencia a las drogas antiretrovirales, parámetros de morbilidad y mortalidad, efectos adversos de los tratamientos). Si bien es necesaria la evaluación de la salud con parámetros clínicos estrictamente cuantitativos, es igualmente necesario considerar la perspectiva cualitativa, ya que aporta una información muy valiosa a la proporcionada por los criterios clínicos, incluyendo estudios que combinan ambos enfoques, como el estudio de la calidad de vida relacionada con la salud (CVRS).

El concepto de CVRS aparece en las sociedades occidentales en un momento en el que la esperanza de vida ha aumentado sensiblemente y en el que predomina la convicción de que el papel de la medicina no debe ser únicamente el de proporcionar muchos años de vida a las personas, sino, sobre todo, el de aportar una mejora en la calidad de los años vividos. ${ }^{70} \mathrm{La}$ medida de la CVRS tiene un particular interés en el escenario de las enfermedades en las que se ha conseguido una supervivencia prolongada mediante intervenciones terapéuticas 
específicas. Estas intervenciones, más allá de su eficacia clínica, producen un impacto global sobre la vida de los pacientes en el que se combinan aspectos positivos y negativos y que requieren instrumentos específicos para su evaluación.

Durante los últimos años se han realizado mediciones de desenlaces mediante la estandarización de la información clínica derivada directamente del paciente con el propósito de transformar estos datos en información científica útil. El concepto de CVRS cobra una creciente importancia desde que la mayor sobrevida de la población ha mejorado a expensas de un mayor número de personas con algún grado de discapacidad y de personas con enfermedades crónicas que padecen los efectos de su enfermedad y del mismo tratamiento. Entre este grupo de pacientes, se incluyen a aquellos que presentan infección por VIH/SIDA.

El término "calidad de vida" pretende valorar aspectos de la enfermedad que no son estrictamente clínicos sino relacionados con la vida diaria del paciente y de qué modo se ve afectada por la presencia de la patología desde el punto de vista del propio paciente, mediante una valoración multidimensional, valorando distintos componentes de la vida cotidiana potencialmente influidos por la enfermedad y su tratamiento y tomando al propio paciente como fuente primaria de los datos. ${ }^{71,72}$

En este contexto ha surgido el estudio de la CVRS, donde su valoración se ha convertido en un objetivo en sí mismo para una atención sanitaria óptima; evaluar la CVRS supone conocer el impacto de la enfermedad en el entorno familiar del paciente, en las relaciones sociales o en su propia autoestima, pero también analizar la eficacia y efectividad de las intervenciones sanitarias. ${ }^{68}$

El concepto de CVRS comenzó a incluirse en el Index Medicus en el año 1966, por lo que sólo hace 41 años que está presente en la literatura médica, enmarcado dentro del modelo biopsicosocial. Su historia en el ámbito de la investigación clínica es, por lo tanto, relativamente breve, contando con la necesidad de un sólido modelo conceptual, una mejor especificación de sus dimensiones y una mejor interpretación del sentido y significado de los resultados obtenidos por las distintas investigaciones. ${ }^{67}$

El significado de CVRS abarca aspectos físicos, psicológicos y sociales de la salud, tal como son percibidos por el paciente según su propia historia y sus expectativas. De hecho, dado que tales expectativas y vivencias tienen la capacidad de modificar la percepción del estado de salud y la satisfacción con la propia vida, dos personas con el mismo estado de salud pueden tener una calidad de vida marcadamente diferente. ${ }^{73}$

En este sentido, si bien no hay una definición única de CVRS, existe acuerdo en que el concepto general se refiere a la valoración que hacen las personas de su propia sensación de 
confort o bienestar, la medida en que son capaces de mantener una función física, emocional e intelectual razonable y el grado en que pueden participar en actividades que consideran importantes en el contexto de su familia, lugar de trabajo y en la comunidad. ${ }^{74}$ Según la OMS, la calidad de vida es "la percepción que un individuo tiene de su lugar en la existencia, en el contexto de la cultura y del sistema de valores en los que viven y en relación con sus objetivos, sus expectativas, sus normas, sus inquietudes. Se trata de un concepto muy amplio que está influido de modo complejo por la salud física del sujeto, su estado psicológico, su nivel de independencia, sus relaciones sociales, así como su relación con los elementos esenciales de su entorno". ${ }^{67}$ Podríamos entonces definir a la CVRS como la valoración subjetiva que el paciente hace de los diferentes aspectos de su vida, en relación con su estado de salud. El modelo biomédico tradicional excluye el hecho de que, en la mayoría de las enfermedades, el estado de salud está profundamente influido por el estado de ánimo, los mecanismos de afrontamiento a las diversas situaciones y el soporte social. ${ }^{73}$

La CVRS define el impacto de la enfermedad sobre la vida y el bienestar del individuo. La medida de la CVRS no incluye únicamente los aspectos fisiopatológicos de una enfermedad sino también los factores psicosociales inherentes a la misma, además de las posibles limitaciones que comporte. No obstante, lo que le confiere una mayor importancia es que permite la evaluación del impacto de la enfermedad y su tratamiento desde la perspectiva personal y singular de la persona afectada.

Actualmente se ha alcanzado un cierto consenso para considerar la CVRS como un concepto multidimensional que incorpora factores físicos, psicosociales, intelectuales, creencias, etc., donde la perspectiva del propio sujeto es fundamental. Al principio, la CVRS incluía un solo campo, la función física; desde entonces se ha expandido para incluir multidimensiones de función y bienestar. Las dimensiones que emergen de forma consistente en la literatura sobre calidad de vida son: funcionamiento físico, cognitivo y social, movilidad y autocuidado y bienestar emocional. El "Estudio de los resultados médicos" (Medical Outocomes Study) definió a la salud física como el funcionamiento físico, las limitaciones de rol debidas a la salud física, el dolor corporal y la salud general y describió a la salud mental como la energía/fatiga, el funcionamiento social, las limitaciones de rol debidas a problemas emocionales y el bienestar emocional. ${ }^{67}$ Shumaker y colaboradores definen tres dimensiones que global e integralmente comprenden la calidad de vida: ${ }^{75}$

1. Dimensión física: es la percepción del estado físico o la salud, entendida como ausencia de enfermedad, los síntomas producidos por la enfermedad y los efectos adversos del 
tratamiento. No hay duda de que estar sano es un elemento escencial para tener una vida de óptima calidad.

2. Dimensión psicológica: es la percepción del individuo de su estado cognitivo y afectivo como el miedo, la ansiedad, la incomunicación, la pérdida de autoestima, la incertidumbre del futuro. También incluye las creencias personales, espirituales y religiosas como el significado de la vida y la actitud ante el sufrimiento.

3. Dimensión sociológica: es la percepción del individuo de las relaciones interpersonales y los roles sociales en la vida como la necesidad de apoyo familiar y social, la relación médico - paciente, el desempeño laboral.

La evaluación de la calidad de vida en los pacientes posee una gran relevancia porque permite: ${ }^{76}$

- Conocer el impacto de la enfermedad y/o el tratamiento a un nivel relevante, diferente y complementario del orgánico.

- Un mejor conocimiento del enfermo, de su evolución y de su adaptación a la enfermedad.

- Conocer mejor los efectos secundarios de los tratamientos.

- Ampliar el conocimiento sobre la evolución de la enfermedad.

- Potenciar la comunicación médico - paciente.

- Ayudar en la toma de decisiones médicas.

- Facilitar la rehabilitación de los pacientes.

Hoy en día y de forma general, la evaluación de la CVRS permitiría mejorar la medición de numerosos desenlaces y debería considerarse como un parámetro más dentro de la práctica clínica que permite valorar la eficacia de los programas e intervenciones terapéuticas, así como también los posibles efectos adversos a corto y largo plazo. Basándose en que evalúa diferentes áreas de la vida del individuo, también afectadas por la presencia de una enfermedad y usualmente no cuantificadas por los indicadores clásicos, ayudaría a un mayor conocimiento de la historia natural de las enfermedades. Además, puede aportar un conocimiento complementario a los puntos de interés clínico más habituales y duros, como suelen ser clasificados los marcadores biológicos de uso habitual. En el contexto de ensayos clínicos cuyo objetivo primario sea la determinación de equivalencia de eficacia entre dos intervenciones, aportaría una utilidad clínica que probablemente será más importante aún en la medida en que se obtengan niveles superiores de eficacia y efectividad de las intervenciones en patologías crónicas, ya que facilitarán, junto con los estudios económicos, la evaluación de la eficiencia de las mismas. ${ }^{77}$ También se constituiría como un indicador 
importante en el contexto de estudios de cohortes y como indicador para evaluación de la calidad asistencial y tecnología médica. ${ }^{78}$

Los instrumentos que miden la CVRS, entendida como aquellos aspectos de la vida que se ven afectados directamente por el estado de salud, son cada vez más utilizados para evaluar procedimientos clínicos, intervenciones terapéuticas y calidad de cuidados suministrados. Debido a que la calidad de vida se basa en mediciones que poseen una carga variable de subjetividad, se requiere de métodos de evaluación válidos, reproductibles y confiables. ${ }^{79}$ El mejor conocimiento de las evaluaciones para medir calidad de vida permitirá incorporar estos instrumentos en la evaluación integral de individuos, en la conducción de ensayos clínicos y en la investigación de servicios de salud.

La importancia creciente que ha adquirido la medida de la CVRS en los últimos años refleja su bien establecida validez y el respaldo metodológico que tienen los instrumentos que la miden, así como el interés por conocer la forma en que el paciente percibe y reacciona a su enfermedad. ${ }^{80}$

La mayoría de los instrumentos para la medición de la CVRS son cuestionarios; estos cuestionarios recaban la información subjetiva proveniente del paciente, relativa a la valoración de diferentes áreas de la vida (dominios) y la expresan en forma cuantitativa a través de perfiles y puntajes agregados. Ya se ha mencionado que la calidad de vida es considerada un concepto multidimensional debido a que tiene en cuenta la valuación de múltiples aspectos relacionados con conductas o experiencias consideradas importantes para los propios individuos en los que se mide. A estos aspectos relevantes se los conoce como dominios o dimensiones. Los dominios considerados más importantes son los de función física, salud mental, función social y los de percepción global de la salud y calidad de vida. Los dominios están representados por ítems, correspondiendo cada uno a una forma particular de registrar una percepción del individuo; cada ítem constituye una expresión de un concepto latente, en general oculto o complejo. Los ítems suelen ser preguntas directas cuyas posibles respuestas se basan en escalas ordinales, aunque también pueden corresponder a la asignación de las opciones "verdadero/falso". Dentro de las características de los cuestionarios que influyen en su desarrollo y mejor aceptación, son la inclusión de frases y expresiones consideradas a partir de los propios pacientes y la determinación de que el propio paciente pueda completarlos (autoadministración). ${ }^{81}$ 
Los cuestionarios deben cumplir con una serie de propiedades que aseguren su validez y fiabilidad; a estas propiedades, por derivar de estudios en psicología, se las denomina psicométricas. Actualmente, además de la validez y de la fiabilidad, se debe incluir entre estas propiedades la sensibilidad al cambio.

La validez es la aproximación que se hace al valor real o verdadero de la característica que se quiere medir, o más sencillamente "medir lo que realmente se quiere medir"; una característica que debe tener una medición es la consistencia, es decir, los datos obtenidos tendrán calidad científica si durante el proceso de medición pueden ser consistentemente repetibles por el mismo observador u otros. Hay varias formas y conceptos de validez: la validez de criterio (se lleva a cabo cuando se tiene un índice estandarizado o "estándar de oro", contra el cual se compara un nuevo índice desarrollado) puede ejemplificarse como la correspondencia entre una versión abreviada de un cuestionario y su versión completa; la validez de contenido (que se refiere a la correcta representación de la noción que se desea medir mediante los ítems propuestos en el cuestionario) y la validez de constructo (que observa si existe relación entre las variables tomadas por el índice y lo que éste quiere evaluar). Así, se puede definir a la validez de constructo como el grado por el cual un cuestionario especifica los factores que inciden en la variabilidad del estado de salud que ese cuestionario desea medir. ${ }^{80,81}$

La fiabilidad es la propiedad que indica la constancia o estabilidad de los resultados cuando se repite la medición en circunstancias similares. Incluye dos aspectos diferentes no sustituibles: fiabilidad test-retest (reproducibilidad) y consistencia interna. ${ }^{74}$ Un instrumento será reproducible si evidencia puntuaciones similares en un paciente o grupo de pacientes, clínicamente estables, en dos oportunidades diferentes separadas por un período determinado.

La consistencia interna corresponde a la estabilidad en términos de coherencia, entre las puntuaciones de los diferentes ítems que componen cada dominio de un cuestionario; corresponde a una medida de homogeneidad y por lo tanto, si un grupo de ítems de un cuestionario mide un mismo concepto, las respuestas (puntuaciones) deberían ser similares entre sí.

La sensibilidad al cambio es una propiedad que señala la capacidad que tiene un instrumento de detectar a través de sus puntuaciones, modificaciones de las variables o del estado global de calidad de vida; conceptualmente puede definirse como el cociente entre una señal (cambio real ocurrido en el tiempo) y un ruido (variabilidad de las puntuaciones no asociadas a un cambio real). Esta propiedad está influida por dos situaciones que deberían ser cuantificadas en todos los estudios de calidad de vida, que son las limitaciones que tienen los 
pacientes con las mejores o peores puntuaciones posibles para reflejar cambios positivos o negativos respectivamente. La factibilidad de un instrumento implica la facilidad para poder administrarlo, es decir, si es aplicable o no; si un instrumento requiere un elevado nivel cultural para comprenderlo o demasiado tiempo para su contestación, no resulta factible. ${ }^{81}$

Existen dos tipos de instrumentos utilizados para medir la CVRS: específicos y genéricos.

Los instrumentos específicos son diseñados para evaluar a un grupo de población particular, a un problema de salud concreto o a una dimensión específica; están basados en las características especiales de un determinado padecimiento, siendo útiles para evaluar cambios físicos y efectos de tratamiento a través del tiempo, dando mayor capacidad de discriminación y predicción y siendo particularmente útiles para ensayos clínicos. Su mayor desventaja radica en que no permiten comparaciones entre diferentes enfermedades $\mathrm{y}$, por lo tanto, no son útiles para conocer la eficacia relativa de diferentes tratamientos. Entre estos instrumentos específicos se encuentran, entre otros, las escalas de incapacidad funcional (Índice de Katz, Barthel o Lawton-Brody), las escalas de dolor (Cuestionario del Dolor en Español, Escala de Incapacidad por Dolor Lumbar de Oswestry), cuestionarios específicos para patologías crónicas (Cuestionario Respiratorio Saint George, Cuestionario de Calidad de Vida para la Enfermedad de Parkinson, Cuestionario de Calidad de Vida en Hipertensión Arterial, Cuestionario de la Enfermedad Renal) o medidores de salud socio familiar (Entrevista Manheim de Apoyo Social). ${ }^{80}$

Los instrumentos genéricos son aquellos que cubren un espectro amplio de la calidad de vida, son independientes del diagnóstico clínico del paciente y permiten su aplicación en diferentes tipos de población, con distintas patologías y presentan la ventaja de que permiten comparar el impacto de diferentes enfermedades sobre la CVRS. ${ }^{82}$ Entre ellos se han validado el Sickness Impact Profile (Perfil de las Consecuencias de la Enfermedad), el Nottingham Health Profile (Perfil de Salud de Nottingham), el Euro Qol-5D (Cuestionario Europeo de calidad de vida de 5 dimensiones), el cuestionario de calidad de vida infantil y el 36 - Item Medical Outcomes Study Short - Form General Health Survey (Cuestionario de los Resultados Médicos Abreviado SF-36), entre otros. ${ }^{67}$ Alonso, Prieto, García Ordoñez y otros autores han llevado a cabo una exhaustiva revisión de las características de los instrumentos mencionados, poniendo especial énfasis en las propiedades psicométricas de validez, fiabilidad y sensibilidad al cambio. De los instrumentos revisados por estos autores, las 
medidas genéricas muestran mejor desarrollo psicométrico que los instrumentos específicos y el resto de las medidas de salud. ${ }^{71,83}$

Entre los diferentes tipos de instrumentos genéricos, uno de los que mejores propiedades psicométricas presenta es el denominado Medical Outcome Study (Estudio de los Resultados Médicos) de Tarlov, Ware y Greenfield, estudio sistemático realizado a lo largo de 4 años que analizó los efectos de la terapéutica médica sobre la salud. ${ }^{84}$ El mayor logro de los investigadores ha sido la obtención de un conjunto de medidas que pueden ser utilizadas en diferentes poblaciones con patologías o libres de ellas. Originalmente fue construido con cinco dimensiones: estado clínico, funcionamiento físico y bienestar, funcionamiento mental, funcionamiento social y percepción y satisfacción por la salud general. ${ }^{84}$ La versión más completa es el Medical Outcome Study Functioning and Well Beeing Profile, del cual derivan todas las demás versiones existentes. Entre ellas, la que ha merecido una especial atención es el cuestionario de salud "36 - Item Medical Outcomes Study Short - Form General Health Survey” (MOS SF-36), desarrollado con 8 dimensiones y un total de 36 ítems. $^{71,83,85-87}$

El cuestionario de salud de forma abreviada de 36 ítems o SF-36, fue desarrollado a principios de la década de 1990 en Estados Unidos para su uso en el Estudio de los Resultados Médicos (Medical Outocomes Study, MOS), A partir de una extensa batería de cuestionarios que incluían cuarenta conceptos relacionados con la salud. Es una escala genérica que proporciona un perfil del estado de salud y es aplicable tanto a los pacientes como a la población general, por lo que ha sido útil para evaluar la CVRS en la población general y en subgrupos específicos, compara la carga de muy diversas enfermedades, detectar los beneficios en la salud producidos por diferentes tratamientos y valorar el estado de salud de pacientes individuales. ${ }^{86}$

Cada vez son más utilizados los instrumentos que miden la CVRS en la atención integral de los pacientes infectados por VIH, ya que detectan cambios en aspectos de la salud que los resultados clínicos tradicionales no reflejan. ${ }^{87-89}$ La infección por el VIH y su progresión a SIDA origina un deterioro de las funciones físicas, psíquicas y sociales de los pacientes que determina un descenso en la sensación de bienestar. A pesar del considerable esfuerzo realizado en los últimos años para mejorar el tratamiento de esta patología, todavía hay un conocimiento limitado del efecto de las terapias antiretrovirales y de la progresión de la enfermedad sobre la calidad de vida en las personas que viven con VIH/SIDA. ${ }^{71,85,89}$ 
La infección por VIH/SIDA cada vez será una enfermedad crónica manejable en mayor medida y será imprescindible detectar disfunciones socio familiares e intervenir potenciando todos los recursos que puedan elevar la calidad de vida de estos pacientes. ${ }^{68}$

Los primeros estudios aplicados de calidad de vida en personas que viven con VIH/SIDA se realizaron como parte de los ensayos clínicos ACTG 014 y ACTG 016 que evaluaron la eficacia y la seguridad de la zidovudina versus placebo; aún cuando se trataron de estudios realizados en muestras reducidas de pacientes, la información derivada de los mismos permitió complementar y mejorar la interpretación de los resultados de eficacia en todos los casos. ${ }^{90,91}$ Los tratamientos más eficaces demuestran también un impacto global sobre la calidad de vida de los pacientes, aunque muchas veces no existen mejorías en todas las áreas evaluadas, ni siquiera en la mayoría de ellas. Sin embargo, a pesar de las deficiencias de muchos de los instrumentos utilizados, la percepción general de la necesidad de evaluar consecuencias más globales de los tratamientos sobre la vida cotidiana de los pacientes ha conducido a que en la actualidad la medición de la CVRS se incluya dentro de los objetivos de la mayoría de los ensayos clínicos de las personas que viven con VIH/SIDA, como método útil y confiable para evaluar el impacto general de la enfermedad.

\section{Objetivos}

En la actualidad no se dispone de datos ni estudios sobre la CVRS en personas con VIH/SIDA que viven en la Argentina. Por lo tanto, son objetivos del presente estudio:

\section{A. Objetivos generales}

1. Evaluar la calidad de vida relacionada con la salud en personas que viven con VIH/SIDA.

2. Relacionar la calidad de vida de las personas que viven con VIH/SIDA con variables sociológicas, clínicas e inmunológicas.

B. Objetivos específicos

1. Caracterizar el perfil socioepidemiológico de la población que vive con VIH/SIDA.

2. Identificar las adicciones que se presentan en dicha población.

3. Especificar las comorbilidades asociadas a la infección por VIH/SIDA.

4. Conocer el grado de inmunosupresión determinado por el recuento de linfocitos T CD4 y de la carga viral plasmática en la población que presenta infección por VIH/SIDA.

5. Conocer el tipo, ocurrencia y distribución de enfermedades marcadoras de SIDA que presentan los pacientes durante la evolución de su enfermedad.

6. Conocer la prevalencia de hospitalización en la población de pacientes. 
7. Conocer los aspectos más relevantes del tratamiento antiretroviral de gran actividad que realizan los pacientes con infección por VIH/SIDA

8. Establecer la relación entre variables sociológicas, clínicas e inmunológicas y la puntuación obtenida en las dimensiones que integran el cuestionario de salud SF-36. 


\section{MATERIAL Y MÉTODOS}

El estudio se realizó en la Unidad de Infectología del Hospital Zonal General de Agudos (HZGA) "Mi Pueblo" de Florencio Varela, provincia de Buenos Aires. Los datos fueron recolectados durante el período comprendido entre el $1^{\circ}$ de agosto de 2005 al 20 de junio de 2007. Se aplicó un diseño no experimental, observacional-correlacional, de corte transversal y retrospectivo.

\section{Participantes}

Se trabajó con un universo de 114 individuos, todos ellos pacientes de la Unidad de Infectología del HZGA “Mi Pueblo”. La selección de los participantes se realizó según los siguientes criterios de inclusión: mayores de 15 años, de ambos sexos, con infección por VIH documentada y residentes en el partido de Florencio Varela. Fueron criterios de exclusión: no querer participar del estudio y tener alguna imposibilidad psíquica o cognitiva para entender y responder preguntas. Se consideraron como criterios de eliminación los cuestionarios con más de una respuesta marcada.

\section{Variables en estudio}

La variable en estudio para el primer objetivo general es la calidad de vida relacionada con la salud. Se la define como la valoración subjetiva que hacen las personas de su propia sensación de confort o bienestar en relación con su estado de salud; la medida en que son capaces de mantener una función física, emocional e intelectual razonable y el grado en que pueden participar en actividades que consideren importantes en el contexto de su familia, lugar de trabajo y en la comunidad. Tiene como instrumento el Cuestionario de Salud SF-36. ${ }^{92}$

Las variables estudiadas para el segundo objetivo general son variables sociológicas, clínicas e inmunológicas.

Se define como variables sociológicas a la caracterización social y epidemiológica de la población estudiada, siendo su indicador la presencia o ausencia de dichas características.

Las variables clínicas son los eventos clínicos que pueden presentarse en los pacientes con infección por VIH/SIDA; las variables clínicas comprenden la presencia de adicciones, comorbilidades, enfermedad marcadora de SIDA, hospitalización y tratamiento antiretroviral 
de gran actividad. Son indicadores las pruebas de laboratorio específicas y el examen clínico de los pacientes. ${ }^{93}$

Las variables inmunológicas se definen como los eventos inmunológicos y virológicos que pueden presentarse en los pacientes con infección por VIH/SIDA; comprenden el recuento en sangre periférica de linfocitos $\mathrm{T}$ CD4+ y la carga viral plasmática o número de copias de RNAVIH/mL. Los indicadores de estas variables se basan en la medición por citometría de flujo y métodos cuantitativos de diagnóstico molecular. ${ }^{94}$

Las variables estudiadas para los objetivos específicos son:

- Perfil socioepidemiológico, que comprende:

- $\quad$ dad

- Género

- $\quad$ Nivel de instrucción ${ }^{95}$

- $\quad$ Empleo ${ }^{96}$

- $\quad$ Planes sociales ${ }^{97}$

- Obra Social $^{98}$

- Los años de diagnóstico de la infección por VIH

- Las vías de transmisión de la infección por VIH: transmisión sexual, drogadicción intravenosa, drogadicción por otras vías, o combinaciones de éstas. ${ }^{99}$

- Causas del diagnóstico de la infección por VIH: comprenden la presentación de enfermedad marcadora de SIDA, diagnóstico de infección por VIH en la pareja sexual, embarazo, conductas de riesgo en el paciente, diagnóstico de infección por VIH en el hijo, donación de sangre y conductas de riesgo en la pareja sexual del paciente. ${ }^{94,100}$

- Pareja actual: pareja con infección por VIH/SIDA

- Conducta de riesgo en la pareja del paciente relacionada con la transmisión del VIH: promiscuidad sexual, drogadicción intravenosa y/o por otras vías, etilismo, varias conductas asociadas o ninguna de ellas. ${ }^{94,101}$

- Adicciones, que comprenden:

- Adicción a drogas ${ }^{102,103}$

- Adicción al alcohol (alcoholismo o etilismo) 101, 104, 105 
- $\quad$ Tabaquismo ${ }^{106,107}$

- Comorbilidades ${ }^{108}$, que incluyen:

- Hepatopatopatía alcohólica ${ }^{109}$

- Hepatitis $C$, hepatitis $B$, hepatitis $C+B^{110}$

- Infecciones de transmisión sexual: sifilis, gonorrea, enfermedad pélvica inflamatoria, herpes genital ${ }^{111}$

- $\quad$ Trastorno mixto ansioso-depresivo ${ }^{112}$

- Desnutrición grave ${ }^{113}$

- Enfermedad cardiovascular / hipertensión arterial ${ }^{114}$

- Diabetes ${ }^{115}$

- Cáncer ${ }^{116}$

- $\quad$ Lipodistrofia ${ }^{117-119}$

- Número de LT CD4+ y carga viral plasmática ${ }^{94}$

- Presencia de enfermedad marcadora de SIDA: neumonía por Pneumocystis jiroveci, toxoplasmosis del sistema nervioso central, criptosporidiosis, candidiasis esofágica, criptococosis meníngea, histoplasmosis, tuberculosis pulmonar y extrapulmonar, infección por virus Herpes simple, sarcoma de Kaposi, encefalopatía por VIH/demencia, sindrome de adelgazamiento por VIH (wasting), carcinoma cervical invasivo 94

- Hospitalización ${ }^{120}$

- Tratamiento antiretroviral de gran actividad (TARGA). El grupo de drogas utilizadas fueron los inhibidores nucleósidos de la transcriptasa reversa (INTR): zidovudina, didanosina, zalcitabina, lamivudina, stavudina, abacavir y tenofovir; inhibidores no nucleósidos de la transcriptasa reversa (INNTR): nevirapina y efavirenz; inhibidores de la proteasa (IP): indinavir, nelfinavir, ritonavir, lopinavir/ritonavir, atazanavir y fosamprenavir (Cuadro 1). Las diferentes combinaciones de drogas administradas a los pacientes fueron la asociación entre 2 INNTR +1 INNTR, 3 INTR, 2 INTR +1 IP, 2 INTR + 2 IP (Cuadro 2). 
Cuadro 1: Clasificación de las drogas utilizadas en el tratamiento antiretroviral de gran actividad administrado a los pacientes con infección por VIH/SIDA de la Unidad de Infectología. Hospital Zonal General de Agudos "Mi Pueblo". Florencio Varela, provincia de Buenos Aires. Argentina. Año 2006.

\begin{tabular}{|ll|}
\hline Inhibidores nucleósidos de la transcriptasa & zidovudina \\
reversa (INTR) & didanosina \\
& zalcitabina \\
& lamivudina \\
& stavudina \\
& abacavir \\
& tenofovir \\
Inhibidores no nucleósidos de la transcriptasa reversa & nevirapina \\
(INNTR) & efavirenz \\
& indinavir \\
Inhibidores de la proteasa (IP) & nelfinavir \\
& ritonavir \\
& lopinavir/ritonavir \\
& atazanavir \\
& fosamprenavir \\
\hline
\end{tabular}

Cuadro 2: Combinaciones del tratamiento antiretroviral de gran actividad administrado a los pacientes con infección por VIH/SIDA de la Unidad de Infectología. Hospital Zonal General de Agudos "Mi Pueblo". Florencio Varela, provincia de Buenos Aires. Argentina. Año 2006.

Combinaciones del TARGA
$2 \mathrm{INTR}^{*}+1 \mathrm{INNTR} * *$
$3 \mathrm{INTR}$
$2 \mathrm{INTR}+1 \mathrm{IP} * * *$
$2 \mathrm{INTR}+2 \mathrm{IP}$
$*$ Inhibidores nucleósidos de la transcriptasa reversa
** Inhibidores no nucleósidos de la transcriptasa reversa
*** Inhibidores de la proteasa

La operacionalización de las variables estudiadas se describe en el Anexo 1. 


\section{Instrumento}

El cuestionario de salud SF-36 está compuesto por 36 preguntas que valoran los estados tanto positivos como negativos de la salud. Para crear el cuestionario se seleccionó el mínimo número de conceptos necesarios para mantener la validez y las características operativas del cuestionario inicial. ${ }^{121,122}$ El cuestionario final es un instrumento genérico que contiene 36 ítems que conforman 8 dimensiones del estado de salud y proporcionan un perfil del mismo. ${ }^{123}$ Las 8 dimensiones evalúan: función física, rol físico, dolor corporal, salud general, vitalidad, función social, rol emocional y salud mental. (Cuadro 3). ${ }^{124}$

Las 8 dimensiones del cuestionario determinan los siguientes aspectos relacionados con la salud: ${ }^{122}$

- Función física: es el grado en que la salud limita las actividades físicas de la vida diaria, como el cuidado personal, caminar, subir escaleras, inclinarse, levantar o cargar peso y realizar esfuerzos moderados o intensos (10 ítems).

- Rol físico: es el grado en que la salud física interfiere en el trabajo y otras actividades diarias, produciendo como consecuencia un rendimiento menor del deseado o limitando el tipo de actividades realizadas o la dificultad en la realización de las mismas (4 ítems).

- Dolor corporal: es la medida de la intensidad del dolor padecido y su efecto en el trabajo habitual y en las actividades del hogar (2 ítems).

- Salud general: es la valoración personal del estado de salud, que incluye la salud actual, las perspectivas de salud en el futuro y la resistencia a enfermar (5 ítems).

- Vitalidad: sentimiento de energía y vitalidad frente al sentimiento de cansancio y agotamiento (4 ítems).

- Función social: grado en que los problemas de salud física o emocional interfieren en la vida social habitual (2 ítems).

- Rol emocional: grado en que los problemas emocionales afectan al trabajo y otras actividades diarias, considerando la reducción del tiempo dedicado, disminución del rendimiento y del esmero en el trabajo ( 3 ítems).

- Salud mental: valoración de la salud mental general, considerando la depresión, ansiedad, control de la conducta y bienestar general (5 ítems).

Los ítems y las dimensiones del cuestionario proporcionan puntuaciones que son directamente proporcionales al estado de salud; estas puntuaciones se transforman en una 
escala que tiene un recorrido desde cero (el peor estado de salud para esa dimensión) hasta cien (el mejor estado de salud). El cuestionario no ha sido diseñado para generar un índice global. ${ }^{125}$

En el cuadro 3 se describe el contenido de las escalas del cuestionario de salud SF-36.

Cuadro 3: Contenido de las escalas del cuestionario de salud SF-36.

Significado de las puntuaciones de 0 a 100

Dimensión $\quad \mathrm{N}^{\mathrm{o}}$ de ítems “Peor" puntuación (0) “Mejor" puntuación (100)

\begin{tabular}{|c|c|c|c|}
\hline $\begin{array}{l}\text { Función } \\
\text { física }\end{array}$ & 10 & $\begin{array}{l}\text { Muy limitado para llevar a cabo } \\
\text { todas las actividades físicas, } \\
\text { incluido bañarse, debido a la salud. }\end{array}$ & $\begin{array}{l}\text { Lleva a cabo todo tipo de actividades } \\
\text { sin ninguna limitación debido a la } \\
\text { salud. }\end{array}$ \\
\hline Rol físico & 4 & $\begin{array}{l}\text { Problemas con el trabajo y en } \\
\text { otras actividades diarias debido a } \\
\text { la salud física. }\end{array}$ & $\begin{array}{l}\text { Ningún problema con el trabajo u } \\
\text { otras actividades diarias debido a la } \\
\text { salud física. }\end{array}$ \\
\hline $\begin{array}{l}\text { Dolor } \\
\text { corporal }\end{array}$ & 2 & $\begin{array}{l}\text { Dolor de mucha intensidad y } \\
\text { extremadamente limitante. }\end{array}$ & $\begin{array}{l}\text { Ningún dolor ni limitaciones debidas } \\
\text { a él. }\end{array}$ \\
\hline $\begin{array}{l}\text { Salud } \\
\text { general }\end{array}$ & 5 & $\begin{array}{l}\text { Evalúa como mala a su propia } \\
\text { salud y cree posible que empeore. }\end{array}$ & $\begin{array}{l}\text { Evalúa a su propia salud como } \\
\text { excelente. }\end{array}$ \\
\hline Vitalidad & 4 & $\begin{array}{l}\text { Se siente cansado y exhausto todo } \\
\text { el tiempo. }\end{array}$ & $\begin{array}{l}\text { Se siente muy dinámico y lleno de } \\
\text { energía todo el tiempo. }\end{array}$ \\
\hline $\begin{array}{l}\text { Función } \\
\text { social }\end{array}$ & 2 & $\begin{array}{l}\text { Interferencia extrema y muy } \\
\text { frecuente con las actividades } \\
\text { sociales normales debido a } \\
\text { problemas físicos y emocionales. }\end{array}$ & $\begin{array}{l}\text { Lleva a cabo actividades sociales } \\
\text { normales sin ninguna interferencia } \\
\text { debido a problemas físicos o } \\
\text { emocionales. }\end{array}$ \\
\hline $\begin{array}{l}\text { Rol } \\
\text { emocional }\end{array}$ & 3 & $\begin{array}{l}\text { Problemas con el trabajo y otras } \\
\text { actividades diarias debido a } \\
\text { problemas emocionales. }\end{array}$ & $\begin{array}{l}\text { Ningún problema con el trabajo y } \\
\text { otras actividades diarias debido a } \\
\text { problemas emocionales. }\end{array}$ \\
\hline $\begin{array}{l}\text { Salud } \\
\text { mental }\end{array}$ & 5 & $\begin{array}{l}\text { Sentimientos de angustia y } \\
\text { depresión todo el tiempo. }\end{array}$ & $\begin{array}{l}\text { Sentimientos de felicidad y calma } \\
\text { durante todo el tiempo. }\end{array}$ \\
\hline
\end{tabular}

Para el cálculo de las puntuaciones, después de la administración del cuestionario, se realizaron los siguientes pasos: 
$\left.1^{\circ}\right)$ Homogenización de las respuestas mediante la recodificación de los 10 ítems que lo requieren, con el fin de que todos los ítems sigan el gradiente de "a mayor puntuación, mejor estado de salud".

$2^{\circ}$ ) Cálculo de la sumatoria de los ítems que componen la escala (puntuación cruda de la escala).

$3^{\circ}$ ) Transformación lineal de las puntuaciones crudas para obtener puntuaciones en una escala entre 0 y 100 (puntuaciones transformadas de al escala).

Así, para cada dimensión, los ítems son codificados, agregados y transformados en una escala que va del 0 al 100. En caso de que falte información, si se han contestado al menos el $50 \%$ de los ítems de una escala, se recomienda sustituir cualquier ítem ausente por el promedio de los ítems completados de ésta. Si más del $50 \%$ de los ítems no fueron contestados, no se debe calcular la puntuación de dicha escala.

Los estudios de análisis factorial realizados en diferentes muestras de distintos países de Europa y Estados Unidos demostraron que las 8 escalas definen dos componentes principales de salud, la componente sumario física (CSF) y la componente sumario mental (CSM). Los pasos principales de los algoritmos de cálculo de las puntuaciones de las dos medidas sumario son; a) estandarización de las 8 escalas del cuestionario SF-36 con la media (x) y la desviación estándar (DE) de la población general; b) ponderación de las escalas aplicando los pasos factoriales obtenidos en un análisis de componentes principales y c) agregación de las escalas y transformación para obtener una media de 50 y un DE de 10 en la población general. $^{126}$

Las puntuaciones de 0 a 100 de las escalas del SF-36 gozan de popularidad por la traducción directa de su máximo y su mínimo al mejor o peor de los estados de salud posibles. Sin embargo, los resultados de las puntuaciones deben interpretarse respecto a la población general del propio país. ${ }^{121}$ En la población general española estos valores son: función física 94,4 (DE 12,8), limitación del rol: problemas físicos 91,1 (DE 25,7), dolor corporal 82,3 (DE 24,8), percepción de la salud general 80 (DE 18,8), vitalidad 69,9 (DE 18,4), función social 96 (DE 14,1), limitación del rol: problemas emocionales 90,1 (DE 26), salud mental 77,7 (DE $17,3)$.

La versión española del cuestionario SF-36 es un instrumento adecuado para su uso en investigación y en la práctica clínica (Ver Anexo 2). Posee una consistencia interna estudiada por el coeficiente $\alpha$ de Cronbach de 0,8 para todas las funciones, menos para la función social 
que es de 0,76. La estabilidad, medida por test-retest con dos semanas de diferencia es de 0,8 para la función física, vitalidad, percepción general de la salud y 0,6 para la función social. ${ }^{125}$

La traducción del cuestionario SF-36 al castellano se basó en el método de traducción y retrotraducción por profesionales, para asegurar la equivalencia conceptual al adoptar un

cuestionario desarrollado en una cultura diferente. ${ }^{125,127}$ En materia de traducción y adaptación transcultural de los instrumentos de medición de la calidad de vida, se recomienda actualmente realizar una validación transcultural de los cuestionarios ya existentes - en lugar de generar escalas originales para cada cultura en particular-, utilizando una metodología clara y precisa. ${ }^{128}$

Este es un cuestionario diseñado para ser autoadministrado, mediante una entrevista por vía telefónica o mediante soporte informático. ${ }^{121}$

En nuestro estudio, la versión española 1.4 de junio de 1999 del cuestionario de salud SF-36, se adaptó al entendimiento de las unidades de observación (individuos) en los siguientes ítems (Ver Anexo 3):

- en el ítem 4: "Su salud actual, ¿le limita para hacer esfuerzos moderados, como mover una mesa, pasar la aspiradora, jugar a los bolos o caminar más de una hora?” se cambió “jugar a los bolos" por "cavar un pozo".

- en el ítem 5: "Su salud actual, ¿le limita para coger o llevar la bolsa de la compra?” se reemplazó "coger" por "levantar".

- en el ítem 9: “Su salud actual, ¿le limita para caminar un kilómetro o más?” se sustituyó “un kilómetro" por "10 cuadras".

- en el ítem 10: "Su salud actual, ¿le limita para caminar varias manzanas (varios centenares de metros)?" se cambió "varias manzanas" por "varias cuadras".

- en el ítem 11: "Su salud actual, ¿le limita para caminar una sola manzana (unos 100 metros)?" se modificó "manzana" por "cuadra".

- en el ítem 25: "Durante las 4 últimas semanas ¿cuánto tiempo se sintió tan bajo de moral que nada podía animarle?" se cambió "bajo de moral" por "deprimido".

\section{Procedimiento}

El paciente asistía al consultorio de Infectología para realizar su visita médica de rutina. Cuando ingresaba al espacio físico del consultorio se le explicaba que se estaba 
realizando un estudio cuyo objetivo era medir la calidad de vida relacionada con la salud que tienen las personas que viven con VIH/SIDA, mediante la realización de una encuesta personalizada y auto administrada, invitándole a participar voluntariamente en el estudio. Si el paciente aceptaba, se lo hacía pasar a un cuarto contiguo al consultorio, donde tomaba asiento y se le daba un impreso de la encuesta y una lapicera. Al otorgársele el cuestionario se le explicaba que las preguntas se referían a lo que pensaba sobre su salud; se le aclaraba que sus respuestas permitirían recabar información acerca de cómo se encontraba y hasta qué punto era capaz de hacer sus actividades habituales. Además, se le explicaba que debían contestar cada pregunta tal como se indicaba en la encuesta y, si no estaba seguro de cómo responder a una pregunta, que contestara lo que le parecía más cierto. Se le indicaba además que podía disponer del tiempo que quisiera para responder la encuesta. El paciente permanecía solo durante el lapso de tiempo en que realizaba la encuesta. La respuesta al cuestionario exigió en nuestra población un promedio de 20 minutos.

Se recolectó información adicional relacionada con su enfermedad mediante la historia clínica del paciente, con el objetivo de describir el perfil clínico y socio-epidemiológico de la población estudiada.

\section{Métodos estadísticos aplicados}

Para la recolección, carga y edición de los datos obtenidos se confeccionó una base de datos utilizando el programa SPSS $11.5{ }^{\circledR}$ para Windows $2003^{\circledR}$. Las técnicas estadísticas utilizadas para analizar los datos correspondientes al primer objetivo son descriptivas, con la utilización de escalas nominales y medidas de resumen. La verificación de relación entre las variables especificadas en el segundo objetivo, se realizó con la utilización de los coeficientes $r$ de Pearson y de Spearman.

\section{Consideraciones éticas}

Para la realización del estudio en el marco hospitalario se obtuvo el aval y la autorización de la Dirección Ejecutiva del Hospital, ante la ausencia de un Comité de Ética en la Institución. Se consideraron los principios éticos para las investigaciones médicas en seres humanos, dispuestas por la "Declaración de Helsinki de la $18^{\circ}$ Asamblea de la Asociación Médica Mundial, de junio de 1964, por consentimiento verbal, como modo de participación en el estudio. ${ }^{129}$ Se resguardó la confidencialidad de cada persona que participó en el estudio, 
según lo establece la ley 23.798 de lucha contra el SIDA, que establece en su artículo $2^{\text {do }}$ la confidencialidad en la relación médico-paciente, es decir, la obligación de guardar el secreto y mantener en reserva todo lo concerniente a la enfermedad, especificando que en ningún caso se podrá exceder el marco de las excepciones legales taxativas al secreto médico e individualizar a las personas. ${ }^{130}$ 


\section{RESULTADOS}

\section{Análisis exploratorio: caracterización de los individuos evaluados}

La población $(\mathrm{n}=114)$ tenía una edad representativa de $36 \pm 9$ años, con una mayor frecuencia en los 33 años, una máxima de 65 y una mínima de 16 años. El coeficiente de Fisher $(\mathrm{g} 1=0,70)$, manifestó una asimetría positiva con una mayor concentración de valores a la derecha de la media. ${ }^{131}$ Estaban representados en un $56 \%(n=64)$ por el género femenino y en un $44 \%(n=50)$ por el masculino (Tabla 3$)$.

Tabla 3: Distribución de pacientes de la Unidad de Infectología, según edad y género. Hospital Zonal General de Agudos "Mi Pueblo". Florencio Varela, provincia de Buenos Aires. Argentina. Agosto 2005 - junio 2007.

\begin{tabular}{|c|c|c|c|c|}
\hline \multirow{2}{*}{ Edad $^{*}$} & \multicolumn{4}{|c|}{ Frecuencia } \\
\cline { 2 - 5 } & \multicolumn{2}{|c|}{ Masculino } & \multicolumn{2}{c|}{ Femenino } \\
\cline { 2 - 5 } & $\mathrm{n}$ & $\%$ & $\mathrm{n}$ & $\%$ \\
\hline $16-24$ & 4 & 8 & 4 & 6 \\
$25-32$ & 12 & 24 & 24 & 38 \\
$33-41$ & 21 & 42 & 25 & 39 \\
$42-50$ & 12 & 24 & 5 & 8 \\
$51-58$ & 1 & 2 & 4 & 6 \\
$59-67$ & 0 & 0 & 2 & 3 \\
\hline Total & 50 & 100 & 64 & 100 \\
\hline
\end{tabular}

* Regla de Sturges: para cálculo de intervalos de clase. Daniel $W^{132}$

El 84,2 \% de los pacientes tenía un nivel de instrucción aceptable, consistente en escolaridad primaria completa o mayor. Un 2,6 \% eran analfabetos y un porcentaje similar $(2,7 \%)$ poseía estudios universitarios. En la figura 28 se grafica el nivel de instrucción de nuestra población de pacientes.

El 59,3 \% de la población no poseía empleo, ni plan social en el 69,3\%. El 81,6 \% de los pacientes no tenía obra social.

El promedio de los años de diagnóstico de la infección por VIH en los pacientes era de $5 \pm 4$ años, con una mayor frecuencia en aquellos que estaban diagnosticados desde hace un año. El $50 \%$ de los pacientes presentaban, 4 años de evolución de la enfermedad desde su diagnóstico (Tabla 4). 


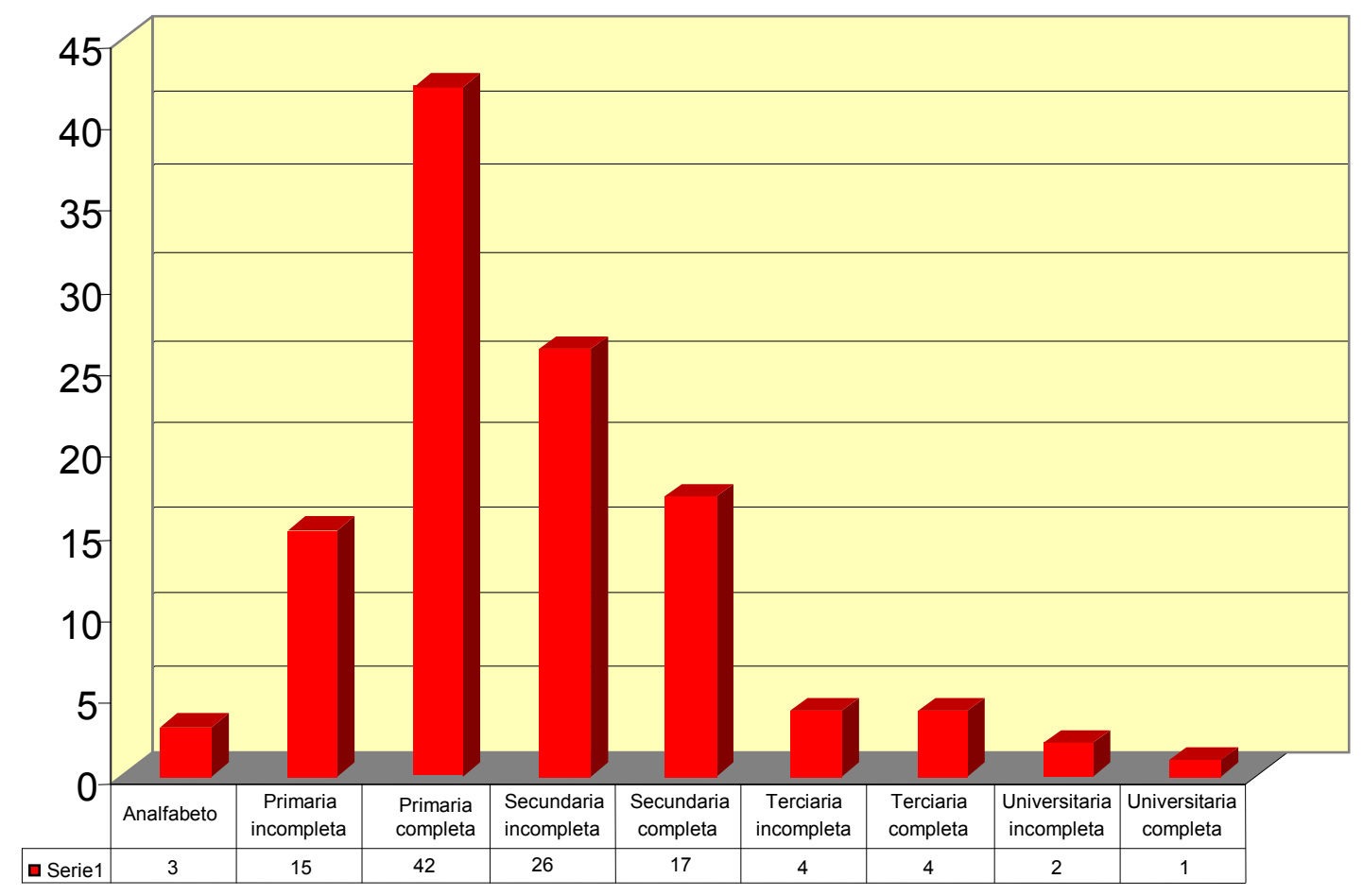

Figura 28: Nivel de instrucción en pacientes de la Unidad de Infectología. Hospital Zonal General de Agudos "Mi Pueblo". Florencio Varela, provincia de Buenos Aires, Argentina. Agosto 2005 junio 2007.

Tabla 4: Distribución de pacientes de la Unidad de Infectología, según años de diagnóstico de la infección por VIH. Hospital Zonal General de Agudos "M Pueblo". Florencio Varela, provincia de Buenos Aires, Argentina. Agosto 2005 - junio 2007.

\begin{tabular}{|c|c|c|}
\hline $\begin{array}{c}\text { Años de diagnóstico de la } \\
\text { infección por VIH }\end{array}$ & \multicolumn{2}{c|}{ Frecuencia } \\
\hline 1 & 25 & 21,9 \\
2 & 19 & 16,7 \\
3 & 9 & 7,9 \\
4 & 9 & 7,9 \\
5 & 6 & 5,3 \\
6 & 9 & 7,9 \\
7 & 6 & 5,3 \\
8 & 8 & 7,0 \\
9 & 3 & 2,6 \\
$>10$ & 20 & 17,5 \\
\hline Total & 114 \\
\hline
\end{tabular}

La distribución de los pacientes, según los años transcurridos desde el diagnóstico de la infección por VIH se grafica en la figura 29. 


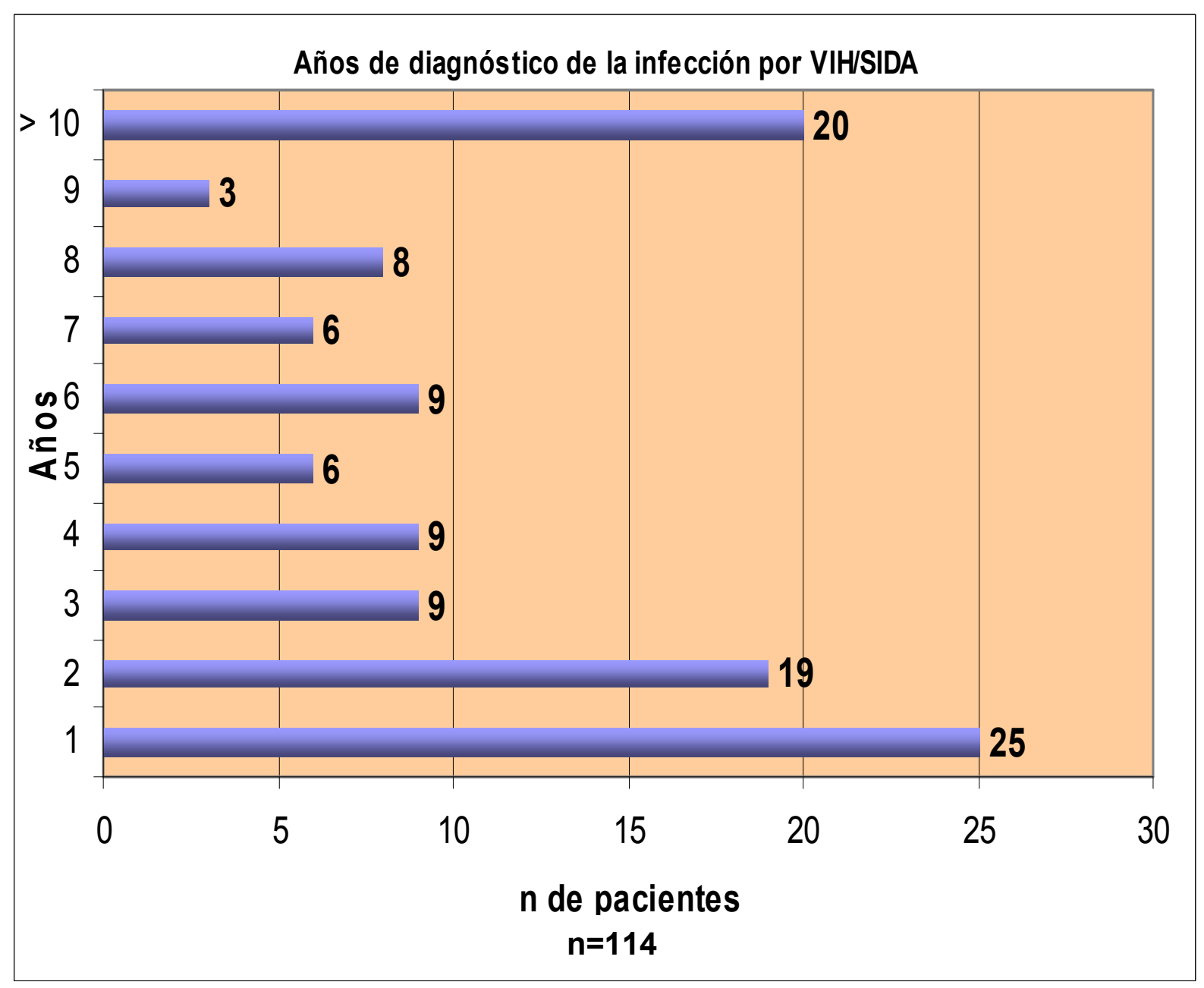

Figura 29: Distribución de pacientes de la Unidad de Infectología, según años de diagnóstico de la infección por VIH. Hospital Zonal General de Agudos "Mi Pueblo". Florencio Varela, provincia de Buenos Aires, Argentina. Agosto 2005 - junio 2007.

El análisis de los años de diagnóstico de la infección por VIH, de acuerdo con la edad y el género, enunció en los rangos etarios de mayor concentración de casos (25 a 41 años), menores años de antigüedad en los diagnósticos en el género femenino (Tabla 5).

Las diferencias manifiestas en las proporciones no fueron estadísticamente significativas $(\mathrm{p}>0,05) .{ }^{132}$ 

Tabla 5: Distribución de pacientes de la Unidad de Infectología según edad, género y años de diagnóstico. Hospital Zonal General de Agudos "Mi Pueblo". Florencio Varela, provincia de Buenos Aires, Argentina. Agosto 2005 - junio 2007.

\begin{tabular}{|c|c|c|c|c|c|c|c|c|c|c|c|c|c|c|c|c|c|c|c|c|c|c|c|c|c|c|}
\hline \multirow{4}{*}{$\begin{array}{c}\text { Años de } \\
\text { diagnóstico }\end{array}$} & \multicolumn{24}{|c|}{ Edad } & \multirow{3}{*}{\multicolumn{2}{|c|}{ Total }} \\
\hline & \multicolumn{4}{|c|}{$16-24$} & \multicolumn{4}{|c|}{$25-32$} & \multicolumn{4}{|c|}{$33-41$} & \multicolumn{4}{|c|}{$42-50$} & \multicolumn{4}{|c|}{$51-58$} & \multicolumn{4}{|c|}{$59-67$} & & \\
\hline & \multicolumn{2}{|c|}{ Femenino } & \multicolumn{2}{|c|}{ Masculino } & \multicolumn{2}{|c|}{ Femenino } & \multicolumn{2}{|c|}{ Masculino } & \multicolumn{2}{|c|}{ Femenino } & \multicolumn{2}{|c|}{ Masculino } & \multicolumn{2}{|c|}{ Femenino } & \multicolumn{2}{|c|}{ Masculino } & \multicolumn{2}{|c|}{ Femenino } & \multicolumn{2}{|c|}{ Masculino } & \multicolumn{2}{|c|}{ Femenino } & \multicolumn{2}{|c|}{ Masculino } & & \\
\hline & $\mathrm{n}$ & $\%$ & $\mathrm{n}$ & $\%$ & $\mathrm{n}$ & $\%$ & $\mathrm{n}$ & $\%$ & $\mathrm{n}$ & $\%$ & $\mathrm{n}$ & $\%$ & $\mathrm{n}$ & $\%$ & $\mathrm{n}$ & $\%$ & $\mathrm{n}$ & $\%$ & $\mathrm{n}$ & $\%$ & $\mathrm{n}$ & $\%$ & $\mathrm{n}$ & $\%$ & $\mathrm{n}$ & $\%$ \\
\hline 1 & 3 & 50 & 1 & 25 & 5 & 19 & 4 & 31 & 3 & 14 & 8 & 40 & & & 1 & 8 & & & & & & & & & 25 & 22 \\
\hline 2 & 1 & 17 & 3 & 75 & 6 & 23 & 1 & 8 & 3 & 14 & 1 & 5 & & & 2 & 17 & & & & & 2 & 100 & & & 19 & 17 \\
\hline 3 & & & & & 1 & 4 & & & 3 & 14 & 2 & 10 & & & 1 & 8 & 1 & 33 & 1 & 100 & & & & & 9 & 8 \\
\hline 4 & & & & & 2 & 8 & 2 & 15 & 3 & 14 & 1 & 5 & & & & & 1 & 33 & & & & & & & 9 & 8 \\
\hline 5 & & & & & 3 & 12 & & & & & 1 & 5 & & & 1 & 8 & 1 & 33 & & & & & & & 6 & 5 \\
\hline 6 & 2 & 33 & & & 4 & 15 & 1 & 8 & 1 & 5 & & & 1 & 20 & & & & & & & & & & & 9 & 8 \\
\hline 7 & & & & & & & & & 3 & 14 & & & 1 & 20 & 2 & 17 & & & & & & & & & 6 & 5 \\
\hline 8 & & & & & 1 & 4 & 3 & 23 & & & 3 & 15 & 1 & 20 & & & & & & & & & & & 8 & 7 \\
\hline 9 & & & & & 1 & 4 & & & 1 & 5 & & & 1 & 20 & & & & & & & & & & & 3 & 3 \\
\hline 10 & & & & & 2 & 8 & & & 1 & 5 & 1 & 5 & & & & & & & & & & & & & 4 & 4 \\
\hline 11 & & & & & & & & & & & 1 & 5 & & & 2 & 17 & & & & & & & & & 3 & 3 \\
\hline 12 & & & & & & & 2 & 15 & & & 1 & 5 & & & 1 & 8 & & & & & & & & & 4 & 4 \\
\hline 13 & & & & & 1 & 4 & & & & & & & 1 & 20 & & & & & & & & & & & 2 & 2 \\
\hline 14 & & & & & & & & & 2 & 9 & & & & & & & & & & & & & & & 2 & 2 \\
\hline 15 & & & & & & & & & 1 & 5 & & & & & 1 & 8 & & & & & & & & & 2 & 2 \\
\hline 17 & & & & & & & & & 1 & 5 & & & & & 1 & 8 & & & & & & & & & 2 & 2 \\
\hline 18 & & & & & & & 0 & & & & 1 & 5 & & & & & & & & & & & & & 1 & 1 \\
\hline Total & 6 & & 4 & & 26 & & 13 & & 22 & & 20 & & 5 & & 12 & & 3 & & 1 & & 2 & & 0 & & 114 & 100 \\
\hline
\end{tabular}


En cuanto a las vías de transmisión de la infección por $\mathrm{VIH}$, las relaciones sexuales fueron la principal vía de contagio en el 80,7\% de la población, siendo las relaciones heterosexuales las de mayor frecuencia (71,0 \%), seguida de la drogadicción (19,3\%). En un $10,5 \%$, la vía de transmisión fue por drogadicción asociada a relaciones sexuales (Figura 30).

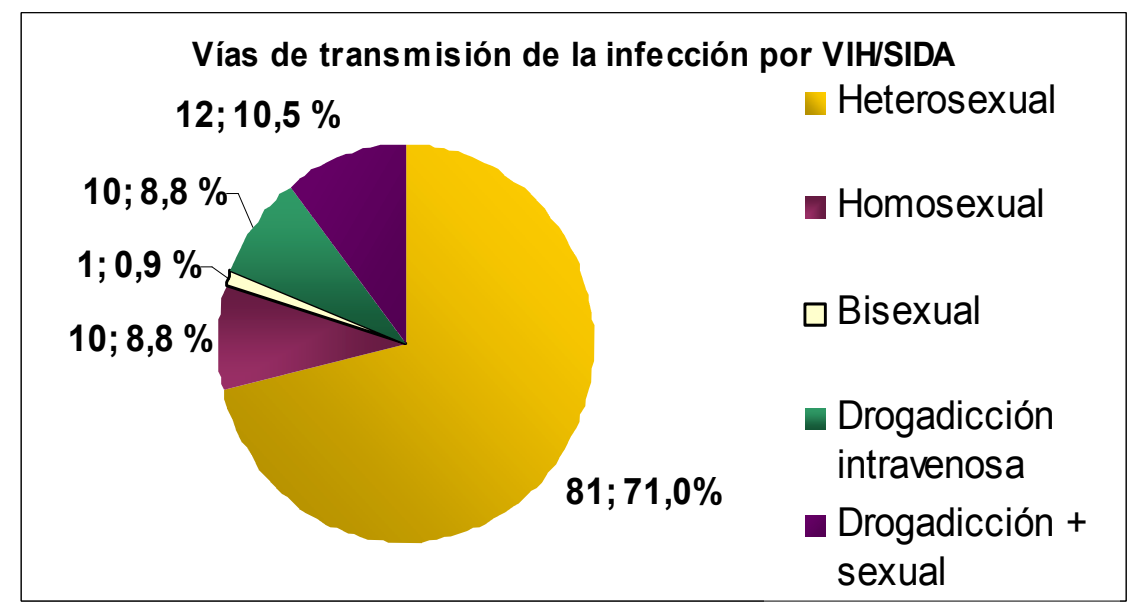

Figura 30: Distribución de pacientes de la Unidad de Infectología según vía de transmisión de la infección por VIH. Hospital Zonal General de Agudos "Mi Pueblo". Florencio Varela, provincia de Buenos Aires, Argentina. Agosto 2005 - junio 2007.

El estudio de la vía de transmisión según el género demostró en el 94,3 \% $(n=64)$ de las mujeres, que la principal vía de transmisión fue la sexual. En los hombres, la mayor frecuencia $(64 \%)$ del contagio fue por vía sexual; de esta población $(n=50)$ el $42 \%$ adquirió la infección por vía heterosexual y el 22 \% por relaciones homo/bisexuales (Tabla 6).

En ambos géneros la infección se transmitió principalmente en el grupo entre los 25 a 41 años de edad. La transmisión por drogadicción prevaleció en los hombres (36 \%) entre los 33 y 41 años de edad y en sólo el 6,2 \% de las mujeres (Tabla 6).

Los principales motivos que determinaron la realización del diagnóstico de la infección por VIH en nuestra población de pacientes fueron: la presentación de enfermedad marcadora de SIDA (35,1\%); el diagnóstico de la infección por VIH en la pareja sexual (23,7 $\%)$; el embarazo (14,9\%); las conductas de riesgo en el paciente (12,3\%); el diagnóstico de la infección por VIH realizado al hijo (7,9\%); la donación de sangre $(4,4 \%)$ y las conductas de riesgo en la pareja sexual $(1,8 \%)$. 
Tabla 6: Distribución de pacientes de la Unidad de Infectología según la vía de transmisión de la infección por VIH, la edad y el género. Hospital Zonal General de Agudos "Mi Pueblo". Florencio Varela, provincia de Buenos Aires, Argentina. Agosto 2005 - junio 2007.

\begin{tabular}{|c|c|c|c|c|c|c|c|c|c|c|c|c|c|c|c|c|c|c|c|c|c|c|c|c|c|c|c|}
\hline \multirow{4}{*}{$\begin{array}{c}\text { Vía de } \\
\text { transmisión }\end{array}$} & \multicolumn{25}{|c|}{ Edad } & \multirow{3}{*}{\multicolumn{2}{|c|}{ Total }} \\
\hline & \multicolumn{4}{|c|}{$16-24$} & \multicolumn{4}{|c|}{$25-32$} & \multicolumn{4}{|c|}{$33-41$} & \multicolumn{5}{|c|}{$42-50$} & \multicolumn{4}{|c|}{$51-58$} & \multicolumn{4}{|c|}{$59-67$} & & \\
\hline & \multicolumn{2}{|c|}{ Femenino } & \multicolumn{2}{|c|}{ Masculino } & \multicolumn{2}{|c|}{ Femenino } & \multicolumn{2}{|c|}{ Masculino } & \multicolumn{2}{|c|}{ Femenino } & \multicolumn{2}{|c|}{ Masculino } & \multicolumn{2}{|c|}{ Femenino } & \multicolumn{3}{|c|}{ Masculino } & \multicolumn{2}{|c|}{ Femenino } & \multicolumn{2}{|c|}{ Masculino } & \multicolumn{2}{|c|}{ Femenino } & \multicolumn{2}{|c|}{$\begin{array}{c}\text { Masculi } \\
\text { no }\end{array}$} & & \\
\hline & $\mathrm{n}$ & $\%$ & $\mathrm{n}$ & $\%$ & $\mathrm{n}$ & $\%$ & $\mathrm{n}$ & $\%$ & $\mathrm{n}$ & $\%$ & $\mathrm{n}$ & $\%$ & $\mathrm{n}$ & $\%$ & & $\mathrm{n}$ & $\%$ & $\mathrm{n}$ & $\%$ & $\mathrm{n}$ & $\%$ & $\mathrm{n}$ & $\%$ & $\mathrm{n}$ & $\%$ & $\mathrm{n}$ & $\%$ \\
\hline Heterosexual & 4 & 100 & & & 23 & 96 & 6 & 50 & 22 & 88 & 8 & 38 & 5 & 10 & & 6 & 50 & 4 & 100 & 1 & 100 & 2 & 100 & & & 81 & 71 \\
\hline Homosexual & & & 2 & 50 & & & 3 & 25 & & & 3 & 14 & & & & 2 & 17 & & & & & & & & & 10 & 9 \\
\hline Bisexual & & & & & & & 1 & 8 & & & & & & & & & & & & & & & & & & 1 & 1 \\
\hline DIV * & & & & & & & 1 & 8 & 1 & 4 & 5 & 24 & & & & 2 & 25 & & & & & & & & & 10 & 9 \\
\hline $\begin{array}{l}\text { Drogadicción } \\
\text { + vía sexual. }\end{array}$ & & & 2 & 50 & 1 & 4 & 1 & 8 & 2 & 8 & 5 & 24 & & & & 1 & 8 & & & & & & & & & 12 & 11 \\
\hline Total & 4 & & 4 & & 24 & & 12 & & 25 & & 21 & & 5 & & & 12 & & 4 & & 1 & & 2 & & 0 & & 114 & 100 \\
\hline
\end{tabular}

* DIV: drogadicción intravenosa 
La distribución de pacientes según la causa del diagnóstico de la infección por VIH se grafica en la figura 31.

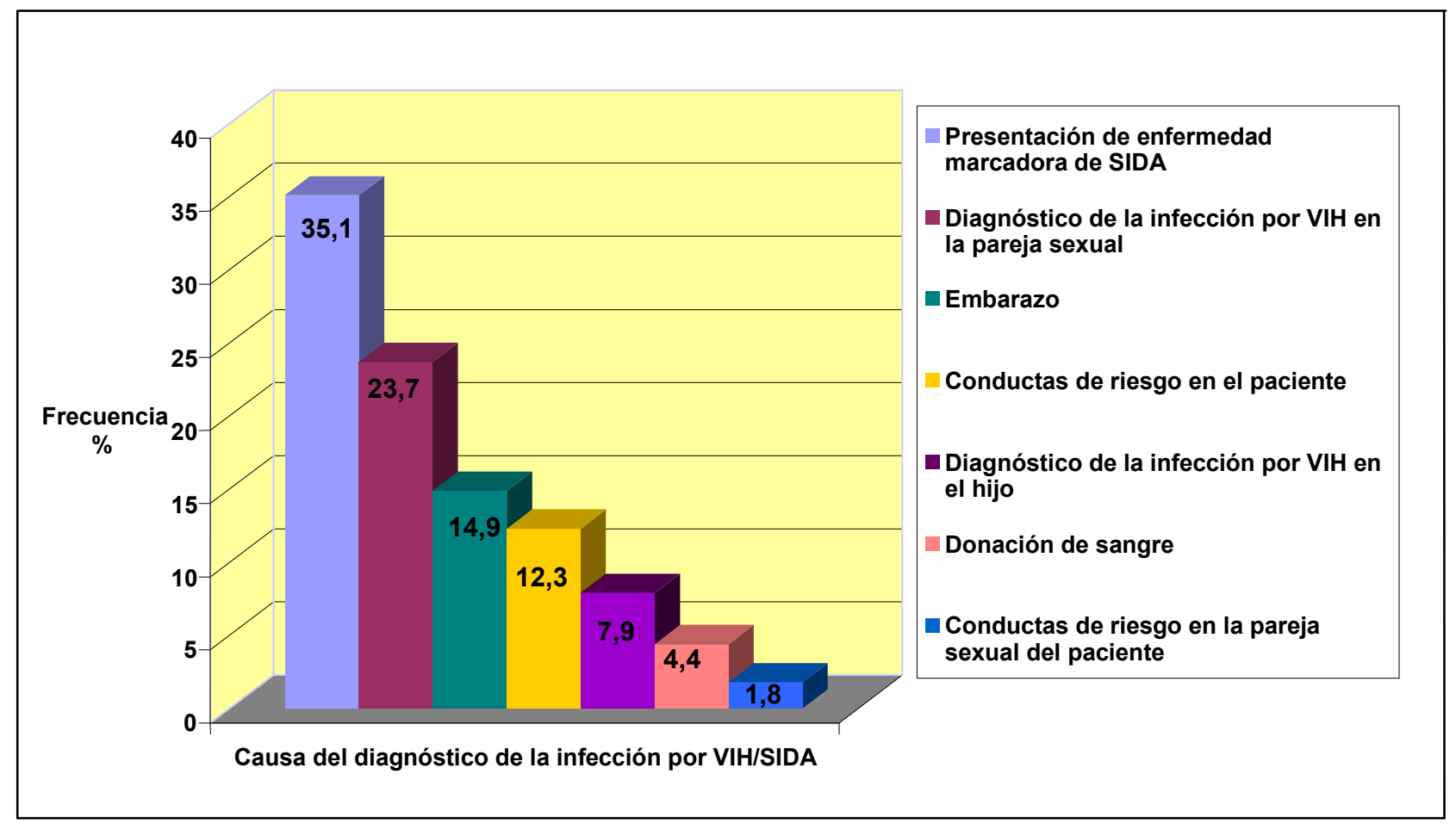

Figura 31: Causas que determinaron la realización del diagnóstico de la infección por VIH y distribución de pacientes de la Unidad de Infectología. Hospital Zonal General de Agudos "Mi Pueblo". Florencio Varela, provincia de Buenos Aires, Argentina. Agosto 2005 - junio 2007.

En las mujeres, las principales causas de realización del diagnóstico fueron el embarazo y el diagnóstico de la infección en la pareja sexual, seguido de la presentación de enfermedad marcadora de SIDA, fundamentalmente en el grupo entre 33 a 41 años de edad.

En los hombres, la primordial causa del diagnóstico fue la presentación de enfermedad marcadora de SIDA en el grupo entre 33 a 41 años de edad, seguida de conductas de riesgo en el grupo de 25 a 41 años de edad (Tabla 7).

No se observaron diferencias estadísticamente significativas con respecto a la causa del diagnóstico de la infección entre los géneros y las diferentes edades $(p>0,05) .{ }^{132}$ 
Tabla 7: Distribución de pacientes de la Unidad de Infectología según causa del diagnóstico de la infección por VIH, edad y género. Hospital Zonal General de Agudos "Mi Pueblo". Florencio Varela, provincia de Buenos Aires, Argentina. Agosto 2005 - junio 2007.

\begin{tabular}{|c|c|c|c|c|c|c|c|c|c|c|c|c|}
\hline \multirow{3}{*}{$\begin{array}{l}\text { Causa del diagnóstico de la } \\
\text { infección por VIH }\end{array}$} & \multicolumn{12}{|c|}{ Edad } \\
\hline & \multicolumn{2}{|c|}{$16-24$} & \multicolumn{2}{|c|}{$25-32$} & \multicolumn{2}{|c|}{$33-41$} & \multicolumn{2}{|c|}{$42-50$} & \multicolumn{2}{|c|}{$51-58$} & \multicolumn{2}{|c|}{$59-67$} \\
\hline & $\mathrm{f}$ & $\mathrm{m}$ & $\mathrm{f}$ & $\mathrm{m}$ & $\mathrm{f}$ & $\mathrm{m}$ & $\mathrm{f}$ & $\mathrm{m}$ & $\mathrm{f}$ & $\mathrm{m}$ & $\mathrm{f}$ & $\mathrm{m}$ \\
\hline $\begin{array}{l}\text { Presentación de } \\
\text { enfermedad marcadora de } \\
\text { SIDA }\end{array}$ & 0 & 2 & 2 & 4 & 10 & 11 & 1 & 8 & 1 & 1 & 0 & 0 \\
\hline $\begin{array}{l}\text { Diagnóstico de la } \\
\text { infección por VIH en la } \\
\text { pareja sexual }\end{array}$ & 0 & 0 & 4 & 3 & 7 & 4 & 3 & 2 & 2 & 0 & 2 & 0 \\
\hline Embarazo & 4 & 0 & 10 & 0 & 3 & 0 & 0 & 0 & 0 & 0 & 0 & 0 \\
\hline $\begin{array}{l}\text { Conductas de riesgo en el } \\
\text { paciente }\end{array}$ & 0 & 2 & 2 & 4 & 1 & 4 & 1 & 0 & 0 & 0 & 0 & 0 \\
\hline $\begin{array}{l}\text { Diagnóstico de la } \\
\text { infección por VIH en el } \\
\text { hijo }\end{array}$ & 0 & 0 & 5 & 1 & 3 & 0 & 0 & 0 & 0 & 0 & 0 & 0 \\
\hline Donación de sangre & 0 & 0 & 0 & 0 & 0 & 2 & 0 & 2 & 1 & 0 & 0 & 0 \\
\hline $\begin{array}{l}\text { Conductas de riesgo en la } \\
\text { pareja sexual del paciente }\end{array}$ & 0 & 0 & 1 & 0 & 1 & 0 & 0 & 0 & 0 & 0 & 0 & 0 \\
\hline
\end{tabular}

En nuestra población, una proporción del 31,6 \% $(n=6)$ de individuos no tenía pareja sexual actual, mientras que el 68,4 \% $(n=78)$ poseía pareja; de ellos, el 16,7 \% ( $\mathrm{n}=13)$ desconocía el estado serológico de su pareja.

El número de hijos promedio, de los pacientes, era de $2,4 \pm 2,1$ con una mayor frecuencia entre 2 y 4 hijos. El número de hijos VIH positivos era de 13,7 \%.

Al investigar las conductas de riesgo relacionadas con la transmisión del VIH en las parejas de nuestros pacientes, manifestaban que sus parejas no presentaban ninguna conducta de riesgo en el 48,7\% $(\mathrm{n}=38)$ de los casos, mientras que el 30,8 \% $(\mathrm{n}=24)$ poseían varias conductas de riesgo asociadas (promiscuidad sexual, drogadicción y alcoholismo) (Tabla 8). 
Tabla 8: Conductas de riesgo en parejas de pacientes de la Unidad de Infectología. Hospital Zonal General de Agudos "Mi Pueblo". Florencio Varela, provincia de Buenos Aires, Argentina. Agosto 2005 - junio 2007.

\begin{tabular}{|l|c|c|}
\hline \multicolumn{1}{|c|}{ Conductas de riesgo en } & \multicolumn{2}{|c|}{ Frecuencia } \\
\cline { 2 - 3 } la pareja & $\mathrm{n}$ & $\%$ \\
\hline Promiscuidad sexual & 6 & 7,7 \\
Drogadicción intravenosa & 5 & 6,4 \\
Drogadicción por otras vías & 2 & 2,6 \\
Alcoholismo & 3 & 3,8 \\
Varias conductas asociadas & 24 & 30,8 \\
Ninguna & 38 & 48,7 \\
\hline Total & 78 & 100,0 \\
\hline
\end{tabular}

Los pacientes que desconocían la condición serológica de su pareja, manifestaron que la mayoría tenían varias conductas de riesgo asociadas (Tabla 9). Los pacientes que tenían parejas discordantes (VIH negativas), refirieron casi en su totalidad que éstas no presentaban conductas de riesgo. Sin embargo, los pacientes con parejas VIH positivas, refirieron en el 50 $\%$ que presentaban varias conductas de riesgo, mientras que la otra mitad manifestó no presentar ninguna conducta de riesgo vinculada a la transmisión de la infección (Tabla 9).

Tabla 9: Conductas de riesgo en parejas de pacientes y su distribución según el conocimiento de su condición serológica. Unidad de Infectología. Hospital Zonal General de Agudos "Mi Pueblo". Florencio Varela, provincia de Buenos Aires, Argentina. Agosto 2005 - junio 2007.

\begin{tabular}{|l|c|c|c|}
\hline $\begin{array}{l}\text { Conductas de riesgo en parejas de } \\
\text { pacientes }\end{array}$ & $\begin{array}{c}\text { Condición serológica } \\
\text { desconocida }\end{array}$ & VIH negativa & VIH positiva \\
\hline Promiscuidad & 0 & 0 & 6 \\
Drogadicción intravenosa & 1 & 1 & 3 \\
Drogadicción por otras vías & 0 & 1 & 1 \\
Alcoholismo & 2 & 1 & 0 \\
Varias conductas de riesgo asociadas & 8 & 0 & 16 \\
Ninguna & 2 & 19 & 17 \\
\hline Total & 13 & 22 & 43 \\
\hline
\end{tabular}

Las parejas sexuales femeninas VIH positivas o con condición desconocida, presentaron en su mayoría varias conductas de riesgo relacionadas. Las parejas masculinas VIH positivas de las pacientes no presentaron en su mayoría conductas de riesgo asociadas (Tabla 10). 
Tabla 10: Conductas de riesgo en parejas de pacientes y su distribución según su conocimiento de la condición serológica y género. Unidad de Infectología. Hospital Zonal General de Agudos "Mi Pueblo". Florencio Varela, provincia de Buenos Aires, Argentina. Agosto 2005 - junio 2007.

\begin{tabular}{|c|c|c|c|c|c|c|c|c|c|c|c|c|c|c|}
\hline \multirow{4}{*}{ Conductas de riesgo en la pareja } & \multicolumn{12}{|c|}{ Condición serológica en la pareja } & \multirow{3}{*}{\multicolumn{2}{|c|}{ Total }} \\
\hline & \multicolumn{4}{|c|}{ Desconocida } & \multicolumn{4}{|c|}{ VIH negativo } & \multicolumn{4}{|c|}{ VIH positivo } & & \\
\hline & \multicolumn{2}{|c|}{ Femenino } & \multicolumn{2}{|c|}{ Masculino } & \multicolumn{2}{|c|}{ Femenino } & \multicolumn{2}{|c|}{ Masculino } & \multicolumn{2}{|c|}{ Femenino } & \multicolumn{2}{|c|}{ Masculino } & & \\
\hline & $\mathrm{n}$ & $\%$ & $\mathrm{n}$ & $\%$ & $\mathrm{n}$ & $\%$ & $\mathrm{n}$ & $\%$ & $\mathrm{n}$ & $\%$ & $\mathrm{n}$ & $\%$ & $\mathrm{n}$ & $\%$ \\
\hline Promiscuidad & 0 & & 0 & & 0 & & 0 & & 3 & & 3 & & 6 & 7,7 \\
\hline Drogadicción intravenosa & 1 & & 0 & & 0 & & 1 & & 3 & & 0 & & 5 & 6,4 \\
\hline Drogadicción por otras vías & 0 & & 0 & & 0 & & 1 & & 1 & & 0 & & 2 & 2,6 \\
\hline Alcoholismo & 2 & & 0 & & 1 & & 0 & & 0 & & 0 & & 3 & 3,8 \\
\hline Varias conductas de riesgo asociadas & 7 & & 1 & & 0 & & 0 & & 14 & & 2 & & 24 & 30,8 \\
\hline Ninguna & 2 & & 0 & & 9 & & 10 & & 3 & & 14 & & 38 & 48,7 \\
\hline Total & 12 & & 1 & & 10 & & 12 & & 24 & & 19 & & 78 & 100,0 \\
\hline
\end{tabular}



Se estudiaron las adicciones que presentaban los pacientes de nuestra población; la mitad de los individuos poseían entre una y cuatro adicciones de distintos tipos: 56 personas (49\%) del total de la población estudiada $(n=114)$ refirió tener adicciones; $23(41,1 \%)$ tenían 1 adicción, 14 (25\%) tenían 2 adicciones, 9 (16 \%) tenían 3 y 10 (17,9\%) tenían 4 adicciones.

La adicción referida con mayor frecuencia fue el tabaquismo en el 39,8 \% ( $n=47)$, seguida del alcoholismo en el 31,4\% $(\mathrm{n}=37)$; la drogadicción se presentó en el 28,8 \% de los casos $(n=34)$, siendo más frecuente la drogadicción no intravenosa $(n=23)$ con 19,5\% seguida de la drogadicción intravenosa con el 9,3\% $(\mathrm{n}=11)$.

El análisis del tipo de adicciones por individuo, expresó: en pacientes con una sola adicción, el tabaquismo fue la más frecuente; en pacientes con 2 adicciones, la asociación más frecuente fue alcoholismo y tabaquismo. En los individuos con 3 adicciones la asociación más frecuente fue alcoholismo/tabaquismo/drogadicción no intravenosa. Sólo 10 individuos $(6,9$ \%) presentaban cuatro tipos de adicciones: alcoholismo, tabaquismo, drogadicción intravenosa y no intravenosa.

Con respecto a la presencia de adicciones según el género, las mujeres presentaron menor frecuencia de adicciones que los hombres. En las mujeres, la adicción más usual fue el tabaquismo (62\%). En los hombres la adicción más frecuente fue la asociación tabaquismo / alcoholismo / drogadicción (25\%).

El rango etario crítico, en el cual se presentaron todo los tipos de adicciones, fue el de 25 a 41 años, con las proporciones más altas de tabaquismo, alcoholismo y combinaciones de ambas (Tabla 11). Se manifestaron diferencias estadísticamente significativas $(p<0,05)$ entre género y edad, con respecto a las adicciones.

El número de comorbilidades promedio fue de $1,2 \pm 1,1$. Los pacientes que presentaron 1 comorbilidad fueron afectados por: hepatopatía alcohólica (21,6\%), síndrome de lipodistrofia (7,8 \%), hepatitis B (6,9\%), síndrome ansioso-depresivo (6\%), cáncer $(6 \%)$, hepatitis $\mathrm{C}(4,3 \%)$, desnutrición grave y sífilis $(3,4 \%)$, hepatitis $\mathrm{C}+\mathrm{B}$ y enfermedad cardiovascular e hipertensión $(2,6 \%)$, enfermedad inflamatoria pélvica $(0,9 \%)$.

Los individuos que presentaron más de una comorbilidad, presentaron en su totalidad (100\%) síndrome ansioso - depresivo y síndrome de lipodistrofia, el $54 \%$ herpes genital, el $50 \%$ hepatitis B, desnutrición grave, enfermedades cardiovasculares e hipertensión e infección gonocócica. 
Tabla 11: Tipo y cantidad de adicciones según edad en pacientes de la Unidad de Infectología. Hospital Zonal General de Agudos "Mi Pueblo". Florencio Varela, provincia de Buenos Aires, Argentina. Agosto 2005 - junio 2007.

\begin{tabular}{|c|c|c|c|c|c|c|c|c|c|c|c|c|c|c|}
\hline \multirow{4}{*}{ Tipo de adicciones } & \multicolumn{14}{|c|}{ Edad } \\
\hline & \multicolumn{2}{|c|}{$16-24$} & \multicolumn{2}{|c|}{$25-32$} & \multicolumn{2}{|c|}{$33-41$} & \multicolumn{2}{|c|}{$42-50$} & \multicolumn{2}{|c|}{$51-58$} & \multicolumn{2}{|c|}{$59-67$} & \multicolumn{2}{|c|}{ Total } \\
\hline & \multicolumn{14}{|c|}{ Frecuencia } \\
\hline & $\mathrm{n}$ & $\%$ & $\mathrm{n}$ & $\%$ & $\mathrm{n}$ & $\%$ & $\mathrm{n}$ & $\%$ & $\mathrm{n}$ & $\%$ & $\mathrm{n}$ & $\%$ & $\mathrm{n}$ & $\%$ \\
\hline Sin adicciones & 2 & & 18 & & 25 & & 7 & & 3 & & 2 & & 57 & \\
\hline \multicolumn{15}{|l|}{ Con adicciones } \\
\hline Alcoholismo & & & 1 & 6 & 2 & 10 & 2 & 20 & & & & & 5 & 9 \\
\hline Tabaquismo & 1 & 20 & 6 & 33 & 5 & 24 & 3 & 30 & 1 & 50 & & & 16 & 29 \\
\hline \multicolumn{15}{|l|}{ Drogadicción intravenosa } \\
\hline $\begin{array}{l}\text { Drogadicción no } \\
\text { intravenosa }\end{array}$ & & & & & 2 & 10 & & & & & & & 2 & 4 \\
\hline Alcoholismo/Tabaquismo & 1 & 20 & 5 & 28 & 3 & 14 & 1 & 10 & 1 & 50 & & & 11 & 20 \\
\hline $\begin{array}{l}\text { Alcoholismo/Drogadicción } \\
\text { no intravenosa }\end{array}$ & 1 & 20 & & & 2 & 10 & & & & & & & 2 & 4 \\
\hline $\begin{array}{l}\text { Alcoholismo/Tabaquismo/ } \\
\text { Drogadicción intravenosa }\end{array}$ & & & & & 1 & & & & & & & & 1 & 2 \\
\hline $\begin{array}{l}\text { Alcoholismo/Tabaquismo/ } \\
\text { Drogadicción no } \\
\text { intravenosa }\end{array}$ & 1 & 20 & 4 & 22 & 2 & 10 & 1 & 10 & & & & & 8 & 15 \\
\hline $\begin{array}{l}\text { Alcoholismo/Tabaquismo/ } \\
\text { Drogadicción no } \\
\text { intravenosa/ Drogadicción } \\
\text { intravenosa }\end{array}$ & 1 & 20 & 2 & 11 & 4 & 19 & 3 & 30 & & & & & 10 & 18 \\
\hline Total Con Adicciones & 5 & & 18 & & 21 & & 10 & & 2 & & & & 55 & \\
\hline
\end{tabular}

El recuento de LT CD4+ expresó que el 36,2 \% de los pacientes tenían inmunosupresión severa, con $<200 / \mathrm{mm}^{3}$ (Figura 32).

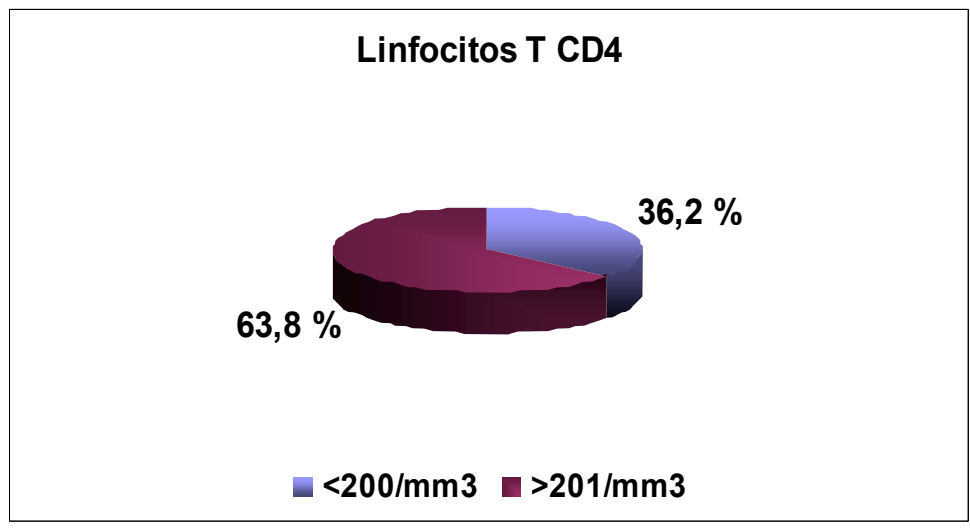

Figura 32: Recuento de linfocitos T CD4 en pacientes de la Unidad de Infectología. Hospital Zonal General de Agudos "Mi Pueblo". Florencio Varela, provincia de Buenos Aires, Argentina. Agosto 2005 - junio 2007. 
La carga viral indetectable ( $<50$ copias $/ \mathrm{mL}$ ) se halló en el $30 \%$ de los individuos. Los sujetos con carga viral detectable ( $>50$ copias $/ \mathrm{mL}$ ) tenían en un $43 \%$ valores menores a 50.000 copias $/ \mathrm{mL}$. Los valores $>100.000$ copias $/ \mathrm{mL}$ se observaron en el 15,5\% (Figura 33).

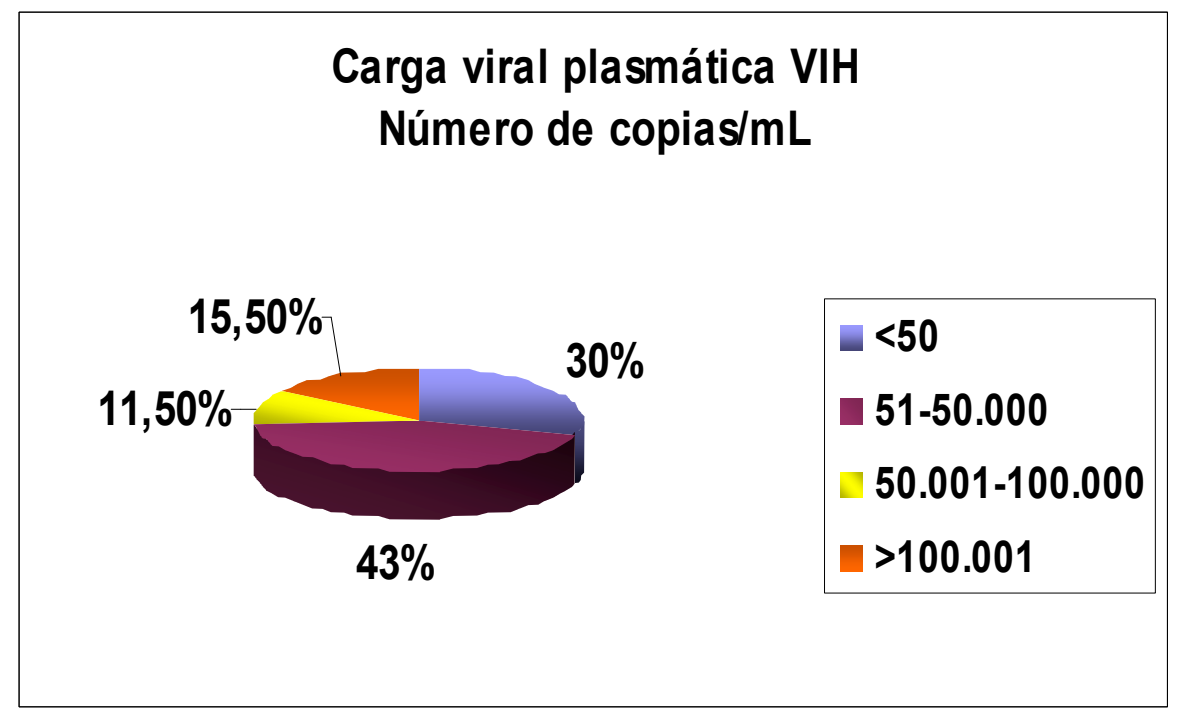

Figura 33: Valores de carga viral plasmática en pacientes de la Unidad de Infectología. Hospital Zonal General de Agudos "Mi Pueblo". Florencio Varela, provincia de Buenos Aires, Argentina. Agosto 2005 - junio 2007.

La presencia de enfermedad marcadora de SIDA en los pacientes, durante la evolución de la infección por VIH, fue del 46,5\% $(\mathrm{n}=53)$, de los cuales el 45,3\% $(\mathrm{n}=24)$ tuvieron un solo evento, el 30,2\% $(n=16)$ tuvieron 2 y $13(24,5 \%)$ padecieron 3 o más.

En el total de la población de pacientes, se documentaron 95 eventos marcadores de SIDA. Las enfermedades marcadoras diagnosticadas fueron, en orden de mayor a menor frecuencia: síndrome consuntivo asociado al VIH (wasting syndrome), candidiosis esofágica, tuberculosis (TB) pulmonar y extrapulmonar, toxoplasmosis cerebral, cáncer invasivo de cuello uterino, neumonía por Pneumocystis jiroveci (PCP), demencia asociada al SIDA (DAS), criptosporidiosis intestinal, criptococosis meníngea, histoplasmosis diseminada, sarcoma de Kaposi, Herpes simple mucocutáneo y leucoencefalopatía multifocal progresiva (LMP) (Tabla 12). 
Tabla 12: Enfermedades marcadoras de SIDA en pacientes de la Unidad de Infectología. Hospital Zonal General de Agudos "Mi Pueblo". Florencio Varela, provincia de Buenos Aires. Argentina. Agosto 2005 - junio 2007.

\begin{tabular}{|l|c|c|}
\hline \multirow{2}{*}{ Enfermedades marcadoras de SIDA } & \multicolumn{2}{|c|}{ Frecuencia } \\
\cline { 2 - 3 } & $\mathrm{n}$ & $\%$ \\
\hline Síndrome consuntivo asociado al SIDA & 29 & 30,5 \\
Candidiosis esofágica & 14 & 14,7 \\
Tuberculosis (pulmonar y extrapulmonar) & 13 & 13,7 \\
Toxoplasmosis cerebral & 7 & 7,4 \\
Cáncer invasor de cuello uterino & 7 & 7,4 \\
Neumonía por Pneumocystis jiroveci & 7 & 7,4 \\
Demencia asociada al SIDA & 6 & 6,3 \\
Criptosporidiosis intestinal & 6 & 6,3 \\
Criptococosis meníngea & 2 & 2,1 \\
Histoplasmosis diseminada & 1 & 1,05 \\
Sarcoma de Kaposi & 1 & 1,05 \\
Herpes simple mucocutáneo & 1 & 1,05 \\
Leucoencefalopatía multifocal progresiva & 1 & 1,05 \\
\hline Total & 95 & 100,0 \\
\hline
\end{tabular}

Las enfermedades marcadoras que con mayor frecuencia marcaron el debut del SIDA en nuestros pacientes son: el síndrome consuntivo asociado al VIH, la TB pulmonar y extrapulmonar, la neumonía por $P$. jiroveci, la toxoplasmosis cerebral y el cáncer invasor de cuello uterino (Tabla 13).

Tabla 13: Presentación de la primera enfermedad marcadora de SIDA en pacientes de la Unidad de Infectología. Hospital Zonal General de Agudos "Mi Pueblo". Florencio Varela, provincia de Buenos Aires, Argentina. Agosto 2005 - junio 2007.

\begin{tabular}{|l|c|c|}
\hline Presentación de la primera enfermedad marcadora & \multicolumn{2}{|c|}{ Frecuencia } \\
\cline { 2 - 3 } de SIDA en pacientes & $\mathrm{n}$ & $\%$ \\
\hline Síndrome consuntivo asociado al SIDA & 14 & 26,4 \\
Tuberculosis (pulmonar y extrapulmonar) & 10 & 18,9 \\
Neumonía por Pneumocystis jiroveci & 7 & 13,2 \\
Toxoplasmosis cerebral & 6 & 11,3 \\
Cáncer invasor de cuello uterino & 5 & 9,4 \\
Demencia asociada al SIDA & 4 & 7,5 \\
Criptococosis meníngea & 2 & 3,8 \\
Candidiosis esofágica & 1 & 1,9 \\
Criptosporidiosis intestinal & 1 & 1,9 \\
Histoplasmosis diseminada & 1 & 1,9 \\
Sarcoma de Kaposi & 1 & 1,9 \\
Leucoencefalopatía multifocal progresiva & 1 & 1,9 \\
\hline Total & 53 & 100,0 \\
\hline
\end{tabular}


La primera enfermedad marcadora se manifestó en el 92,4\% de los casos, en el grupo entre 25 y 50 años (Tabla 14).

Tabla 14: Distribución de la presentación de la primera enfermedad marcadora de SIDA en pacientes de la Unidad de Infectología. Hospital Zonal General de Agudos "Mi Pueblo". Florencio Varela, provincia de Buenos Aires, Argentina. Agosto 2005 - junio 2007.

\begin{tabular}{|c|c|c|c|c|c|}
\hline \multirow{2}{*}{ Edad } & \multicolumn{4}{|c|}{ Enfermedad marcadora } & \multirow{2}{*}{ Total } \\
\cline { 2 - 5 } & \multicolumn{2}{|c|}{ Sín } & \multicolumn{2}{|c|}{ No } & \\
\cline { 2 - 5 } & $\mathrm{n}$ & $\%$ & $\mathrm{n}$ & $\%$ & 8 \\
\hline $16-24$ & 2 & 3,8 & 6 & 9,8 & 36 \\
$25-32$ & 13 & 24,5 & 23 & 37,7 & 46 \\
$33-41$ & 24 & 45,3 & 22 & 36,1 & 17 \\
$42-50$ & 12 & 22,6 & 5 & 8,2 & 5 \\
$51-58$ & 2 & 3,8 & 3 & 4,9 & 2 \\
$59-67$ & 0 & 0 & 2 & 3,3 & 114 \\
\hline Total & 53 & 100,0 & 61 & 100,0 & \\
\hline
\end{tabular}

La ocurrencia de enfermedades marcadoras, se registró con la mayor frecuencia en el grupo etario de 33 a 41 años. La tuberculosis, en sus dos formas clínicas, se presentó en los individuos más jóvenes, entre 25 y 32 años.

En el grupo de menor edad, las enfermedades marcadoras que se hallaron en mayor proporción fueron la toxoplasmosis cerebral y la criptococosis meníngea. La mayoría de los casos de cáncer invasivo de cuello uterino se dieron en mujeres jóvenes entre los 25 y 41 años, así también como la demencia asociada al SIDA, que ocurrió en personas jóvenes entre 25 a 50 años.

Se observa que en la población de mayor edad (59 a 67 años), no se manifestaron enfermedades relacionadas al SIDA (Tabla 15).

Al considerar la presentación de enfermedad marcadora de SIDA según el género, del total de la población femenina $(n=64), 23(43,4 \%)$ tuvo enfermedad marcadora. En la población masculina $(\mathrm{n}=50)$, el 56,6 \% padeció de enfermedad marcadora de SIDA. En el grupo de mujeres, las principales enfermedades marcadoras fueron el síndrome consuntivo asociado al SIDA, la candidiosis esofágica y el cáncer invasivo de cuello. En el grupo de hombres, las principales enfermedades marcadoras fueron el síndrome consuntivo asociado al SIDA, la tuberculosis y la candidiosis esofágica. La principal enfermedad marcadora en ambos géneros, fue el síndrome consuntivo asociado al SIDA (Tablas 16 y 17). 
Tabla 15: Distribución de la presentación y clase de la primera enfermedad marcadora de SIDA según la edad, en pacientes de la Unidad de Infectología. Hospital Zonal General de Agudos "Mi Pueblo". Florencio Varela, provincia de Buenos Aires, Argentina. Agosto 2005 - junio 2007.

\begin{tabular}{|c|c|c|c|c|c|c|c|c|c|c|c|c|c|c|}
\hline \multirow{3}{*}{$\begin{array}{c}\text { Enfermedad } \\
\text { marcadora de SIDA }\end{array}$} & \multicolumn{12}{|c|}{ Edad } & \multirow{2}{*}{\multicolumn{2}{|c|}{ Total }} \\
\hline & \multicolumn{2}{|c|}{$16-24$} & \multicolumn{2}{|c|}{$25-32$} & \multicolumn{2}{|c|}{$33-41$} & \multicolumn{2}{|c|}{$42-50$} & \multicolumn{2}{|c|}{$51-58$} & \multicolumn{2}{|c|}{$59-67$} & & \\
\hline & $\mathrm{n}$ & $\%$ & $\mathrm{n}$ & $\%$ & $\mathrm{n}$ & $\%$ & $\mathrm{n}$ & $\%$ & $\mathrm{n}$ & $\%$ & $\mathrm{n}$ & $\%$ & $\mathrm{n}$ & $\%$ \\
\hline $\begin{array}{l}\text { Síndrome } \\
\text { consuntivo asociado } \\
\text { al SIDA }\end{array}$ & & & 2 & 14,2 & 9 & 64,3 & 3 & 21,5 & & & & & 14 & 100,0 \\
\hline $\begin{array}{l}\text { Tuberculosis } \\
\text { pulmonar y } \\
\text { extrapulmonar }\end{array}$ & & & 4 & 40 & 3 & 30 & 3 & 30 & & & & & 10 & 100,0 \\
\hline $\begin{array}{l}\text { Neumonía por } P \text {. } \\
\text { jiroveci }\end{array}$ & & & & & 6 & 85,7 & & & 1 & 14,3 & & & 7 & 100,0 \\
\hline $\begin{array}{l}\text { Toxoplasmosis } \\
\text { cerebral }\end{array}$ & 1 & 16,7 & 1 & 16,7 & 3 & 50 & 1 & 16,7 & & & & & 6 & 100,0 \\
\hline $\begin{array}{l}\text { Cáncer invasivo de } \\
\text { cuello uterino }\end{array}$ & & & 2 & 40 & 2 & 40 & & & 1 & 20 & & & 5 & 100,0 \\
\hline $\begin{array}{l}\text { Demencia asociada } \\
\text { al SIDA }\end{array}$ & & & 2 & 50 & & & 2 & 50 & & & & & 4 & 100,0 \\
\hline $\begin{array}{l}\text { Criptococosis } \\
\text { meníngea }\end{array}$ & 1 & 50 & 1 & 50 & & & & & & & & & 2 & 100,0 \\
\hline $\begin{array}{l}\text { Candidiosis } \\
\text { esofágica }\end{array}$ & & & & & 1 & 100 & & & & & & & 1 & 100,0 \\
\hline $\begin{array}{l}\text { Criptosporidiosis } \\
\text { intestinal }\end{array}$ & & & & & & & 1 & 100 & & & & & 1 & 100,0 \\
\hline $\begin{array}{l}\text { Histoplasmosis } \\
\text { diseminada }\end{array}$ & & & & & & & 1 & 100 & & & & & 1 & 100,0 \\
\hline $\begin{array}{l}\text { Sarcoma de } \\
\text { Kaposi }\end{array}$ & & & & & & & 1 & 100 & & & & & 1 & 100,0 \\
\hline $\begin{array}{l}\text { Leucoencefalopatía } \\
\text { multifocal } \\
\text { progresiva }\end{array}$ & & & 1 & 100 & & & & & & & & & 1 & 100,0 \\
\hline Total & 2 & 100,0 & 13 & 100,0 & 24 & 100,0 & 12 & 100,0 & 2 & 100,0 & 0 & 100,0 & 53 & 100,0 \\
\hline
\end{tabular}

Tabla 16: Presentación de enfermedad marcadora de SIDA según el género, en pacientes de la Unidad de Infectología. Hospital Zonal General de Agudos "Mi Pueblo". Florencio Varela, provincia de Buenos Aires, Argentina. Agosto 2005 - junio 2007.

\begin{tabular}{|c|c|c|c|c|c|}
\hline \multirow{2}{*}{ Género } & \multicolumn{4}{|c|}{ Enfermedad marcadora } & \multirow{2}{*}{ Total } \\
\cline { 2 - 5 } & \multicolumn{2}{|c|}{ Sí } & \multicolumn{2}{c|}{ No } & \\
\cline { 2 - 5 } & $\mathrm{n}$ & $\%$ & $\mathrm{n}$ & $\%$ & \\
\hline Femenino & 23 & 43,4 & 41 & 67,2 & 64 \\
Masculino & 30 & 56,6 & 20 & 32,8 & 50 \\
\hline Total & 53 & 100,0 & 61 & 100,0 & 114 \\
\hline
\end{tabular}


Tabla 17: Distribución de la presentación de enfermedad marcadora de SIDA según el género, en pacientes de la Unidad de Infectología. Hospital Zonal General de Agudos "Mi Pueblo". Florencio Varela, provincia de Buenos Aires, Argentina. Agosto 2005 - junio 2007.

\begin{tabular}{|c|c|c|c|c|c|c|}
\hline \multirow{3}{*}{$\begin{array}{c}\text { Enfermedad } \\
\text { marcadora de SIDA }\end{array}$} & \multicolumn{4}{|c|}{ Género } & & \\
\hline & \multicolumn{2}{|c|}{ Femenino } & \multicolumn{2}{|c|}{ Masculino } & \multicolumn{2}{|c|}{ Total } \\
\hline & $\mathrm{n}$ & $\%$ & $\mathrm{n}$ & $\%$ & $\mathrm{n}$ & $\%$ \\
\hline $\begin{array}{l}\text { Síndrome consuntivo } \\
\text { asociado al SIDA }\end{array}$ & 14 & 48,3 & 15 & 51,7 & 29 & 100,0 \\
\hline $\begin{array}{l}\text { Tuberculosis pulmonar y } \\
\text { extrapulmonar }\end{array}$ & 4 & 30,8 & 9 & 69,2 & 13 & 100,0 \\
\hline Neumonía por $P$. jiroveci & 3 & 42,9 & 4 & 57,1 & 7 & 100,0 \\
\hline Toxoplasmosis cerebral & 3 & 42,9 & 4 & 57,1 & 7 & 100,0 \\
\hline $\begin{array}{l}\text { Cáncer invasivo de cuello } \\
\text { uterino }\end{array}$ & 7 & 100,0 & & & 7 & 100,0 \\
\hline Demencia asociada al SIDA & 4 & 66,7 & 2 & 33,3 & 6 & 100,0 \\
\hline Criptococosis meníngea & & & 2 & 100,0 & & 100,0 \\
\hline Candidiosis esofágica & 8 & 57,1 & 6 & 42,9 & 14 & 100,0 \\
\hline Criptosporidiosis intestinal & 3 & 50,0 & 3 & 50,0 & 6 & 100,0 \\
\hline Histoplasmosis diseminada & & & 1 & 100,0 & 1 & 100,0 \\
\hline Sarcoma de Kaposi & & & 1 & 100,0 & 1 & 100,0 \\
\hline $\begin{array}{l}\text { Leucoencefalopatía } \\
\text { multifocal progresiva }\end{array}$ & & & 1 & 100,0 & 1 & 100,0 \\
\hline Herpes simple mucocutáneo & & & 1 & 100,0 & 1 & 100,0 \\
\hline Total & 46 & 48,4 & 49 & 51,6 & 95 & 100,0 \\
\hline
\end{tabular}

El 47,4 \% de los pacientes $(n=60)$ requirió hospitalización en algún momento en la evolución de su enfermedad: $62 \%$ de la población masculina y 35,9 \% de la población femenina.

La antigüedad del TARGA se halló entre 1 y 3 años en el $65 \%$ de los casos. El 72,8 \% de los pacientes estaban en tratamiento farmacológico con antiretrovirales, en diferentes asociaciones; el $46 \%$ de los pacientes recibían 2 INTR + 1 INNTR, el 13,8 \% 2 INTR + 1 IP, el $6 \% 2$ INTR + 2 IP y el 4,3\% 3 INTR. El 42,2 \% de los pacientes había cambiado una vez de tratamiento (switch), 12,9\% 2 veces, el 7,8\% 3 veces y el 7,7 \% más de 4 veces. 


\section{Análisis de las dimensiones del Cuestionario de Salud SF-36}

Las puntuaciones medias de cada una de las dimensiones del cuestionario se describen en la tabla 18 y se ilustran en la figura 34.

Las puntuaciones medias variaron de 79 en la función física a 58 en el rol emocional. En todos los casos se observaron puntuaciones mínimas (0) y máximas (100), por lo que el rango observado se situó en 100 .

La totalidad de las puntuaciones mínimas y máximas obtenidas en la aplicación del cuestionario SF-36 a la población estudiada coincide en todas las dimensiones con los valores posibles según la escala del cuestionario SF-36 (Tabla 19). Para una sola dimensión (rol físico) el porcentaje de individuos con la puntuación máxima (techo) fue superior al $50 \%$.

Con excepción de la dimensión del rol físico y emocional, la proporción de individuos con puntuación mínima (piso) fue menor del $4 \%$.

En el total de la población estudiada, la puntuación más baja obtenida fue en el rol emocional, con un elevado porcentaje de individuos con puntuación mínima (Figura 34).

Las mujeres presentaron mejores puntuaciones en 5 dimensiones: función física, rol físico, salud general, vitalidad y función social. Los varones presentaron puntuaciones más elevadas solamente en 3 dimensiones: dolor corporal, rol emocional y salud mental (Figura $35)$.

La verificación de contraste de puntuaciones medias de las distintas dimensiones del cuestionario, entre género, analizada mediante pruebas paramétricas, manifestó diferencias estadísticas sólo en el rol emocional $(\mathrm{p}<0,05){ }^{133,134}$

Con respecto a la edad, al realizarse el análisis de varianza, se observaron diferencias técnica y estadísticamente significativas y presentó asociación sólo en el rol físico $(p<0,05)$; las menores puntuaciones se obtuvieron en la franja etaria de 59 a 67 años, en todas las dimensiones del cuestionario (Tabla 20). ${ }^{133,134}$

Al comparar las puntuaciones con el género y grupos etarios, se observó que sólo en el rol emocional las mujeres presentaron puntuaciones más bajas que en los hombres, en todos los grupos etarios (Tabla 21). 
Tabla 18: Distribución de las puntuaciones de las dimensiones que integran la versión española del Cuestionario de Salud SF-36 según el género, en pacientes de la Unidad de Infectología. Hospital Zonal General de Agudos "Mi Pueblo". Florencio Varela, provincia de Buenos Aires, Argentina. Agosto 2005 - junio 2007.

\begin{tabular}{|c|c|c|c|c|c|c|c|c|}
\hline & $\begin{array}{c}\text { Función } \\
\text { física }\end{array}$ & $\begin{array}{c}\text { Rol } \\
\text { físico }\end{array}$ & $\begin{array}{c}\text { Dolor } \\
\text { corporal }\end{array}$ & $\begin{array}{l}\text { Salud } \\
\text { general }\end{array}$ & Vitalidad & $\begin{array}{c}\text { Función } \\
\text { social }\end{array}$ & $\begin{array}{c}\text { Rol } \\
\text { emocional }\end{array}$ & $\begin{array}{c}\text { Salud } \\
\text { mental }\end{array}$ \\
\hline \multicolumn{9}{|l|}{ Total $(n=144)$} \\
\hline Media (DE) & $79(27)$ & $72(41)$ & $67(27)$ & $61(23)$ & $65(21)$ & $73(27)$ & $58(47)$ & $64(22)$ \\
\hline Mediana & 90 & 100 & 72 & 62 & 70 & 75 & 100 & 64 \\
\hline $\begin{array}{c}\text { Porcentaje con } \\
\text { puntación máxima } \\
(100)\end{array}$ & 32 & 56 & 25 & 1,7 & 3,4 & 35 & 49 & 3,4 \\
\hline $\begin{array}{c}\text { Porcentaje con } \\
\text { puntación mínima }(0)\end{array}$ & 4 & 17 & 2,6 & 0,9 & 0,9 & 0,9 & 26 & 0,9 \\
\hline \multicolumn{9}{|l|}{ Varones $(n=50)$} \\
\hline Media & $76(31)$ & $69(45)$ & $69(27)$ & $58(26)$ & $64(22)$ & $71(28)$ & $69(47)$ & $64(25)$ \\
\hline Mediana & 90 & 100 & 72 & 62 & 67 & 75 & 199 & 64 \\
\hline $\begin{array}{l}\text { Porcentaje con } \\
\text { puntación máxima } \\
(100)\end{array}$ & 40 & 52 & 30 & 4 & 2 & 38 & 60 & 6 \\
\hline $\begin{array}{l}\text { Porcentaje con } \\
\text { puntación mínima }(0)\end{array}$ & 8 & 20 & 2 & 2 & 2 & 6 & 22 & 2 \\
\hline \multicolumn{9}{|l|}{ Mujeres $(n=64)$} \\
\hline Media & $80(24)$ & $74(39)$ & $66(26)$ & $63(20)$ & $67(19)$ & $74(26)$ & $50(46)$ & $63(21)$ \\
\hline Mediana & 90 & 100 & 63 & 62 & 70 & 75 & 33 & 64 \\
\hline $\begin{array}{l}\text { Porcentaje con } \\
\text { puntación máxima } \\
(100)\end{array}$ & 27 & 64 & 22 & 1,6 & 4,7 & 33 & 42 & 1,6 \\
\hline $\begin{array}{l}\text { Porcentaje con } \\
\text { puntación mínima }(0)\end{array}$ & 1,6 & 16 & 3 & 3,1 & 1,6 & 1,6 & 30 & 1,6 \\
\hline
\end{tabular}

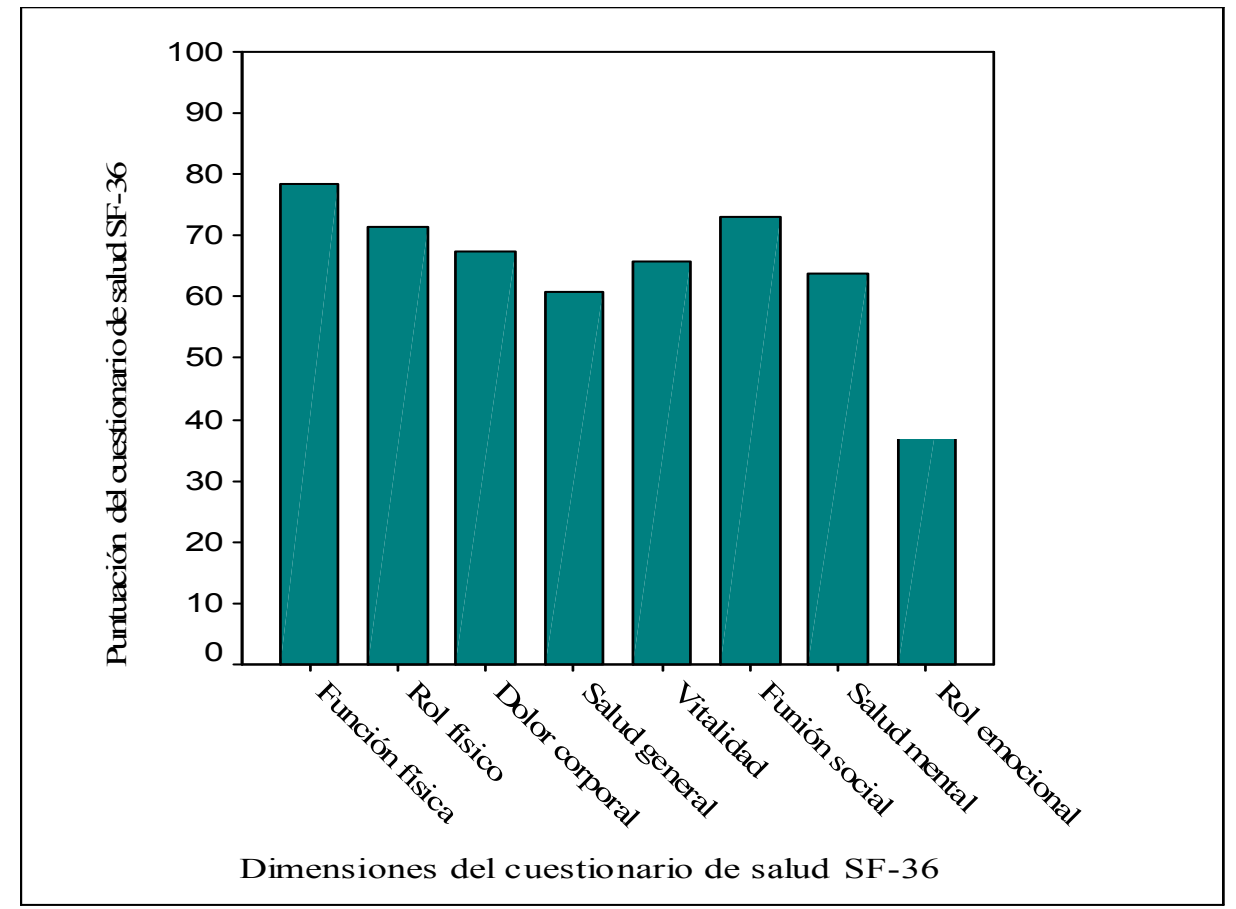

Figura 34: Distribución de las puntuaciones de las dimensiones que integran la versión española del Cuestionario de Salud SF-36 en pacientes de la Unidad de Infectología. Hospital Zonal General de Agudos "Mi Pueblo". Florencio Varela, provincia de Buenos Aires, Argentina. Agosto 2005 - junio 2007. 


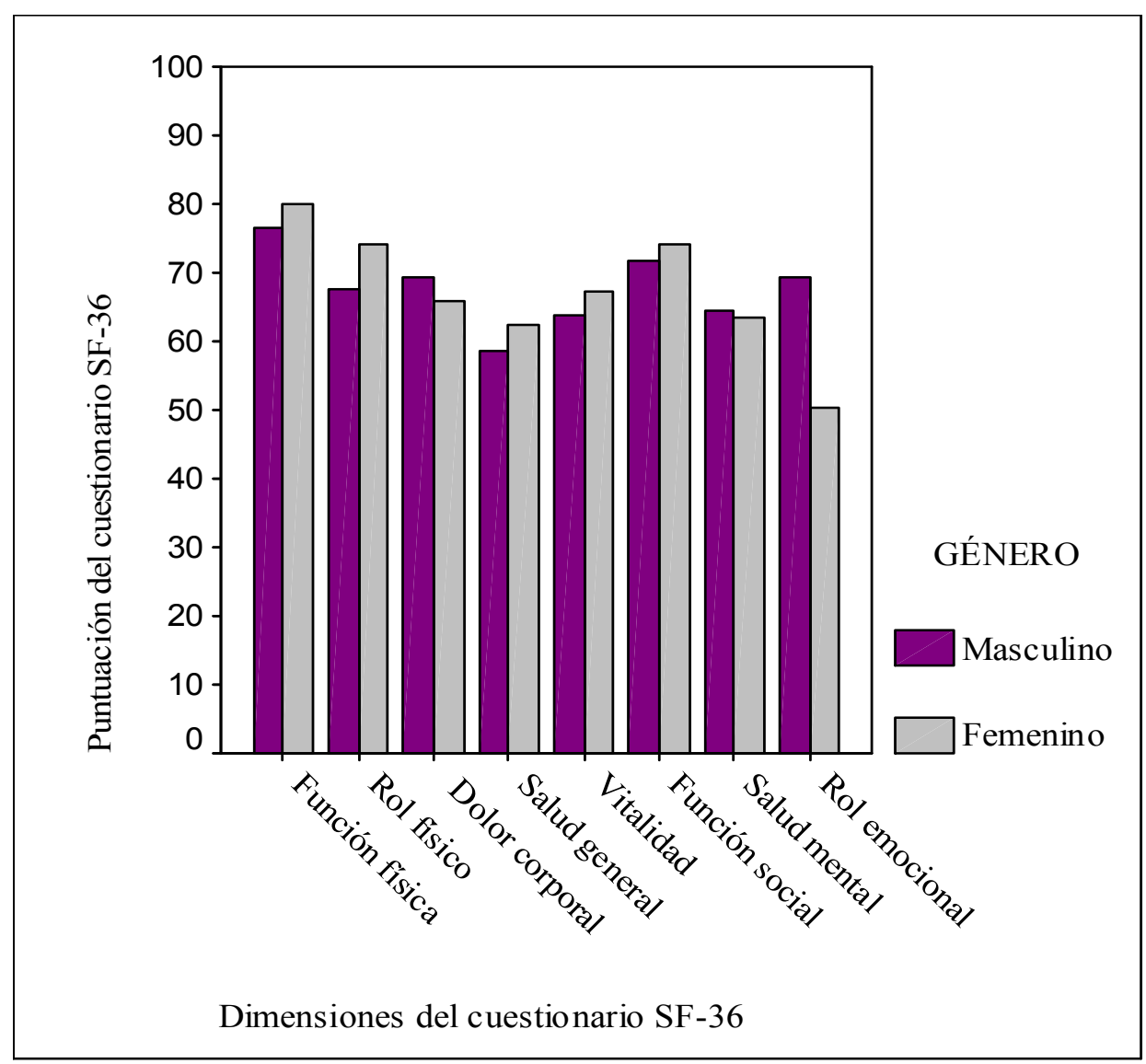

Figura 35: Distribución de las puntuaciones de las dimensiones que integran la versión española del Cuestionario de Salud SF-36, según el género en pacientes de la Unidad de Infectología. Hospital Zonal General de Agudos "Mi Pueblo". Florencio Varela, provincia de Buenos Aires, Argentina. Agosto 2005 - junio 2007.

Tabla 19: Puntuaciones mínimas y máximas obtenidas en las dimensiones del Cuestionario de Salud SF-36 en pacientes de la Unidad de Infectología. Hospital Zonal General de Agudos "Mi Pueblo". Florencio Varela, provincia de Buenos Aires, Argentina. Agosto 2005 - junio 2007.

\begin{tabular}{|l|c|c|c|c|c|}
\hline \multirow{2}{*}{ Dimensión } & \multicolumn{5}{|c|}{ Puntuaciones mínimas y máximas } \\
\cline { 2 - 6 } & Posibles según Escala SF-36 & \multicolumn{2}{c|}{ Valores Reales Cuestionario 2006 } \\
\cline { 2 - 6 } & Mínimo & Máximo & Mínimo & Máximo & Promedio \\
\hline Función física & 10 & 30 & 10 & 30 & 25,7 \\
Rol físico & 4 & 8 & 4 & 8 & 6,8 \\
Dolor Corporal & 2 & 12 & 2 & 12 & 8,7 \\
Salud General & 5 & 25 & 5 & 25 & 17,1 \\
Vitalidad & 2 & 24 & 4 & 24 & 17,1 \\
Función Social & 2 & 10 & 2 & 10 & 7,8 \\
Rol Emocional & 3 & 6 & 3 & 6 & 4,7 \\
Salud Mental & 5 & 30 & 5 & 30 & 20,9 \\
\hline
\end{tabular}


Tabla 20: Distribución de las puntuaciones de las dimensiones obtenidas del Cuestionario de Salud SF36 según grupos de edades, en pacientes de la Unidad de Infectología. Hospital Zonal General de Agudos "Mi Pueblo". Florencio Varela, provincia de Buenos Aires, Argentina. Agosto 2005 - junio 2007.

\begin{tabular}{|c|c|c|c|c|c|c|c|c|}
\hline \multirow{2}{*}{$\begin{array}{c}\text { Grupos de } \\
\text { edades (años) }\end{array}$} & \multicolumn{9}{|c|}{ Dimensiones } \\
\cline { 2 - 9 } & $\begin{array}{c}\text { Función } \\
\text { Física }\end{array}$ & $\begin{array}{c}\text { Rol } \\
\text { Físico }\end{array}$ & $\begin{array}{c}\text { Dolor } \\
\text { Corporal }\end{array}$ & $\begin{array}{c}\text { Salud } \\
\text { General }\end{array}$ & Vitalidad & $\begin{array}{c}\text { Función } \\
\text { Social }\end{array}$ & $\begin{array}{c}\text { Rol } \\
\text { Emocional }\end{array}$ & $\begin{array}{c}\text { Salud } \\
\text { Mental }\end{array}$ \\
\hline $16-24$ & 83 & 62 & 75 & 53 & 66 & 81 & 64 & 46 \\
$25-32$ & 76 & 64 & 67 & 59 & 64 & 69 & 63 & 50 \\
$33-41$ & 80 & 76 & 67 & 64 & 69 & 77 & 66 & 69 \\
$42-50$ & 81 & 78 & 72 & 58 & 63 & 73 & 63 & 63 \\
$51-58$ & 72 & 80 & 59 & 60 & 57 & 65 & 58 & 53 \\
$59-67$ & 47 & 37 & 30 & 63 & 62 & 50 & 50 & 17 \\
\hline
\end{tabular}

Tabla 21: Distribución de las puntuaciones de las dimensiones obtenidas del Cuestionario de Salud SF36, según género y grupos de edad, en pacientes de la Unidad de Infectología. Hospital Zonal General de Agudos "Mi Pueblo". Florencio Varela, provincia de Buenos Aires, Argentina. Agosto 2005 - junio 2007.

\begin{tabular}{|c|c|c|c|c|c|c|c|c|c|c|c|c|c|c|c|c|}
\hline \multirow[b]{3}{*}{ Género } & \multicolumn{16}{|c|}{ Dimensiones } \\
\hline & \multicolumn{2}{|c|}{$\begin{array}{c}\text { Función } \\
\text { física }\end{array}$} & \multicolumn{2}{|c|}{ Rol físico } & \multicolumn{2}{|c|}{$\begin{array}{c}\text { Dolor } \\
\text { corporal }\end{array}$} & \multicolumn{2}{|c|}{$\begin{array}{c}\text { Salud } \\
\text { general }\end{array}$} & \multicolumn{2}{|c|}{ Vitalidad } & \multicolumn{2}{|c|}{$\begin{array}{c}\text { Función } \\
\text { social }\end{array}$} & \multicolumn{2}{|c|}{$\begin{array}{c}\text { Rol } \\
\text { emocional }\end{array}$} & \multicolumn{2}{|c|}{$\begin{array}{c}\text { Salud } \\
\text { mental }\end{array}$} \\
\hline & f & $\mathbf{m}$ & f & $\mathbf{m}$ & f & $\mathbf{m}$ & $\mathbf{f}$ & $\mathbf{m}$ & f & $\mathbf{m}$ & f & $\mathbf{m}$ & f & $\mathbf{m}$ & $\mathbf{f}$ & $\mathbf{m}$ \\
\hline $\begin{array}{c}\text { Grupo d } \\
\text { edades } \\
\text { (años) }\end{array}$ & & & & & & & & & & & & & & & & \\
\hline $16-24$ & 84 & 83 & 81 & 44 & 76 & 74 & 62 & 43 & 62 & 69 & 81 & 81 & 17 & 75 & 62 & 66 \\
\hline $25-32$ & 84 & 61 & 74 & 46 & 71 & 60 & 65 & 48 & 71 & 52 & 71 & 64 & 65 & 60 & 44 & 61 \\
\hline $33-41$ & 79 & 82 & 73 & 71 & 64 & 67 & 62 & 70 & 67 & 71 & 78 & 75 & 64 & 75 & 65 & 66 \\
\hline $42-50$ & 86 & 79 & 90 & 73 & 69 & 73 & 58 & 58 & 71 & 60 & 80 & 70 & 47 & 69 & 59 & 65 \\
\hline $51-58$ & 65 & 100 & 75 & 100 & 55 & 74 & 56 & 72 & 51 & 80 & 62 & 75 & 58 & 68 & 56 & 33 \\
\hline $59-67$ & 47 & --- & 37 & --- & 30 & --- & 63 & --- & 62 & --- & 50 & --- & 50 & --- & 17 & --- \\
\hline
\end{tabular}

f: femenino; m: masculino

\section{Correlación entre calidad de vida y variables clínicas, inmunológicas y sociológicas}

Se realizó el análisis bivariado con el objeto de conocer cuáles son las variables que se correlacionan más significativamente con la calidad de vida y el estado de salud percibido por los pacientes, presentándose las puntuaciones para cada dimensión del Cuestionario SF-36 correspondientes a las variables sociológicas, clínicas e inmunológicas. ${ }^{132-135}$ 


\section{Correlación entre variables sociológicas y puntuación obtenida en el Cuestionario de}

\section{Salud SF-36}

Al analizar la relación entre calidad de vida y las variables sociológicas, se advirtió que la correlación entre todas las dimensiones del cuestionario y la edad, la vía de contagio de la infección por VIH y la causa del diagnóstico de la infección por VIH era escasa y no significativa, con excepción del nivel de instrucción, donde se evidenció cierto grado de correlación significativa (Tabla 22).

La distribución de la puntuación obtenida en las dimensiones del cuestionario y las variables sociológicas se muestra en la tabla 23.

Tabla 22: Correlación entre calidad de vida relacionada con la salud y variables sociológicas, en pacientes de la Unidad de Infectología. Hospital Zonal General de Agudos "Mi Pueblo". Florencio Varela, provincia de Buenos Aires, Argentina. Agosto 2005 - junio 2007.

\begin{tabular}{|l|c|c|c|c|c|c|c|c|}
\hline \multirow{2}{*}{$\begin{array}{l}\text { Variables } \\
\text { sociológicas }\end{array}$} & \multicolumn{7}{|c|}{ Dimensiones (Coeficiente de Correlación) } \\
\cline { 2 - 9 } & $\begin{array}{c}\text { Función } \\
\text { física }\end{array}$ & $\begin{array}{c}\text { Rol } \\
\text { físico }\end{array}$ & $\begin{array}{c}\text { Dolor } \\
\text { corporal }\end{array}$ & $\begin{array}{c}\text { Salud } \\
\text { general }\end{array}$ & Vitalidad & $\begin{array}{c}\text { Función } \\
\text { social }\end{array}$ & $\begin{array}{c}\text { Rol } \\
\text { emocional }\end{array}$ & $\begin{array}{c}\text { Salud } \\
\text { mental }\end{array}$ \\
\hline Edad & $\begin{array}{c}0,064 \\
(>0,05)\end{array}$ & $\begin{array}{c}0,082 \\
(>0,05)\end{array}$ & $\begin{array}{c}0,107 \\
(>0,05)\end{array}$ & $\begin{array}{c}0,053 \\
(>0,05)\end{array}$ & $\begin{array}{c}0,041 \\
(>0,05)\end{array}$ & $\begin{array}{c}0,067 \\
(>0,05)\end{array}$ & $\begin{array}{c}0,052 \\
(>0,05)\end{array}$ & $\begin{array}{c}0,053 \\
(>0,05)\end{array}$ \\
\hline $\begin{array}{l}\text { Vías de contagio } \\
\text { de la infección por } \\
\text { VIH }\end{array}$ & $\begin{array}{c}0,028 \\
(>0,05)\end{array}$ & $\begin{array}{c}0,008 \\
(>0,05)\end{array}$ & $\begin{array}{c}0 \\
(>0,05)\end{array}$ & $\begin{array}{c}0,033 \\
(>0,05)\end{array}$ & $\begin{array}{c}0,050 \\
(>0,05)\end{array}$ & $\begin{array}{c}0,082 \\
(>0,05)\end{array}$ & $\begin{array}{c}0,118 \\
(>0,05)\end{array}$ & $\begin{array}{c}0,019 \\
(>0,05)\end{array}$ \\
\hline $\begin{array}{l}\text { Causa del } \\
\text { diagnóstico de la } \\
\text { infección por VIH }\end{array}$ & $\begin{array}{c}0,182 \\
(>0,05)\end{array}$ & $\begin{array}{c}0,077 \\
(>0,05)\end{array}$ & $\begin{array}{c}0,065 \\
(>0,05)\end{array}$ & $\begin{array}{c}0,117 \\
(>0,05)\end{array}$ & $\begin{array}{c}0,049 \\
(>0,05)\end{array}$ & $\begin{array}{c}0,043 \\
(>0,05)\end{array}$ & $\begin{array}{c}0,025 \\
(>0,05)\end{array}$ & 0,012 \\
\hline $\begin{array}{l}\text { Nivel de } \\
\text { instrucción }\end{array}$ & $\begin{array}{c}0,261 \\
(<0,05)\end{array}$ & $\begin{array}{c}0,178 \\
(>0,05)\end{array}$ & $\begin{array}{c}0,092 \\
(>0,05)\end{array}$ & $\begin{array}{c}0,034 \\
(>0,05)\end{array}$ & $\begin{array}{c}0,080 \\
(>0,05)\end{array}$ & $\begin{array}{c}0,132 \\
(>0,05)\end{array}$ & $\begin{array}{c}0,125 \\
(>0,05)\end{array}$ & 0,130 \\
$(>0,05)$ \\
\hline
\end{tabular}

Con respecto al nivel de instrucción, los pacientes con estudios universitarios tuvieron las menores puntuaciones en el rol emocional.

Los pacientes que no poseían obra social, plan social y empleo, presentaron las puntuaciones más bajas en el rol emocional.

Aquellos individuos que no tenían pareja alcanzaron las puntuaciones más bajas en todas las dimensiones del cuestionario, mientras que las puntuaciones más altas se obtuvieron en personas que desconocían si su pareja tenía o no infección por VIH. 
Tabla 23. Variables sociológicas y puntuación obtenida en el Cuestionario de Salud SF-36, en pacientes de la Unidad de Infectología. Hospital Zonal General de Agudos "Mi Pueblo". Florencio Varela, provincia de Buenos Aires, Argentina. Agosto 2005 - junio 2007.

\begin{tabular}{|c|c|c|c|c|c|c|c|c|}
\hline \multirow{2}{*}{$\begin{array}{l}\text { Variables } \\
\text { sociológicas }\end{array}$} & \multicolumn{8}{|c|}{ Dimensiones } \\
\hline & $\begin{array}{c}\text { Función } \\
\text { física }\end{array}$ & $\begin{array}{c}\text { Rol } \\
\text { físico }\end{array}$ & $\begin{array}{c}\text { Dolor } \\
\text { corporal }\end{array}$ & $\begin{array}{c}\text { Salud } \\
\text { general }\end{array}$ & Vitalidad & $\begin{array}{c}\text { Función } \\
\text { social }\end{array}$ & $\begin{array}{c}\text { Rol } \\
\text { emocional }\end{array}$ & $\begin{array}{c}\text { Salud } \\
\text { mental }\end{array}$ \\
\hline $\begin{array}{l}\text { Tiene pareja } \\
\text { Sí } \\
\text { No }\end{array}$ & $\begin{array}{l}79 \\
78\end{array}$ & $\begin{array}{l}72 \\
69\end{array}$ & $\begin{array}{l}67 \\
67\end{array}$ & $\begin{array}{l}62 \\
58\end{array}$ & $\begin{array}{l}66 \\
64\end{array}$ & $\begin{array}{l}73 \\
72\end{array}$ & $\begin{array}{l}59 \\
58\end{array}$ & $\begin{array}{l}64 \\
64\end{array}$ \\
\hline $\begin{array}{l}\text { Tiene VIH su pareja } \\
\text { Sí } \\
\text { No } \\
\text { Desconoce }\end{array}$ & $\begin{array}{l}74 \\
88 \\
79\end{array}$ & $\begin{array}{l}66 \\
77 \\
83\end{array}$ & $\begin{array}{l}65 \\
69 \\
72\end{array}$ & $\begin{array}{l}60 \\
66 \\
66\end{array}$ & $\begin{array}{l}62 \\
71 \\
73\end{array}$ & $\begin{array}{l}68 \\
77 \\
85\end{array}$ & $\begin{array}{l}48 \\
70 \\
77\end{array}$ & $\begin{array}{l}58 \\
69 \\
73\end{array}$ \\
\hline $\begin{array}{l}\text { Tiene empleo } \\
\text { Sí } \\
\text { No }\end{array}$ & $\begin{array}{l}87 \\
73\end{array}$ & $\begin{array}{l}78 \\
66\end{array}$ & $\begin{array}{l}68 \\
67\end{array}$ & $\begin{array}{l}66 \\
57\end{array}$ & $\begin{array}{l}67 \\
65\end{array}$ & $\begin{array}{l}81 \\
68\end{array}$ & $\begin{array}{l}71 \\
51\end{array}$ & $\begin{array}{l}70 \\
59\end{array}$ \\
\hline $\begin{array}{l}\text { Nivel de instrucción } \\
\text { Analfabeto } \\
\text { Primaria incompleta } \\
\text { Primaria completa } \\
\text { Secundaria incompleta } \\
\text { Secundaria completa } \\
\text { Terciaria incompleta } \\
\text { Terciaria completa } \\
\text { Universitaria incompleta } \\
\text { Universitaria completa }\end{array}$ & $\begin{array}{c}70 \\
80 \\
69 \\
78 \\
92 \\
91 \\
97 \\
90 \\
100 \\
\end{array}$ & $\begin{array}{c}67 \\
68 \\
67 \\
66 \\
81 \\
81 \\
100 \\
87 \\
100 \\
\end{array}$ & $\begin{array}{l}59 \\
63 \\
70 \\
61 \\
73 \\
74 \\
81 \\
57 \\
84 \\
\end{array}$ & $\begin{array}{l}81 \\
51 \\
63 \\
57 \\
67 \\
48 \\
57 \\
66 \\
82 \\
\end{array}$ & $\begin{array}{l}80 \\
64 \\
65 \\
59 \\
73 \\
69 \\
75 \\
72 \\
70 \\
\end{array}$ & $\begin{array}{c}92 \\
68 \\
69 \\
69 \\
87 \\
69 \\
91 \\
62 \\
100 \\
\end{array}$ & $\begin{array}{l}67 \\
53 \\
51 \\
56 \\
78 \\
75 \\
83 \\
50 \\
33 \\
\end{array}$ & $\begin{array}{l}73 \\
58 \\
64 \\
57 \\
74 \\
70 \\
71 \\
62 \\
88 \\
\end{array}$ \\
\hline $\begin{array}{l}\text { Tiene obra social } \\
\text { Sí } \\
\text { No }\end{array}$ & $\begin{array}{l}82 \\
78 \\
\end{array}$ & $\begin{array}{l}78 \\
70\end{array}$ & $\begin{array}{l}57 \\
70\end{array}$ & $\begin{array}{l}61 \\
61\end{array}$ & $\begin{array}{l}64 \\
63\end{array}$ & $\begin{array}{l}71 \\
73\end{array}$ & $\begin{array}{l}54 \\
60\end{array}$ & $\begin{array}{l}63 \\
64\end{array}$ \\
\hline $\begin{array}{l}\text { Tiene plan social } \\
\text { Sí } \\
\text { No }\end{array}$ & $\begin{array}{l}84 \\
76\end{array}$ & $\begin{array}{l}69 \\
72\end{array}$ & $\begin{array}{l}68 \\
67\end{array}$ & $\begin{array}{l}62 \\
60\end{array}$ & $\begin{array}{l}65 \\
66\end{array}$ & $\begin{array}{l}78 \\
71\end{array}$ & $\begin{array}{l}64 \\
57\end{array}$ & $\begin{array}{l}62 \\
64\end{array}$ \\
\hline
\end{tabular}

\section{Correlación entre variables clínicas y puntuación obtenida en el Cuestionario de Salud} SF-36

La correlación entre el rol físico, dolor corporal, salud general, vitalidad, función social y salud mental con las variables clínicas, fue escasa.

Se evidenció fuerte relación no significativa entre el rol emocional y los años de diagnóstico de la infección por VIH.

Se observó escasa correlación significativa entre el rol físico y la ocurrencia de hospitalizaciones, entre salud general y el número de tratamientos antiretrovirales, entre vitalidad y número de adicciones, entre función social, presencia y número de adicciones y entre la salud mental con el número de tratamientos antiretrovirales recibidos. ${ }^{132,133}$

No se encontró correlación entre enfermedad marcadora y dolor corporal.

Se encontró cierto grado de correlación significativa entre la función física, el número de enfermedades marcadoras de SIDA y las hospitalizaciones. 
La correlación entre la función física con el número de comorbilidades y el tipo tratamiento antiretroviral fue escasa y técnicamente significativa, mientras que el número de adicciones, presencia de adicciones, comorbilidades, inicio del tratamiento antiretroviral y número de tratamientos antiretrovirales realizados con la función física presentaron una correlación escasa y no significativa. ${ }^{133,134}$

Se evidenció escasa correlación significativa entre los años de diagnóstico de la infección por VIH y la función física, el rol físico, el dolor corporal y la vitalidad (Tabla 24). 134,135

Tabla 24: Correlación entre calidad de vida relacionada con la salud y variables clínicas, en pacientes de la Unidad de Infectología. Hospital Zonal General de Agudos "Mi Pueblo". Florencio Varela, provincia de Buenos Aires, Argentina. Agosto 2005 - junio 2007.

\begin{tabular}{|c|c|c|c|c|c|c|c|c|}
\hline \multirow{2}{*}{$\begin{array}{l}\text { Variables } \\
\text { clínicas }\end{array}$} & \multicolumn{8}{|c|}{ Dimensiones (Coeficiente de Correlación) } \\
\hline & $\begin{array}{c}\text { Función } \\
\text { física }\end{array}$ & $\begin{array}{c}\text { Rol } \\
\text { físico }\end{array}$ & $\begin{array}{c}\text { Dolor } \\
\text { corporal }\end{array}$ & $\begin{array}{c}\text { Salud } \\
\text { general }\end{array}$ & Vitalidad & $\begin{array}{c}\begin{array}{c}\text { Función } \\
\text { social }\end{array} \\
\end{array}$ & $\begin{array}{c}\text { Rol } \\
\text { emocional }\end{array}$ & $\begin{array}{c}\text { Salud } \\
\text { mental }\end{array}$ \\
\hline $\begin{array}{l}\text { Años de } \\
\text { diagnóstico de la } \\
\text { infección por } \\
\text { VIH }\end{array}$ & $\begin{array}{c}0,233 \\
(>0,05)\end{array}$ & $\begin{array}{c}0,192 \\
(>0,05)\end{array}$ & $\begin{array}{c}0,248 \\
(<0,05)\end{array}$ & $\begin{array}{c}0,115 \\
(>0,05)\end{array}$ & $\begin{array}{c}0,203 \\
(<0,05)\end{array}$ & $\begin{array}{c}0,183 \\
(>0,05)\end{array}$ & $\begin{array}{l}1,090 \\
(>0,05)\end{array}$ & $\begin{array}{c}0,155 \\
(>0,05)\end{array}$ \\
\hline $\begin{array}{l}\text { Número de } \\
\text { enfermedades } \\
\text { marcadoras de } \\
\text { SIDA }\end{array}$ & $\begin{array}{c}0,321 \\
(<0,05)\end{array}$ & $\begin{array}{c}0,063 \\
(>0,05)\end{array}$ & $\begin{array}{c}0 \\
(>0,05)\end{array}$ & $\begin{array}{c}0,074 \\
(>0,05)\end{array}$ & $\begin{array}{c}0,047 \\
(>0,05)\end{array}$ & $\begin{array}{c}0,087 \\
(>0,05)\end{array}$ & $\begin{array}{c}0,028 \\
(>0,05)\end{array}$ & $\begin{array}{c}0,022 \\
(>0,05)\end{array}$ \\
\hline $\begin{array}{l}\text { Número de } \\
\text { adicciones }\end{array}$ & $\begin{array}{c}0,142 \\
(>0,05)\end{array}$ & $\begin{array}{c}0,182 \\
(>0,05)\end{array}$ & $\begin{array}{c}0,015 \\
(>0,05)\end{array}$ & $\begin{array}{c}0,112 \\
(>0,05)\end{array}$ & $\begin{array}{c}0,191 \\
(<0,05)\end{array}$ & $\begin{array}{c}0,244 \\
(<0,05)\end{array}$ & $\begin{array}{c}0,038 \\
(>0,05)\end{array}$ & $\begin{array}{c}0,106 \\
(>0,05)\end{array}$ \\
\hline Adicciones & $\begin{array}{c}0,001 \\
(>0,05)\end{array}$ & $\begin{array}{c}0,126 \\
(>0,05)\end{array}$ & $\begin{array}{c}0,066 \\
(>0,05)\end{array}$ & $\begin{array}{c}0,096 \\
(>0,05)\end{array}$ & $\begin{array}{c}0,102 \\
(>0,05)\end{array}$ & $\begin{array}{c}0,185 \\
(<0,05)\end{array}$ & $\begin{array}{c}0,027 \\
(>0,05)\end{array}$ & $\begin{array}{c}0,071 \\
(>0,05)\end{array}$ \\
\hline $\begin{array}{l}\text { Número de } \\
\text { comorbilidades }\end{array}$ & $\begin{array}{c}0,183 \\
(<0,05)\end{array}$ & $\begin{array}{c}0,091 \\
(>0,05)\end{array}$ & $\begin{array}{c}0,052 \\
(>0,05)\end{array}$ & $\begin{array}{c}0,162 \\
(>0,05)\end{array}$ & $\begin{array}{c}0,126 \\
(>0,05)\end{array}$ & $\begin{array}{c}0,166 \\
(>0,05)\end{array}$ & $\begin{array}{c}0,068 \\
(>0,05)\end{array}$ & $\begin{array}{c}0,116 \\
(>0,05)\end{array}$ \\
\hline Comorbilidades & $\begin{array}{c}0,084 \\
(>0,05)\end{array}$ & $\begin{array}{c}0,080 \\
(>0,05)\end{array}$ & $\begin{array}{c}0,155 \\
(>0,05)\end{array}$ & $\begin{array}{c}0,162 \\
(>0,05)\end{array}$ & $\begin{array}{c}0,123 \\
(>0,05)\end{array}$ & $\begin{array}{c}0,027 \\
(>0,05)\end{array}$ & $\begin{array}{c}0,103 \\
(>0,05)\end{array}$ & $\begin{array}{c}0,128 \\
(>0,05)\end{array}$ \\
\hline $\begin{array}{l}\text { Inicio de } \\
\text { tratamiento } \\
\text { antiretroviral }\end{array}$ & $\begin{array}{c}0,161 \\
(>0,05)\end{array}$ & $\begin{array}{c}0,103 \\
(>0,05)\end{array}$ & $\begin{array}{c}0,043 \\
(>0,05)\end{array}$ & $\begin{array}{c}0,139 \\
(>0,05)\end{array}$ & $\begin{array}{c}0,149 \\
(>0,05)\end{array}$ & $\begin{array}{c}0,033 \\
(>0,05)\end{array}$ & $\begin{array}{c}0,052 \\
(>0,05)\end{array}$ & $\begin{array}{c}0,101 \\
(>0,05)\end{array}$ \\
\hline $\begin{array}{l}\text { Tipo de } \\
\text { tratamiento } \\
\text { antiretroviral }\end{array}$ & $\begin{array}{c}0,225 \\
(<0,05)\end{array}$ & $\begin{array}{c}0,066 \\
(>0,05)\end{array}$ & $\begin{array}{c}0,027 \\
(>0,05)\end{array}$ & $\begin{array}{c}0,063 \\
(>0,05)\end{array}$ & $\begin{array}{c}0,115 \\
(>0,05)\end{array}$ & $\begin{array}{c}0,021 \\
(>0,05)\end{array}$ & $\begin{array}{c}0,048 \\
(>0,05)\end{array}$ & $\begin{array}{c}0,011 \\
(>0,05)\end{array}$ \\
\hline $\begin{array}{l}\text { Número de } \\
\text { tratamientos } \\
\text { antiretrovirales } \\
\text { recibidos (switch) }\end{array}$ & $\begin{array}{c}0,178 \\
(>0,05)\end{array}$ & $\begin{array}{c}0,121 \\
(>0,05)\end{array}$ & $\begin{array}{c}0,064 \\
(>0,05)\end{array}$ & $\begin{array}{c}0,218 \\
(<0,05)\end{array}$ & $\begin{array}{c}0,203 \\
(<0,05)\end{array}$ & $\begin{array}{c}0,176 \\
(>0,05)\end{array}$ & $\begin{array}{c}0,083 \\
(>0,05)\end{array}$ & $\begin{array}{c}0,238 \\
(<0,05)\end{array}$ \\
\hline Hospitalizaciones & $\begin{array}{c}0,275 \\
(<0,05)\end{array}$ & $\begin{array}{c}0,188 \\
(<0,05)\end{array}$ & $\begin{array}{c}0,118 \\
(>0,05)\end{array}$ & $\begin{array}{c}0,128 \\
(>0,05)\end{array}$ & $\begin{array}{c}0,134 \\
(>0,05)\end{array}$ & $\begin{array}{c}0,164 \\
(>0,05)\end{array}$ & $\begin{array}{c}0,003 \\
(>0,05)\end{array}$ & $\begin{array}{c}0,090 \\
(>0,05)\end{array}$ \\
\hline
\end{tabular}

Los pacientes que tuvieron enfermedad marcadora de SIDA presentan más bajas puntuaciones en la función física, rol físico, salud general, vitalidad y función social (Tabla 25). 
Tabla 25: Ocurrencia de enfermedad marcadora y puntuación obtenida en el cuestionario de salud SF36, en pacientes de la Unidad de Infectología. Hospital Zonal General de Agudos "Mi Pueblo". Florencio Varela, provincia de Buenos Aires, Argentina. Agosto 2005 - junio 2007.

\begin{tabular}{|l|c|c|c|c|c|c|c|c|}
\hline \multirow{2}{*}{$\begin{array}{c}\text { Ocurrencia } \\
\text { de } \\
\text { enfermedad } \\
\text { marcadora }\end{array}$} & \multicolumn{7}{|c|}{ Dimensiones } \\
\cline { 2 - 9 } & $\begin{array}{c}\text { Función } \\
\text { física }\end{array}$ & $\begin{array}{c}\text { Rol } \\
\text { físico }\end{array}$ & $\begin{array}{c}\text { Dolor } \\
\text { corporal }\end{array}$ & $\begin{array}{c}\text { Salud } \\
\text { general }\end{array}$ & Vitalidad & $\begin{array}{c}\text { Función } \\
\text { social }\end{array}$ & $\begin{array}{c}\text { Rol } \\
\text { emocional }\end{array}$ & $\begin{array}{c}\text { Salud } \\
\text { mental }\end{array}$ \\
\hline Sí & 74 & 68 & 68 & 59 & 64 & 71 & 62 & 64 \\
No & 82 & 74 & 67 & 63 & 67 & 75 & 56 & 64 \\
\hline
\end{tabular}

Las puntuaciones del cuestionario disminuyeron al aumentar el número de enfermedades marcadoras padecidas por los pacientes, en la función física, dolor corporal, vitalidad, función social y salud mental (Tabla 26).

Tabla 26: Número de enfermedades marcadoras y puntuación obtenida en el cuestionario de salud en pacientes de la Unidad de Infectología. Hospital Zonal General de Agudos "Mi Pueblo". Florencio Varela, provincia de Buenos Aires, Argentina. Agosto 2005 - junio 2007.

\begin{tabular}{|l|c|c|c|c|c|c|c|c|}
\hline \multirow{2}{*}{$\begin{array}{c}\text { Número de } \\
\text { enfermedades } \\
\text { marcadoras }\end{array}$} & \multicolumn{7}{|c|}{ Dimensiones } \\
\cline { 2 - 9 } & $\begin{array}{c}\text { Función } \\
\text { física }\end{array}$ & $\begin{array}{c}\text { Rol } \\
\text { físico }\end{array}$ & $\begin{array}{c}\text { Dolor } \\
\text { corporal }\end{array}$ & $\begin{array}{c}\text { Salud } \\
\text { general }\end{array}$ & Vitalidad & $\begin{array}{c}\text { Función } \\
\text { social }\end{array}$ & $\begin{array}{c}\text { Rol } \\
\text { emocional }\end{array}$ & $\begin{array}{c}\text { Salud } \\
\text { mental }\end{array}$ \\
\hline Una & 87 & 71 & 70 & 60 & 64 & 72 & 68 & 61 \\
Dos & 73 & 59 & 65 & 58 & 63 & 73 & 65 & 72 \\
Tres & 50 & 73 & 71 & 57 & 70 & 69 & 45 & 58 \\
Cuatro & 60 & 75 & 57 & 66 & 50 & 56 & 83 & 58 \\
\hline
\end{tabular}

Cuanto más años han transcurrido desde el diagnóstico de la infección por VIH/SIDA, se presenta menor puntuación en todas las dimensiones; los puntajes más bajos se observaron en los pacientes con 10 años desde el diagnóstico, principalmente en el rol emocional (Tabla 27).

Los pacientes que requirieron hospitalización en algún momento de la evolución de su enfermedad han tenido puntuaciones más bajas en todas las dimensiones del cuestionario (Tabla 28). 
Tabla 27: Años de diagnóstico de la infección por VIH y puntuación obtenida en el cuestionario de salud SF-36, en pacientes de la Unidad de Infectología. Hospital Zonal General de Agudos "Mi Pueblo”. Florencio Varela, provincia de Buenos Aires, Argentina. Agosto 2005 - junio 2007.

\begin{tabular}{|l|c|c|c|c|c|c|c|c|}
\hline \multirow{2}{*}{$\begin{array}{c}\text { Años de } \\
\text { diagnóstico }\end{array}$} & \multicolumn{7}{|c|}{ Dimensiones } \\
\cline { 2 - 8 } & $\begin{array}{c}\text { Función } \\
\text { física }\end{array}$ & $\begin{array}{c}\text { Rol } \\
\text { físico }\end{array}$ & $\begin{array}{c}\text { Dolor } \\
\text { corporal }\end{array}$ & $\begin{array}{c}\text { Salud } \\
\text { general }\end{array}$ & Vitalidad & $\begin{array}{c}\text { Función } \\
\text { social }\end{array}$ & $\begin{array}{c}\text { Rol } \\
\text { emocional }\end{array}$ & $\begin{array}{c}\text { Salud } \\
\text { mental }\end{array}$ \\
\hline Dos & 78 & 76 & 73 & 68 & 73 & 80 & 68 & 74 \\
Seis & 81 & 69 & 55 & 60 & 60 & 75 & 59 & 65 \\
Diez & 49 & 63 & 69 & 61 & 62 & 53 & 8 & 55 \\
\hline
\end{tabular}

Tabla 28: Hospitalizaciones y puntuación obtenida en el cuestionario de salud SF-36, en pacientes de la Unidad de Infectología. Hospital Zonal General de Agudos "Mi Pueblo". Florencio Varela, provincia de Buenos Aires, Argentina. Agosto 2005 - junio 2007.

\begin{tabular}{|l|c|c|c|c|c|c|c|c|}
\hline \multirow{2}{*}{$\begin{array}{c}\text { Tuvo } \\
\text { hospitalizaciones }\end{array}$} & \multicolumn{7}{|c|}{ Dimensiones } \\
\cline { 2 - 9 } & $\begin{array}{c}\text { Función } \\
\text { física }\end{array}$ & $\begin{array}{c}\text { Rol } \\
\text { físico }\end{array}$ & $\begin{array}{c}\text { Dolor } \\
\text { corporal }\end{array}$ & $\begin{array}{c}\text { Salud } \\
\text { general }\end{array}$ & Vitalidad & $\begin{array}{c}\text { Función } \\
\text { social }\end{array}$ & $\begin{array}{c}\text { Rol } \\
\text { emocional }\end{array}$ & $\begin{array}{c}\text { Salud } \\
\text { mental }\end{array}$ \\
\hline Sí & 71 & 63 & 64 & 58 & 63 & 68 & 59 & 62 \\
No & 86 & 78 & 70 & 64 & 68 & 77 & 59 & 66 \\
\hline
\end{tabular}

El aumento en el número de adicciones también determinó las puntuaciones más bajas en todas las dimensiones, sobre todo en los pacientes con 4 o más adicciones, principalmente en salud general, rol físico y rol emocional (Tabla 29).

Tabla 29: Número de adicciones y puntuación obtenida en el cuestionario de salud SF-36, en pacientes de la Unidad de Infectología. Hospital Zonal General de Agudos "Mi Pueblo". Florencio Varela, provincia de Buenos Aires, Argentina. Agosto 2005 - junio 2007.

\begin{tabular}{|l|c|c|c|c|c|c|c|c|}
\hline \multirow{2}{*}{$\begin{array}{c}\text { Número de } \\
\text { adicciones }\end{array}$} & \multicolumn{9}{|c|}{ Dimensiones } \\
\cline { 2 - 9 } & $\begin{array}{c}\text { Función } \\
\text { física }\end{array}$ & $\begin{array}{c}\text { Rol } \\
\text { físico }\end{array}$ & $\begin{array}{c}\text { Dolor } \\
\text { corporal }\end{array}$ & $\begin{array}{c}\text { Salud } \\
\text { general }\end{array}$ & Vitalidad & $\begin{array}{c}\text { Función } \\
\text { social }\end{array}$ & $\begin{array}{c}\text { Rol } \\
\text { emocional }\end{array}$ & $\begin{array}{c}\text { Salud } \\
\text { mental }\end{array}$ \\
\hline Ninguna & 83 & 76 & 66 & 61 & 68 & 77 & 57 & 65 \\
Una & 71 & 78 & 73 & 62 & 68 & 73 & 71 & 67 \\
Dos & 74 & 62 & 70 & 65 & 59 & 72 & 52 & 60 \\
Tres & 92 & 69 & 62 & 64 & 67 & 71 & 63 & 62 \\
Cuatro & 62 & 47 & 64 & 45 & 53 & 50 & 47 & 58 \\
\hline
\end{tabular}


Los individuos con mayor número de comorbilidades presentaron menores puntuaciones en todas las dimensiones, especialmente en salud general y rol emocional (Tabla 30).

Tabla 30: Número de comorbilidades y puntuación obtenida en el cuestionario de salud SF-36, en pacientes de la Unidad de Infectología. Hospital Zonal General de Agudos "Mi Pueblo". Florencio Varela, provincia de Buenos Aires, Argentina. Agosto 2005 - junio 2007.

\begin{tabular}{|l|c|c|c|c|c|c|c|c|}
\hline \multirow{2}{*}{$\begin{array}{c}\text { Número de } \\
\text { comorbilidades }\end{array}$} & \multicolumn{8}{|c|}{ Dimensiones } \\
\cline { 2 - 9 } & $\begin{array}{c}\text { Función } \\
\text { física }\end{array}$ & $\begin{array}{c}\text { Rol } \\
\text { físico }\end{array}$ & $\begin{array}{c}\text { Dolor } \\
\text { corporal }\end{array}$ & $\begin{array}{c}\text { Salud } \\
\text { general }\end{array}$ & Vitalidad & $\begin{array}{c}\text { Función } \\
\text { social }\end{array}$ & $\begin{array}{c}\text { Rol } \\
\text { emocional }\end{array}$ & $\begin{array}{c}\text { Salud } \\
\text { mental }\end{array}$ \\
\hline Ninguna & 84 & 82 & 75 & 70 & 71 & 81 & 66 & 70 \\
Una & 78 & 63 & 59 & 56 & 63 & 69 & 58 & 62 \\
Dos & 80 & 64 & 63 & 49 & 59 & 72 & 40 & 53 \\
Tres & 68 & 73 & 72 & 63 & 66 & 67 & 63 & 66 \\
\hline
\end{tabular}

Aquellos pacientes que recibían TARGA desde hace 8 o más años, tenían los puntajes más bajos en el rol emocional, salud general, vitalidad, dolor corporal, salud mental, función social y función física (Tabla 31).

Tabla 31: Inicio de tratamiento antiretroviral de gran actividad y puntuación obtenida en el cuestionario de salud SF-36, en pacientes de la Unidad de Infectología. Hospital Zonal General de Agudos "Mi Pueblo". Florencio Varela, provincia de Buenos Aires, Argentina. Agosto 2005 - junio 2007.

\begin{tabular}{|l|c|c|c|c|c|c|c|c|}
\hline \multirow{2}{*}{$\begin{array}{c}\text { Inicio del } \\
\text { TARGA }\end{array}$} & \multicolumn{7}{|c|}{ Dimensiones } \\
\cline { 2 - 8 } & $\begin{array}{c}\text { Función } \\
\text { física }\end{array}$ & $\begin{array}{c}\text { Rol } \\
\text { físico }\end{array}$ & $\begin{array}{c}\text { Dolor } \\
\text { corporal }\end{array}$ & $\begin{array}{c}\text { Salud } \\
\text { general }\end{array}$ & Vitalidad & $\begin{array}{c}\text { Función } \\
\text { social }\end{array}$ & $\begin{array}{c}\text { Rol } \\
\text { emocional }\end{array}$ & $\begin{array}{c}\text { Salud } \\
\text { mental }\end{array}$ \\
\hline No inició & 84 & 75 & 73 & 65 & 70 & 79 & 66 & 67 \\
Inició & & & & & & & & \\
hace 1 año & 83 & 65 & 75 & 57 & 69 & 72 & 67 & 56 \\
hace 4 años & 85 & 79 & 76 & 72 & 65 & 71 & 59 & 83 \\
hace 8 años & 72 & 80 & 67 & 57 & 63 & 70 & 52 & 60 \\
\hline
\end{tabular}

El tipo de tratamiento antiretroviral también condicionó diferencias en las puntuaciones observadas; la menor puntuación en la función física y el rol físico se presentaron en los pacientes medicados con regímenes que incluían drogas inhibidoras de la proteasa, asociadas a otros inhibidores de la transcriptasa reversa (Tabla 32). 
Tabla 32: Asociación de drogas antiretrovirales recibidas y puntuación obtenida en el cuestionario de salud SF-36, en pacientes de la Unidad de Infectología. Hospital Zonal General de Agudos "Mi Pueblo”. Florencio Varela, provincia de Buenos Aires, Argentina. Agosto 2005 - junio 2007.

\begin{tabular}{|l|c|c|c|c|c|c|c|c|}
\hline \multirow{2}{*}{$\begin{array}{c}\text { Asociación de } \\
\text { drogas } \\
\text { antiretrovirales }\end{array}$} & \multicolumn{7}{|c|}{ Dimensiones } \\
\cline { 2 - 9 } & $\begin{array}{c}\text { Función } \\
\text { física }\end{array}$ & $\begin{array}{c}\text { Rol } \\
\text { físico }\end{array}$ & $\begin{array}{c}\text { Dolor } \\
\text { corporal }\end{array}$ & $\begin{array}{c}\text { Salud } \\
\text { general }\end{array}$ & Vitalidad & $\begin{array}{c}\text { Función } \\
\text { social }\end{array}$ & $\begin{array}{c}\text { Rol } \\
\text { emocional }\end{array}$ & $\begin{array}{c}\text { Salud } \\
\text { mental }\end{array}$ \\
\hline 2 INTR + 1 INNTR & 79 & 70 & 63 & 59 & 64 & 67 & 50 & 62 \\
3 INTR & 95 & 85 & 59 & 73 & 72 & 85 & 70 & 80 \\
2 INTR + 1 IP & 69 & 69 & 66 & 53 & 61 & 73 & 60 & 60 \\
2 INTR + 2 IP & 59 & 61 & 84 & 67 & 63 & 84 & 76 & 72 \\
\hline
\end{tabular}

INTR: Inhibidor nucleósido de la transcriptasa reversa;

INNTR: Inhibidor no nucleósido de la transcriptasa reversa

IP: inhibidor de la proteasa

Se observó que los pacientes que durante el transcurso de su enfermedad requirieron cuatro o más cambios en el TARGA, poseían puntuaciones más bajas en la función física, rol físico y vitalidad (Tabla 33).

Tabla 33: Número de tratamientos antiretrovirales recibidos (switch) y puntuación obtenida en el cuestionario de salud SF-36, en pacientes de la Unidad de Infectología. Hospital Zonal General de Agudos "Mi Pueblo". Florencio Varela, provincia de Buenos Aires, Argentina. Agosto 2005 - junio 2007.

\begin{tabular}{|l|c|c|c|c|c|c|c|c|}
\hline $\begin{array}{c}\text { Número de } \\
\text { tratamientos } \\
\text { antiretrovirales } \\
\text { recibidos } \\
\text { (switch) }\end{array}$ & \multicolumn{9}{|c|}{ Dimensiones } \\
\cline { 2 - 9 } & $\begin{array}{c}\text { Función } \\
\text { física }\end{array}$ & $\begin{array}{c}\text { Rol } \\
\text { físico }\end{array}$ & $\begin{array}{c}\text { Dolor } \\
\text { corporal }\end{array}$ & $\begin{array}{c}\text { Salud } \\
\text { general }\end{array}$ & Vitalidad & $\begin{array}{c}\text { Función } \\
\text { social }\end{array}$ & $\begin{array}{c}\text { Rol } \\
\text { emocional }\end{array}$ & $\begin{array}{c}\text { Salud } \\
\text { mental }\end{array}$ \\
\hline Ninguno & 84 & 75 & 73 & 65 & 70 & 79 & 66 & 67 \\
Uno & 79 & 70 & 63 & 59 & 64 & 67 & 50 & 62 \\
Dos & 95 & 85 & 59 & 73 & 72 & 85 & 80 & 69 \\
Tres & 69 & 69 & 66 & 53 & 61 & 73 & 60 & 60 \\
Cuatro & 54 & 61 & 85 & 67 & 63 & 84 & 76 & 72 \\
\hline
\end{tabular}

\section{Correlación entre variables inmunológicas y puntuación obtenida en el Cuestionario de}

\section{Salud SF-36}

La correlación entre rol físico, dolor corporal, vitalidad, función social, rol emocional, salud mental y las variables inmunológicas fue escasa y técnicamente no significativa. 
Se observó escasa correlación significativa entre el recuento de $\mathrm{LT}$ CD4+, la presencia de carga viral detectable, número de copias de RNA viral y salud general.

La correlación entre función física y variables inmunológicas tuvo un comportamiento diferencial; la carga viral y el número de copias expresó escasa correlación, mientras que se manifestó cierto grado de correlación significativo con el recuento de LT CD4+ (Tabla 34). $131-134$

En las tablas 35 y 36 se presentan las puntuaciones obtenidas en las dimensiones del cuestionario según la situación inmunológica y virológica del paciente.

Los individuos que se encontraban en fases avanzadas de la infección por VIH/SIDA, es decir, que poseían un recuento de LT CD4+ menor de $200 / \mathrm{mm}^{3}$ y carga viral plasmática mayor de 100.000 copias/mL, presentaron puntuaciones menores en todas las dimensiones, salvo en dolor corporal.

Tabla 34: Correlación entre calidad de vida relacionada con la salud y variables inmunológicas, en pacientes de la Unidad de Infectología. Hospital Zonal General de Agudos "Mi Pueblo". Florencio Varela, provincia de Buenos Aires, Argentina. Agosto 2005 - junio 2007.

\begin{tabular}{|l|c|c|c|c|c|c|c|c|}
\hline \multirow{2}{*}{$\begin{array}{c}\text { Variables } \\
\text { inmunológicas }\end{array}$} & \multicolumn{7}{|c|}{ Dimensiones (Coeficiente de Correlación) } \\
\cline { 2 - 9 } & $\begin{array}{c}\text { Función } \\
\text { física }\end{array}$ & $\begin{array}{c}\text { Rol } \\
\text { físico }\end{array}$ & $\begin{array}{c}\text { Dolor } \\
\text { corporal }\end{array}$ & $\begin{array}{c}\text { Salud } \\
\text { general }\end{array}$ & Vitalidad & $\begin{array}{c}\text { Función } \\
\text { social }\end{array}$ & $\begin{array}{c}\text { Rol } \\
\text { emocional }\end{array}$ & $\begin{array}{c}\text { Salud } \\
\text { mental }\end{array}$ \\
\hline Linfocitos T & 0,315 & 0,175 & 0,035 & 0,257 & 0,167 & 0,141 & 0,117 & 0,122 \\
$\mathrm{CD} 4+$ & $(<0,05)$ & $(>0,05)$ & $(>0,05)$ & $(<0,05)$ & $(>0,05)$ & $(>0,05)$ & $(>0,05)$ & $(>0,05)$ \\
\hline $\begin{array}{l}\text { Carga viral } \\
\text { detectable/ } \\
\text { indetectable }\end{array}$ & 0,084 & 0,087 & 0,093 & 0,217 & 0,044 & 0,030 & 0,004 & 0,042 \\
\hline $\begin{array}{l}\mathrm{N}^{\circ} \text { copias carga } \\
\text { viral }\end{array}$ & $\begin{array}{c}(>0,05) \\
(>0,05)\end{array}$ & $(>0,05)$ & $(<0,05)$ & $(>0,05)$ & $(>0,05)$ & $(>0,05)$ & $(>0,05)$ \\
\hline & $(>0,05)$ & $(>0,05)$ & 0,071 & 0,249 & 0,054 & 0,045 & 0,009 & 0,031 \\
$(>0,05)$ & $(<0,05)$ & $(>0,05)$ & $(>0,05)$ & $(>0,05)$ & $(>0,05)$ \\
\hline
\end{tabular}

Tabla 35: Recuento de linfocitos T CD4 y puntuación obtenida en el cuestionario de salud SF-36, en pacientes de la Unidad de Infectología. Hospital Zonal General de Agudos "Mi Pueblo". Florencio Varela, provincia de Buenos Aires, Argentina. Agosto 2005 - junio 2007.

\begin{tabular}{|l|c|c|c|c|c|c|c|c|}
\hline $\begin{array}{c}\text { Recuento de } \\
\text { linfocitos T } \\
\text { CD4+ }\end{array}$ & \multicolumn{9}{|c|}{ Dimensiones } \\
\cline { 2 - 9 } & $\begin{array}{c}\text { Función } \\
\text { física }\end{array}$ & $\begin{array}{c}\text { Rol } \\
\text { físico }\end{array}$ & $\begin{array}{c}\text { Dolor } \\
\text { corporal }\end{array}$ & $\begin{array}{c}\text { Salud } \\
\text { general }\end{array}$ & Vitalidad & $\begin{array}{c}\text { Función } \\
\text { social }\end{array}$ & $\begin{array}{c}\text { Rol } \\
\text { emocional }\end{array}$ & $\begin{array}{c}\text { Salud } \\
\text { mental }\end{array}$ \\
\hline$<200$ & 66 & 59 & 68 & 53 & 61 & 68 & 52 & 62 \\
$201-350$ & 86 & 80 & 69 & 63 & 67 & 74 & 61 & 62 \\
$>350$ & 86 & 76 & 65 & 67 & 70 & 78 & 65 & 69 \\
\hline
\end{tabular}


Tabla 36: Número de copias de carga viral y puntuación obtenida en el cuestionario de salud SF-36, en pacientes de la Unidad de Infectología. Hospital Zonal General de Agudos "Mi Pueblo". Florencio Varela, provincia de Buenos Aires, Argentina. Agosto 2005 - junio 2007.

\begin{tabular}{|l|c|c|c|c|c|c|c|c|}
\hline $\begin{array}{c}\text { Número de } \\
\text { copias de } \\
\text { carga viral } \\
\text { plasmática }\end{array}$ & \multicolumn{9}{|c|}{ Dimensiones } \\
\cline { 2 - 9 } & $\begin{array}{c}\text { Función } \\
\text { física }\end{array}$ & $\begin{array}{c}\text { Rol } \\
\text { físico }\end{array}$ & $\begin{array}{c}\text { Dolor } \\
\text { corporal }\end{array}$ & $\begin{array}{c}\text { Salud } \\
\text { general }\end{array}$ & Vitalidad & $\begin{array}{c}\text { Función } \\
\text { social }\end{array}$ & $\begin{array}{c}\text { Rol } \\
\text { emocional }\end{array}$ & $\begin{array}{c}\text { Salud } \\
\text { mental }\end{array}$ \\
\hline$<50.000$ & 81 & 78 & 74 & 64 & 49 & 76 & 65 & 68 \\
$50.001-$ & 84 & 65 & 61 & 51 & 69 & 74 & 77 & 64 \\
100.000 & 62 & 47 & 60 & 41 & 54 & 60 & 31 & 52 \\
$>100.000$ & & & & & & & & \\
\hline
\end{tabular}




\section{DISCUSIÓN}

En este estudio se ha administrado la versión española del Cuestionario de Salud SF36 a la población de pacientes que viven con VIH/SIDA en el partido de Florencio Varela, mayores de 16 años, que se atienden en la Unidad de Infectología del Hospital Zonal General de Agudos "Mi Pueblo".

La ventaja de utilizar este instrumento genérico para evaluar la CVRS reside en la posibilidad de poder comparar los resultados obtenidos de nuestra población con valores de referencia de la población general Argentina y con otras poblaciones que padecen diferentes enfermedades crónicas.

Se han estudiado características socio-epidemiológicas, clínicas, e inmunológicas para conocer el perfil de los individuos evaluados.

Se trata de una población de adultos jóvenes, con una edad promedio de 33 años y predominio de mujeres. Son personas con un escaso nivel socio cultural; en su mayoría poseen escolaridad primaria completa; dos tercios no poseen empleo ni perciben planes sociales y sólo 2 de cada 10 sujetos poseen obra social. Estas características hacen que los pacientes dependan exclusivamente del sistema de salud estatal, tanto del hospital como del Programa Nacional de SIDA para el suministro de atención médica, tratamiento antiretroviral y realización de estudios de laboratorio y otros exámenes complementarios para el control y seguimiento clínico de su enfermedad. Gran parte de los individuos requiere de los bolsones de alimentos que entrega la Secretaría de Acción Social de la Municipalidad para poder alimentar a sus familias y a sí mismos, lo que los sitúa en un contexto de gran vulnerabilidad, ya que los vaivenes de la situación política son los que, lamentablemente, rigen la mayor o menor afluencia de elementos para paliar las necesidades básicas de estas personas.

Argentina figura entre los países del mundo que afrontó los elevados costos de la terapéutica antiretroviral a escala poblacional a través de su compra y provisión a las jurisdicciones sanitarias por parte de un programa nacional y a través de normas regulatorias del ámbito de salud de obras sociales y empresas de medicina prepagas. Este acceso se inició a principios de la década de 1990 y se generalizó a partir de 1997, con cierta demora respecto de otros países más desarrollados del mundo pero antes que muchos otros países latinoamericanos. Sin embargo, vemos día a día que la mera provisión de antiretrovirales está muy lejos de ser suficiente para el tratamiento integral de nuestros pacientes. Los fármacos utilizados para el tratamiento de otras comorbilidades que presentan los pacientes, que no suministra el 
Programa Nacional de SIDA (antibióticos, hipoglucemiantes orales, anticonvulsivantes, antihipertensivos, etc.) son provistos por donaciones de la industria farmacológica en algunos casos; en otros pocos casos su compra es solventada por el Hospital y para el resto de los pacientes no hay tratamiento disponible. Un Programa Nacional eficiente debería solventar e implementar todos los requerimientos necesarios para el tratamiento integral de las personas que viven con VIH/SIDA.

La mitad de la población se diagnostica luego de los primeros 5 años de la infección, lo que en muchos casos implica un diagnóstico tardío, cuando se presenta la enfermedad marcadora de SIDA, con el impacto que esta etapa produce en la salud del individuo y con el riesgo de muerte y secuelas que conlleva.

Al analizar los años transcurridos desde la infección hasta el diagnóstico de la infección por VIH, se evidencia que las mujeres de 25 a 41 años son el grupo en que se realiza el diagnóstico en forma más temprana. Este hecho se debe probablemente a la obligatoriedad en la solicitud del test de VIH a toda gestante, lo que ha producido un doble beneficio, ya que no sólo permite diagnosticar la infección por VIH en etapas tempranas de la enfermedad, evitando la progresión a SIDA y la diseminación de la infección, sino que previene la transmisión vertical al recién nacido. ${ }^{136}$

El patrón que identifica las vías de transmisión de las personas infectadas en nuestra población, se asocia preponderantemente a la vía sexual heterosexual, tanto en hombres como en mujeres: el 94,3\% de las mujeres y el $64 \%$ de los varones se infectaron por esa vía, lo que implica que las relaciones sexuales son la práctica de riesgo de mayor prevalencia para la transmisión de la infección por VIH y a dónde deben dirigirse los mayores esfuerzos para la prevención. Para el logro de este objetivo deben implementarse programas de educación sexual y para la salud a través del proceso educativo, en el nivel de la escuela primaria y especialmente en la secundaria, pero también mediante el trabajo comunitario en organizaciones barriales, sociedades de fomento y centros de atención primaria de la salud, de forma tal que toda la población pueda acceder a la información.

La segunda causa de transmisión del VIH en nuestros pacientes es la drogadicción, principalmente en el grupo entre los 25 a 41 años de edad. Ésta constituye una característica particular de nuestra población, posiblemente porque sus escasos recursos económicos impiden el fácil acceso a las costosas drogas de uso endovenoso, a diferencia de otras poblaciones de Municipios vecinos (Quilmes, Berazategui, Almirante Brown) que tienen gran parte de sus pacientes infectados por uso de drogas intravenosas. ${ }^{60,137-139}$ Aún así, los casos de drogadicción endovenosa se dan casi exclusivamente en los hombres. 
El principal motivo que determina la realización del diagnóstico de la infección por VIH en la población masculina, es la presentación de enfermedad marcadora de SIDA. Este hecho demuestra que el diagnóstico se hace tardíamente, en pacientes que presentan intenso deterioro psico-orgánico e inmunológico, lo que deriva en numerosos casos a un inicio tardío del tratamiento antiretroviral y la quimioprofilaxis contra las infecciones oportunistas y a la presentación de secuelas permanentes que impactan profundamente en la calidad de vida de los pacientes.

La segunda causa que lleva a la confirmación de la infección en los hombres es el diagnóstico de la infección por VIH en la pareja sexual. Esto se debe a que, cuando a un individuo se le realiza el diagnóstico en nuestra Unidad de Infectología, es abordado en forma inmediata por el equipo multidisciplinario de trabajo en VIH, donde intervienen, además del médico, el psicólogo y el trabajador social, con el objetivo de realizar el relevamiento de la situación familiar del paciente y proceder a la asesoría o counseling de sus integrantes, que incluye la realización del test de VIH a su pareja o parejas sexuales, hijos y/u otros convivientes.

Por otra parte, en las mujeres, la principal causa de realización del diagnóstico de infección por VIH es el embarazo, seguida del diagnóstico de la infección en la pareja sexual. La implementación de la obligatoriedad del ofrecimiento del test diagnóstico del VIH a toda mujer embarazada como parte del cuidado prenatal normal ha llevado a que en nuestra población femenina el embarazo sea la principal causa de la realización del diagnóstico de la infección por VIH. ${ }^{136}$ Si bien se considera que la situación ideal sería que el diagnóstico se hiciera con anterioridad al embarazo y no cuando éste ya está en curso, la realización del testeo en las gestantes es de crucial importancia, dado que de esa forma se implementan medidas para la prevención de la transmisión vertical, que en el Municipio de Florencio Varela, con 4500 partos anuales, presenta una prevalencia del 4,3\%0. ${ }^{140}$

Más de la mitad de la población estudiada tiene pareja sexual, aunque casi el $17 \%$ desconoce el estado serológico de su pareja; esta situación se sostiene en muchos casos durante años, donde la conocedora de su diagnóstico es la mujer, que por temor a diferentes situaciones, principalmente a la discriminación y al abandono, sostiene esta situación en el tiempo, cargando con todo el peso de la responsabilidad. Los pacientes que desconocen la condición serológica de sus parejas manifiestan que la mayoría posee varias conductas de riesgo. Los pacientes con parejas VIH positivas refieren que éstas presentan varias conductas de riesgo vinculadas a la transmisión de la infección; las conductas de riesgo relacionadas con 
la transmisión del VIH en sus parejas sexuales fueron la promiscuidad sexual, la drogadicción y el alcoholismo. ${ }^{138}$

La mitad de la población estudiada posee adicciones; de ella el $60 \%$ tiene dos o más tipos de adicciones, siendo las de mayor frecuencia la asociación de alcoholismo, tabaquismo y drogadicción no intravenosa. Se observa en nuestros pacientes, que el rango etario crítico en el cual se presentan las adicciones es en el de 25 a 41 años.

En relación directa con el tipo de adicciones observadas se presenta la principal comorbilidad en nuestra población, que es la hepatopatía alcohólica. El hígado se encuentra afectado en el $60 \%$ de los pacientes VIH positivos, porcentaje que se incrementa en forma proporcional al grado de inmunodeficiencia, siendo máximo en el SIDA. El alcohol, además de ocasionar daño hepático, puede inducir actividad enzimática microsomal, potenciando la hepatotoxicidad de algunas drogas que se utilizan en el TARGA, fundamentalmente la nevirapina. Pero también efavirenz puede ocasionar, cuando se administra con en el TARGA, efectos adversos a nivel del SNC, desde leves (mareos, insomnio, pesadillas) hasta síntomas graves como depresión, confusión, despersonalización e ideación suicida. ${ }^{141}$ Se ha reportado que las personas con infección por VIH son más propensas a consumir mayores cantidades de alcohol, lo que puede dificultar la adherencia al tratamiento antiretroviral; este hecho se observa frecuentemente en nuestros pacientes. ${ }^{142}$

La segunda comorbilidad hallada, en orden de frecuencia, es el síndrome de lipodistrofia (SLD). El SLD asociado al SIDA es una comorbilidad ocasionada por el TARGA, relacionado primordialmente con la duración del tratamiento antiretroviral. Puede presentarse como lipoatrofia o lipohipertrofia y habitualmente se asocia a alteraciones metabólicas (como hiperlipidemia, resistencia a la insulina, hiperlacticidemia, enfermedad cardiovascular, accidente cerebro vascular, ateroesclerosis, pancreatitis) y efectos estéticos por el síndrome de redistribución adiposa corporal. ${ }^{143}$

La presentación de trastornos metabólicos implica en general la incorporación de nuevos tratamientos farmacológicos que deben agregarse a las drogas antiretrovirales que recibe el individuo, con la consiguiente aparición de efectos secundarios indeseables que se suman a los ocasionados por el TARGA, como malestar gastrointestinal, diarrea, náuseas y vómitos, neuropatía y hepatotoxicidad, que producen un gran deterioro en la calidad de vida de los pacientes.

Los efectos estéticos y de la imagen corporal son los que más negativamente inciden en los aspectos psicológicos, socio-laborales y de adherencia al tratamiento. ${ }^{144}$ El SLD es la principal complicación del TARGA a mediano plazo y además de los riesgos clínicos que 
involucra, produce una profunda influencia en la CVRS, disminución en la autoestima y perturba el funcionamiento social de los pacientes que experimentan esta condición. ${ }^{145}$ Las modificaciones del esquema corporal que se evidencian, llevan al consecuente riesgo de estigmatización sobre los pacientes (Figura 36). ${ }^{146-148}$ Es por ello que la presentación de este síndrome implica el abordaje psicológico del individuo, ya que ha ocasionado el abandono del TARGA en muchos de nuestros pacientes, principalmente mujeres, quienes prefieren someterse a la progresión al SIDA con tal de evitar los estragos que producen las drogas antiretrovirales en su imagen corporal, con todas sus implicancias.
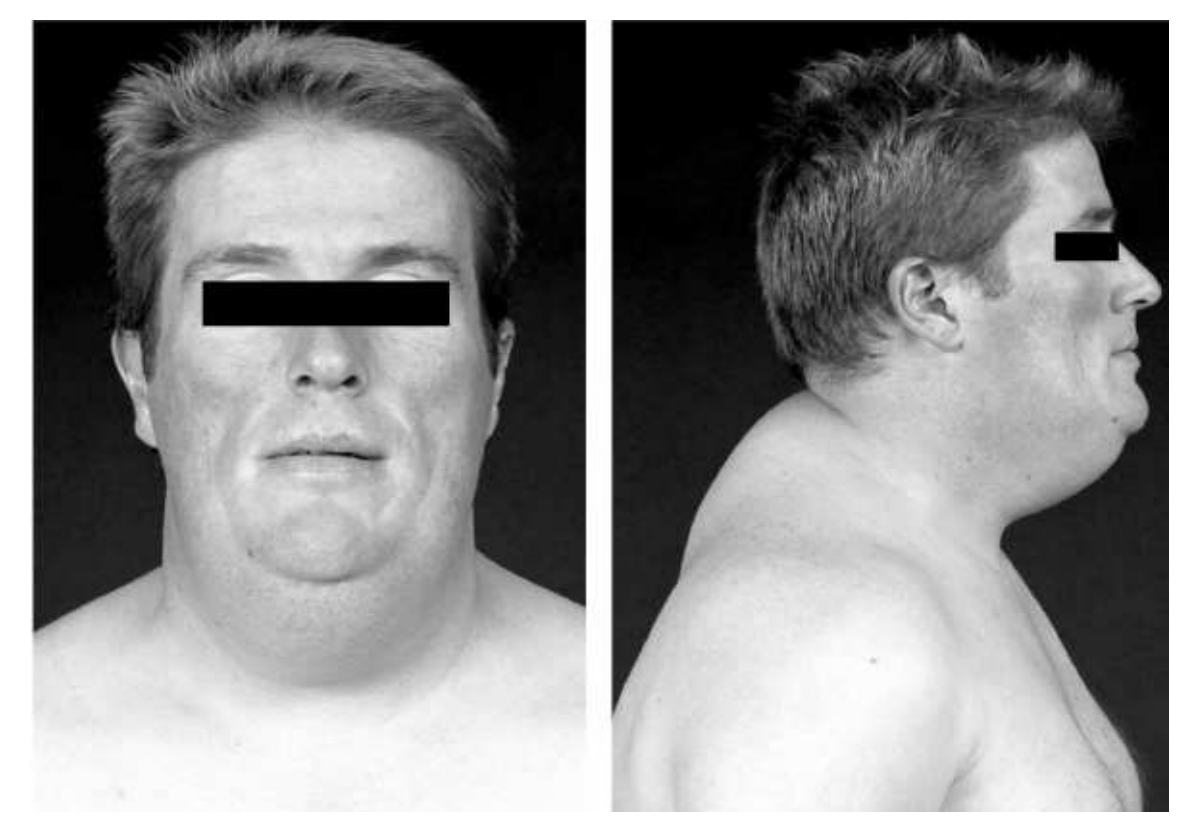

Figura 36: Síndrome de redistribución de la grasa corporal por lipodistrofia en un paciente bajo TARGA. (Fotografía tomada de Woolley y colaboradores).

La lipoatrofia facial es el signo más estigmatizante de la lipodistrofia, ya que el rostro no puede ser escondido o disimulado con ropas y usualmente es percibido como la expresión de nuestra salud (Figura 37). ${ }^{148}$

El temor a la modificación del aspecto corporal tiene un indudable impacto negativo en la CVRS en personas que viven con VIH/SIDA, lo cual fue demostrado en un estudio de preferencias realizado por Lenert y colaboradores, en el que dos tercios de los pacientes evaluados se manifestaron dispuestos a resignar tiempo de supervivencia a cambio de no padecer los cambios físicos causados por el SLD. ${ }^{149}$ 


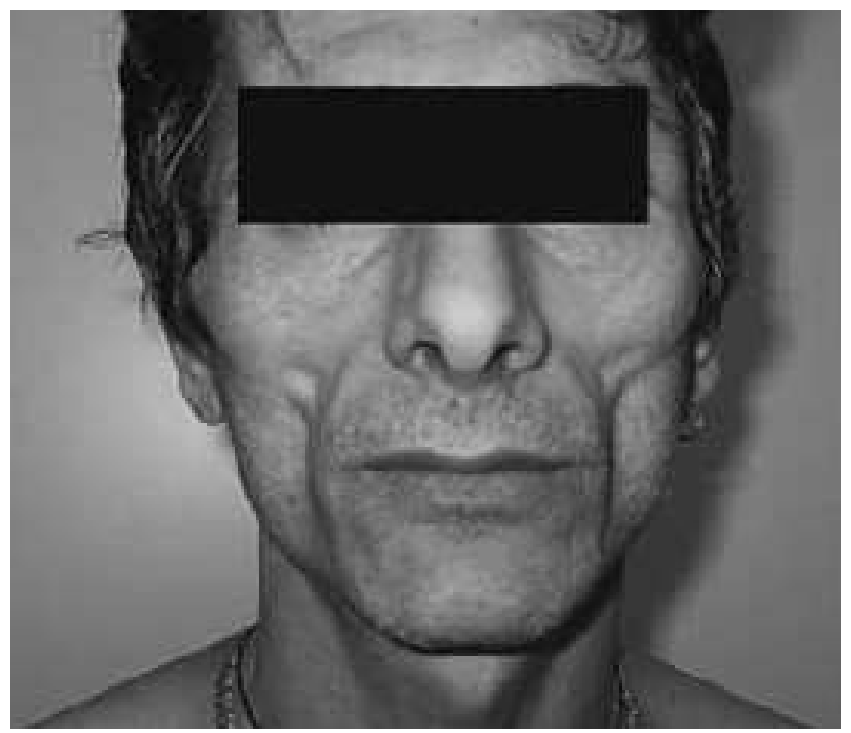

Figura 37: Lipoatrofia facial en un paciente que recibe TARGA (Fotografía tomada de Guaraldi y colaboradores)

El SLD asociado al tabaquismo, presente en una gran parte de la población, agrava este cuadro; diversas investigaciones señalan que, en algunos años, un tercio de los pacientes en tratamiento antiretroviral padecerán este síndrome. ${ }^{150}$

La hepatitis B se presenta como tercera comorbilidad, lo que se relaciona con la principal vía de contagio del VIH en nuestra población que es la sexual y demuestra a su vez la inadmisible falta de accesibilidad de nuestros pacientes a la vacuna que previene el contagio de esta enfermedad. Nos encontramos entonces ante un "círculo de comorbilidades" que se agravan unas a otras, impactando negativamente en la salud del individuo con infección por VIH: hepatotoxicidad por el TARGA, alcoholismo y hepatitis B; si a esto le sumamos la presencia de coinfección por hepatitis $\mathrm{C}$, tenemos un $40 \%$ de nuestra población con hepatopatía crónica por las causas mencionadas, sumado a que la coinfección con el virus de la hepatitis $\mathrm{C}(\mathrm{HCV})$ constituye la principal causa de muerte por enfermedad hepática terminal, originada por el desarrollo de fibrosis, cirrosis y carcinoma hepatocelular que sigue a la infección de larga evolución. La coinfección con $\mathrm{HCV}$ es actualmente una de las principales causas de morbimortalidad en individuos con VIH/SIDA. ${ }^{151}$ La enfermedad hepática subyacente es siempre una cuestión a tener presente cuando se debe indicar el TARGA a un paciente, ya que, como se ha mencionado, varios de estos fármacos, como nevirapina, efavirenz y los IP, han demostrado tener un efecto devastador en el hígado. ${ }^{152}$

Las coinfecciones por HBV y HCV en pacientes infectados por el VIH son un hallazgo frecuente en virtud de las similares vías de transmisión que estos agentes presentan 
(sexual, parenteral y vertical). ${ }^{151-153}$ Su prevalencia parece diferir considerablemente según los distintos grupos de riesgo y las distintas regiones geográficas; en un estudio desarrollado en Argentina en 2005 por Laufer y colaboradores en pacientes VIH positivos, se encontró una seroprevalencia de marcadores de HBV del 29,3 \% y del 21,7 \% para HCV; sin embargo, los pacientes estudiados fueron en su mayoría $\mathrm{UDI}_{\mathrm{s}}$, a diferencia de nuestra población, donde la prevalencia de adictos a DIV es sólo del $8,8 \%{ }^{153}$

En la era "pre-TARGA" la consecuencia de la enfermedad crónica por HCV y HBV estaba oculta por la elevada mortalidad debida a enfermedades extra-hepáticas. Desde que se introdujo el TARGA se evidenció una marcada disminución en la morbimortalidad de los pacientes, los que ante la prolongación de su sobrevida comenzaron a presentar las complicaciones crónicas de las coinfecciones con estos virus hepatotropos, convirtiéndose la enfermedad hepática en una de las primeras causas de morbimortalidad en estos pacientes. ${ }^{153}$

El síndrome ansioso-depresivo (SAD) es otra comorbilidad presente en nuestra población, con una prevalencia del $6 \%$; Cielsa y colaboradores han encontrado una prevalencia del SAD, en pacientes con VIH/SIDA, del 5 al $23 \%$. ${ }^{154}$

A este síndrome se lo ha asociado con problemas de adherencia al tratamiento antiretroviral y con un profundo impacto negativo sobre la calidad de vida de estos pacientes. La identificación de un trastorno depresivo mediante el uso de un instrumento de CVRS puede contribuir a acelerar una necesaria intervención, que en muchas ocasiones puede no ser advertida en el examen clínico de rutina. La mejoría de los síntomas de depresión se ha asociado con una optimización de la adherencia al TARGA y a la CVRS. ${ }^{155}$

El cáncer cervical se convirtió en enfermedad marcadora de SIDA a partir del año 1993, debido a la elevada incidencia de displasia cervical, específicamente la neoplasia cervical intraepitelial grado III (CIN III), en pacientes infectados con VIH, en comparación con aquellos VIH negativos. ${ }^{156}$ El cáncer observado con mayor frecuencia en nuestra población afecta a las mujeres jóvenes y es el cáncer de cuello uterino, relacionado en el 100 $\%$ de los casos a infección por virus del papiloma humano. ${ }^{157}$ La supresión viral incompleta, aún en pacientes bajo TARGA es el mayor predictor para el desarrollo de cánceres relacionados con el SIDA, independientemente del recuento de LT CD4+. Muchas de las neoplasias en pacientes con infección por VIH están relacionadas con otras enfermedades virales (virus de Epstein Barr, HSV 8, HPV, HCV y HBV). ${ }^{158}$

Al analizar el estado inmunológico de nuestros pacientes, se observa con inquietud el hecho de que el $70 \%$ de los pacientes posee carga viral detectable, a pesar de estar bajo TARGA; hallamos que el $36 \%$ tiene inmunosupresión severa, dada por un recuento de LT 
CD4 $+<200 / \mathrm{mm}^{3}$, lo cual implica que poseen condición clínica de SIDA, a pesar de que el 73 $\%$ recibe tratamiento antiretroviral. Muchos de estos tratamientos son iniciados tardíamente (por diagnóstico tardío con enfermedad por VIH avanzada), lo que implica que la reconstitución inmunológica, en numerosas oportunidades, no llega a producirse (aún con óptima respuesta virológica), o son pacientes con múltiples fallos al TARGA con problemas de adherencia al mismo, lo que los coloca en riesgo de progresión de enfermedad o aumenta el riesgo de presentar un evento oportunista relacionado con el SIDA.

La adherencia de los pacientes al tratamiento es una de las principales dificultades que se presentan actualmente y que se presenta en todos los lugares del mundo, ya que la adherencia determina las posibilidades futuras de disponibilidad de esquemas terapéuticos útiles para ese sujeto y por ende su supervivencia. Mirando un poco más allá de esta cuestión, se deduce que también determinará la futura diseminación en la comunidad de virus resistentes a las drogas antiretrovirales disponibles en uso.

Uno de los factores que dificulta la adherencia al tratamiento a largo plazo es la intrusividad del mismo, entendiéndose por intrusividad aquellas características del régimen terapéutico que interfieren en la vida cotidiana de la persona, impidiendo el desarrollo habitual de la misma. Esto sucede cuando el paciente debe tomar su medicación en horario de trabajo o cuando se presentan efectos adversos durante el mismo (diarrea, somnolencia), o simplemente cuando está fuera de su hogar. La adherencia al tratamiento también supone que deben resolverse cuestiones paralelas que usualmente se presentan en los pacientes como la depresión, la ansiedad, el consumo y abuso de drogas. Sin embargo, no debemos olvidar nunca, que antes de pretender que el paciente cumpla con el tratamiento antiretroviral que le hemos indicado, debe tener cubiertas sus necesidades sociales mínimas, como por ejemplo, vivienda y alimentación. De nada sirve pretender adherencia al tratamiento indicando potentes fármacos que deben conservarse refrigerados, cuando el paciente no posee heladera y vive en una casilla con techo de chapas donde en verano la temperatura alcanza los $50{ }^{\circ} \mathrm{C}$. No tiene ningún sentido indicar el mejor tratamiento disponible si para ello el paciente debe ingerirlo con determinado tipo de alimentos, cuando en realidad sólo puede realizar una sola comida al día. El Programa Nacional de SIDA debe terminar su disociación con el entorno social y considerar la provisión no sólo de medicamentos sino de los insumos necesarios para proporcionar un tratamiento integral y permitir al sujeto llevar su situación de enfermo con la mayor dignidad posible.

En nuestra población, los eventos marcadores de SIDA se registran con mayor frecuencia en el grupo etario de 33 a 41 años; el hecho de que la principal enfermedad 
marcadora sea el síndrome consuntivo asociado al VIH (wasting syndrome) en ambos géneros implica que, efectivamente, el diagnóstico se realiza en los estadíos más avanzados del SIDA, al igual que ocurre en países de África y otros países en vías de desarrollo. ${ }^{2}$ Además, evidencia la falta de accesibilidad a los servicios de salud por parte de sectores de la población.

La candidiosis esofágica es una enfermedad marcadora que se presenta frecuentemente, ya sea como evento solitario o asociada a otras infecciones oportunistas, dado que es un cuadro ligado al deterioro orgánico severo y a la inmunodepresión. ${ }^{159}$

La tuberculosis (TB) pulmonar y extrapulmonar le sigue en orden de frecuencia. La mayor prevalencia de TB en nuestros pacientes se observa en individuos jóvenes, entre 25 y 32 años y está relacionada con la elevada incidencia de tuberculosis en nuestro municipio (36,04 / 100.000, en el año 2006). La infección por VIH/SIDA constituye una de las causas del incremento de la incidencia de TB en la Argentina en los últimos años, por lo que representa uno de los principales problemas de salud en pacientes infectados por VIH, con un gran impacto en la calidad de vida; la incidencia de TB en personas con SIDA es casi 500 veces mayor que la incidencia en la población general. ${ }^{66,160}$

La TB aumenta la replicación del VIH, probablemente por inducir la producción de factor de necrosis tumoral $\alpha$, interleuquina 1 y 6 en los macrófagos; el riesgo de muerte en pacientes VIH positivos es el doble que en pacientes con infección por VIH sin TB, independientemente del recuento de LT CD4+. La elevada mortalidad entre pacientes con TB se relaciona más con la progresión de la infección por VIH que con la TB y el grado de inmunosupresión es el predictor más importante de la sobrevida. Además, la rifampicina, droga de primera línea utilizada para el tratamiento de la TB, está contraindicada con muchas de las drogas que se utilizan para el tratamiento antiretroviral, lo que constituye un problema para la selección de esquemas farmacológicos en aquellos pacientes experimentados, con historia de múltiples fallos al tratamiento o con progresión de enfermedad, donde el médico debe decidir qué enfermedad debe priorizar y cuál tratamiento instaurar primero. El uso del TARGA en estos pacientes se ve limitado por la superposición de efectos tóxicos, las interacciones farmacológicas, la mala absorción de las drogas y las reacciones paradojales al tratamiento, (síndrome inflamatorio de reconstitución inmune). ${ }^{161}$

La neumonía por Pneumocystis jiroveci y la toxoplasmosis cerebral son otros eventos relacionados frecuentemente con el debut del SIDA en nuestros pacientes, probablemente porque al momento del diagnóstico no reciben quimioprofilaxis para estas infecciones 
oportunistas, además de la elevada prevalencia de serología positiva para toxoplasmosis, que en nuestros pacientes fue del 80,9\%, reportada en el año 2003. ${ }^{162}$

La demencia asociada al SIDA se presenta como primer evento marcador en el 7,5 \% de nuestra población; afecta a personas jóvenes entre los 25 y 50 años de edad que se encuentran en estadíos avanzados de la enfermedad. Las alteraciones de las esferas cognitiva y motora son las más estrechamente vinculadas; se ha observado en un gran número de nuestros pacientes, una serie de trastornos cognitivos leves, como la pérdida de la memoria reciente, episodios transitorios de desorientación y dificultad para concentrarse para leer o para recordar números o fechas, que si bien no cumplen con los criterios para definir demencia, suelen precederla. Dichos trastornos leves suelen mejorar o desaparecen cuando se instaura el TARGA. ${ }^{163}$

Cryptosporidium spp fue la causa del $59 \%$ de las diarreas de origen parasitario reportadas en nuestra población en el año 2004 y representa el 6,3 \% del total de las enfermedades marcadoras observadas en nuestro estudio. ${ }^{164}$

Teniendo en cuenta que la primera enfermedad marcadora de SIDA se presenta en más del $80 \%$ de los casos en el grupo entre 25 y 41 años, se deduce que, considerando un período promedio de evolución a SIDA de 7 a 10 años, estos individuos se han infectado entre los 15 y 33 años de edad, lo que establece la necesidad impostergable de implementar políticas y estrategias de educación para la prevención de la infección, que deben iniciarse en la niñez y proseguir durante la adolescencia. Para ello es imprescindible la capacitación de equipos docentes, la inclusión del tema en las agendas de trabajo, la producción de material educativo, la realización de encuentros para compartir experiencias y otras acciones.

Aproximadamente la mitad de los pacientes han requerido hospitalización por algún evento relacionado al VIH/SIDA, en algún momento de la evolución de su enfermedad. Datos publicados por Murri y colaboradores demuestran que la hospitalización es un determinante importante en la CVRS en pacientes con infección por VIH, a pesar de no ser un predictor futuro de CVRS. ${ }^{165}$

En numerosas publicaciones internacionales se reporta una "dramática reducción" en el número de las hospitalizaciones a partir de la administración del TARGA a los pacientes con VIH/SIDA. ${ }^{166-168}$ Esa realidad está muy lejos de ser la que ocurre en los hospitales del conurbano bonaerense. El número de pacientes hospitalizados en nuestra Institución por causas relacionadas con el VIH no sólo no se ha reducido, sino que ha aumentado. Muchas de esas hospitalizaciones son debidas a la ocurrencia de infecciones oportunistas, comorbilidades, consecuencia de efectos adversos al TARGA (hepatotoxicidad, reacciones 
severas de hipersensibilidad, trastornos neurológicos) o la suma de ellas. La reducción del número de hospitalizaciones en un futuro, sería un factor que podría contribuir en la mejoría de la CVRS.

La introducción del TARGA ha modificado la historia natural de la enfermedad, transformándola de una infección de curso progresivo y mortal a una patología crónica, permitiendo la supervivencia de los pacientes. Más del $70 \%$ de nuestros pacientes están en tratamiento farmacológico con antiretrovirales, con diferentes asociaciones; el $46 \%$ de ellos recibe un esquema que incluye 2 INTR + 1 INNTR, el $20 \%$ con esquemas que contienen IP y el $4 \%$ con 3 INTR. El $70 \%$ de los pacientes que componen nuestra población ya han cambiado una o más veces el tratamiento, por diversos motivos; intolerancia, toxicidad o fallo virológico.

Como se mencionó, la terapia antiretroviral produce efectos adversos en un gran número de pacientes, causa malestar, intolerancia y preocupación y demanda en la mayoría de los casos, drásticos cambios en el estilo de vida. En los esquemas habituales del TARGA se cuentan desde un mínimo de 4 hasta más de 10 pastillas por día que deben ser ingeridas por boca en esquemas horarios fijos, de manera ininterrumpida en el tiempo y sin omisiones, si es que se quiere obtener su máximo beneficio. Los sujetos que toman los medicamentos antiretrovirales perciben que éste interfiere marcada y frecuentemente en su salud física, mental y en sus actividades sociales. ${ }^{169}$ En conocimiento de las dificultades que plantea la correcta adherencia a estos tratamientos, el equipo de salud debe trabajar cotidianamente en la búsqueda de las mejores formas de que las personas viviendo con VIH/SIDA puedan cumplir con sus tratamientos, compatibilizándolos con sus modos de vida, hábitos y recursos.

Se han comparado las puntuaciones obtenidas en el Cuestionario de Salud SF-36 en nuestra población, con los valores poblacionales de referencia de la versión española del Cuestionario de Salud SF-36, publicados por Alonso y colaboradores en $1998^{72}$, ya que no existen estudios realizados en la población general de nuestro país, ni de nuestra región.

Al realizar el análisis de las puntuaciones obtenidas en el Cuestionario de Salud SF36, se observa que en ningún caso las puntuaciones medias recogidas en cada una de las dimensiones se sitúan en el máximo valor, indicando que los individuos evaluados no están libres de problemas de salud percibida. Esta situación es especialmente evidente para las dimensiones de salud general, vitalidad y salud mental y coincide con los valores poblacionales españoles. ${ }^{170}$ 
En nuestra población, la puntuación más baja fue obtenida en el rol emocional, con un elevado porcentaje de individuos con puntuación mínima. Las otras dos dimensiones con las menores puntuaciones fueron salud general y salud mental.

Martín Suárez y colaboradores publicaron en el año 2002 los resultados obtenidos de la aplicación del cuestionario SF-36 a 52 pacientes españoles con infección por VIH/SIDA, obteniendo las más bajas puntuaciones en la limitación del rol por problemas físicos y en la percepción general de la salud personal. ${ }^{163}$

García Ordoñez y colaboradores evaluaron en el año 2001 a 300 pacientes españoles infectados por VIH, utilizando el Cuestionario de Salud SF-36. Los puntajes más bajos se obtuvieron en las dimensiones de rol físico, salud general y rol emocional. ${ }^{83}$

Otros autores latinoamericanos han evaluado la salud en personas que viven con VIH/SIDA. Rivero-Méndez y colaboradores estudiaron los síntomas físicos y psicológicos que impactan en la CVRS en 44 mujeres, hombres y transgénero viviendo con VIH en Puerto Rico, encontrando que las dimensiones más afectadas fueron el dolor corporal y el rol emocional. $^{171}$

Bastardo y Kimberlin estudiaron la CVRS en 118 personas con VIH/SIDA en Venezuela, mediante el Cuestionario de Salud SF-36, observando que las menores puntuaciones se obtuvieron en las dimensiones de salud general, salud mental y rol emocional. ${ }^{169}$

Por ende, podemos afirmar que, tanto en nuestros pacientes como en otras poblaciones estudiadas, la infección por VIH causa deterioro de la salud percibida, afectando tanto las dimensiones físicas como psíquicas. Se evidencia entonces la importancia que adquiere no sólo el abordaje médico sino también psicológico y sociológico cuando se diseña el plan terapéutico de estos pacientes, que no debe limitarse simplemente a la prescripción de estudios de laboratorio, drogas antiretrovirales y quimioprofilaxis para prevenir la ocurrencia de infecciones oportunistas, sino la provisión de un "espacio" para el tratamiento de la problemática integral de estas personas.

Al analizar la distribución de las puntuaciones obtenidas en nuestros pacientes según el género y grupos de edades, se advierte que las mujeres presentaron puntuaciones mayores en todas las dimensiones, excepto en el rol emocional, salud mental y dolor corporal. Esto es diferente a lo observado en los valores poblaciones de referencia españoles, donde los varones presentan puntuaciones mayores que las mujeres en todas las dimensiones. 
Otros autores (Rao y colaboradores, Hudson y colaboradores) han reportado en estudios de CVRS en personas que viven con VIH/SIDA realizados en Puerto Rico y Estados Unidos, que el género es un predictor de bienestar psico-físico, siendo la depresión y el dolor corporal los síntomas de mayor prevalencia en las mujeres. ${ }^{172,173}$

Mrus y colaboradores y dos Santos y colaboradores, evaluaron diferencias de género en CVRS en pacientes con VIH/SIDA de Estados Unidos y Brasil respectivamente, hallando que las mujeres presentan más bajos escores en la CVRS que los hombres. ${ }^{174,175}$

Para explicar estas diferencias de género se postula una multiplicidad de causas: diferencias en la percepción de la salud entre el hombre y la mujer, una mayor prevalencia en las mujeres de desórdenes del comportamiento y ansiedad, un mayor impacto en las mujeres de las situaciones de estrés, una disminución en la autoestima y la imagen corporal, la necesidad de las mujeres de conciliar un conjunto de compromisos como el trabajo doméstico y el cuidado de los hijos, haciendo que se prioricen estas actividades y fundamentalmente, el impacto de la desigualdad de género en la sociedad. ${ }^{174-176}$

La edad también juega un rol determinante en la CVRS, ya que las menores puntuaciones en todas las dimensiones se obtuvieron en el grupo de pacientes mayores de 59 años. Esta situación se observa en numerosos trabajos, donde se relaciona a la vejez con una peor calidad de vida y en la cual influye probablemente la declinación en la funcionalidad física global por causas fisiológicas o por enfermedades concurrentes. ${ }^{177-179}$

Las puntuaciones más bajas en todas las franjas etarias de nuestros pacientes, se observan en el rol emocional.

En este estudio se ha encontrado que la única variable sociológica que se relaciona significativamente con la calidad de vida y el estado de salud percibido por nuestros pacientes ha sido el nivel de instrucción; los individuos con estudios universitarios obtuvieron las menores puntuaciones en el rol emocional, probablemente por la capacidad de poder percibir a su propia enfermedad no sólo desde un punto de vista meramente orgánico sino también como una consecuencia de la afección psico social que le dio origen.

Esta observación también coincide con el trabajo realizado en España por Martín Suárez y colaboradores, que hallaron una elevada prevalencia de trastornos de ansiedad y depresión en los pacientes de mayor nivel socio cultural. ${ }^{163}$

Sin embargo, otros autores han encontrado resultados disímiles; Worthington y Krentz, en un estudio realizado en Canadá sobre 300 personas que viven con VIH, hallaron que los mayores niveles de instrucción se correlacionan con las mayores puntuaciones en 
todas las dimensiones. ${ }^{180}$ Lo mismo fue observado por dos Santos y colaboradores, en un estudio llevado a cabo en San Pablo, Brasil, sobre 385 pacientes VIH positivos, hallando escalas de puntaje más elevadas en las dimensiones físicas para aquellos sujetos con nivel superior de educación. ${ }^{175}$

Si bien no se encontró relación significativa, los pacientes que no poseen plan social y empleo presentan bajas puntuaciones, fundamentalmente en el rol emocional y salud mental, lo que merece el análisis de esta observación. Más allá de la verdadera finalidad de los planes sociales o "subsidios a la pobreza" que en el conurbano bonaerense han sido distribuidos generosamente en una gran parte de la población y tratando de eliminar toda apreciación subjetiva al respecto, lo cierto es que la mayoría de nuestros pacientes que perciben planes sociales no tienen otra fuente de ingresos económicos, dependiendo para poder paliar sus necesidades básicas, del exiguo monto de dinero que reciben de esta ayuda social. En estos últimos años, el número de planes sociales que se distribuyeron en Florencio Varela ha ido disminuyendo en forma sostenida, por lo que muchos individuos han perdido la única fuente de ingresos para la manutención de su hogar, con todas las implicancias médicas y psicosociales que este hecho comporta. Probablemente, esta sea la principal causa de las bajas puntuaciones obtenidas en el rol emocional en los individuos que no perciben planes sociales.

El empleo, provee no sólo beneficios económicos sino que además constituye la fuente de la estructura social de una comunidad, le brinda al individuo su identidad y su razón de ser y está asociado con una mejoría global de la CVRS. Su relación con el funcionamiento psicológico de la persona es un fenómeno complejo que se halla aún en estudio. ${ }^{181}$ Se han publicado trabajos que demuestran que los individuos desempleados generalmente presentan niveles mayores de ansiedad, depresión, aislamiento social y baja autoestima que los sujetos que poseen empleo. Blalock y colaboradores, Liu y colaboradores y Wothington y Krentz han concluido que en los individuos que viven con VIH/SIDA, el empleo es un fuerte predictor de niveles elevados de CVRS. ${ }^{178,180,181}$

Sanzero Eller reportó que personas norteamericanas con infección por VIH/SIDA que se encontraban desempleadas, presentaban una peor CVRS que aquellas que tenían trabajo. ${ }^{182}$

Los individuos de nuestra población que no tienen pareja alcanzaron las puntuaciones más bajas en todas las dimensiones del cuestionario; sin embargo, los que tienen pareja con infección por VIH presentaron las más bajas puntuaciones en el rol emocional y salud mental. Se ha reportado la ausencia de relación significativa entre estas variables y la CVRS. ${ }^{180,183}$ 
La progresión en años transcurridos desde el diagnóstico de la infección por VIH, influyen negativamente en la CVRS de nuestra población, evidenciándose una fuerte relación no significativa entre esta variable y el rol emocional. Este hallazgo coincide con los resultados publicados por dos Santos en la población brasileña con VIH. ${ }^{175}$ Entre los factores que estarían relacionados con este hallazgo tendríamos que considerar la progresión de la enfermedad en algunos casos y en otros la indicación de iniciar el TARGA, que representa una modificación sustancial en el status del paciente y en sus hábitos de vida.

La necesidad de hospitalización por algún evento relacionado con el SIDA presenta en nuestros pacientes cierto grado de correlación significativa con la función física, aunque al observar los valores obtenidos en todas las dimensiones, se constatan menores puntajes en aquellos individuos que requirieron internación. En general, se advierte que la internación por alguna causa relacionada con la enfermedad, produce un importante impacto psíquico en el paciente, siendo uno de los momentos donde muchas veces éste toma verdadera conciencia de su estado de salud y donde la intervención psicológica sería de vital utilidad, para facilitar el "afrontamiento" de estas personas con la nueva situación en la que se ven inmersas.

En la literatura revisada se ha comunicado que los pacientes que han padecido eventos marcadores de SIDA presentan, en general, bajas puntuaciones que se relacionan con una menor CVRS. ${ }^{83,163,165,169,176,177,180,184-186}$

En este trabajo, se ha encontrado que el número de enfermedades marcadoras de SIDA que han padecido los pacientes tiene cierto grado de correlación significativa con la función física, observándose bajas puntuaciones en aquellas personas que han padecido más de 3 eventos definitorios. Esto se explica principalmente por el profundo deterioro psico-orgánico y las secuelas que puede producir la enfermedad marcadora, si bien depende del tipo y de la gravedad de la misma. Su ocurrencia delimita un punto de inflexión en la historia de la infección; a partir de allí, la persona tiene SIDA y si no realiza el TARGA morirá en un lapso de aproximadamente 18 meses. El paso del estado de "infectado" a "tener SIDA" conlleva una importante carga sintomática que causa, en general, un considerable deterioro en la salud percibida por el propio paciente.

La presencia de adicciones se ha correlacionado en este estudio con una escasa significación, sólo en la dimensión vitalidad. Aún así, se observa que los individuos con la 
mayor cantidad de adicciones presentan muy bajas puntuaciones en todas las dimensiones del cuestionario.

La adicción más frecuente advertida en nuestra población es la asociación alcoholismo/tabaquismo/drogadicción. Cuando estas adicciones se combinan con la infección por VIH y otras comorbilidades asociadas, el manejo clínico y psicológico de estos pacientes se torna extremadamente complejo. En primer lugar, la enfermedad hepática que genera el etilismo crónico agrava condiciones preexistentes (por ejemplo, la coinfección con HCV y HBV) y aumenta la toxicidad hepática que pueden producir las drogas antiretrovirales, principalmente los INNTR e IP. ${ }^{152,} 187$ En segundo lugar, el tabaquismo produce lesión endotelial, que se suma a las alteraciones metabólicas, particularmente del metabolismo lipídico, que producen en mayor o menor medida todos los antiretrovirales, aumentando aún más el riesgo de ateroesclerosis y enfermedad cardio y cerebro vascular. En tercer lugar, el consumo de drogas dificulta la adherencia al tratamiento antiretroviral, además de afectar las funciones cognitivas, motoras y generar trastornos de adaptación social.

En la actualidad, esta situación se ha incrementado en nuestra población en forma alarmante, relacionada con el consumo de "paco", donde se observa, un rápido y sostenido deterioro de las funciones mentales superiores en pacientes con este problema de adicción y donde sostener la adherencia a un tratamiento prolongado se torna prácticamente imposible de lograr.

Las adicciones se asocian en general a una menor CVRS, donde interaccionan, además de los problemas médicos, intrincados aspectos psico-sociales. ${ }^{177,188}$

No se halló relación significativa entre comorbilidades y las puntuaciones del cuestionario SF-36; sin embargo, se observa que aquellos individuos con comorbilidades presentan más bajas puntuaciones que los que no presentan enfermedades asociadas. El 21,6 $\%$ de nuestros pacientes con comorbilidad tienen hepatopatía alcohólica — la comorbilidad más frecuente en nuestra población-, por dependencia y abuso del alcohol. La información obtenida de la bibliografía es controvertida; algunos autores concluyen que estas personas presentan un sustancial impacto negativo en la CVRS, aunque otros manifiestan que no se asocian con una disminución en dicha calidad de vida. ${ }^{188}$

La medición de la CVRS en coinfectados con VIH, HCV y/o HBV se ha comunicado en numerosos trabajos de investigación clínica, donde se reporta una menor calidad de vida en estos pacientes. ${ }^{177,189-191}$ 
Existe una abrumadora evidencia que indica que la depresión es comúnmente hallada en pacientes con infección por VIH y se la asocia con un riesgo incrementado de limitación funcional diaria y morbimortalidad. ${ }^{188,192,193-197}$

La depresión interfiere con todas las dimensiones de la persona; también es frecuente observar síntomas neurovegetativos, tales como anorexia, trastornos del sueño, temblor, diaforesis. Además pueden asociarse disfunción cognitiva, desconcentración mental, bradipsiquia y deterioro en la función motora fina. Esto refuerza el hecho de que la percepción que tienen los pacientes de su calidad de vida está directamente relacionada con su habilidad para funcionar en la sociedad y poder realizar sus actividades cotidianas. ${ }^{163,197}$

El TARGA constituye per se un vasto capítulo dentro de la CVRS en personas con infección por VIH/SIDA; existe gran cantidad de ensayos clínicos publicados al respecto. En este sentido, aspectos como la adecuada adherencia o las combinaciones farmacológicas específicas han sido estudiados en relación a la CVRS. El efecto neto del TARGA en la calidad de vida es considerado como el balance entre la mejoría clínica —a través de una disminución en la morbilidad relacionada con el VIH- y la presentación de toxicidad y de efectos adversos. ${ }^{163,178,198}$

Lo que el tratamiento significa y produce en las personas que viven con VIH ha sido ejemplificado claramente por $\mathrm{E} \mathrm{D}$, uno de mis más antiguos pacientes, que lleva ya 10 años bajo tratamiento antiretroviral y que en una oportunidad me ha dicho: “...todos los días al tomar mi medicación, pago el precio de estar vivo ... y a veces, jese precio resulta caro!”.

Al analizar los resultados de nuestra población en relación al TARGA, se observa que, si bien no se ha hallado una relación significativa, los pacientes que están medicados desde hace más años tienen los puntajes más bajos en todas las dimensiones, excepto en el rol físico, lo que es absolutamente coherente con lo esperado de un tratamiento efectivo. Pero curiosamente, la menor puntuación se observa en el rol emocional. Por lo tanto existe una notable contradicción entre el rol del TARGA y la CVRS, lo que obliga, en este punto, a preguntarse: ¿Cuál es la CVRS que obtienen nuestros pacientes bajo TARGA? ¿Le ofrecemos una superior CVRS porque viven mejor o porque viven más? ¿La mayor supervivencia y mejoría física es consistente con el bienestar emocional? A diario observamos que, en numerosas oportunidades, el bienestar físico está supeditado a los efectos adversos producidos por las drogas antiretrovirales, que a su vez generan nuevas comorbilidades que requieren la administración de otros tratamientos farmacológicos que se suman a los ya indicados. Son pacientes que toman una extensa lista de medicamentos: antiretrovirales, hipolipemiantes, insulina o hipoglucemiantes orales, beta bloqueantes, antihipertensivos, analgésicos y otros. 
En muchos de nuestros pacientes la administración del TARGA ha impedido en forma eficiente que se mueran de SIDA pero al prolongar su supervivencia lo único que se ha logrado es que fallezcan por sus enfermedades asociadas, como cirrosis por alcoholismo o hepatitis $\mathrm{C}$, enfermedad cerebro o cardiovascular, complicaciones de la diabetes mellitus. Desde esta perspectiva se puede entender de qué manera limitada se ha mejorado la CVRS en estas personas. Este punto resulta crucial para comprender y -de ser posible- comenzar a modificar la finalidad que debe tener el tratamiento para nuestros pacientes.

Cuando iniciamos el abordaje terapéutico de un paciente con infección por VIH/SIDA, consideramos como el objetivo primordial del tratamiento, instaurar una asociación farmacológica que permita prolongar su vida mediante el aumento en el recuento de los linfocitos $\mathrm{T}$ CD4+, la rápida supresión de la replicación viral, evitar la presentación de infecciones oportunistas y prevenir la progresión al SIDA. Vemos habitualmente que estos objetivos se cumplen en mayor o menor medida, obteniendo el éxito inmunológico y virológico en el corto o mediano plazo y prolongando la sobrevida de los pacientes a niveles inimaginables hace tan sólo una década atrás. Nos preocupa el incremento de la resistencia a las drogas antiretrovirales y monitoreamos escrupulosamente la adherencia al tratamiento de los pacientes, detectando las mutaciones virales que conducen al fallo virológico del tratamiento mediante costosas pruebas de resistencia, que nos permiten obtener la tan ansiada “indetectabilidad" de la carga viral plasmática. Procedemos con todos los pacientes de esta misma manera porque, según las normas y recomendaciones nacionales e internacionales vigentes, son estos parámetros los que definen el "éxito terapéutico".

Todas estas acciones otorgan un claro beneficio clínico global para los pacientes. Pero, a diferencia de lo esperado, la mejoría de la situación física no se acompaña paralelamente de la mejoría de su estado emocional, ni de la percepción de una mejor calidad de vida. Entonces, ¿cuán exitoso es el tratamiento que les brindamos a nuestros pacientes?

Si consideramos a la persona en forma integral, deberíamos poder ofrecer alternativas terapéuticas que no solamente incluyan drogas para la mejoría física, sino otras estrategias de tratamiento, en aras de optimizar globalmente su calidad de vida.

La cuestión que subyace al observar las puntuaciones obtenidas en el cuestionario de salud SF-36 aplicado a la población que vive con VIH/SIDA en Florencio Varela, es que los programas de tratamiento del SIDA — ya sean provenientes de instituciones de salud estatales o privadas-, no deben limitarse sólo a la provisión de medicamentos y pruebas de laboratorio, sino que deben contemplar ya mismo la incorporación de nuevos abordajes 
terapéuticos con el objetivo de mejorar no sólo las dimensiones físicas del individuo sino también las psíquicas y sociales.

En la literatura revisada se han publicado resultados de gran disparidad con respecto al TARGA, la mayoría de ellos en personas que viven en países desarrollados — aún cuando la mayoría de las personas con VIH/SIDA viven en países en vías de desarrollo-, por lo que probablemente los resultados no puedan extrapolarse a una población como la nuestra.

Bastardo y Kimberlin publicaron en su estudio sobre CVRS en personas con VIH en Venezuela, que el uso del TARGA se asoció con bajos escores en todos los dominios que ponderan CVRS. ${ }^{169}$. El trabajo realizado en San Pablo por dos Santos y colaboradores, sobre 365 pacientes VIH positivos, no identificó diferencias estadísticamente significativas entre los dominios de la CVRS y el uso de TARGA. ${ }^{175}$ Jelsma y colaboradores estudiaron CVRS en pacientes sudafricanos viviendo con VIH que recibían TARGA, concluyendo que éste mejora la calidad de vida, debido a que mejora la salud en forma global. ${ }^{199}$

En este trabajo, el tipo de tratamiento antiretroviral, es decir, la asociación de drogas antiretrovirales recibidas, condicionó diferencias en las puntuaciones observadas; la menor puntuación en las dimensiones físicas se observó en los pacientes con regímenes que incluyen drogas IP, si bien esta correlación es escasa y técnicamente significativa. En varios estudios sobre CVRS en personas que reciben IP como parte de su tratamiento se describen resultados disímiles; Ruiz Pérez y colaboradores, Murri y colaboradores encontraron que la combinación farmacológica que incluye IP no afecta la calidad de vida, de forma diferente que la combinación que no contiene IP. ${ }^{165,200}$

Fumaz y colaboradores, hallaron un deterioro en la calidad de vida en los pacientes tratados con esquemas que incluían IP, comparado con el grupo tratado con una combinación farmacológica que incluía efavirenz. ${ }^{201}$

Debe considerarse al respecto que, los pacientes que en general reciben IP son los que tienen enfermedad más avanzada y por ende una menor CVRS. Pero, por otra parte, los IP pueden causar múltiples efectos adversos incluyendo problemas de toxicidad e intolerancia gastrointestinal. Por lo que se concluye que el efecto de los IP en la CVRS aún no está claro. En la práctica, puede ser de utilidad discutir con los pacientes los potenciales efectos positivos y negativos de la terapia con IP, antes de indicar su administración, teniendo en cuenta que muchas veces es preferible prescindir de la potencia de un esquema y ganar en adherencia, ya que el mejor tratamiento será aquél que el paciente pueda cumplir. 
La mayor cantidad de cambios de los esquemas de tratamiento antiretroviral recibidos (switch) durante el transcurso de la enfermedad también condiciona una disminución en las puntuaciones del cuestionario, principalmente en las dimensiones que evalúan el aspecto físico y la vitalidad, lo que constituye un hecho esperable, ya que en general, cada cambio de esquema terapéutico se realiza por progresión de enfermedad clínica, por fallo virológico, inmunológico o por presencia de efectos adversos o de intolerancia ocasionados por las drogas. Y usualmente, cuanta más cantidad de veces se realiza el switch, más complejo se torna el esquema, implicando habitualmente la incorporación de un mayor número de fármacos y por consiguiente un mayor número de comprimidos, con todas las consecuencias que esto supone en la vida diaria del paciente.

La relación entre variables inmunológicas y CVRS ha sido intensamente estudiada en muchas partes del mundo, ya que, tanto el recuento de LT CD4+ como la carga viral plasmática son variables utilizadas para valorar la salud del individuo, predictoras de la progresión a SIDA y del fallo terapéutico. ${ }^{83,172,176,180,182,185,186,200-205}$

En este estudio se ha encontrado cierto grado de correlación significativa entre el recuento de LT CD4+ y la función física. Worthington y colaboradores, Jia y colaboradores, Sanzero Eller y colaboradores, Vidrine y colaboradores, han encontrado evidencia de que el recuento de LT CD4+ no posee ningún efecto en el status funcional y la CVRS del individuo. $180,182,185,186$

Algunos estudios han hallado relación consistente entre estos marcadores biológicos y las escalas de funcionamiento físico de la CVRS, ${ }^{91}$ 176, 184, 205 mientras que sólo unos pocos trabajos han hallado asociación entre marcadores biológicos y las dimensiones que valoran los aspectos psicosociales; entre estos, mencionamos el de Chandra y colaboradores, que reportaron en su estudio realizado en 2006 en la India, asociación significativa entre valores de LT CD4+ menores a $200 / \mathrm{mm}^{3}$ y los dominios psicosociales, aunque no encontraron diferencias significativas para los dominios relacionados con la salud física. ${ }^{91,184,203}$

Ruiz Pérez y colaboradores reportaron una mayor CVRS en sujetos españoles con baja $\mathrm{CV}$ y elevados niveles de LT CD4+, encontrando relación significativa y mejores puntuaciones en todas las dimensiones, físicas y psico-sociales. ${ }^{200}$

Los mismos hallazgos fueron publicados por Bing y colaboradores en pacientes norteamericanos. $^{201}$

$\mathrm{Al}$ analizar las puntuaciones obtenidas en nuestros pacientes, se observa que, las personas que presentan SIDA, es decir, aquellas que poseen un conteo de LT CD4+ menor a 200/. $\mathrm{mm}^{3}$ 
y valores elevados de carga viral plasmática, presentan bajas puntuaciones en las dimensiones que valoran tanto la función física como la psico-social. Si bien no se encontró relación significativa, se comprueban las escalas de menor puntuación en el rol emocional, lo que demuestra cuan negativo es el impacto de la enfermedad avanzada o sintomática en los pacientes.

Se demuestra, por lo tanto, de qué manera la infección avanzada por VIH causa deterioro en la salud percibida por el propio paciente, afectándose la CVRS en una forma multidimensional. 


\section{CONCLUSIONES}

La realización de este trabajo ha demostrado que:

1. La CVRS es un aspecto imprescindible a considerar cuando se planifica el tratamiento que recibirán nuestros pacientes; su medición permite detectar aspectos del estado de salud que los resultados clínicos tradicionales no reflejan y aportan una medida de resultado que incorpora la percepción del paciente.

2. Considerando el total de la población estudiada a la cual se le administró el cuestionario de salud SF-36, la puntuación más baja fue obtenida en el rol emocional, con un elevado porcentaje de individuos con puntuación mínima. Si bien existen diferencias entre género, edad y otros factores socio-epidemiológicos y clínicos, se ha demostrado que el estado emocional, la ansiedad y la depresión tienen un fundamental e importante efecto en la CVRS de la población y puede alterar la percepción de mejorías del estado de salud general.

3. El Cuestionario MOS SF-36 fue comprendido por nuestros pacientes, permitiendo su administración, por lo que el procedimiento de adaptación transcultural realizado para nuestra población del conurbano de la provincia de Buenos Aires permitirá utilizarlo en otras poblaciones de la Argentina.

4. El perfil - clínico epidemiológico de la población de pacientes que viven con VIH/SIDA en Florencio Varela, justifica que es imperativo el trabajo prioritario sobre dos ejes fundamentales: la educación para la salud y la creación de redes de accesibilidad a los servicios de salud, tanto en el primero como en el segundo nivel de atención. Dado que estas personas dependen casi exclusivamente del sector de salud estatal para poder realizar su tratamiento, es necesaria la urgente e inmediata inversión en planes de salud destinados a este nivel.

5. Nuestros pacientes se infectan a una temprana edad; la mayoría de ellos contraen la infección durante la adolescencia o siendo adultos jóvenes y la transmisión se asocia preponderantemente a la vía heterosexual.

6. El principal motivo que lleva a la realización del diagnóstico de la infección por VIH en nuestra población es la presentación de enfermedad marcadora de SIDA; el diagnóstico tardío es la resultante de grandes deficiencias en los programas de salud y de políticas que interfieren en la accesibilidad y eficacia de las medidas de prevención y atención relacionadas con el VIH. 
7. La mejoría en la condición física de los pacientes no se acompaña paralelamente de la mejoría de su estado emocional, ni de la percepción de una mejor calidad de vida.

8. Los programas de tratamiento del SIDA - ya sean provenientes de instituciones de salud estatales o privadas-, no deben limitarse sólo a la provisión de medicamentos y pruebas de laboratorio, sino que deben contemplar ya mismo la incorporación de nuevos abordajes terapéuticos con el objetivo de mejorar no sólo las dimensiones físicas del individuo sino también las psíquicas y sociales.

9. Los valores poblacionales de referencia de CVRS en personas que viven con VIH/SIDA, obtenidos mediante la aplicación del cuestionario de salud SF-36 en nuestra población, permitirán la contextualización e interpretabilidad de los resultados obtenidos en futuros trabajos.

10. El desarrollo de estudios de CVRS en la población general y en diferentes tipos de patologías crónicas, son objetivos prioritarios para lograr la implementación generalizada de la medición de la CVRS como método útil, confiable y necesario para evaluar el impacto general de la enfermedad por VIH.

Se debe comprender que el SIDA no es una mera enfermedad; es un revelador social que pone de manifiesto situaciones de exclusión e injusticia de naturaleza preexistente a la aparición de la epidemia. Por este motivo, es inadmisible la falta de implementación en nuestra comunidad, de políticas y estrategias de educación para la prevención de la infección por VIH en niños y jóvenes, recordando que toda educación para la prevención que quiera ser eficaz debe tener en cuenta las múltiples causas que favorecen la transmisión y difusión de la enfermedad, intensificando estas acciones en los grupos más vulnerables.

Después de un cuarto de siglo de epidemia, la respuesta a la infección por VIH/SIDA sigue siendo una encrucijada; muchos países han realizado avances importantes en la ampliación del acceso al tratamiento antiretroviral, incluyendo a la Argentina, pero se ha tenido escaso éxito en el esfuerzo por llevar al nivel necesario un tratamiento multidimensional, que sea capaz de abarcar el impacto global que esta enfermedad produce en aquellos individuos que la padecen. Por ello, es un aspecto imprescindible a considerar cuando se planifica el tratamiento que recibirán nuestros pacientes.

Los resultados presentados en este trabajo enfatizan la necesidad de un abordaje terapéutico integrado entre médicos infectólogos, clínicos, especialistas en rehabilitación, servicios de salud mental y de asistencia social, considerando a la persona que vive con 
VIH/SIDA como un fenómeno complejo, que requiere el diseño de intervenciones más efectivas mediante un abordaje multidimensional.

Es sólo con esta nueva mirada integradora del individuo que lograremos el más sublime de los éxitos terapéuticos: una mayor sobrevida con la mejor calidad de vida posible. 


\section{REFERENCIAS BIBLIOGRÁFICAS}

1. Sepkowitz KA. AIDS - the first 20 years. N Engl J Med 2001; 344(23): 1764-72.

2. UNAIDS 2007. AIDS epidemic update: December 2007. Geneva, Switzerland: UNAIDS (www.unaids.org).

3. Rosenberg C. What is an epidemic? AIDS in historical perspective. Daedalus 1989; 118(2): 1-19.

4. Bagasra O. A unified concept of HIV latency. Expert Opin Biol Ther 2006; 6(11): 1135-49.

5. Gallo RC, Montagnier L. The discovery of HIV as the cause of AIDS. N Engl J Med 2003; 349 (24): 2283-5.

6. Peeters M, Sharp PM. Genetic diversity of HIV 1: the moving target. AIDS 2000; 14: 5129-40.

7. Voevodin AF, Johnson BK, Samilchuk EI, Stone GA, Druilhet R, Greer WJ, Gibbs Jr CJ. Phylogenetic analysis of simian T-lymphotropic virus type I (STLV-I) in common chimpanzees (Pan troglodytes): evidence for interspecies transmission of the virus between chimpanzees and humans in Central Africa. Virology 1997; 238: 212-20.

8. Gessain A. Origine et diversité génétique des HTLV-1/STLV-1: des singes aux hommes. Virologie 1999; 3: 403-17.

9. Gao F, Bailes E, Robertson DL, Chen Y, Rodenburg CM, Michael SF, Cummins LB, Arthur LO, Peeters M, Shaw GM, Sharp PM, Hahn BH. Origin of HIV-1 in the chimpanzee Pan troglodytes troglodytes. Nature 1999; 397(6719): 436-41.

10. Hahn BH, Shaw GM, De Cock KM, Sharp PM. AIDS as a zoonosis: scientific and public health implications. Science 2000; 287: 607-14.

11. Hirsch VM, Olmsted RA, Murphey-Corb M, Purcell RH, Johnson PR. An African primate lentivirus (SIVsm) closely related to HIV-2. Nature 1989; 339: 398-92.

12. Sharp PM, Bailes E, Chaudhuri RR, Rodenburg CM, Santiago MO, Hahn BH. The origins of acquired immune deficiency syndrome viruses: where and when? Phil Trans R Soc Lond B 2001; 356(1410): 867-76.

13. Simon F, Mauclere P, Roques P, Loussert-Ajaka I, Müller-Trutwin M, Saragosti S, GeorgesCourbot MC, Barré-Sinoussi F, Brun-Vezinet P. Identification of a new human immunodeficiency virus type 1 distinct from Group M and Group O. Nature Med 1998; 4(9): 1032-7.

14. Cleghorn FR, Reitz Jr MS, Popovic M, Gallo RC. Virus de la inmunodeficiencia humana. En: Mandell GL, Bennett JE, Dolin R. Enfermedades infecciosas. Principios y práctica. Madrid: Elsevier España; 2006. p. 2119-33.

15. Corbet S, Muller-Trutwin MC, Versmisse P, Delarue S, Ayouba A, Lewis J, Brunak S, Martin P, Brun-Vezinet F, Simon F, Barre-Sinoussi F, Mauclere P. env sequences of simian immunodeficiency viruses from chimpanzees in Cameroon are strongly related to those of human immunodeficiency virus group $\mathrm{N}$ from the same geographic area. J Virol 2000; 74(1): 529-34.

16. Rambaut A, Robertson DL, Pybus OG, Peeters M, Holmes C. Phylogeny and the origin of HIV-1. Nature 2001; 410: 1047-8. 
17. Zhu T, Korber BT, Nahmias AJ, Hooper E, Sharp PM, Ho DD. An African HIV-1 sequence from 1959 and implications for the origin of the epidemic. Nature 1998; 391: 594-7.

18. Korber BT, Muldoon M, Theiler J, Gao F, Gupta R, Lapedes A, Hahn BH, Wolinsky S, Bhattacharya T. Timing the ancestor of the HIV-1 pandemic strains. Science 2000; 288(5742): 1789-96.

19. Sharp PM, Bailes E, Beer BE, Hirsch VM, Hahn BH. Origin and evolution of AIDS viruses: estimating the time-scale. Biochem Soc Trans 2000; 28: 275-82.

20. Burr T, Hyman JM, Myers G. The origin of acquired immune deficiency syndrome: Darwinian or Lamarkian? Phil Trans R Soc Lond B 2001; 356(1410): 877-87.

21. Yusim K, Peeters M, Pybus OG, Bhattacharya T, Delaporte E, Mulanga C, Muldoon M, Theiler J, Korber B. Using human immunodeficiency virus type 1 sequences to infer historical features of the acquired immune deficiency syndrome epidemic and human immunodeficiency virus evolution. Phil Trans R Soc Lond B 2001; 356(1410): 855-66.

22. Robinson JG, Redford KH, Bennet EL. Wildlife harvest in logged tropical forests. Science 1999; 284(5414): 595-6.

23. Hooper E. Search for the origin of HIV and AIDS. Science 2000; 289(5482): 1140.

24. Hooper E. The river: a journey back to the source of HIV and AIDS. New York: Little, Brown and York; 1999.

25. De Cock KM. Epidemiology and the emergence of human immunodeficiency virus and acquired immune deficiency syndrome. Phil Trans R Soc Lond B 2001; 356(1410): 795-8.

26. Cribb J. The origin of acquired immune deficiency syndrome: can science afford to ignore it? Phil Trans R Soc Lond B 2001; 356(1410): 935-8.

27. Low-Beer D. The distribution of early acquired immune deficiency syndrome cases and conditions for the establishment of new epidemics. Phil Trans R Soc Lond B 2001; 356(1410): $927-31$.

28. Fauci AS. The AIDS epidemic. Considerations for the 21st century. N Engl J Med 1999; 341(14): 1046-50.

29. Chitnis A, Rawls D, Moore J. Origins of HIV type 1 in colonial French Equatorial Africa. AIDS Res Hum Retroviruses 2000; 16: 5-8.

30. Warrilow D, Harrich D. HIV-1 replication from after cell entry to the nuclear periphery. Curr HIV Res 2007; 5(3); 293-9.

31. Le Rouzic E, Benichou S. The Vpr protein from HIV-1: distinct roles along the viral life cycle. Retrovirology 2005; 22: 2-11.

32. Lehman-Che J, Saib A. Early stages of HIV replication: how to hijack cellular functions for a successful infection. AIDS Rev 2004; 6(4): 199-207.

33. Freed FO. HIV-1 replication. Somat Cell Mol Genet 2001; 26(1-6):13-33.

34. Hollingsworth TD, Anderson RM, Fraser C. HIV-1 Transmission, by Stage of Infection. J Infect Dis 2008; 198(5): 687-93. 
35. Schacker TW, Hughes JP, Shea T, Coombs RW, Corey L. Biological and virologic characteristics of primary HIV infection. Ann Intern Med 1998; 128(8): 613-20.

36. Montero A. Fisiopatología de la infección. En: Lupo S. Clínica y terapéutica de la infección por VIH y SIDA. Rosario: Editorial de la Universidad Nacional de Rosario; 2003. p. 39-49.

37. Fauci AS, Pantaleo G, Stanley D. Immunopathogenic mechanism of HIV infection. Ann Intern Med 1996; 124: 654-63.

38. Lyles C, Dorrucci M, Vlahov D, Pezzotti P, Angarano G, Simicco A, Alberici F, Alcorn TM, Vella S, Rezza G for the Italian Seroconversion Study. Longitudinal human immunodeficiency virus type 1 load in the italian seroconversión study: correlates and temporal trends of virus load. J Infect Dis 1999; 180:1018-24.

39. Petruckevitch A, Del Amo J, Phillips AN, Johnson AM, Stephenson J, Desmond N, Hanscheid T, Low N, Newell A, Obasi A, Paine K, Pym A, Theodore C, De Cock KM. Disease progression and survival following specific AIDS-defining conditions: a retrospective cohort study of $2048 \mathrm{HIV}$ infected persons in London. AIDS 1998; 12(9): 1007-13.

40. Mocroft A, Ledergerber B, Katlama C, Kirk D, Reiss P, d'Arminio Monforte A. Decline in the AIDS and death rates in the EuroSIDA study: an observational study. Lancet 2003; 362: 22-9.

41. CDC 1997. Case definitions for infectious conditions under public health surveillance. MMWR 1997; 46(No. RR-10): 1-55.

42. CDC 1993. Revised classification system for HIV infection and expanded surveillance case definition for AIDS among adolescents and adults. MMWR 1992; 41(No. RR-17): 1-19.

43. Ho DJ, Dondero TJ, Mastro TD, Gayle HD. Global and molecular epidemiology of HIV. En: Wormser G ed. AIDS and other manifestations of HIV infection. Philadelphia: Lippnicott-Raven Publishers; 1998. p. 27-40.

44. Weiss RA, Wain Hobson S, eds. Origins of HIV and the AIDS epidemic. Papers of a discussion meeting. Phil Trans R Soc Lond B 2001; 356(1410): 777-977.

45. Plotkin SA. CHAT oral polio vaccine was not the source of human immunodeficiency virus type 1 group $\mathrm{M}$ for humans. Clin Infect Dis 2001; 32(7): 1068-84.

46. Vangroenweghe D. The earliest cases of human immunodeficiency virus type 1 group $\mathrm{M}$ in Congo-Kinshasa, Rwanda and Burundi and the origin of acquired immune deficiency syndrome. Phil Trans R Soc Lond B 2001; 356(1410): 923-5.

47. Bayer R, Oppenheimer GM. Pioneers in AIDS care - Reflections on the epidemic's early years. N Engl J Med 2006; 355(22): 2273-5.

48. Martin B. Investigating the origin of AIDS: some ethical dimensions. J Med Ethics 2003; 39: 2536.

49. Weiss RA. Natural and iatrogenic factors in human immunodeficiency virus transmission. Phil Trans R Soc Lond B 2001; 356 (1410): 947-53.

50. Perrin L, Kaiser L, Yerly S. Travel and spread of HIV-1 genetic variants. Lancet 2003; 3(1): 2227.

51. Pneumocystis pneumonia - Los Angeles. MMWR Morb Mortal Wkly Rep 1981; 30: 250-2. 
52. da Silva ZJ, Oliveira I, Andersen A, Dias F, Rodrigues A, Holmgren B, Andersson S, Aaby P. Changes in prevalence and incidence of HIV-1, HIV-2 and dual infections in urban areas of Bissau, Guinea-Bissau: is HIV-2 dissapearing? AIDS 2008; 22(10): 1195-202.

53. Sepkowitz KA. One disease, two epidemics - AIDS at 25. N Engl J Med 2006; 354(23): 2411-4.

54. Comisión Caribeña de Salud y Desarrollo 2005. Report of the Caribbean Commission on Health and Development for the $26^{\text {th }}$ Meeting of the CARICOM Heads of Government: Overview. July 3-6. Saint Lucia. Disponible en: http://www.cpc-paho.org/publications/publication.aspx?id=59.

55. Cohen J. The overlooked epidemic. Science 2006; 313(5786): 468-9.

56. Rusell KL, Carcamo C, Watts DM, Sanchez J, Gotuzzo E, Euler A, Blanco JC, Galeano A, Alava A, Mullins JI, Holmes KK, Carr JK. Emerging genetic diversity of HIV 1 in South America. AIDS 2000; 14: 1785-91.

57. Montano SM, Sanchez JL, Laguna-Torres A, Cuchi P, Avila M, Weissenbacher M, Serra M, Vignoles J, Russi JC, Aguayo N, Galeano A, Gianella A, Andrade R, Arredondo A, Ramirez E, Acosta ME, Alava A, Montoya O, Guevara A, Manrique H, Sanchez JL, Lama JR, de la Hoz, F, Sanchez GI, Ayala C, Pacheco ME, Carrion G, Chauca Gloria, Perez JJ, Negrete M, Russell, KL, Bautista CT, Olson, JG, Watts DM, Birx DL, Carr, JK, for the South American HIV Molecular Surveillance Working Group. Prevalences, genotypes and risk factors for HIV transmission in South America. J Acquir Immune Defic Syndr 2005; 40(1): 57-64.

58. Bautista CT, Sanchez JL, Montano SM, Laguna-Torres A, Suarez L, Sanchez J, Campos P, Gallardo C, Mosquera C, Vilafañe M, Aguayo N, Avila MM, Weissenbacher M, Ramirez E, Child R, Serra M, Aponte C, Mejia A, Velasquez M, Gianella A, Perez J, Olson JG, Carr JK. Seroprevalence of and risk factors for HIV infection among female commercial sex workers in South America. Sex Transm Infect 2006; 82(4): 311-6.

59. Okie S. Fighting HIV- lessons from Brazil. N Engl J Med 2006; 354 (19): 1977-81.

60. Boletín sobre el VIH - SIDA en la Argentina. Dirección de SIDA y Enfermedades de Transmisión Sexual. Ministerio de Salud de la Nación. Buenos Aires: Agosto 2008. Año XI, número 25.

61. Pando MA, Berini C, Bibini M, Fernandez M, Reinaga E, Maulen S, Marone R, Biglione M, Montano SM, Bautista CT, Weissenbacher M, Sanchez JL, Avila MM. Prevalence of HIV and other sexually transmitted infections among female commercial sex workers in Argentina. Am J Trop Med Hyg 2006; 74(2): 233-8.

62. Perfil epidemiológico en la Argentina - Período: 1982-2004. Boletín sobre el SIDA en la República Argentina y elaboración propia a partir de sus datos. Ministerio de Salud. Programa Nacional de la Lucha contra los Retrovirus del Humano, SIDA y ETS. Actualizaciones en SIDA 2005; 13(47): 25-32.

63. Programa Provincial de VIH/SIDA y Enfermedades de Transmisión Sexual. Ministerio de Salud de la provincia de Buenos Aires, región Sanitaria VI, 2007.

64. Cohen J. South America. Science 2006; 313(5786): 484.

65. Cohen J. Up in smoke: epidemic changes course. Science 2006; 313(5786): 487-8.

66. Pando MA, De Salvo C, Bautista CT, Eyzaguirre L, Carrion G, Feota M, Lado I, Hoffman M, Biglione MM, Carr JK, Montano SM, Sanchez JL, Weissenbacher M, Avila MM. Human 
immunodeficiency virus and tuberculosis in Argentina: prevalence, genotypes and risk factors. $\mathrm{J}$ Med Microbiol 2008; 57(2): 190-7.

67. Hammer SM, Eron Jr JJ, Reiss P, Schooley RT, Thompson MA, Walmsley S, Cahn P, Fischl MA, Gatell JM, Hirsch MS, Jacobsen DM, Montaner JSG, Richman DD, Yeni PG, Volberding PA. Antiretroviral Treatment of Adult HIV Infection 2008. Recommendations of the International AIDS Society-USA Panel. JAMA 2008; 300(5): 555-70.

68. Padilla GV. Calidad de vida: Panorámica de investigaciones clínicas. Revista Colombiana de Psicología 2005; 13: 80-8.

69. Remor E. Apoyo social y calidad de vida en la infección por el VIH. Aten Primaria 2002; 30(3): 143-9.

70. Siegrist J, Fernández-López JA, Hernández-Mejía R. Perspectiva sociológica de la calidad de vida. Med Clin (Barc) 2000; 114: 22-4.

71. Badia X, Carné X. La evaluación de la calidad de vida en el contexto del ensayo cínico Med Clin (Barc) 1998; 110: 550-6.

72. Alonso J, Prieto L, Antó JM. La versión española del SF-36 Health Survey (Cuestionario de Salud SF-36): un instrumento para la medida de los resultados clínicos. Med Clin (Barc) 1998; 104(20): $771-6$.

73. Franchi D, Wenzel R. Measuring health-related quality of life among patients. Clin Infect Dis 1998; 26: 20-6.

74. Burgoyne R, Renwick R. Social support and quality of life over time among adults living with HIV in the HAART era. Soc Sci Med 2004; 58(7): 1353-66.

75. Testa MA, Simonson DC. Assessment of quality of life outcomes. N Engl J Med 1996; 334: 83540.

76. Shumaker SA, Ellis S, Naughton M. Assessing health-related quality of life in HIV disease: key measurement issues. Clin Infect Dis 1998; 26: 20-6.

77. Pace JC, Stables JL. Correlates of spiritual well-being in terminally ill persons with AIDS and terminally ill persons with cancer. J Assoc Nurses AIDS Care 1997; 8: 31-42.

78. Bergner M. Quality of life, health status, and clinical research. Med Care 1988; 27 Supl 3: S14856.

79. Higginson IJ, Carr AJ. Using quality of life measures in the clinical setting. BMJ 2001; 322: 1297-300.

80. Asadi-Lari M, Tamburini M, Gray D. Patients' needs, satisfaction, and health-related quality of life: towards a comprehensive model. Health Qual Life Outcomes 2004; 2: 3.2.

81. Velarde-Jurado E, Ávila-Figueroa C. Consideraciones metodológicas para evaluar la calidad de vida. Salud Publica Mex 2002; 44: 448-63.

82. Consiglio E, Belloso WH. Nuevos indicadores clínicos. La calidad de vida relacionada con la salud. Medicina (B Aires) 2003; 63:172-8. 
83. García Ordoñez MA, Mansilla Francisco JJ, Nieto Aragón E, Cereto MR, Salas Semper F, Vallejo Díaz M, Martínez González J. Calidad de vida relacionada con la salud de pacientes infectados por VIH medida por el Cuestionario de Salud SF-36. An Med Interna (Madrid) 2001; 18(2): 74-9.

84. Tarlov AR, Ware JE Jr, Greenfield S, Nelson EC, Perrin E, Zubkoff M. The Medical Outcomes Study: an application of methods for monitoring the results of medical care. JAMA 1989; 262: 925-30.

85. Wu AW, Revicki DA, Malitz F. Evidence for reliability, validity and usefulness of the Medical Outcomes Study HIV Health Survey (MOS HIV). Qual Life Res 1997; 6(6): 481-93.

86. Hyland M. A brief guide to the selection of quality of life instrument. Health Qual Life Outcomes 2003; $1: 24$.

87. Wu AW, Hays RD, Kelly S, Malitz F, Bozzette SA. Applications of the Medical Outcomes Study health-related quality of life measures in HIV/AIDS. Qual Life Res 1997; 6(6): 531-54.

88. Burckhardt CS, Anderson KL. The Quality of Life Scale (QOLS): reliability, validity and utilization. Health Qual Life Outcomes 2003, 1: 60.

89. Clayson DJ, Wild DJ, Quarterman P, Duprat-Lomon I, Kubin M, Coons SJ. A comparative review of health-related quality-of-life measures for use in HIV/AIDS clinical trials. Pharmacoeconomics 2006; 24(8): 751-65.

90. Badia X, Podzamczer D, Casado A, López-Lavid C, García M. Evaluating changes in health status in HIV-infected patients: Medical Outcomes Study-HIV and Multidimensional Quality of Life HIV quality of life questionnaires. AIDS 2000; 14: 1439-47.

91. Badia X, Podzamczer D, Garcia M, López-Lavid C, Consiglio E and the Spanish MOS-HIV and MDQOL-HIV Validation Group. A randomized study comparing instruments for measuring heath related quality of life in HIV-infected patients. AIDS 1999; 13(13): 1727-35.

92. Testa MA, Simonson DC. Assessment of quality of life outcomes. N Engl J Med 1996; 334: 83540.

93. Integrated management of adolescent and adult illness, chronic HIV care with ARV therapy and prevention, 2006. [acceso 8 de marzo de 2008]; Disponible en http:/www.who.arvkit.net/arv/media/chronic care 3 may 06.pdf.

94. Recomendaciones para el seguimiento y tratamiento de la infección por VIH, SADI 2008.

95. Ley de Educación Nacional No 26.206, Capítulo I, artículo 17. 2006. Ley de Educación Nacional No26.206, Capítulo V, artículo 34. 2006.

96. Coutrot T. Trabajo, empleo, actividad. En: Gentili P, Frigoto G. La ciudadanía negada. Políticas de exclusión en la educación y el trabajo. Buenos Aires: Consejo Latinoamericano de Ciencias Sociales; 2000. p. 13-33.

97. Dinatale M. El festival de la pobreza. Buenos Aires: Editorial La Crujía; 2004. p. 5-9.

98. Tobar F. ¿Cómo curar al sistema de salud argentino? Rev Panam Salud Publica 2002; 11(4): 27782 .

99. Palazzi J. Patogénesis viral. En: Lupo S. Clínica y terapéutica de la infección por VIH y SIDA. Rosario: Editorial de la Universidad Nacional de Rosario; 2003. p. 51-67. 
100.DC 1997. Case definitions for infectious conditions under public health surveillance. MMWR 1997; 46 (No. RR-10): 1-55.

101. Comité de Expertos de la OMS en Problemas Relacionados con el Consumo de Alcohol. Meeting (2a: 2006: Ginebra, Suiza).

102.Comité de Expertos de la OMS en Farmacodependencia. $33^{\circ}$ informe. Ginebra, Organización Mundial de la Salud, 2003. OMS, Serie de Informes Técnicos No 915.

103. Samet S, Waxman R, Hatzenbuehler M, Hasin D. Assesing Addiction: Concepts and Instruments. Addict Sci Clin Pract 2007; 4(1):19-31.

104. Contel M, Gual A, Colom J. Test para la identificación de trastornos por uso de alcohol (AUDIT): traducción y validación del AUDIT al catalán y castellano. Adicciones 1999; 11: 337-47.

105.Saiz PA, Portilla MP, Paredes MB, Bascarán MT, Bobes J. Instrumentos de evaluación en alcoholismo. Adicciones 2002; 14 Supl 1: 387-403.

106. Torrecilla García M, Domínguez Grantal F, Torres Lana A, Cabezas Peña C, Jiménez Ruiz CA, Barrueco Ferrero M, Solano Reina S, de Granda Orive II, Díaz-Maroto Muñoz JL, Alonso J, Martínez ML, García S, de la Cruz Amorós E, Abengozar Muela R, Ramos Postigo F, Ayesta J. Recomendaciones en el abordaje diagnóstico y terapéutico del fumador. Documento de consenso. Aten Primaria 2002; 30(5): 310-7.

107.de Granda Orive II, Carrión F, Alonso S, Márquez FL, Riesco JA, Sampablo I, Alvarez FJ, Barrueco M, Carreras JM, Jiménez CA, Nerón I, Pérez Trullén A, Rodríguez Hermosa JL, Romero PJ, Sánchez Agudo L, Sánchez I, Solano S, Álvarez-Sala JL; Área de Tabaquismo de la Sociedad Española de Neumonología y Cirugía Torácica (SEPAR). Madrid, España. Tobacco addicion: care and services. Arch Bronconeumol 2006; 42(11): 600-4.

108. Charlson ME, Pompei P, Ales KL, McKenzie CR. A new method of classifying prognostic comorbidity in longitudinal studies: Development and validation. J Chron Dis 1987; 40: 373-83.

109. Caballería J, Caballería LI, Parés A. Enfermedad hepática alcohólica. Medicine 2000; 8(9): 43541.

110. Abdo Francis JM. Hepatitis viral. $1^{\text {o }}$ ed. México DF: Editorial El Manual Moderno, 2003.

111. Guía de Manejo de las Infecciones de Transmisión Sexual 2004. Programa Nacional de Lucha contra los Retrovirus del humano, SIDA y ETS Ministerio de Salud y Ambiente de la Nación.

112. Ayuso Gutiérrez JL. Comorbilidad depresión-ansiedad: aspectos clínicos. Psiquiatría.COM [revista en internet] 1997 Marzo [acceso 8 de marzo de 2008]; 1(1): [15 pantallas]; Disponible en: http://www.psiquiatria.com/psiquiatria/vol1num1/art_2.htm

113. García Luna PP, Parejo Campos J, Pereira Cunill JL. Causas e impacto clínico de la desnutrición y caquexia en el paciente oncológico. Nutr Hosp 2006; 21 Supl 3: 10-6.

114. Consenso Latinoamericano de Hipertensión Arterial. Consejo de Hipertensión Arterial "Dr. Eduardo Braun Menéndez", Sociedad Argentina de Cardiología. Rev Argent Cardiol 2000; 68 Supl 6: 1-32.

115. Gagliardino JJ, Sereday M, González C, Domínguez JM, Mazza CS, en representación de los integrantes del Comité de Expertos de la Sociedad Argentina de Diabetes. Conclusiones de la 
reunión de consenso sobre criterio diagnóstico de la glucemia de ayunas alterada, de la Sociedad Argentina de Diabetes. Rev Soc Arg Diabetes 2007; 41(3): 95-104.

116. Antuña Egocheaga A, López González M L, Lobo Fernández J, Fernández Bustamante J, Moris de la Tassa J, Cueto Espinar A. Protocolo diagnóstico del cáncer de origen desconocido: Revisión de 157 casos. An Med Interna (Madrid) 2002; 19(8): 29-32.

117. Stankov MV, Behrens GM. HIV-therapy associated lipodystrophy: experimental and clinical evidence for the pathogenesis and treatment. Endocr Metab Immune Disord Drug Targets 2007; 7 (4): 237-49.

118.Wierzbicki AS, Purdon SD, Hardman TC, Kulasegaram R, Peters BS. HIV lipodystrophy and its metabolic consequences: implications for clinical practice. Curr Med Res Opin 2008; 24(3): 60924.

119.Uurlings F, Moutschen M. Lipodystrophy syndrome in HIV infected patients. Rev Med Liege. 2007; 62(11): 669-74.

120.Real Academia Española. Diccionario de la lengua española. 22a edición. Madrid: Espasa - Calpe S.A., 2001.

121.Ware Jr JE, Sherbourne CD. The MOS 36-Item Short-Form Health Survey (SF-36). Medical Care 1992; 30(6): 473-81.

122.Villagut G, Ferrer M, Rajmil L, Rebollo P, Permanyer-Miralda G, Quintana JM, Santed R, Valderas JM, Ribera A, Domingo-Salvany A, Alonso J. El Cuestionario de Salud SF-36 español; una década de experiencia y nuevos desarrollos. Gac Sanit 2005; 19(2): 135-50.

123. Shahriar J, Delate T, Hays RD, Coons SJ. Commentary on using the SF-36 or MOS-HIV in studies of persons with HIV disease. Health Qual Life Outcomes 2003; 1:25 [en línea] Disponible en URL: http://www.hqlo.com/content/1/1/25 (consultado el 23 de julio de 2007).

124. Hays RD, Shapiro MF. An overview of generic health-related quality of life measures for HIV research. Qual Life Res 1992; 1(2): 91-7.

125.Alonso J, Prieto L, Antó JM. La versión española del SF-36 Health Survey (Cuestionario de Salud SF-36): un instrumento para la medida de los resultados clínicos. Med Clin (Barc) 1995; 104(20): $771-6$.

126. Ware Jr JE, Kosinski M, Gandek B, Aaronson NK, Apolone G, Bech P, Brazier J. Bullinger M, Kaasa S, Leplège A, Prieto L, Sullivan M. The factor structure of the SF-36 Health Survey in 10 countries: results from the IQOLA Project. J Clin Epidemiol 1998; 51(11): 1159-65.

127.Bullinger M, Alonso J, Apolone G, Leplège A, Sullivan M, Wood-Dauphinee S, Gandek B, Wagner A, Aaronson N, Bech P, Fukuhara S. Kaasa S, Ware Jr JE. Translating health status questionnaires and evaluating their quality: The IQOLA Project Approach. J Clin Epidemiol 1998; 51(11): 913-23.

128.Peña de León E, Aguilar Gaytán SS, Suárez Mendoza AA, Reyes Terán G. Validación mexicana de la escala MOS-HIV de calidad de vida en pacientes infectados por el VIH. Rev Panam Salud Publica 2007; 21(5): 313-9.

129.Álvarez Cáceres R. Estadística aplicada a las Ciencias de la Salud. España: Ediciones Díaz de Santos; 2007. 
130.1ª Asamblea Médica Mundial. Asociación Médica Mundial, Helsinki, Finlandia, junio de 1964.

131.Ley Nacional de SIDA No 23.798, artículo $2^{\text {do }} .1990$.

132.Daniel W. Bioestadística. Base para el análisis de las Ciencias de la Salud. Noriega Editores: México; 1993.

133.Pagano M. Gauvreau K. Fundamentos de Bioestadística. $5^{\circ}$ ed. Universidad de Thomson Learning Editores; 2001.

134. Basualdo JA, Grenóvero MS, Minvielle MC, Barengo N. Nociones básicas de Metodología de la Investigación en Ciencias de la Salud. $1^{\circ}$ ed. La Plata: Gráfica Alemana; 2004.

135.Dawson-Saunders B. Bioestadística Médica. México: El Manual Moderno; 1995.

136. Ley Nacional 25.543/01. Test diagnóstico del virus de inmunodeficiencia humana. Obligatoriedad del ofrecimiento a toda mujer embarazada como parte del cuidado prenatal normal.

137. Bernstein J, Mattarollo N. Análisis clínico-epidemiológico de pacientes con HIV/SIDA asistidos en un consultorio de Infectología. Abstract $N^{\circ} 138$, pág. 57. $6^{\circ}$ Congreso Argentino de SIDA. Buenos Aires, 20 al 23 de noviembre de 2003.

138. Bernstein JC, Scandizzo HE, Valenzuela V, Ariza HA, Serrano MI. Socio epidemiological and clinical features of people living with HIV/AIDS in Buenos Aires, Argentina. CDD0105, XVI International AIDS Conference. Toronto (Canada) 13-18 August 2006.

139. Scandizzo HE, Bernstein J, Litrenta MJ, Barrionuevo O, Corazza M. Prevalencia de la infección por VIH y variables epidemiológicas de pacientes asistidos en el hospital "Mi Pueblo" de Florencio Varela, Buenos Aires. Resumen $\mathrm{N}^{\circ} 155$, pág. 44. $7^{\circ}$ Congreso Argentino de SIDA. La Plata, 24 al 26 de noviembre de 2005.

140. Scandizzo H, Bernstein J, Litrenta M, Rosales MV, Serrano M. Hijos de madre infectada con VIH/SIDA: evaluación de un trabajo en red multidisciplinario. Resumen $\mathrm{N}^{\circ} 22626$, pág 41. $8^{\circ}$ Congreso Argentino de la Sociedad Argentina de Infectología 2008. Mar del Plata, 22 al 24 de mayo de 2008.

141.Cocozella DR, Albuquerque MM, Borzi S, Barrio M, Dascenso V, Santecchia JC, González J, Adrover RE, Meneses C, Fraquelli E, Curciarello JO. Prevalencia de afectación hepática, alcoholismo, hepatitis B, C y HIV en pacientes con antecedente de consumo de drogas. Acta Gastroenterol Latinoam 2003; 33(4): 177-81.

142. Chincha O, Samalvides F, Bernabé Ortiz A, Kruger H, Gotuzzo E. Asociación entre el consumo de alcohol y la infección por virus de la inmunodeficiencia humana. Rev Chil Infect 2008; 25(1): 49-53.

143. Lichtenstein K, Balasubramanyam A, Sekhar R, Freedland E. HIV-associated adipose redistribution syndrome (HARS): definition, epidemiology and clinical impact. AIDS Research and Therapy 2007, 4:16.

144. Mutimura E, Stewart A, Crowther NJ. Assessment of quality of life in HAART-treated HIVpositive subjects with body fat redistribution in Rwanda. AIDS Research and Therapy 2007, 4:19.

145.Collins E, Wagner C, Walmsley S. Psychosocial impact of the lipodystrophy syndrome in HIV infection. AIDS Read 2000; 10(9): 546-50. 
146. Woolley IJ, Mijch AM, Carter VM, Archer B, Hoy JF. Anterior neck fat deposition in lipodystrophy syndrome; a new variant on a theme? AIDS 2003; 7 (12): 1857-8.

147. Santos CP, Felipe YX, Braga PE, Ramos D, Lima R O, Segurado AC. Self-perception of body changes in persons living with HIV/AIDS: prevalence and associated factors. AIDS 2005; 19(4): S14-S21.

148. Guaraldi G, Murri R, Orlando G, Squillace N, Stentarelli C, Zona S, Garlassi E, Martinez E. Lipodystrophy and quality of life of HIV-infected persons. AIDS Rev 2008; 10 (3): 152-61.

149.Lenert LA, Feddersen M, Sturley A, Lee D. Adverse effects of medications and trade-offs between lenght of life and quality of life in human immunodeficiency virus infection. Am J Med 2002; 113: 229-32.

150. Mc Comsey G, Maa JF. Host factors may be more important than choice of antiretrovirals in the development of lipoatrophy. AIDS Read 2003; 13(11): 539-42.

151. Thomas DL. Hepatitis C and Human Immunodeficiency Virus. Hepatology 2002; 36(5) Suppl 1: S201-9.

152. Bessone G, Belloso W, Schroder T. Hepatotoxicidad en pacientes coinfectados. Acta Gastroenterol Latinoam 2006; 36(Supl. 1): S43-S45.

153.Laufer NL, Quarleri JF, Bouzas MB, Pérez HM, Salomón H, Cahn P. Coinfección por HBV y HCV en pacientes HIV positivos en la "era HAART": nuevos desafíos. Medicina (B Aires) 2007; 67(1): 82-91.

154.Cielsa JA, Roberts JE, Meta-analysis of the relationship between HIV infection and risk for depressive disorders. Am J Psychiatry 2001; 158(5): 725-30.

155. Starace F, Ammassari A, Trotta MP, Murri R, De Longis P, Izzo C, Salzini A, d'Arminio Monforte A, Wu AW, Antinori A. Depression is a risk factor for suboptimal adherence to highly active antiretroviral therapy. J Acquir Immune Defic Syndr 2002; 31 Suppl 3: S136-9.

156.Leitao Jr MM, White P, Cracchiolo B. Cervical cancer in patients infected with the human immunodeficiency virus. Cancer 2008; 112(12): 2683-89.

157. Bernstein J, Bulgherini M, Boccia M, Ludueña M, Knauer R, Mattarollo P. Prevalencia de cáncer cervical femenino e infección por VIH. Resumen $\mathrm{N}^{\circ}$ 174, pág. 47. $7^{\circ}$ Congreso Argentino de SIDA. La Plata, 24 al 26 de noviembre de 2005.

158. Valencia Ortega ME. AIDS-related malignancies. A new approach. AIDS Rev 2008; 10(2): 1257.

159. Bernstein J. Candidiasis. En: Cecchini E, González Ayala SE. Infectología y enfermedades infecciosas. Buenos Aires: Ediciones Journal; 2008. Cap. 70, p. 489-505.

160. Notificación de casos de tuberculosis en la República Argentina. Documento técnico 07/07. INER “Dr. Emilio Coni”. Ministerio de Salud Presidencia de la Nación, 2008.

161.Lawn SD, Bekker LG, Miller RF. Immune reconstitution disease associated with mycobacterial infections in HIV-infected individuals receiving antiretrovirals. Lancet Infect Dis 2005; 5(6):36173. 
162. Bernstein J, Sevillano G, Mattarollo N. Seroprevalencia de toxoplasmosis en una población de pacientes con VIH/SIDA del conurbano bonaerense. Acta Bioquim Clin Latinoam 2003; Supl 1: 92.

163. Martín Suárez I, Cano Monchul R, Pérez de Ayala P, Aguayo Canela M, Cuesta F, Rodríguez P, Pujol de la Llave E. Calidad de vida, aspectos psicológicos y sociales en pacientes con infección VIH avanzada. An Med Interna (Madrid) 2002; 19(8): 396-404.

164. Bernstein J, Mattarollo P, Jeschke L, Gatti E, Bottega A. Criptosporidiosis intestinal en pacientes con infección por VIH/SIDA. Abstract I450. XII Congreso Latinoamericano de Microbiología. X Congreso Argentino de Microbiología. Buenos Aires, 17 al 21 de octubre de 2004.

165. Murri R, Fantoni M, Del Borgo C, Visona R, Barranco A, Zambelli A, Testa L, Orchi N, Tosi V, Bosco O, Wu AW. Determinants of health-related quality of life in HIV-infected patients. AIDS Care 2003; 15(4): 581-90.

166.Inouye SK, Zhang Y, Jones RN, Shi P, Cupples A, Calderon HN, Marcantonio ER. Risk factors for hospitalization among community-dwelling primary care older patients: development and validation of a predictive model. Med Care; 2008 46(7): 726-31.

167. Mathews WC, May S. EuroQol (EQ-5D) measure of quality of life predicts mortality, emergency department utilization, and hospital discharge rates in HIV-infected adults under care. Health Qual Life Outcomes; 2007; 5: 5.

168. Barbour KM, Fabio A, Pearlman DN. Inpatient charges among HIV/AIDS patients in Rhode Island from 2000-2004. BMC Health Serv Res; 2009; 9: 3.

169. Bastardo YM, Kimberlin CL. Relationship between quality of life, social support and diseaserelated factors in HIV-infected persons in Venezuela. AIDS Care 2000; 12(5): 673-84.

170. Alonso J, Regidor E, Barrio G, Prieto L, de la Fuente L. Valores poblacionales de referencia de la versión española del Cuestionario de Salud SF-36. Med Clin (Barc) 1998; 111(11): 410-6.

171. Rivero Méndez M, Portillo C, Solis Baez SS, Wantland D, Holzemer WL. Symptoms and quality of life for people living with HIV infection in Puerto Rico. PR Health Sci J 2009; 28 (1): 54-9.

172. Rao D, Hahn EA, Cella D, Hernández L. The health-related quality of life outcomes of English and Spanish speaking persons living with HIV/AIDS from the continental United States and Puerto Rico. AIDS Patients Care STDs 2007; 21(5): 339-46.

173. Hudson A, Kirksey K, Holzemer W. The influence of symptoms on quality of life among HIVinfected women. West J Nurs Res 2004; 26(1): 9-23.

174. Mrus JM, Williams Pl, Tsevat J, Cohn SE. Wu AW. Gender differences in health-related quality of life in patients with HIV/AIDS. Qual Life Res 2005; 14(2): 479-91.

175. dos Santos ECM, França Jr I, Lopes F. Qualidade de vida de pessoas viviendo com HIV/AIDS em Sâo Paulo. Rev Saúde Pública 2007; 41(Supl. 2): 64-71.

176. Kohili RM, Sane S, Kumar K, Paranjape RS, Mehendale SM. Assesment of quality of life among HIV-infected persons in Pune, India. Qual Life Res 2005; 14(6): 1641-7.

177. Ruiz Perez I, Rodriguez Baño J, Lopez Ruz MA, del Arco Gimenez A, Causse Prados M, Pasquau Liaño J, Martin Rico P, de la Torre Lima J, Prada Pardal JL, Lopez Gomez M, Muñoz N, Morales 
D, Marcos M. Health-related quality of life of patients with HIV: Impact of sociodemographic, clinical and psychological factors. Health Qual Life Res 2005; 14(5): 1301-10.

178. Liu C, Johnson L. Ostrow D, Silvestre A, Visscher B, Jacobson LP. Predictors for lower quality of life in the HAART era among HIV-infected men. J Acquir Defic Syndr 2006; 42(4): 470-7.

179. Hays RD, Cunningham WE, Sherbourne CD, Wilson JB, Wu AW, Cleary PD, Mc Caffey DF, Fleishman JA, Crystal S, Collins R, Eggan F, Shapiro MF, Bozzette SA. Health-related quality of life in patients with immunodeficiency virus infection in the United Sates: results from the HIV Cost and Services Utilization Study. Am J Med 2000; 108(9): 714-22.

180. Worthington C, Krentz HB. Socio-economic factors and health-related quality of life in adults living with HIV. Int J STD AIDS 2005; 16: 608-14.

181. Blalock AC, Mc Daniel JS, Farber EW. Effect of employment on quality of life and psychological functioning in patients with HIV/AIDS. Psychosomatics 2002; 43(5): 400-4.

182. Sanzero Eller L, Quality of life in persons living with AIDS. Clin Nurs Res 2001; 10(4):401-23.

183. Burgoyne RW, Saunders DS. Quality of life among urban Canadian HIV/AIDS clinic outpatients. Int J STD AIDS 2001; 12: 505-12.

184.Campsmith ML, Nakashima AK, Davidson AJ. Self-reported health-related quality of life in persons with HIV infection: results Form a multi-site interview project. Health Qual Life Outcomes 2003; 1:12.

185. Vidrine DJ, Amick III BC, Gritz ER, Arduino RC. Assesing a conceptual framework of healthrelated quality of life in HIV/IDS population. Qual Life Res 2005: 14(4): 923-33.

186. Jia H, Uphold CR, Zheng Y, Wu S, Chen JG, Findley K, Duncan PW. A further investigation of health-related quality of life over time among men with HIV infection in the HAART era. Qual Life Res 2007; 16(6): 961-8.

187.Pérez Pegué E, Hidalgo S. Tratamientos y calidad de vida en las personas coinfectadas. Acta Gastroenterol Latinoam 2006; 36(Supl. 1):S39-S40.

188. Sherbourne CD, Hays RD, Fleishman JA, Vitiello B, Magruder KM, Bing EG, Mc Caffrey D, Burnam A, Longshore D, Eggan F, Bozzette SA, Shapiro MF. Impact of psychiatric conditions on health-related quality of life in persons with HIV infection. Am J Psychiatry 2000; 157(2): 24854.

189. Bondini S, Kallman J, Dan A, Younoszai Z, Ramsay L, Nader F, Younossi ZM. Health-related quality of life in patients with chronic hepatitis B. Liver Int 2007; 27(8): 1119-25.

190.Kwan JW, Cronkite RC, Yiu A, Goldstein MK, Kazis L, Cheung RC. The impact of chronic hepatitis C and co-morbid illness on health-related quality of life. Qual Life Res 2008; 17(5): 71524.

191.Fleming CA, Christiansen D, Nunes D, Heeren T, Thornton D, Robert Horsburgh Jr C, Koziel MJ, Graham C, Craven DE. Health-related quality of life of patients with HIV disease: impact of hepatitis C coinfection. Clin Infect Dis 2004; 38(4): 572-8.

192. Tabrizian S, Mittermeier O. HIV and Psychiatric Disorders. En: Hoffman C, Rockstroh JK, Kamps BS. HIV Medicine 2007. 15 ed. Paris, Calgari, Wuppertal: Flying Publisher; 2007. p. 66575. 
193.Parsons TD, Braaten AJ, Hall CD, Robertson KR. Better quality of life with neuropsychological improvement on HAART. Health Qual Outcomes 2006; 4:11.

194. Osowiecki DM, Cohen RA, Morrow KM, Paul RH, Carpenter CCJ, Flanigan T, Boland RJ. Neurocognitive and psychological contributions to quality of life in HIV-1-infected women. AIDS 2000; 14: 1327-32.

195. Cielsa JA, Roberts JE. Meta-analysis of the relationship between HIV infection and risk for depressive disorders. Am J Psychiatry 2001; 158(5): 725-30.

196. Knox SA, King MT. Validation and calibration of the SF-36 health transition question against an external criterion of clinical change in health status. Qual Life Res 2009; 18(5): 637-45.

197. Trépanier LL, Rourke SB, Bayouri AM, Halman MH, Krzyzanowski S, Power C. The impact of neuropsychological impairment and depression on health-related quality of life in HIV-infection. J Clin Exp Neuropsychol 2005; 27: 1-15.

198. Knobel H. Calidad de vida, satisfacción, adherencia y efectividad del tratamiento antiretroviral. Enf Infecc Microbiol Clin 2005; 23(10): 579-80.

199. Jelsma J, Maclean E, Hughes J, Tinise X, Darder M. An investigation into the Health-related quality of life of individuals living with HIV who are receiving HAART. AIDS Care 2005; 17(5): $579-88$.

200. Ruiz Pérez I, Labry Lima AO, López Ruz MA, del Arco Jiménez A, Rodríguez Baño J, Causse Prados M, Pasquau Liaño J, Martín Rico P, Prada Pardal JL, de la Torre Lima J, López Gómez M, Marcos M, Muñoz N, Morales D, Muñoz I. Estado clínico, adherencia al TARGA y calidad de vida en pacientes con infección por el VIH tratados con antiretrovirales. Enferm Infecc Microbiol Clin 2005; 23(10): 581-5.

201.Fumaz CR, Tuldrá A, Ferrer MJ, Paredes R, Bonjoch A, Jou T, Negredo E, Romeu J, Sirera G, Tural C, Clotet B. Quality of life, emotional status and adherence of HIV-1-infected patients treated with Efavirenz versus protease inhibitor-containing regimens. J Acquir Immune Defic Syndr 2002; 29(3): 244-53.

202. Bing EG, Hays RD, Jacobson LP, Chen B, Gange SJ, Kass NI, Chmiel JS, Zucconi SL. Healthrelated quality of life among people with HIV disease: results from the Multicenter AIDS Cohort Study. Qual Life Res 2000; 9: 55-63.

203. Chandra PS, Gandhi C, Satishchandra P, Kamat A, Desai A, Ravi V, Ownby RL, Subbakrishna DK, Kumar M. Quality of life in HIV subtype C infection among asymptomatic subjects and its association with CD4 counts and viral loads - a study from South India. Qual Life Res 2006; 15: 1597-605.

204. Weinfurt KP, Willke RJ, Glick HA, Freimuth WW, Schulman KA. Relationship between CD4 count, viral burden and quality of life over time in HIV-1 infected patients. Med Care 2000; 38(4): 404-10.

205.Cederfjäll CG, Langius-Eklöf A, Lidman K, Wredling R. A longitudinal study on health related quality of life in patients with HIV infection. Qual Life Res 2001; 10(3): 269. 


\section{ANEXO 1}

\section{OPERACIONALIZACIÓN DE LAS VARIABLES ESTUDIADAS}




\section{ANEXO 1 \\ OPERACIONALIZACIÓN DE LAS VARIABLES ESTUDIADAS}

\section{Variable en estudio para el primer objetivo general}

La variable en estudio para el primer objetivo general el es la calidad de vida relacionada con la salud. Se la define como la valoración subjetiva que hacen las personas de su propia sensación de confort o bienestar en relación con su estado de salud; la medida en que son capaces de mantener una función física, emocional e intelectual razonable y el grado en que pueden participar en actividades que consideren importantes en el contexto de su familia, lugar de trabajo y en la comunidad. Tiene como instrumento el Cuestionario de Salud SF-36. ${ }^{92}$

\section{Variables en estudio para el segundo objetivo general}

Las variables estudiadas para el segundo objetivo general son variables sociológicas, clínicas e inmunológicas.

Se define como variables sociológicas a la caracterización social y epidemiológica de la población estudiada, siendo su indicador la presencia o ausencia de dichas características. Las variables clínicas son los eventos clínicos que pueden presentarse en los pacientes con infección por VIH/SIDA; las variables clínicas comprenden la presencia de adicciones, tratamiento antiretroviral de gran actividad. Son indicadores las pruebas de laboratorio específicas y el examen clínico de los pacientes. ${ }^{93}$

Las variables inmunológicas se definen como los eventos inmunológicos y virológicos que pueden presentarse en los pacientes con infección por VIH/SIDA; comprenden el recuento en sangre periférica de linfocitos $\mathrm{T} C \mathrm{CD} 4+$ y la carga viral plasmática o número de copias de RNAVIH/mL. Los indicadores de estas variables se basan en la medición por citometría de flujo y métodos cuantitativos de diagnóstico molecular. ${ }^{94}$

\section{Variables en estudio para los objetivos específicos}

Las variables estudiadas para los objetivos específicos son: 
- Perfil socioepidemiológico: se define como la caracterización social y epidemiológica de la población estudiada, siendo su indicador la presencia o ausencia de las características socio-epidemiológicas estudiadas. El perfil socioepidemiológico comprende:

- La edad, que son los años de vida que posee la persona, midiéndose en número de años.

- El género, que se establece como la condición biológica de varón o mujer; los indicadores para esta variable son masculino o femenino.

- El nivel de instrucción, se refiere a los niveles de enseñanza en que se estructura el sistema educativo formal; la estructura del Sistema Educativo Nacional comprende cuatro niveles: la Educación Inicial, la Educación Primaria, la Educación Secundaria y la Educación Superior (que comprende las Universidades e Institutos Universitarios y los Institutos de Educación Superior, nacionales o provinciales, de gestión estatal o privada). Se denomina analfabeta a la persona que no lee ni escribe. El nivel de instrucción realizado por la persona se clasifica en: analfabeta, educación primaria incompleta, primaria completa, secundaria incompleta, secundaria completa, terciaria incompleta, terciaria completa, universitaria incompleta y universitaria completa. ${ }^{95}$

- Empleo: es la realización de un trabajo bajo una relación contractual entre la persona que realiza las funciones y tareas del puesto y la empresa que contrata a dicha persona. Se toma como indicador la "Tasa de empleo", calculada como porcentaje entre la población ocupada y la población total. Los «ocupados plenos» son aquellos que trabajan 35 horas o más y no buscan otra actividad. ${ }^{96}$

- Los planes sociales están destinados a familias sin ingresos en situación de pobreza y desempleo con hijos menores de 18 años y para personas mayores de 70 años sin cobertura provisional y perteneciente a hogares pobres, orientados a la cobertura de necesidades básicas, vinculación al mundo del trabajo y la producción y desarrollo local; consisten en ayuda económica directa, con contraprestación de obras de infraestructura social y económica, como la pavimentación de calles, reparación de escuelas o la limpieza de la vía pública. El indicador es el registro de tenencia de plan social. ${ }^{97}$

- La Obra Social es una entidad, mediante las cuales los trabajadores en relación de dependencia, trabajadores autónomos, los jubilados, pensionados y los beneficiarios de pensiones no contributivas, así como sus respectivos grupos familiares, reciben prestaciones médico-asistenciales y otras de carácter social. El indicador es el registro de tenencia de obra social. ${ }^{98}$ 
- Los años de diagnóstico se refiere a los años transcurridos desde la realización del diagnóstico de la infección por VIH hasta el momento actual; se indican en número de años.

- Las vías de transmisión de la infección por VIH es el modo en que se transmite la infección por el VIH desde la fuente de infección a la persona susceptible.

Se denomina vía de transmisión sexual al contagio de la infección por contacto sexual a través del semen, secreciones vaginales o sangre de un individuo infectado, con la mucosa de los orificios naturales del huésped; es heterosexual cuando se transmite por relaciones sexuales con personas del sexo opuesto, homosexual cuando se transmite por relaciones sexuales con personas del mismo sexo y bisexual cuando se transmite por relaciones sexuales con ambos sexos.

La vía de transmisión por drogadicción intravenosa es la adquisición de la infección por VIH mediante el uso de drogas de inyección intravenosa, lo que genera la contaminación sangre-sangre, principalmente por el uso de jeringas con sangre contaminada entre drogadictos endovenosos.

La vía de transmisión por drogadicción por otras vías comprende principalmente la aspiración e inhalación de sustancias y la ingestión de drogas. El indicador de esta variable se realiza mediante el registro de la vía de transmisión de la infección: sexual (heterosexual, homosexual o bisexual), por drogadicción intravenosa o por otras vías o por combinaciones de éstas. ${ }^{99}$

- Causas del diagnóstico de la infección por VIH: comprenden la presentación de enfermedad marcadora de SIDA, diagnóstico de infección por VIH en la pareja sexual, embarazo, conductas de riesgo en el paciente, diagnóstico de infección por VIH en el hijo, donación de sangre y conductas de riesgo en la pareja sexual del paciente.

La presentación de enfermedad marcadora de SIDA es la ocurrencia de infecciones oportunistas mayores; corresponde a la categoría C del CDC. Se utiliza como indicador el registro de enfermedad marcadora de SIDA. ${ }^{94,100}$

El diagnóstico de la infección por VIH en la pareja sexual se refiere a la pareja sexual del paciente infectada con el VIH, cuyo diagnóstico permitió el diagnóstico de la infección en el paciente; se realiza el registro de pareja VIH positiva. 
El embarazo constituye una causa de diagnóstico de la infección por $\mathrm{VIH}$, en el marco de la obligatoriedad del ofrecimiento del test diagnóstico del virus VIH a toda mujer embarazada, según lo establece la Ley $\mathrm{N}^{\mathrm{o}} 25.543$, promulgada de hecho el 7 de enero de 2002, con el objetivo de prevenir la transmisión perinatal del VIH al hijo. Se realiza el registro de embarazo. ${ }^{94}$

Las conductas de riesgo en el paciente y las conductas de riesgo en la pareja se refieren al diagnóstico de la infección debido a la detección de conductas de riesgo para la adquisición de la infección por VIH en el paciente y en su pareja sexual; éstas son: múltiples parejas sexuales, contacto sexual con alguna persona con serología positiva para el VIH o un contacto sexual sin preservativo con una persona cuya serología es desconocida, víctima de abuso sexual, consumo de drogas por vía intravenosa y/o exposición ocupacional al VIH. Se toman como indicadores el registro de conductas de riesgo en el paciente y de conductas de riesgo en la pareja sexual del paciente. ${ }^{94}$

El diagnóstico de infección por VIH en el hijo es el hijo infectado con el VIH, cuyo diagnóstico permitió hacer el diagnóstico de la infección en la madre, padre, hermanos y otros integrantes del núcleo familiar. Se registra al hijo VIH positivo como causa de diagnóstico de la infección por VIH en el paciente.

El diagnóstico de la infección por VIH mediante la donación de sangre, se hace mediante la realización de pruebas serológicas de tamizaje en la persona que realiza la donación de sangre, tomando como indicador el registro de donación de sangre. ${ }^{94}$

- Pareja actual se define como la pareja sexual actual del paciente, siendo su indicador la presencia o ausencia de pareja actual. La variable pareja con infección por VIH/SIDA es la pareja sexual actual del paciente con confirmación diagnóstica de infección por VIH/SIDA. Se toma como indicador la presencia, ausencia o desconocimiento de la infección por VIH/SIDA en la pareja actual del paciente.

- Conducta de riesgo en la pareja del paciente relacionada con la transmisión del VIH, se refiere a la presencia de conductas o factores de riesgo en la pareja sexual del paciente relacionados con el contagio de la infección por VIH: promiscuidad sexual, drogadicción intravenosa y/o por otras vías, etilismo, varias conductas asociadas o ninguna de ellas.

Se define promiscuidad como la tenencia de múltiples parejas sexuales.

Drogadicto intravenoso es la persona que utiliza drogas de inyección intravenosa, lo que genera la contaminación sangre-sangre, principalmente por el uso de jeringas con 
sangre contaminada entre drogadictos endovenosos. La drogadicción por otras vías comprende principalmente la aspiración e inhalación de sustancias y la ingestión de drogas.

El etilismo es el estado de dependencia psicopatológica y física hacia el etanol que produce un cambio en el comportamiento del individuo, manifestado por el consumo progresivo e incontrolado de bebidas alcohólicas, de manera no aprobada por su entorno inmediato que produce enfermedad física y psíquica.

Varias conductas asociadas: presencia de uno o más conductas o factores de riesgo en la pareja sexual del paciente. Se toma como indicador el registro de condiciones de riesgo en la pareja sexual del paciente: promiscuidad, drogadicción intravenosa, drogadicción por otras vías, etilismo, varias conductas asociadas o ausencia de condiciones de riesgo. ${ }^{94,101}$

- Adicciones: Se llama adicción al estado de dependencia física y psíquica, causado por la utilización, en un organismo vivo, de una sustancia o fármaco. Son indicadores el registro de la presencia o ausencia de adicción, número de adicciones (1 adicción, 2 o más adicciones) y el tipo de adicción: etilismo o alcoholismo, tabaquismo, drogas (a drogas intravenosas o no intravenosas). ${ }^{102}$

- Adicción a drogas es el estado de intoxicación periódica o crónica producido por el consumo repetido de una droga natural o sintética, caracterizado por modificaciones del comportamiento y por otras reacciones que comprenden siempre un impulso irreprimible por tomar el fármaco en forma reiterada con el fin de experimentar sus efectos psíquicos y físicos y evitar el malestar producido por la privación. Puede presentarse una o más adicciones. El indicador es el registro de la adicción a drogas intravenosas y/o no intravenosas. La adicción se puede valorar mediante el "Índice de severidad de la adicción" que es un instrumento semiestructurado que valora al paciente en 7 dominios: estado médico general, situación laboral y financiera, consumo de alcohol, consumo de drogas, problemas legales, familia y relaciones sociales y estado psicológico. La puntuación va de 0 (ausencia del problema) a 9 (problema extremo). También se debe establecer el tipo de adicción (a drogas intravenosas o no intravenosas) y el número (1 adicción, 2 o más adicciones). ${ }^{102,103}$

- Adicción al alcohol (alcoholismo o etilismo): es un estado de dependencia psicopatológica y física hacia el etanol que produce un cambio en el comportamiento del 
individuo, manifestado por el consumo progresivo e incontrolado de bebidas alcohólicas, de manera no aprobada por su entorno inmediato que produce enfermedad física y psíquica. Se considera a un individuo alcohólico cuando consume $80 \mathrm{~g} /$ día de alcohol (en los hombres) y $40 \mathrm{~g} /$ día (en las mujeres). ${ }^{101,104,105}$

- Tabaquismo. Es una enfermedad crónica sistémica perteneciente al grupo de las adicciones que consiste en la adicción al tabaco provocada principalmente por uno de sus componentes activos, la nicotina. Se toma como indicador la cantidad de tabaco consumido, que es igual al número de cigarrillos consumidos por día y el tiempo. ${ }^{106,107}$

- Comorbilidades. Se llama comorbilidad a la coexistencia en el mismo individuo de una o más enfermedades entre sujetos con una enfermedad índice. Son indicadores: presencia o ausencia de comorbilidad, número de comorbilidades (1 comorbilidad, 2 o más comorbilidades) y el tipo de comorbilidad (hepatopatía alcohólica, hepatitis $\mathrm{C}$, hepatitis $\mathrm{B}$, hepatitis $\mathrm{B}+\mathrm{C}$, trastorno mixto ansioso-depresivo, infecciones de transmisión sexual: sífilis, gonorrea, enfermedad pélvica inflamatoria y herpes genital, desnutrición grave, hipertensión arterial / enfermedad cardiovascular, diabetes, cáncer y lipodistrofia).

La comorbilidad se puede medir por la suma del número de enfermedades presentes en el individuo, por medio de escalas de comorbilidad que combinan el número y gravedad de las enfermedades presentes, como el "Índice de comorbilidad de Charlson". 108

- Hepatopatopatía alcohólica. Enfermedad hepática producida por el consumo excesivo de alcohol; no se trata de un único cuadro clínico, sino que pueden presentarse varias modalidades dependiendo de la cantidad de alcohol consumida, el tiempo durante el que se consuma y la susceptibilidad individual.

Hay tres grandes cuadros de enfermedad hepática producida por alcohol que, de menor a mayor gravedad son: la esteatosis hepática alcohólica, la hepatitis alcohólica y la cirrosis etílica; en muchos pacientes aparecen las tres de manera consecutiva a lo largo de los años. La presencia de hepatopatía alcohólica se establece cuando el consumo es superior a 80 gramos de alcohol al día en los varones y a 50 gramos en las mujeres, durante al menos 5 años. El diagnóstico se realiza basándose en la historia de consumo de alcohol, la exploración física, análisis de la función hepática, ecografía abdominal y, en muchos casos, es necesaria la realización de una biopsia hepática para obtener el diagnóstico definitivo. ${ }^{109}$ 
- Hepatitis $C$, hepatitis $B$, hepatitis $C+B$. La hepatitis $C$ es una infección sistémica que afecta en forma primordial al hígado, de curso agudo o crónico, de transmisión primordialmente parenteral y en menor grado sexual y transplacentaria, debida al virus de la hepatitis $\mathrm{C}(\mathrm{HCV})$. La hepatitis B es la lesión necroinflamatoria del hígado causada por el virus de la hepatitis B (HBV), de curso agudo o crónico, de transmisión principalmente sexual, parenteral y perinatal. La hepatitis $\mathrm{C}+\mathrm{B}$ es la coinfección hepática con los virus de la hepatitis B y C.

Son indicadores la determinación de anticuerpos séricos Ig M e Ig G anti HCV, y la determinación del genoma del HCV en plasma mediante la reacción en cadena de la polimerasa (PCR). La hepatitis B: se determina con la detección sérica de los marcadores anti $\mathrm{HBc}$, anti $\mathrm{HBe}$, anti $\mathrm{HBs}, \mathrm{Hbs} \mathrm{Ag}, \mathrm{HBe} \mathrm{Ag}$ y del genoma viral en plasma mediante PCR. Para realizar el diagnóstico de hepatitis B y C debe realizarse la determinación sérica de ambos marcadores para HCV y HBV y eventualmente la detección del genoma viral por PCR. ${ }^{110}$

- Infecciones de transmisión sexual: sifilis, gonorrea, enfermedad pélvica inflamatoria, herpes genital. Las ITS constituyen un grupo heterogéneo de patologías transmisibles cuyo único elemento en común es el compartir la vía sexual como mecanismo de transmisión. Las manifestaciones clínicas comprometen, en la mayoría de los casos, el área genital y las mucosas pero en muchos casos tienen manifestaciones sistémicas; las ITS halladas en nuestra población fueron: sífilis, gonorrea, enfermedad pélvica inflamatoria (EPI) y herpes genital.

La sífilis es una infección de curso crónico y afección multisistémica, causada por Treponema pallidum.

La gonorrea es la infección producida por Neisseria gonorrhoeae, transmitida casi exclusivamente por contacto sexual o en el período perinatal, que afecta las mucosas del tracto genitourinario inferior y con menor frecuencia las del recto, orofaringe y conjuntivas causando uretritis o cerviscitis mucopurulenta, rectitis, faringitis $\mathrm{o}$ conjuntivitis. Constituye una de las principales causas de EPI por infección genital ascendente.

La EPI se define como un síndrome clínico no relacionado con el embarazo ni cirugías, que se presenta por la infección ascendente de gérmenes cervicales produciendo 
uno o más de los siguientes trastornos inflamatorios: endometritis, salpingitis, peritonitis pelviana o absceso tubo ovárico.

El herpes genital es la infección causada por el virus Herpes simple 1 y 2, que produce vesículas, pústulas y úlceras dolorosas a nivel de la piel y mucosa oral, genital, rectal y perirectal.

Los indicadores son: el diagnóstico clínico de ITS mediante el examen físico, la solicitud de serología para sífilis (VDRL, FTA-ABS / Microhemaglutinación) y microscopía de campo oscuro, examen en fresco y cultivo microbiológico del flujo vaginal, exudado endocervical y uretral, prueba de ELISA o inmunofluorescencia directa en secreción endocervical para Chlamydia y Herpes simple tipo 1 y 2, examen ginecológico con colposcopía y tinción de Papanicolau. ${ }^{111}$

- Trastorno mixto ansioso-depresivo. La "Clasificación Estadística Internacional de Enfermedades y otros Problemas de Salud de la OMS" (CIE-10) introdujo el concepto de trastorno mixto de ansiedad y depresión (F41.2) para definir una categoría clínica en la que los pacientes presentan síntomas ansiosos y depresivos en número y/o intensidad limitados. El síndrome es definido como una mezcla de síntomas ansiosos y depresivos de similar importancia, asociados con algunos síntomas autonómicos, como temblor, palpitaciones y molestias gástricas. El indicador se basa en la detección de la presencia de ambos síntomas ansiosos y depresivos en número y/o intensidad limitados, es decir, no suficientemente intensos para poder cumplir con los criterios diagnósticos del trastorno depresivo o del trastorno de ansiedad, asociados con algunos síntomas autonómicos, como temblor, palpitaciones y molestias gástricas. ${ }^{112}$

- Desnutrición grave. Es el estado generado por un inadecuado aporte de calorías y nutrientes escenciales necesarios para el mantenimiento de la salud, cuya causa puede ser una enfermedad o una combinación de varias, incluyendo también aspectos sociales, económicos, psicológicos, culturales, religiosos e incluso políticos. Para determinar la presencia de desnutrición grave se deben realizar determinaciones antropométricas, como la determinación del peso, la talla, el coeficiente peso/talla (en el desnutrido grave es $<80$ $\%$ del estándar), la circunferencia en la mitad del brazo (en el desnutrido grave es $<15$ $\mathrm{cm})$, la medición del pliegue cutáneo del tríceps mediante la medición de la grasa corporal ( $<$ de $8 \mathrm{~mm}$ en el hombre y $<10 \mathrm{~mm}$ en las mujeres con desnutrición) y aspecto de clara inanición. Además se deben realizar exámenes complementarios y pruebas de laboratorio para realizar el diagnóstico de la etiología de la desnutrición y para evaluar la 
funcionalidad hepática, renal, el medio interno, la presencia de anemia, el estado de las proteínas corporales y la función inmunitaria. ${ }^{113}$

- Enfermedad cardiovascular / hipertensión arterial. Se define a la hipertensión arterial como la persistencia de una presión sanguínea superior a $140 \mathrm{~mm}$ de $\mathrm{Hg}$ para la presión sistólica y $90 \mathrm{~mm}$ de $\mathrm{Hg}$ para la presión diastólica, para la población general mayor de 18 años, no variando los criterios con la edad. La hipertensión arterial reconoce múltiples causas y es el factor de riesgo aislado que más predispone a la enfermedad cardiovascular, entendiéndose por ésta al extenso conjunto de patologías que afectan globalmente al corazón y a los vasos sanguíneos.

La enfermedad cardiovascular comprende: la cardiopatía coronaria, las enfermedades cerebrovasculares, las arteriopatías periféricas, la cardiopatía reumática, las cardiopatías congénitas y las trombosis venosas profundas y embolias pulmonares.

La hipertensión arterial se establece con los valores obtenidos de la toma de la tensión arterial, durante tres visitas (excluida la primera), realizando tres mediciones en cada oportunidad, tomando el valor promedio de las mediciones como la presión arterial de cada consulta. El diagnóstico se realiza con los datos de presión arterial obtenidos en posición de sentado; la medición debe hacerse luego de un reposo de 5 minutos, por triplicado y con el brazo apoyado y a la altura del corazón. Para el diagnóstico de enfermedad cardiovascular debe realizarse la anamnesis, el examen físico y solicitarse exámenes complementarios de diagnóstico. ${ }^{114}$

- Diabetes. La diabetes es una enfermedad caracterizada por una insuficiencia absoluta o relativa de la secreción de insulina y por una insensibilidad o resistencia de los tejidos al efecto metabólico de la insulina, que trae como consecuencia inevitable la hiperglucemia. En las fases finales de la enfermedad puede producirse una afectación multisistémica: microangiopatía, macroangiopatía, neuropatía, atrofia muscular y disminución de la resistencia a las infecciones. Se establece el diagnóstico con la presencia de hiperglucemia basal con valores de glucosa sérica $>110 \mathrm{mg} / \mathrm{dL}$ o $6,1 \mathrm{mmol} / \mathrm{L}$, obtenida de una muestra extraída del paciente en las primeras horas de la mañana, con un mínimo de 8 horas de ayuno previo. ${ }^{115}$

- Cáncer. El cáncer es un crecimiento tisular producido por la proliferación continua de células anormales con capacidad de invasión y destrucción de otros tejidos, que puede originarse a partir de cualquier tipo de célula en cualquier tejido corporal; no es 
una enfermedad única sino un conjunto de enfermedades que se clasifican en función del tejido y célula de origen.

Los indicadores son múltiples y varían según la patología neoplásica y su localización; además de la anamnesis y el examen físico se solicitan métodos de diagnóstico como la citología cervical o Papanicolau, la determinación de células malignas en sangre, orina y líquido cefalorraquídeo (LCR) la determinación de marcadores tumorales en sangre, la endoscopía, broncoscopía, la gammagrafía, ecografía, mamografía, radiografía, arteriografía, tomografía, resonancia magnética. ${ }^{116}$

- Lipodistrofia. Es el cambio en la distribución de la grasa corporal o anormalidades en el metabolismo de los lípidos que derivan en hiperlipidemia en los pacientes infectados con VIH, relacionada con la administración de fármacos inhibidores nucleósidos de la transcriptasa reversa (INTR); los pacientes con lipodistrofia pueden experimentar tanto un aumento de la adiposidad localizada (lipohipertrofia) como la pérdida anormal de grasa (lipoatrofia).

La lipodistrofia se cuantifica con la absorciometría de rayos $\mathrm{X}$ de energía dual (DEXA), la cual puede determinar con exactitud la grasa corporal total y regional y el tejido magro; también puede utilizarse la tomografía para medir la grasa visceral. ${ }^{117-119}$

- Número de LT CD4+ y carga viral plasmática. El número de LT CD4+ se refiere al recuento de LT CD4 $/ \mathrm{mm}^{3}$ de sangre periférica; dicho valor se divide en categorías, siendo el recuento menor de $200 / \mathrm{mm}^{3}$ lo que establece la inmunodepresión severa.

La carga viral plasmática es el número de copias de RNAVIH/mL; es indetectable cuando su valor se encuentra por debajo de las 50 copias $/ \mathrm{mL}$ y detectable cuando se halla por encima de ese valor. Las personas con más de 100.000 copias $/ \mathrm{mL}$ requieren inicio de TARGA.

La medición del número de LT CD4+ se realiza por citometría de flujo y los valores obtenidos (agrupados en $<200$, de 201 a 350 y $>351$ LT CD4/mm ${ }^{3}$ ) permiten categorizar la inmunodeficiencia del paciente.

La cuantificación de la carga viral plasmática por DNA ramificado (b-DNA) y categorización de los valores obtenidos en indetectables $(<50$ copias $/ \mathrm{mL})$ y detectables ( $>50$ copias $/ \mathrm{mL}$ ) permiten clasificar estos últimos en $<50.000,50.001$ a 100.000 y $>100.001$ copias/mL. ${ }^{94}$ 
- Presencia de enfermedad marcadora de SIDA: neumonía por Pneumocystis jiroveci, toxoplasmosis del sistema nervioso central, criptosporidiosis, candidiasis esofágica, criptococosis meníngea, histoplasmosis, tuberculosis pulmonar y extrapulmonar, infección por virus Herpes simple, sarcoma de Kaposi, encefalopatía por VIH/demencia, síndrome de adelgazamiento por VIH (wasting), carcinoma cervical invasivo. Enfermedad marcadora de SIDA es la presencia de un evento definitorio de SIDA en la población adulta. Estos eventos hallados en nuestra población de pacientes fueron,

- Neumonía por Pneumocystis jiroveci, que se define como la disnea de esfuerzo o tos no productiva de reciente comienzo, taquipnea y fiebre, radiografía de tórax con infiltrados difusos intersticiales bilaterales y ausencia de neumonía bacteriana. Indicador: citología o inmunofluorescencia indirecta en muestra de esputo o lavado bronquioalveolar.

- Toxoplasmosis del sistema nervioso central, que consiste en el inicio reciente de alteraciones focales neurológicas o reducción en el nivel de conciencia y respuesta dentro de los 10 días al tratamiento específico. Indicadores: Detección de anticuerpos séricos positivos para toxoplasmosis y lesiones de masa intracraneales únicas o múltiples en la tomografía axial computada (TAC) o resonancia magnética nuclear de encéfalo (RMN).

- Criptosporidiosis es la diarrea con más de un mes de evolución causada por especies de Cryptosporidium. Indicador: Identificación de ooquistes en las heces mediante tinción de Kinyoun o inmunofluorescencia directa.

- Candidiosis esofágica es definida como el inicio reciente de dolor retroesternal o dificultad para tragar en presencia de candidiosis oral. Indicador: endoscopía y estudio macroscópico de lesiones y/o estudio histológico/microbiológico.

- Criptococosis meníngea es la presentación de meningitis subaguda, cefalea progresiva severa, meningismo, confusión y cambios en la conducta. Indicador: aislamiento de Cryptococcus neoformans de un sitio extrapulmonar/LCR o antígeno positivo en LCR/sangre.

- Histoplasmosis es una micosis profunda granulomatosa de infección exógena causada por Histoplasma capsulatum, con tendencia a la diseminación en el huésped inmunocomprometido. Indicador: estudio histopatológico. Detección de antígenos o cultivos de materiales clínicos o sangre.

- La tuberculosis pulmonar se define como la presencia de los siguientes signos y síntomas crónicos que duran más de dos semanas: tos, hemoptisis, disnea, dolor torácico, pérdida 
de peso, fiebre, sudoración nocturna más una baciloscopía en esputo positiva o una baciloscopía en esputo negativa con radiografía de tórax compatible. Indicador: aislamiento de Mycobacterium tuberculosis en cultivo de esputo o histología de biopsia pulmonar sumado a síntomas compatibles.

- La tuberculosis extrapulmonar se define como una enfermedad sistémica (presencia de fiebre, sudores nocturnos, debilidad y pérdida de peso) de localización en diferentes sitios: pleural, pericárdica, peritoneo, meníngea, ganglionar, ósea. Indicador: aislamiento de Mycobacterium tuberculosis en cultivo o histología compatible del sitio apropiado o evidencia radiológica de tuberculosis miliar en la radiografía de tórax.

- Infección por el virus Herpes simple (HSV) consiste en ulceraciones dolorosas y progresivas anogenitales u orolabiales causadas por HSV, recurrentes por más de un mes. Indicador: cultivo positivo o reacción en cadena de la polimerasa (PCR) DNA positiva para HSV o citología/histología compatible.

- Sarcoma de Kaposi es la aparición típica en piel u orofaringe de parches inicialmente planos color rojizo que evolucionan a placas violáceas o nódulos. Indicador: examen histológico de las lesiones.

- Encefalopatía por VIH/demencia consiste en hallazgos clínicos de disfunción cognitiva y/o motora que interfiere con actividades de la vida diaria progresivas a lo largo de semanas o meses en ausencia de una enfermedad concurrente o condición fuera de la infección por VIH. Indicador: diagnóstico de exclusión y neuroimágenes (TAC o RMN).

- El síndrome de adelgazamiento por VIH (wasting) es definida como la pérdida involuntaria e inexplicada de peso mayor al $10 \%$ de lo habitual, con índice de masa corporal menor a 18,5 y diarrea crónica inexplicada o reporte de fiebre o sudoración nocturna prolongada. Indicador: diagnóstico de exclusión.

- Carcinoma cervical invasivo es la enfermedad neoplásica del cuello uterino, asociada a la infección por virus del papiloma humano (HPV). Indicador: examen histológico o citológico. $^{94}$

- Hospitalización. Es el ingreso de una persona enferma al hospital, por algún evento relacionado con la infección por VIH/SIDA, para que permanezca allí durante su tratamiento y reciba la asistencia necesaria. Indicador: registro en la historia clínica. En la base de datos se registra si el paciente tuvo o no hospitalización en algún momento de su enfermedad. ${ }^{120}$ 
- Tratamiento antiretroviral de gran actividad (TARGA). Es el uso combinado de drogas que se administran a un individuo con el objetivo de lograr la máxima supresión de la replicación viral y mantener este nivel de supresión por el mayor período de tiempo posible. Indicador: se registra si el paciente inició o aún no inició el TARGA y el período de tiempo desde que comenzó (número de años).

El grupo de drogas utilizadas fueron los inhibidores nucleósidos de la transcriptasa reversa (INTR): zidovudina, didanosina, zalcitabina, lamivudina, stavudina, abacavir y tenofovir; inhibidores no nucleósidos de la transcriptasa reversa (INNTR): nevirapina y efavirenz; inhibidores de la proteasa (IP): indinavir, nelfinavir, ritonavir, lopinavir/ritonavir, atazanavir y fosamprenavir.

Las diferentes combinaciones de drogas administradas a los pacientes fueron la asociación entre 2 INNTR + 1 INNTR, 3 INTR, 2 INTR + 1 IP, 2 INTR + 2 IP. 
ANEXO 2

CUESTIONARIO DE SALUD SF-36

VERSIÓN ESPAÑOLA 1.4 (junio de 1999) 


\section{CUESTIONARIO DE SALUD SF-36}

VERSIÓN ESPAÑOLA 1.4 (junio de 1999)

\section{INSTRUCCIONES:}

Las preguntas que siguen se refieren a lo que usted piensa sobre su salud. Sus respuestas permitirán saber cómo se encuentra usted y hasta qué punto es capaz de hacer sus actividades habituales

Conteste cada pregunta tal como se indica. Si no está seguro/a de cómo responder a una pregunta, por favor conteste lo que le parezca más cierto.

\section{Copyright $\odot 1995$ Medical Outcomes Trust}

All rights reserved.

(Versión 1.4, Junio 1.999)

Correspondencia:

Dr. Jordi Alonso

Unidad de Investigación en Servicios Sanitarios I.M.I.M.

Doctor Aiguader, 80

E- 08003 Barcelona, España

Tel. + 3432211009

ax. +3432213237

E-mail: pbarbas@imim.es 


\section{MARQUE UNA SOLA RESPUESTA}

1. En general, usted diría que su salud es:

$1 \square$ Excelente

$2 \square$ Muy buena

$3 \square$ Buena

$4 \square$ Regular

$5 \square$ Mala

2. ¿Cómo diría que es su salud actual, comparada con la de hace un año?

$1 \square$ Mucho mejor ahora que hace un año

$2 \square$ Algo mejor ahora que hace un año

$3 \square$ Más o menos igual que hace un año

$4 \square$ Algo peor ahora que hace un año

$5 \square$ Mucho peor ahora que hace un año

LAS SIGUIENTES PREGUNTAS SE REFIEREN A ACTIVIDADES O COSAS QUE USTED PODRÍA HACER EN UN DÍA NORMAL.

3. Su salud actual, ¿le limita para hacer esfuerzos intensos, tales como correr, levantar objetos pesados, o participar en deportes agotadores?

$1 \square$ Sí, me limita mucho

$2 \square$ Sí, me limita un poco

$3 \square$ No, no me limita nada 
4. Su salud actual, ¿le limita para hacer esfuerzos moderados, como mover una mesa, pasar la aspiradora, jugar a los bolos o caminar más de una hora?

$1 \square$ si, me limita mucho

$2 \square$ Sí, me limita un poco

$3 \square$ No, no me limita nada

5. Su salud actual, ¿le limita para coger o llevar la bolsa de la compra?

$1 \square$ Sí, me limita mucho

$2 \square$ Sí, me limita un poco

$3 \square$ No, no me limita nada

6. Su salud actual, ¿le limita para subir varios pisos por la escalera?

$1 \square$ Si, me limita mucho

$2 \square$ Si, me limita un poco

$3 \square$ No, no me limita nada

7. Su salud actual, ¿le limita para subir un solo piso por la escalera?

$1 \square$ Sí, me limita mucho

$2 \square$ Sí, me limita un poco

$3 \square$ No, no me limita nada

8. Su salud actual, ¿le limita para agacharse $o$ arrodillarse?

$1 \square$ Sí, me limita mucho

$2 \square$ Sí, me limita un poco

$3 \square$ No, no me limita nada 
9. Su salud actual, ¿le limita para caminar un kilómetro o más?

$1 \square$ Si, me limita mucho

$2 \square$ Si, me limita un poco

$3 \square$ No, no me limita nada

10. Su salud actual, ¿le limita para caminar varias manzanas (varios centenares de metros)?

$1 \square$ Sí, me limita mucho

$2 \square$ Si, me limita un poco

$3 \square$ No, no me limita nada

11. Su salud actual, ¿le limita para caminar una sola manzana (unos 100 metros)?

$1 \square$ Si, me limita mucho

$2 \square$ Si, me limita un poco

$3 \square$ No, no me limita nada

12. Su salud actual, ¿le limita para bañarse o vestirse por sí mismo?

$1 \square$ Si, me limita mucho

$2 \square$ Si, me limita un poco

$3 \square$ No, no me limita nada 
13. Durante las 4 últimas semanas, ¿tuvo que reducir el tiempo dedicado al trabajo o a sus actividades cotidianas, a causa de su salud física?

$1 \square \mathrm{Si}$

$2 \square$ No

14. Durante las 4 últimas semanas, ¿hizo menos de lo que hubiera querido hacer, a causa de su salud física?
$1 \square$ Sí
$2 \square$ No

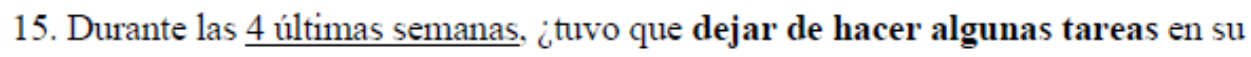
trabajo o en sus actividades cotidianas, a causa de su salud física?
$1 \square \mathrm{Si}$
$2 \square$ No

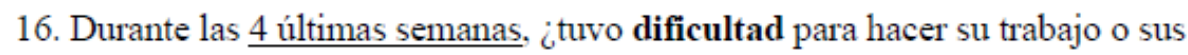
actividades cotidianas (por ejemplo, le costó más de lo normal), a causa de su salud fisica?
$1 \square$ Si
$2 \square$ No 
17. Durante las 4 últimas semanas, ¿tuvo que reducir el tiempo dedicado al trabajo o a sus actividades cotidianas, a causa de algún problema emocional (como estar triste, deprimido, o nervioso?
$1 \square \mathrm{Si}$
$2 \square$ No

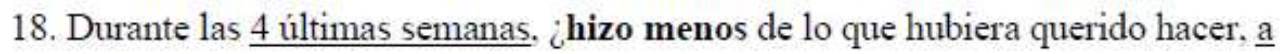
causa de algún problema emocional (como estar triste, deprimido, o nervioso)?

$1 \square$ Sí

$2 \square$ No

19. Durante las 4 últimas semanas, ¿no hizo su trabajo o sus actividades cotidianas tan cuidadosamente como de costumbre, a causa de algún problema emocional (como estar triste, deprimido, o nervioso)?

$1 \square \mathrm{Si}$

$2 \square$ No

20. Durante las 4 últimas semanas, ¿hasta qué punto su salud física o los problemas emocionales han dificultado sus actividades sociales habituales con la familia, los amigos, los vecinos u otras personas?

$1 \square$ Nada

$2 \square$ Un poco

$3 \square$ Regular

$4 \square$ Bastante

$5 \square$ Mucho 
21. ¿Tuvo dolor en alguna parte del cuerpo durante las 4 últimas semanas?

$1 \square$ No, ninguno

$2 \square$ Si, muy poco

$3 \square$ Sí, un poco

$4 \square$ Sí, moderado

$5 \square$ Si, mucho

$6 \square$ Si, muchísimo

22. Durante las $\underline{4}$ últimas semanas, ¿hasta qué punto el dolor le ha dificultado su trabajo habitual (incluido el trabajo fuera de casa y las tareas domésticas)?

$1 \square$ Nada

$2 \square$ Un poco

$3 \square$ Regular

$4 \square$ Bastante

$5 \square$ Mucho

LAS PREGUNTAS QUE SIGUEN SE REFIEREN A CÓMO SE HA SENTIDO Y CÓMO LE HAN IDO LAS COSAS DURANTE LAS 4 ÚLTIMAS SEMANAS. EN CADA PREGUNTA RESPONDA LO QUE SE PAREZCA MÁS A CÓMO SE HA SENTIDO USTED.

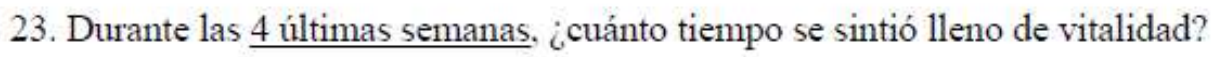

$1 \square$ Siempre

$2 \square$ Casi siempre

$3 \square$ Muchas veces

$4 \square$ Algunas veces

$5 \square$ Sólo alguna vez

$6 \square$ Nunca 


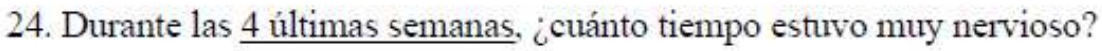

$1 \square$ Siempre

$2 \square$ Casi siempre

$3 \square$ Muchas veces

$4 \square$ Algunas veces

$5 \square$ Sólo alguna vez

$6 \square$ Nunca

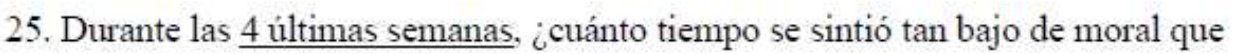
nada podía animarle?
$1 \square$ Siempre
$2 \square$ Casi siempre
$3 \square$ Muchas veces
$4 \square$ Algunas veces
$5 \square$ Sólo alguna vez
$6 \square$ Nunca

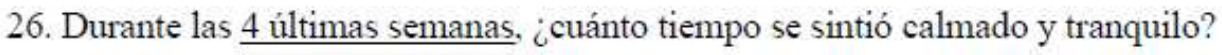

$1 \square$ Siempre

$2 \square$ Casi siempre

$3 \square$ Muchas veces

$4 \square$ Algunas veces

$5 \square$ Sólo alguna vez

$6 \square$ Nunca 
27. Durante las 4 últimas semanas, ¿cuánto tiempo tuvo mucha energía?
$1 \square$ Siempre
$2 \square$ Casi siempre
$3 \square$ Muchas veces
$4 \square$ Algunas veces
$5 \square$ Sólo alguna vez
$6 \square$ Nunca

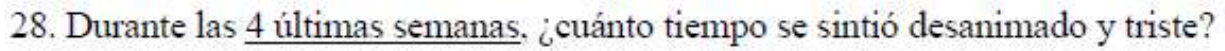
$1 \square$ Siempre
$2 \square$ Casi siempre
$3 \square$ Muchas veces
$4 \square$ Algunas veces
$5 \square$ Sólo alguna vez
$6 \square$ Nunca

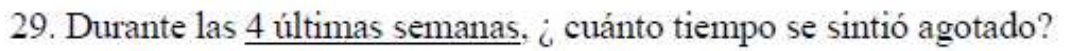
$1 \square$ Siempre
$2 \square$ Casi siempre
$3 \square$ Muchas veces
$4 \square$ Algunas veces
$5 \square$ Sólo alguna vez
$6 \square$ Nunca 


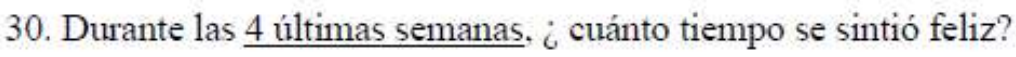

$1 \square$ Siempre

$2 \square$ Casi siempre

$3 \square$ Muchas veces

$4 \square$ Algunas veces

$5 \square$ Sólo alguna vez

$6 \square$ Nunca

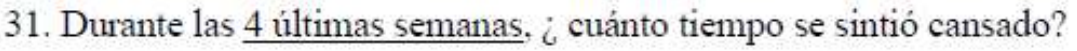

$1 \square$ Siempre

$2 \square$ Casi siempre

$3 \square$ Muchas veces

$4 \square$ Algunas veces

$5 \square$ Sólo alguna vez

$6 \square$ Nunca

32. Durante las 4 últimas semanas, ¿con qué frecuencia la salud física o los problemas emocionales le han dificultado sus actividades sociales (como visitar a los amigos o familiares)?

$1 \square$ Siempre

$2 \square$ Casi siempre

$3 \square$ Algunas veces

$4 \square$ Sólo alguna vez

$5 \square$ Nunca 
POR FAVOR, DIGA SI LE PARECE CIERTA O FALSA

CADA UNA DE LAS SIGUIENTES FRASES.

33. Creo que me pongo enfermo más fácilmente que otras personas.

$1 \square$ Totalmente cierta

$2 \square$ Bastante cierta

$3 \square$ No lo sé

$4 \square$ Bastante falsa

$5 \square$ Totalmente falsa

34. Estoy tan sano como cualquiera.

$1 \square$ Totalmente cierta

$2 \square$ Bastante cierta

$3 \square$ No lo sé

$4 \square$ Bastante falsa

$5 \square$ Totalmente falsa

35. Creo que mi salud va a empeorar.

$1 \square$ Totalmente cierta

$2 \square$ Bastante cierta

$3 \square$ No lo sé

$4 \square$ Bastante falsa

$5 \square$ Totalmente falsa

36. Mi salud es excelente.

$1 \square$ Totalmente cierta

$2 \square$ Bastante cierta

$3 \square$ No lo sé

$4 \square$ Bastante falsa

$5 \square$ Totalmente falsa 


\section{ANEXO 3}

\section{CUESTIONARIO DE SALUD SF-36 CON ADAPTACIÓN TRANSCULTURAL PARA LA POBLACIÓN DE PACIENTES DE FLORENCIO VARELA, BUENOS AIRES}




\section{INSTRUCCIONES:}

Las preguntas que siguen se refieren a lo que usted piensa sobre su salud. Sus respuestas permitirán saber cómo se encuentra usted y hasta qué punto es capaz de hacer sus actividades habituales.

Conteste cada pregunta tal como se indica. Si no está seguro/a de cómo responder a una pregunta, por favor conteste lo que le parezca más cierto. Muchas gracias por su colaboración.

\section{MARQUE UNA SOLA RESPUESTA}

1. En general usted diria que su salud es:

$\begin{array}{ll}1 & \text { Excelente } \\ 2 & \text { Muy buena } \\ 3 & \text { Buena } \\ 4 & \text { Regular } \\ 5 & \text { Mala }\end{array}$

2. ¿Cómo diría que es su salud actual, comparada con la de hace un año?

1 Mucho mejor ahora que hace un año

2 Algo mejor ahora que hace un año

3 Más o menos igual que hace un año

4 Algo peor ahora que hace un año

5 Mucho peor ahora que hace un año

Las siguientes preguntas se refieren a actividades o cosas que usted podría hacer en un día normal

3. Su salud actual, ¿le limita para hacer esfuerzos intensos, tales como correr, levantar objetos

pesados, o participar en deportes agotadores?

1 Si, me limita mucho

2 Si, me limita un poco

3 No, no me limita nada

4. Su salud actual, ¿le limita para hacer esfuerzos moderados, como mover una mesa, cavar un pozo, limpiar la casa, o caminar más de una hora?
1 Sí, me limita mucho
2 Si, me limita un poco
3 No, no me limita nada

5. Su salud actual, ¿le limita levantar o llevar las bolsas con las compras?

1 Si, me limita mucho

2 Si, me limita un poco

3 No, no me limita nada 
6. Su salud actual, ¿le limita subir varios pisos por la escalera?

1 Si, me limita mucho

2 Si, me limita un poco

3 No, no me limita nada

7. Su salud actual, ¿le limita para subir un solo piso por la escalera?

1 Si, me limita mucho

2 Si, me limita un poco

3 No, no me limita nada

8. Su salud actual, ¿le limita para agacharse o arrodillarse?

$\begin{array}{ll}1 & \text { Si, me limita mucho } \\ 2 & \text { Si, me limita un poco } \\ 3 & \text { No, no me limita nada }\end{array}$

9. Su salud actual, ¿le limita para caminar 10 cuadras o más?

1 Si, me limita mucho

2 Si, me limita un poco

3 No, no me limita nada

10. Su salud actual, ¿le limita para caminar varias cuadras (varios centenares de metros)?

1 Si, me limita mucho

2 Si, me limita un poco

3 No, no me limita nada

11. Su salud actual, ¿le limita para caminar una sola cuadra (unos 100 metros)?

1 Si, me limita mucho

2 Si, me limita un poco

3 No, no me limita nada

12. Su salud actual, ¿le limita para bañarse o vestirse por sí mismo?

1 Si, me limita mucho

2 Si, me limita un poco

3 No, no me limita nada

Las siguientes preguntas se refieren a problemas en su trabajo o en sus actividades diarias

13. Durante las 4 últimas semanas ¿tuvo que reducir el tiempo dedicado al trabajo o a sus actividades cotidianas, a causa de su salud fisica?

$1 \quad \mathrm{Si}$

2 No 
14. Durante las 4 últimas semanas ¿hizo menos de lo que hubiera querido hacer, a causa de su salud fisica?

$\begin{array}{ll}1 & \text { Si } \\ 2 & \text { No }\end{array}$

15. Durante las 4 últimas semanas ¿tuvo que dejar de hacer algunas tareas en su trabajo o en sus actividades diarias, a causa de su salud fisica?

1 Si

2 No

16. Durante las 4 últimas semanas ¿tuvo dificultad para hacer su trabajo o sus actividades diarias (por ejemplo, le costó mas de lo normal), a causa de su salud física?

1 Si

2 No

17. Durante las 4 últimas semanas ¿tuvo que reducir el tiempo dedicado al trabajo o a sus actividades diarias, a causa de algún problema emocional (como estar triste, deprimido, o nervioso)?

$1 \mathrm{Si}$

2 No

18. Durante las 4 últimas semanas ¿Hizo menos de lo que hubiera querido hacer, a causa de algún problema emocional (como estar triste, deprimido, o nervioso)?

1 Si

2 No

19. Durante las 4 últimas semanas tno hizo su trabajo o sus actividades diarias tan cuidadosamente como de costumbre, a causa de algín problema emocional (como estar triste, deprimido, o nervioso)?.

1 Si

2 No

20. Durante las 4 últimas semanas ¿hasta qué punto su salud fisica o los problemas emocionales han dificultado sus actividades sociales habituales con la familia, los amigos, los vecinos u otras personas?
$1 \quad$ Nada
2 Un poco
3 Regular
$4 \quad$ Bastante
5 Mucho 
21. Tuvo dolor en alguna parte del cuerpo durante las 4 últimas semanas?

1 No, ninguno

2 Si, muy poco

3 Si, un poco

$4 \quad$ Si, moderado

5 Si, mucho

6 Si, muchísimo

22. Durante las 4 últimas semanas chasta qué punto el dolor le ha dificultado su trabajo habitual (incluido el trabajo fuera de casa y las tareas domésticas)?
$1 \quad$ Nada
2 Un poco
3 Regular
4 Bastante
5 Mucho

Las preguntas que siguen se refieren a cómo se ha sentido y cómo le han ido las cosas durante las 4 últimas semanas. En cada pregunta responda lo que se parezca más a cómo se ha sentido usted.

23. Durante las 4 últimas semanas ¿cuánto tiempo se sintió lleno de vitalidad?
1 Siempre
2 Casi siempre
3 Muchas veces
$4 \quad$ Algunas veces
5 Sólo alguna vez
6 Nunca

24. Durante las 4 últimas semanas ¿cuánto tiempo estuvo muy nervioso?

$\begin{array}{ll}1 & \text { Siempre } \\ 2 & \text { Casi siempre } \\ 3 & \text { Muchas Veces } \\ 4 & \text { Algunas veces } \\ 5 & \text { Sólo alguna vez } \\ 6 & \text { Nunca }\end{array}$

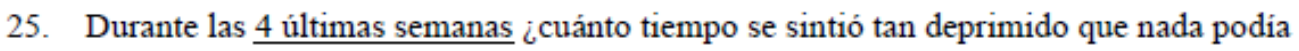
animarlo?

$\begin{array}{ll}1 & \text { Siempre } \\ 2 & \text { Casi siempre } \\ 3 & \text { Muchas Veces } \\ 4 & \text { Algunas veces } \\ 5 & \text { Sólo alguna vez } \\ 6 & \text { Nunca }\end{array}$


26. Durante las 4 últimas semanas ¿cuánto tiempo se sintió calmado y tranquilo?

1 Siempre

2 Casi siempre

3 Muchas Veces

$4 \quad$ Algunas veces

5 Sólo alguna vez

6 Nunca

27. Durante las 4 últimas semanas ¿cuánto tiempo tuvo mucha energía?

1 Siempre

2 Casi siempre

3 Muchas veces

$4 \quad$ Algunas veces

5 Sólo alguna vez

6 Nunca

28. Durante las 4 últimas semanas ¿cuánto tiempo se sintió desanimado y triste?

$\begin{array}{ll}1 & \text { Siempre } \\ 2 & \text { Casi siempre } \\ 3 & \text { Muchas veces } \\ 4 & \text { Algunas veces } \\ 5 & \text { Sólo alguna vez } \\ 6 & \text { Nunca }\end{array}$

29. Durante las 4 últimas semanas ¿cuánto tiempo se sintió agotado?

$\begin{array}{ll}1 & \text { Siempre } \\ 2 & \text { Casi siempre } \\ 3 & \text { Muchas veces } \\ 4 & \text { Algunas veces } \\ 5 & \text { Sólo alguna vez } \\ 6 & \text { Nunca }\end{array}$

30. Durante las 4 últimas semanas ¿cuánto tiempo se sintió feliz?

1 Siempre

2 Casi siempre

3 Muchas veces

$4 \quad$ Algunas veces

5 Sólo alguna vez

6 Nunca

31. Durante las 4 últimas semanas, ¿cuánto tiempo se sintió cansado?

$\begin{array}{ll}1 & \text { Siempre } \\ 2 & \text { Casi siempre } \\ 3 & \text { Muchas veces } \\ 4 & \text { Algunas veces } \\ 5 & \text { Sólo alguna vez } \\ 6 & \text { Nunca }\end{array}$


32. Durante las 4 últimas semanas, ¿con qué frecuencia la salud fisica o los problemas emocionales le han dificultado sus actividades sociales (como visitar a los amigos o familiares)?

$\begin{array}{ll}1 & \text { Siempre } \\ 2 & \text { Casi siempre } \\ 3 & \text { Algunas veces } \\ 4 & \text { Sólo alguna vez } \\ 5 & \text { Nunca }\end{array}$

Por favor, diga si le parece cierta o falsa cada una de las siguientes frases

33. Creo que me pongo enfermo más fácilmente que otras personas.
1 Totalmente cierto
2 Bastante cierto
3 No lo sé
4 Bastante falso
5 Totalmente falso

34. Estoy tan sano como cualquier persona.

$\begin{array}{ll}1 & \text { Totalmente cierto } \\ 2 & \text { Bastante cierto } \\ 3 & \text { No lo sé } \\ 4 & \text { Bastante falso } \\ 5 & \text { Totalmente falso }\end{array}$

35. Creo que mi salud va a empeorar.
1 Totalmente cierto
2 Bastante cierto
3 No lo sé
4 Bastante falso
5 Totalmente falso

36. Mi salud es excelente.
1 Totalmente cierto
2 Bastante cierto
3 No lo sé
4 Bastante falso
5 Totalmente falso 